\title{
Ultrasonic tomography for the characterization of the weathering state of marble
}

A systematic study about influencing parameters

\author{
Dissertation \\ zur Erlangung des mathematisch-naturwissenschaftlichen Doktorgrades \\ „Doctor rerum naturalium“ \\ der Georg-August-Universität Göttingen \\ im Promotionsprogramm Geowissenschaften \\ der Georg-August University School of Science (GAUSS)
}

vorgelegt von

Rahel Johanna Menningen

aus Adenau

Göttingen 2020 
Betreuungsausschuss

Prof. Dr. Siegfried Siegesmund

Abteilung Strukturgeologie und Geodynamik

Geowissenschaftliches Zentrum der Georg-August-Universität Göttingen

Prof. Dr. Jonas Kley

Abteilung Strukturgeologie und Geodynamik

Geowissenschaftliches Zentrum der Georg-August-Universität Göttingen

Mitglieder der Prüfungskommission

$\underline{\text { Referent }}$

Prof. Dr. Siegfried Siegesmund

Abteilung Strukturgeologie und Geodynamik

Geowissenschaftliches Zentrum der Georg-August-Universität Göttingen

$\underline{\text { Korreferent }}$

Prof. Dr. Rolf Snethlage

Naturstein, Bauchemie und Bauphysik in der Denkmalpflege, Bamberg

Weitere Mitglieder der Prüfungskommission:

Prof. Dr. R. Sobott

Labor für Baudenkmalpflege, Naumburg

Prof. Dr. J. Kley

Abteilung Strukturgeologie und Geodynamik

Geowissenschaftliches Zentrum der Georg-August-Universität Göttingen

Dr. G. Sosa

Abteilung Angewandte Geologie

Geowissenschaftliches Zentrum der Georg-August-Universität Göttingen

Dr. B. Leiss

Abteilung Strukturgeologie und Geodynamik

Geowissenschaftliches Zentrum der Georg-August-Universität Göttingen

Tag der mündlichen Prüfung: 26.05.2020 


\section{Abstract}

The present thesis investigated the application of ultrasonic tomography to evaluate the weathering condition of different marble varieties. Ultrasound analysis is a non-destructive examination method which is often used in the field of monument conservation to determine the condition of important monuments and sculptures made of marble. Based on these measurements, it is possible not only to measure in transmission but also to generate a tomogram of planes when the measuring procedure is changed. However, since the ultrasonic velocity of the P-wave is influenced to a large extent by various extrinsic and intrinsic influences, which can significantly change the interpretation of the data, these influences were determined and quantified in this work on different marble varieties.

For this purpose, varieties of particular importance in the context of monument conservation were selected and characterised on the basis of all relevant structural features and their weathering-sensitive petrographic parameters with regard to their directional dependence in the unweathered state. By means of systematic artificial weathering, the varieties of Estremoz, Blanco Macael, Carrara Gioia, Lasa, Großkunzendorf and Wunsiedel marble were gradually alterated and the changes in rock properties were determined. All weathering steps were investigated with special attention to the change of the ultrasonic wave velocity in dry and water saturated conditions in transmission and on spherical samples with regard to the spatial change of the velocity distribution.

In addition, tomograms were generated on marble phantoms in both unweathered and alterated state to analyse the results under defined conditions. In the course of three measurement campaigns additional valuable results could be obtained with regard to the application of the measurement on naturally weathered objects. Basically, the intrinsic velocity distribution is dominant with regard to the formation of tomograms. Here, the rock-specific anisotropy of the wave velocity must be taken into account. Changes in the tomogram are due to extrinsic influences, whereby the resolution of these influences depends on the selected ultrasonic frequency. It would be useful to carry out further investigations on tomograms in different spatial positions with regard 
to the foliation in order to create a kind of blueprint for the evaluation of the tomograms.

The weathered samples were then consolidated with the consolidation materials KSE, KSE HV, Paraloid B72 and the acrylic total impregnation (ATI) in order to determine the changes, ultrasonic investigations were performed. A subsequent additional thermal load showed that, apart from the application of the ATI, all consolidation agents resulted in a strong reduction of the velocity and their effectiveness is therefore questionable. Based on the ultrasound measurements, however, it was possible to plan possible further investigations.

Basically, the performance of ultrasonic tomography is a valuable tool to define the weathering status of marble. It is important to know the influencing parameters and to consider them for the evaluation and interpretation. In addition to the rock properties, a mapping of decay for the object in question is an important tool for the optimal interpretation of tomograms. 


\section{Zusammenfassung}

Die vorliegende Arbeit untersuchte die Anwendung von Ultraschalltomographie zur Evaluierung des Verwitterungszustandes unterschiedlicher Marmorvarietäten. Die Ultraschallanalyse ist eine zerstörungsfreie Untersuchungsmethode, die insbesondere in der Denkmalpflege häufig genutzt wird, um den Zustand wichtiger Monumente und Skulpturen aus Marmor zu bestimmen. Basierend auf diesen Messungen ist es neben der Transmissionsmessung auch möglich, bei verändertem Messablauf ein Tomogramm von Schnittflächen zu erstellen. Da die Ultraschalllaufgeschwindigkeit der P-Welle jedoch in großem Maße durch unterschiedliche extrinsische und intrinsische Einflüsse beeinflusst wird, welche insbesondere die Interpretation der Daten erheblich verändern kann, wurden in dieser Arbeit diese an Einflüsse an unterschiedlichen Marmorvarietäten bestimmt und quantifiziert.

Hierzu wurden Varietäten von besonderer Bedeutung im Kontext der Denkmalpflege ausgewählt und anhand aller relevanter Gefügemerkmale und ihrer verwitterungssensiblen petrographischen Parameter im Hinblick auf ihre Richtungsabhängigkeit im bruchfrischen Zustand charakterisiert. Anhand einer systematischen künstlichen Verwitterung wurden die Varietäten des Estremoz, Blanco Macael, Carrara Gioia, Lasa, Großkunzendorfer und Wunsiedel Marmors stufenweise alteriert und die Änderungen der Eigenschaften ermittelt. Sämtliche Verwitterungsschritte wurden unter besonderem Augenmerk auf die Veränderung der Ultraschalllaufgeschwindigkeit im trockenen und wassergesättigten Zustand in Transmission und an Kugelproben im Hinblick auf die räumliche Änderung der Geschwindigkeitsverteilung untersucht.

Ergänzend wurden Tomogramme an Marmorphantomen im bruchfrischen sowie alteriertem Zustand erzeugt, um die Ergebnisse unter definierten Bedingungen zu analysieren. Im Zuge von drei Messkampagnen konnten zusätzliche wertvolle Ergebnisse im Hinblick auf die Anwendung der Messung an natürlich verwitterten Objekten gewonnen werden. Grundsätzlich ist die intrinsische Geschwindigkeitsverteilung dominant im Hinblick auf die Ausbildung von Tomogrammen, hierbei muss die gesteinsspezifische Anisotropie der Laufgeschwindigkeit zwingend berücksichtigt werden. Veränderungen am Tomogramm sind auf extrinsische Einflüsse zurückzuführen, wobei die Auflösung dieser 
Einflüsse in Abhängigkeit zur gewählten Ultraschallfrequenz steht. Es wäre sinnvoll weiter Untersuchungen zu Tomogrammen in unterschiedlicher Raumlage zur Foliation durchzuführen, um eine Art Blaupause für die Auswertung der Tomogramme zu erstellen.

Die verwitterten Proben wurden anschließend mit den Konservierungsmitteln KSE, KSE HV, Paraloid B72 und der Acrylharzvolltränkung (AVT) gefestigt, um die Veränderungen mittels Ultraschall zu bestimmen. Eine anschließende erneute thermische Belastung zeigte hierbei, dass außer Anwendung der AVT sämtliche Mittel eine starke Reduzierung der Laufgeschwindigkeiten zur Folge hatte und ihre Wirksamkeit somit fraglich ist. Hierbei konnte jedoch basierend auf den Ultraschallmessungen eine gute Planung möglicher weiterer Untersuchungen erfolgen.

Grundsätzlich ist die Durchführung von Ultraschalltomographie ein wertvolles Mittel, um den Verwitterungsstand von Marmor zu definieren. Hierbei ist es wichtig die beeinflussenden Parameter zu kennen und in der Auswertung zu berücksichtigen. Neben den Gesteinskennwerten ist eine Kartierung der Schäden am vorliegenden Objekt ein wichtiges Hilfsmittel, um eine optimale Interpretation von Tomogrammen zu ermöglichen. 


\section{Table of Content}

Abstract

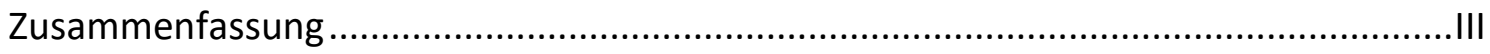

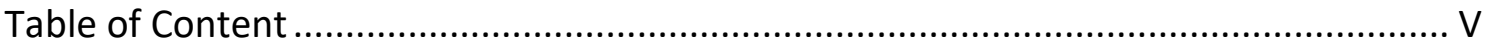

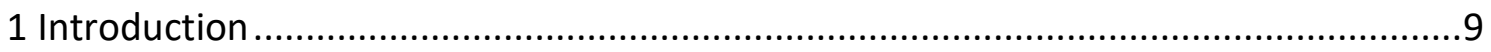

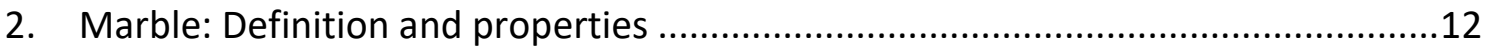

2.1 Marble: Definition and mineralogical composition .....................................12

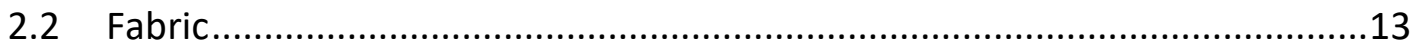

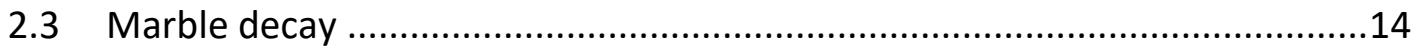

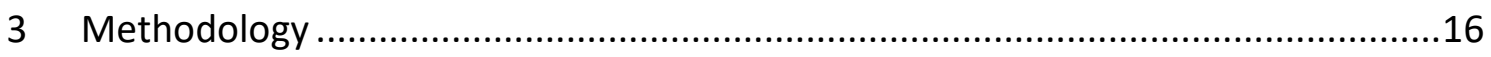

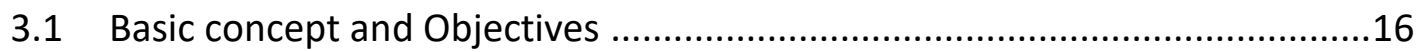

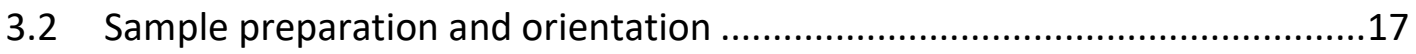

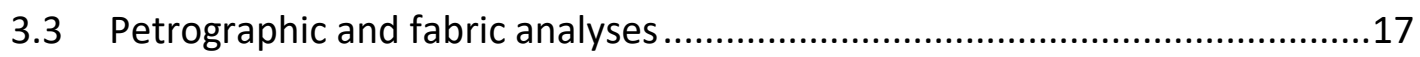

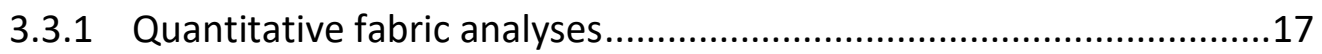

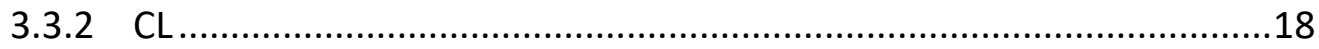

3.3.3 X-Ray Goniometer, EBSD measurements .....................................18

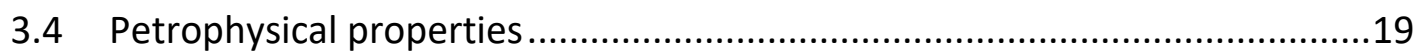

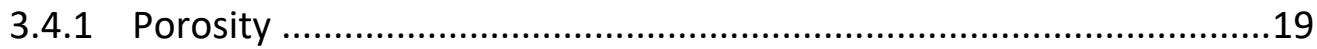

3.4.2 Ultrasonic measurements ..........................................................20

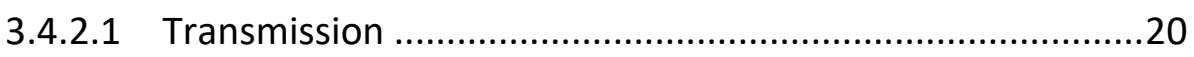

3.4.2.2 $360^{\circ}$ measurements ...................................................21

3.4.2.3 Tomographic inversion...................................................21

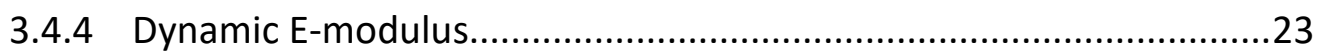

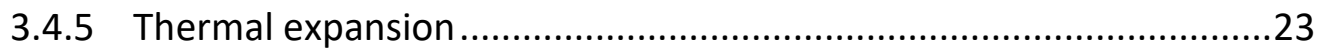

3.4.6 Resistance of marble to thermal and moisture cycles.......................24

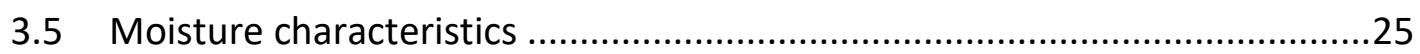

3.5.1 Capillary water uptake ..............................................................25

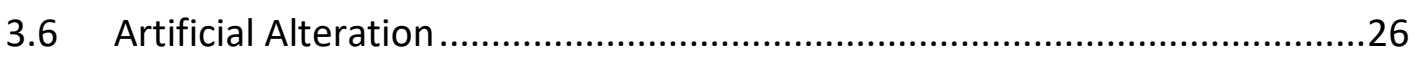

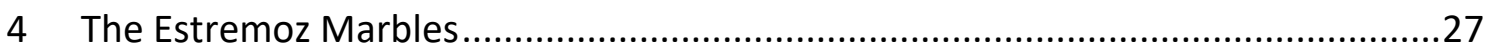

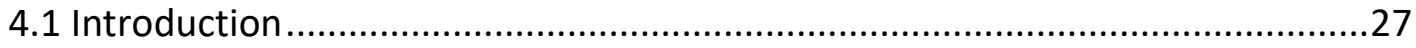

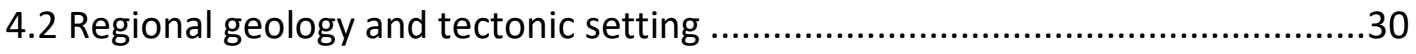

4.3 Estremoz Marble: heritage, commercial varieties, applications and economy.33

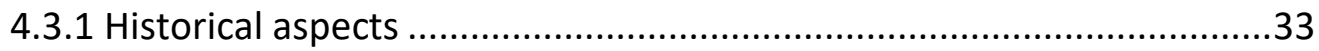

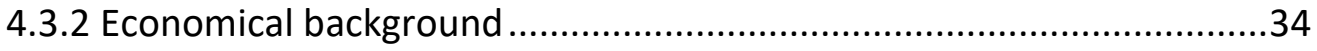

4.4 Characterisation of representative marble samples ....................................39 


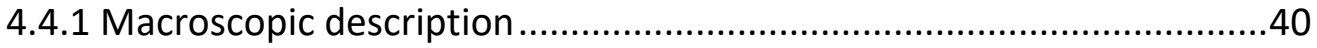

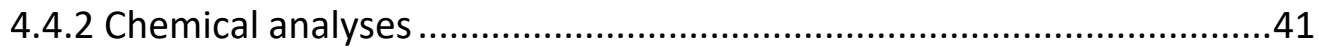

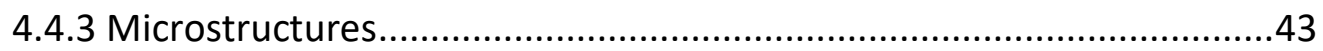

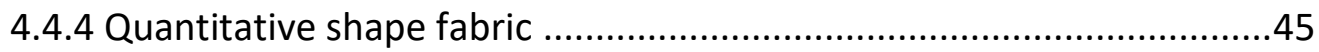

4.4.5 Cathodoluminescence......................................................................47

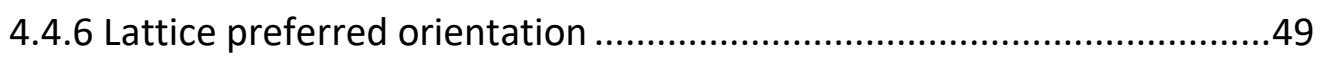

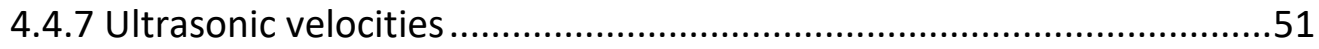

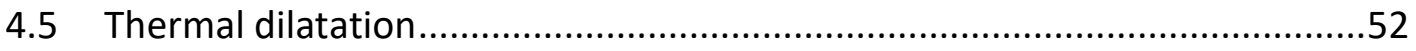

4.5.1 Residual strain $\left(\varepsilon_{\mathrm{RS}}\right)$ under dry conditions .......................................54

4.5.2 Thermal dilatation and residual strain ................................................55

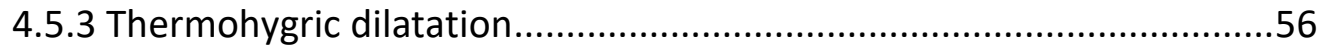

4.5.4 Residual strain under wet and dry conditions ...................................57

4.6. Application of the Estremoz marble:...........................................................60

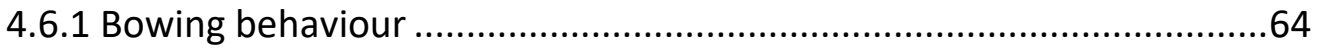

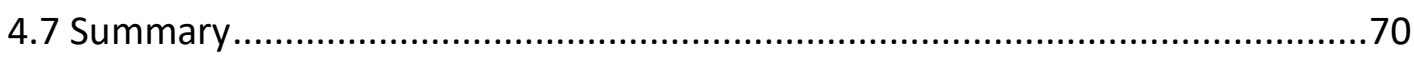

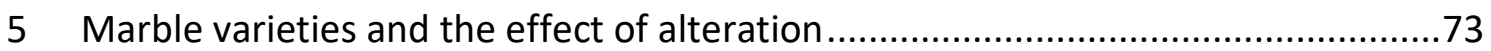

5.1 Provenance, macroscopic description and decay phenomena .....................73

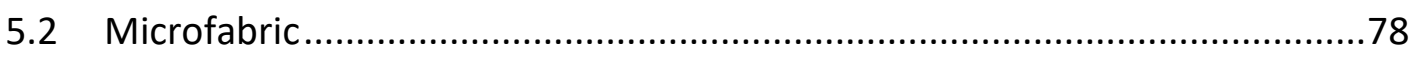

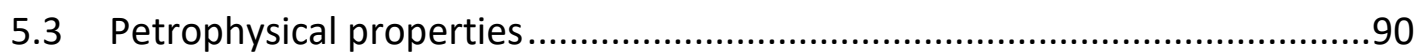

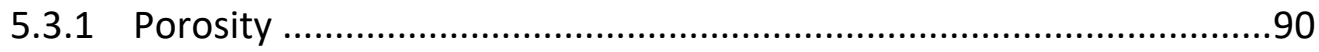

5.3.3 Capillary water uptake ..................................................................91

5.3.2 Ultrasonic measurements ...........................................................94

5.3.2.1 Transmission measurements .........................................95

5.3.2.2 Influence of humidity and water saturation ......................97

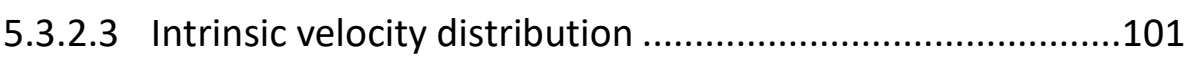

5.3.2.4 $360^{\circ}$ measurements ...................................................102

5.3.2.5 Relationship of velocity and porosity..............................108

5.3.2.6 Experimental tomography ..............................................111

5.3.2.7 Dynamic E-modulus .....................................................117

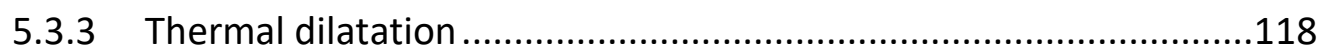

5.3.4 Resistance of marble to thermal and thermohygric cycles ..............124

6. The marble Obelisk at the Neuen Garten, Potsdam ..........................................126

6.1 The Obelisk, historic background and description ...................................126

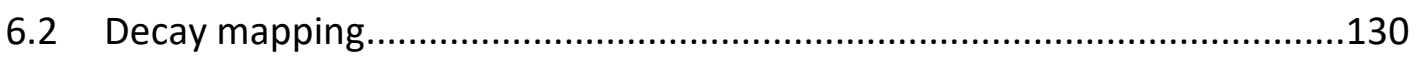

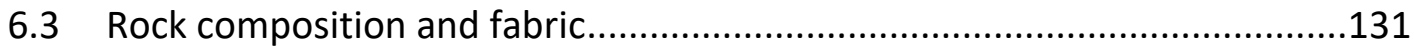

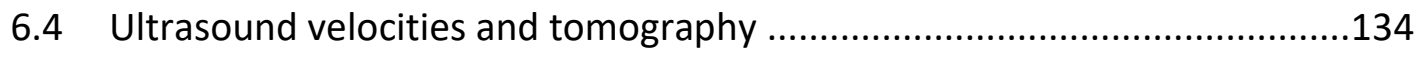

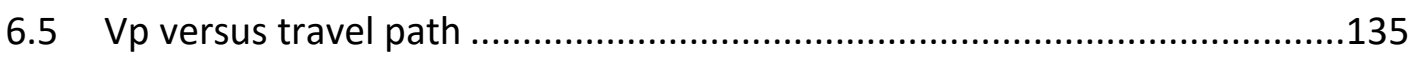

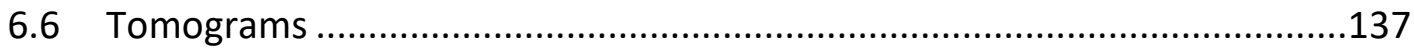

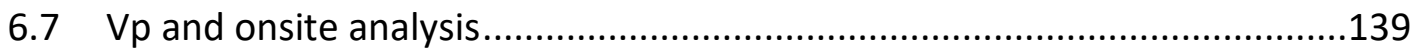




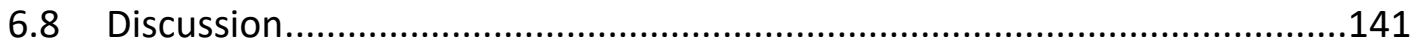

6.9 What affects Vp?: Controlled alteration under laboratory conditions ........141

6.10 Quantification of velocity reduction: Directional dependence of Vp...........142

6.11 Ultrasonic-tomography: modelling vs field data ........................................145

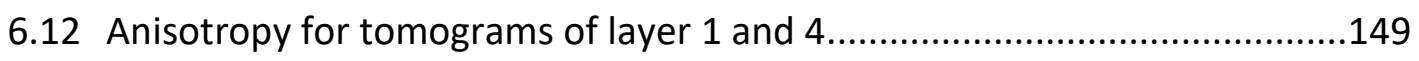

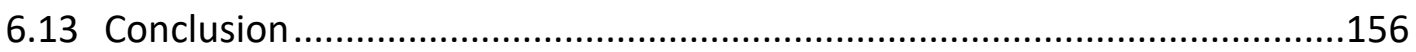

7 Scharnhorst and Bülow, comparative investigations.......................................157

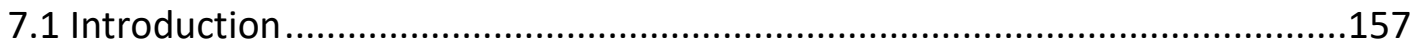

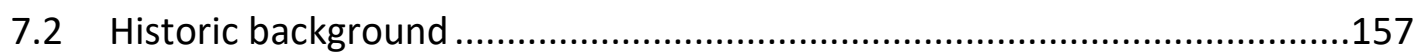

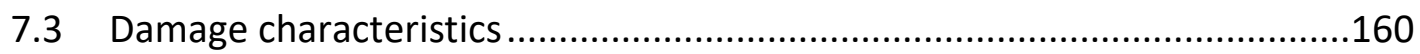

7.3.1 Decay phenomena and rock status .............................................160

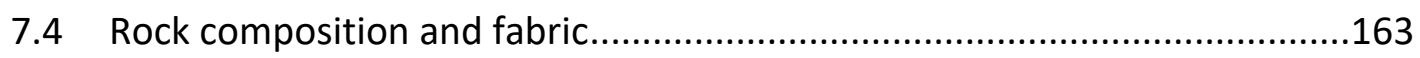

7.4.1 Lattice preferred Orientation .......................................................163

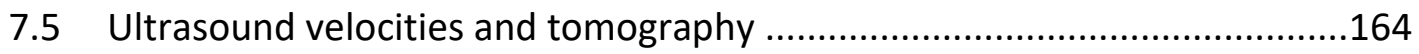

7.5.1 On site ultrasonic diagnostics - ....................................................164

7.5.2 Vp versus Travelpath .....................................................................165

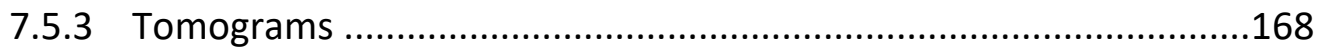

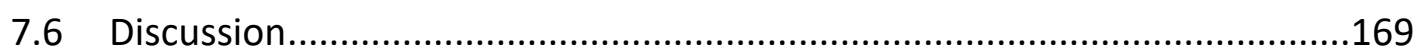

7.6.1 Transmission measurements ........................................................170

7.6.2 Laboratory measurements ......................................................174

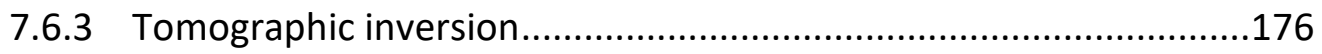

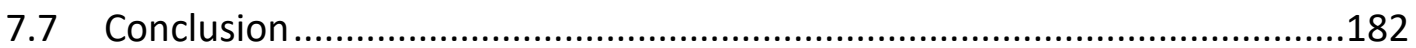

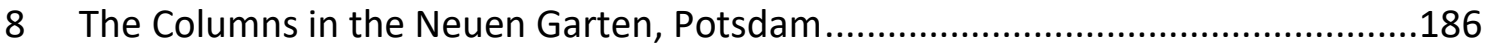

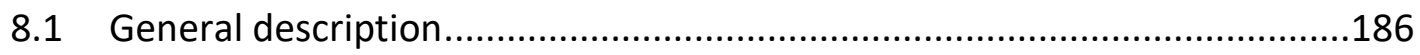

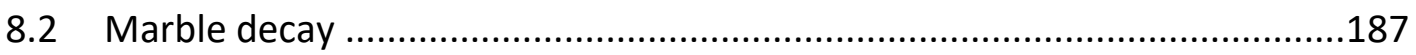

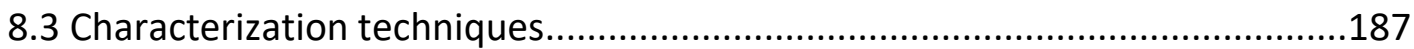

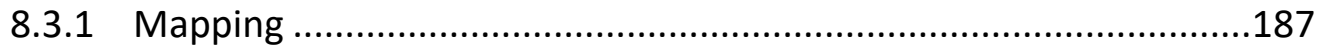

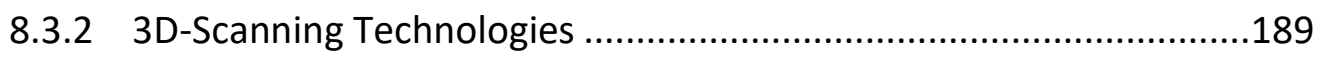

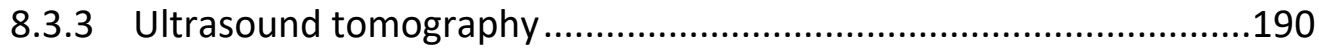

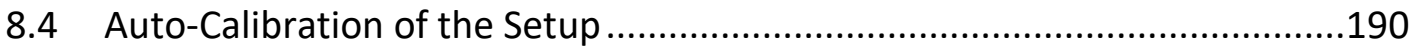

8.5 Merging, Meshing and Texture Mapping .................................................191

8.6 Documentation of Measuring Positions ...................................................191

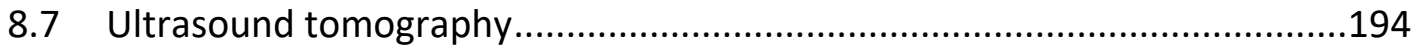

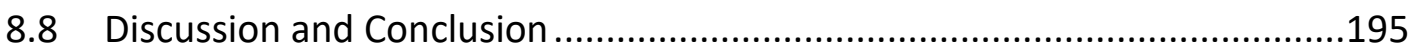

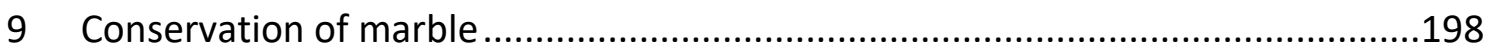

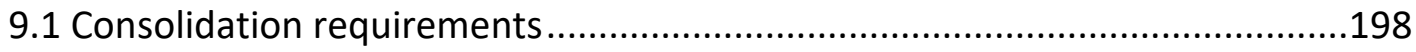

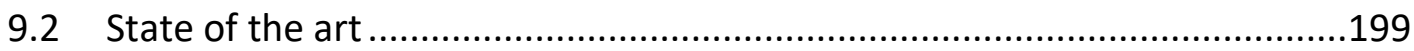

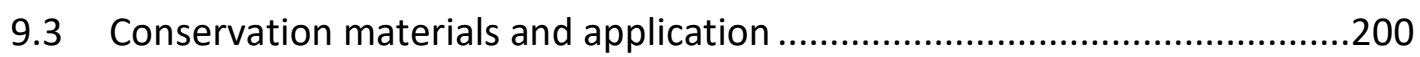

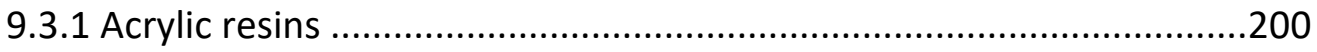




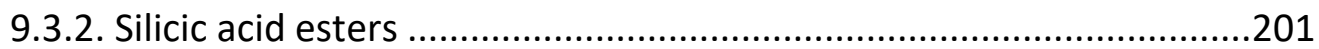

9.4 Modification of petrophysical properties, based on the consolidation. ......202

9.4.1 Ultrasonic measurements ..........................................................202

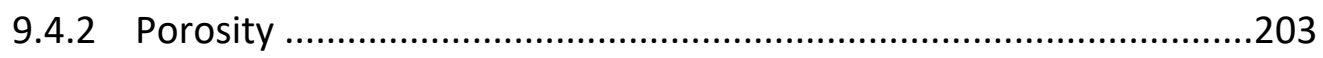

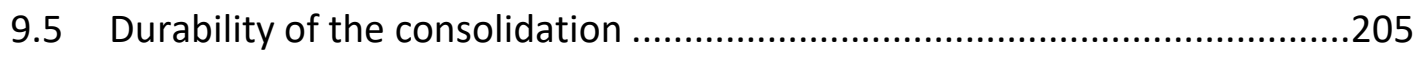

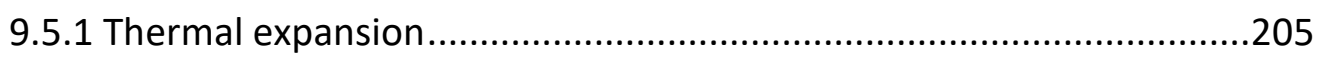

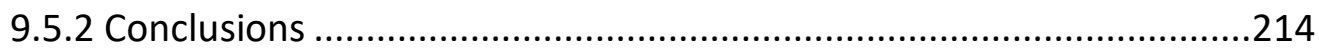

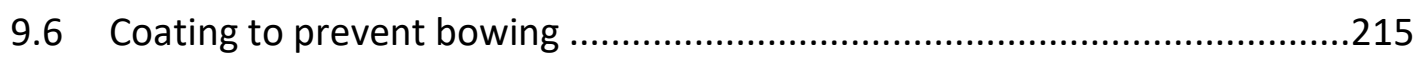

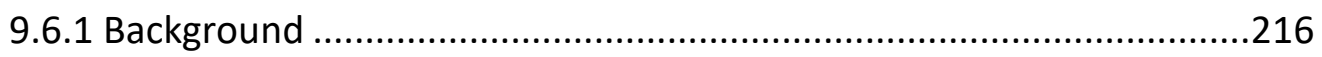

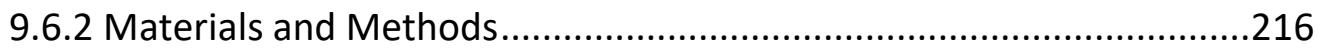

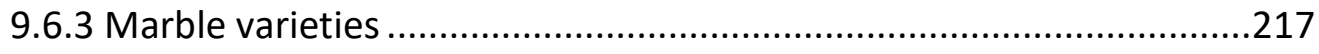

9.6.5 Durability of the consolidation....................................................218

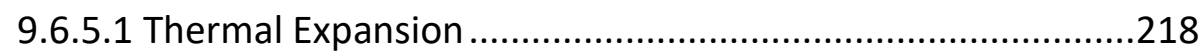

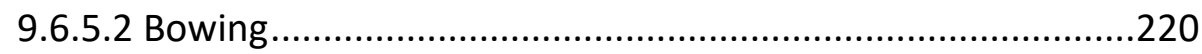

9.6.5.3 Ultrasonic velocities ........................................................221

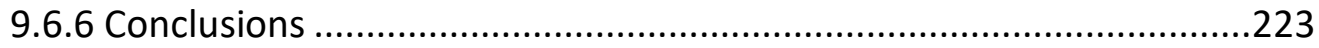

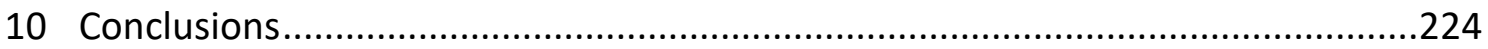

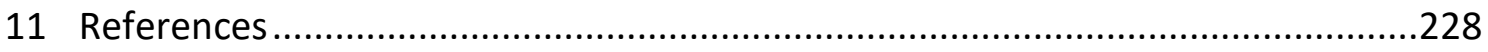

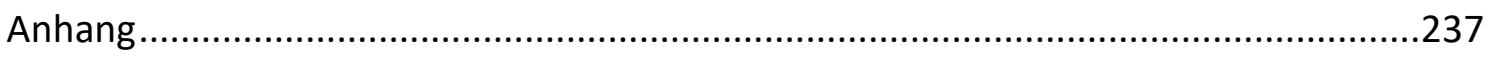

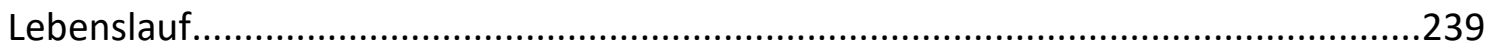




\section{Introduction}

Marble has been used as a precious building stone since antiquity. Appearance and processing properties are some of the reasons why it was and still is an often chosen material for many purposes. Famous sculptures, like Cupid and Psyche, by Antonio Canova (Louvre, Paris), the David sculpture created by Michelangelo as a masterpiece of Renaissance art (Florence), ancient buildings, like the Parthenon in Greece, the Leaning Tower of Pisa or even the Marmorpalais in Potsdam (Germany) are just a few examples of objects and monuments made of marble.

Even if built for eternity, it is well known that weathering caused by physical, chemical, biological and anthropogenic influences, results in deterioration. In contrast to other natural stones, however, crystalline marble also shows a unique weathering behaviour. For marbles, a complete fabric-controlled destruction is a frequently discussed weathering scenario. Objects damaged in this way are in risk of complete structural collapse. This was the case for a sculpture made from Carrara marble (Figure 1) in the Orangery, Sanssouci Park in Potsdam, Germany (Köhler, 1988; Siegesmund et al., 2004a).
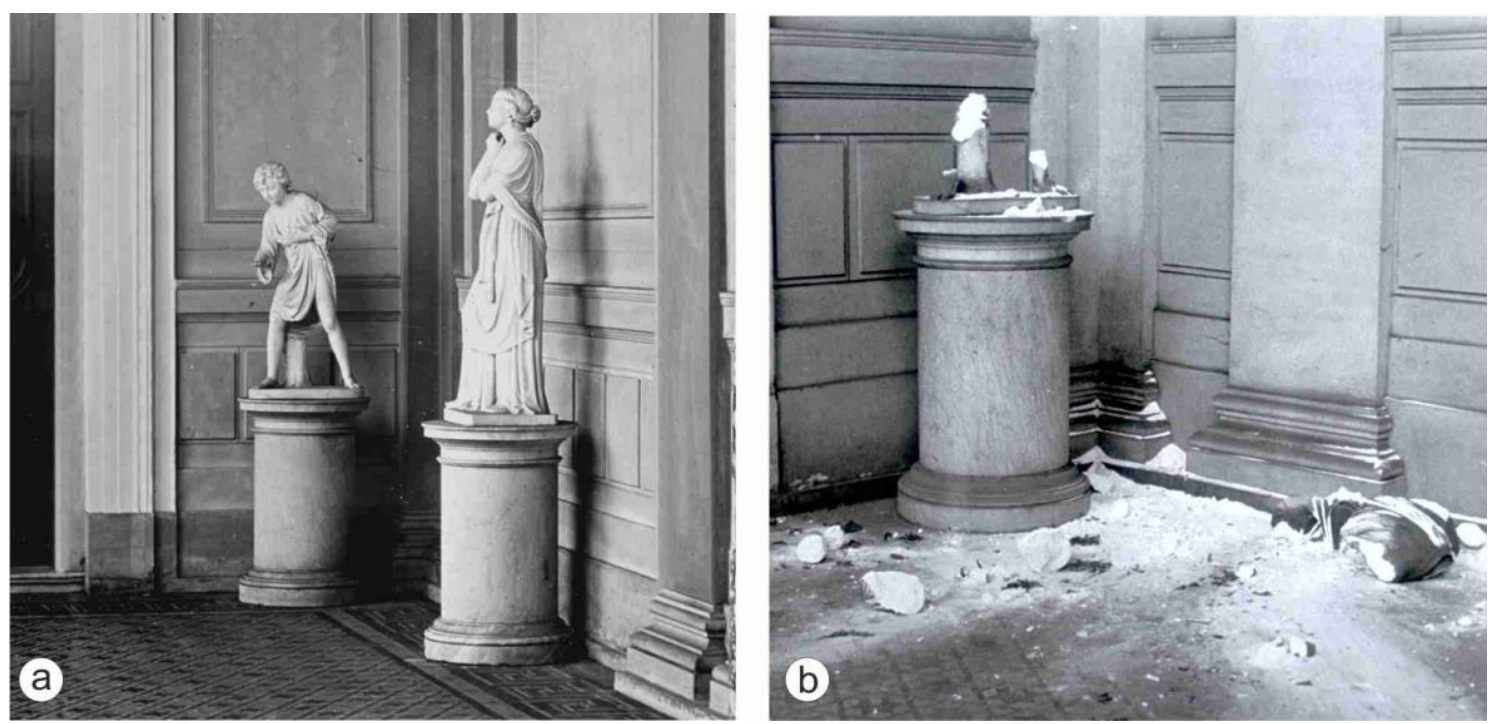

Figure 1 a) Sculpture in the Orangery, Potsdam, before total structural collapse in 1978 and b) after complete collapse after 110 years of exposure (modified after Siegesmund et al., 2004a). 
Immovable, high-ranking cultural heritage, landmark buildings and sculptures made of natural stones require for their investigation the usage of test methods with a non-destructive nature, to evaluate their state of weathering. These methods need to be resource-saving and should provide as far as possible unequivocal results. In the last 30 years, ultrasound measurements (routinely used as a transmission method) have developed into a state-of-the-art testing approach for characterizing the damage state of monuments. The basis for this is-the correlation of the longitudinal velocities $(\mathrm{Vp})$ with the weathering state. Constraints and limitations of this method, however, demonstrate that the uncritical use permits only relative descriptions of the weathering state. These can vary within wide ranges due to specific material constants (e.g. mineralogical composition, areas of homogeneity, pore space, pore content, degree of water saturation, etc.).

Besides the transmission measurements, the application of ultrasonic tomography is a tool for a detailed insight into the internal structure of marble objects. Main problem in this context, is the interpretation of those tomograms, which is not trivial, due to the different intrinsic and extrinsic influences on the ultrasonic wave velocity.

Main aim of this thesis is to analyse the main influencing parameters of different, often used marble varieties on the ultrasonic wave velocities to improve the interpretation of ultrasonic tomograms. Besides laboratory analyses, different measurement campaigns have been performed to receive data under environmental conditions and compare them to the experimental data.

As the results received for an ultrasonic investigation are often connected to the question which treatments can be used to improve the conditions of the object, different consolidation materials and their influence on the ultrasonic velocity have also been investigated.

This thesis incorporates the following publications:

Chapter 4: Menningen, J., Siegesmund, S., Lopes, L., Martins, R., \& Sousa, L. (2018). The Estremoz marbles: an updated summary on the geological, mineralogical and rock physical characteristics. Environmental Earth Sciences, 77(5), 191. https://doi.org/10.1007/s12665-018-7328-3 
Chapter 5: $\quad$ Siegesmund, S., Menningen, J., Shushakova, V. (2021). Marble decay: towards a meausure of marble degradation based on ultrasonic wave velocities and thermal expansion data. Environmental Earth Sciences (Accepted for publication). Own contribution: Sample preparation, implementation of experiments, data evaluation and writing of the parts: Rock materials; Macroscopic description; and decay phenomena; Petrophysical properties, Capillary water uptake; Transmission measurements; Influence of humidity and water saturation; Intrinsic velocity distribution; Ultrasonic wave velocity measured on spherical samples; Crack related velocity reduction; Relationship of velocity and porosity; Experimental tomography; Dynamic E-modulus and Thermal dilatation.

Chapter 6: Menningen, J., Siegesmund, S., Tweeton, D., \& Träupmann, M. (2018). Ultrasonic tomography: non-destructive evaluation of the weathering state on a marble obelisk, considering the effects of structural properties. Environmental Earth Sciences, 77(17), 601. https://doi.org/10.1007/s12665-018-7776-9

Chapter 7: $\quad$ Menningen, J., Siegesmund, S., Krompholz, R., Rieffel, Y. (2020) The marble sculptures General Bülow and Scharnhorst in Berlin - Comparative, nondestructive analysis of the weathering state after 12 years of exposure. Environmental Earth Sciences, 79, 249. https://doi.org/10.1007/s12665-02008984-7

Chapter 8: $\quad$ Menningen, J.*, Fetzer, T.*, Schäfer, A., Reis, G., Siegesmund, S. (2020) Marble columns and sculptures from the Marmorpalais and Park Sanssouci in Potsdam: Ultrasound tomography and 3D scanning technologies as a tool to constrain the state of weathering; In: Siegesmund, S. \& Middendorf, B. (Eds.): Monument Future: Decay and Conservation of Stone.- Proceedings of the 14 th International Congress on the deterioration of Stone - Mitteldeutscher Verlag 2020. (*equally contributed)

Chapter 9 Menningen, J., Sassoni, E., Sobott, R., Siegesmund, S. (2021) Constraints of the durability of inorganic and organic consolidants for marble. Environ Earth Sci 80, 370. https://doi.org/10.1007/s12665-021-09664-w

Chapter 9.5 Menningen, J., Sassoni, E. Siegesmund, S. (2020) Marble bowing: Prevention by the application of Hydroxyapatite - a systematic study In: Siegesmund, S. \& Middendorf, B. (Eds.): Monument Future: Decay and Conservation of Stone.- Proceedings of the 14 th International Congress on the deterioration of Stone - Mitteldeutscher Verlag 2020. 


\section{Marble: Definition and properties}

\subsection{Marble: Definition and mineralogical composition}

Marble is a sedimentary limestone transformed by regional- or contact metamorphism to a crystalline marble. Based on the Appendix B of the North American Geologic-Map Data Model Science Language Technical Team, 2004, a marble is defined as a monomineralic rock in which carbonate minerals form $>75 \%$ of the material. A calcite marble is defined as a rock, consisting of more than $75 \%$ of carbonate minerals, where more than $75 \%$ of the carbonate minerals are formed of calcite. In a dolomitic marble, more than $75 \%$ of those carbonate minerals are formed by dolomite. Depending on the further content of additional minerals and contaminations of the former limestone, the marble contents black to colourful bandings or an all over colour like reddish or brownish.

The rock properties of a marble are characterised by his fabric, the single crystal properties of his main mineral phase's calcite or dolomite and the crystallographic preferred orientation of them. Even if marble has a relatively simple composition, its physical properties are mainly influenced by the strongly anisotropic single crystal properties of calcite. Main point of interest for this work is the anisotropic compressional wave velocity $\left(V_{p}\right)$ as well as the thermal dilatation coefficient $\alpha$ for calcitic marbles. Both parameters are extremely anisotropic with regard to the specific crystallographic axis (Figure 2).

According to the c-axis, the wave velocities of a calcite single crystal are about $5.71 \mathrm{~km} / \mathrm{s}$, while they are much higher $(7.73 \mathrm{~km} / \mathrm{s})$ according to their a-axes (Dandekar, D., P., 1968). The thermal dilatation coefficient $\alpha$ shows additionally an opposed behaviour; according to the c-axis the thermal dilatation leads to an expansion due to heating $\left(\alpha=26^{*} 10^{-6}\right)$, while it contracts according to the a-axes $\left(\alpha=-6^{*} 10^{-6}\right)$ (Kleber et al., 2010). 

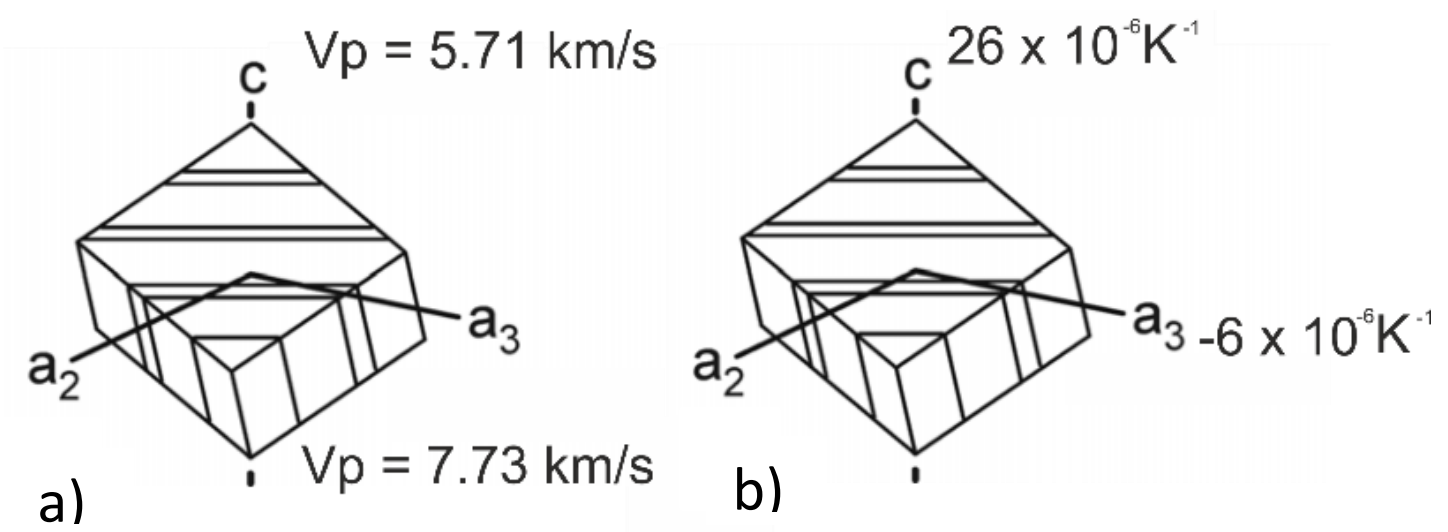

Figure 2 Anisotropy of the compressive wave velocity (a) and the thermal expansion coefficient $\alpha$ (b). (modified after Koch, 2006 and Ruedrich, 2003).

\subsection{Fabric}

The main mineralogical components in marble are calcite and dolomite, where the deformation mechanisms and slip systems influence the formation of its fabric (Koch, 2006). Fabric elements themselves may consist of foliation, lineation, or lattice preferred orientation (Passchier and Trouw, 2005). A foliation is a layered fabric within a rock, as a plane, while the lineation is a linear feature. In marbles, a foliation is often caused by a grain shape preferred orientation caused by deformed grains, which can also cause a preferred orientation of the grain boundaries (Koch, 2006).

The crystallographic or lattice preferred orientation is the so-called texture. The texture describes the statistical preferred orientation of the crystal lattices of a population of crystals in a rock (Passchier and Trouw, 2005). It is characterized by intensity, orientation and distribution pattern of the crystals and can be categorized for marbles in two main distribution pattern (see Figure 3): The c-axis fibre type and the a-axis fibre type (Leiss and Ullemeyer, 1999). 


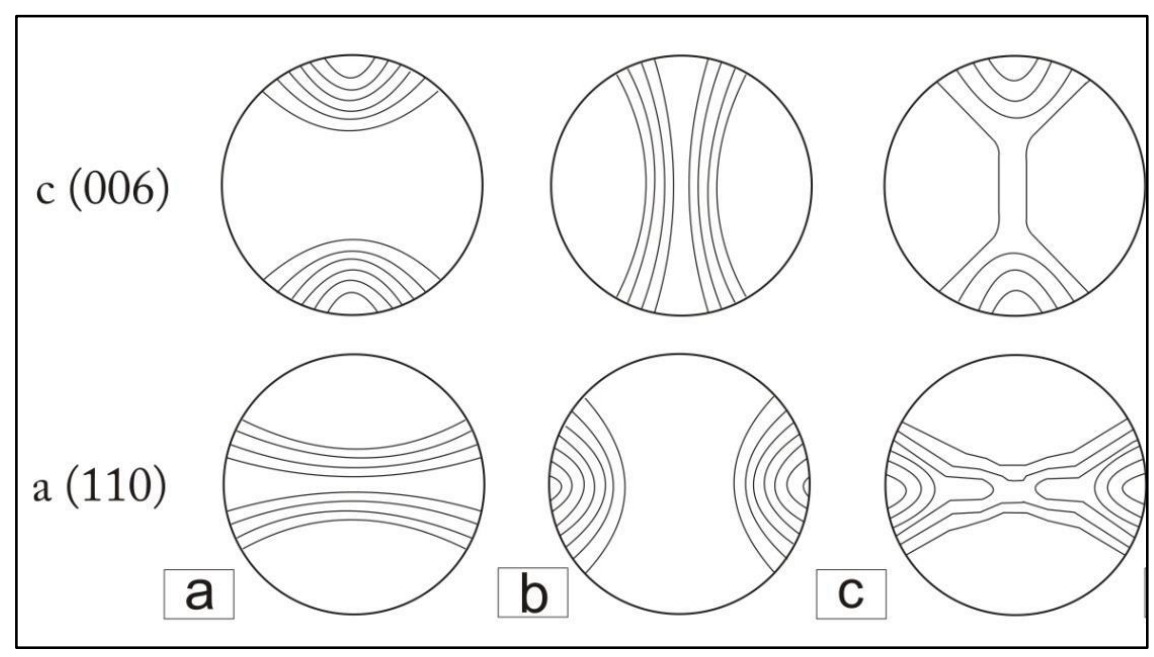

Figure 3 Idealised texture for the c-axis fibre type(a), a-axis fibre type (b) and the intermediary fibre type (c) (stereographic projection, lower hemisphere), modified after Shushakova, 2013.

Another important parameter is the grain fabric with grainsize, grain shape and grain boundary geometry. The grainsize is important regarding the frequency of grain boundaries, which are a potential zone of mechanical weakness. The grain boundary geometry can be divided into polygonal (straight grain boundaries), interlobate (irregular, lobate grain boundaries) and amoeboid with curved and interlocking grain boundaries. The grain size distribution is classified after Passchier and Trouw, 2005 as equigranular (all grains have almost equal size), inequigranular (e.g. bimodal distribution) and seriate (a complete gradation of fine- to coarse-grained).

\subsection{Marble decay}

Marble exposed to the exterior environment suffers due to various factors, which in most cases are mutually dependent and cause the damage to progress. The reasons include chemical, biological and physical processes, as well as parameters inherent to the rock, which are conducive to the weathering process. The extrinsic and intrinsic weathering mechanisms of marble in outdoor have been the basis of numerous studies. (Gherardi et al., 2019; Goretzki et al., 1987; Grelk et al., 2007; Koch, 2006; Koch and Siegesmund, 2002; Köhler, 1991; Ruedrich, 2003) 
The visually detectable damage phenomena range from scaling, sugaring, peeling to the deformation of marble slabs. The phenomenon of granular disintegration inside a marble is often only visually perceptible when irreparable damage has occurred, such as total loss (Köhler, 1991).

The pore space of marble is actually represented by open microcracks. In its untouched state, i.e. before quarrying, marble is a compact crystalline rock, which occasionally shows open microcracks. The majority of those microcracks are the result of mining, processing and weathering. The anisotropy of the calcite crystals under thermal stress is considered to be the initiator of marble weathering. The pronounced directional orientation of the calcite crystals, coupled with an anisotropy under thermal stress, is an important factor in marble, which contributes to disintegration and is described by Ruedrich, 2003 as "(...) a decisive process which initiates (...) structural disintegration (...)". The different expansion coefficients of the respective crystallographic axis of the calcite crystal generates stresses and promotes the expansion of the microstructure. A widening of the structure results in an increased absorption of water, which, in addition leads to damage mechanisms such as disintegration through freeze-thaw changes and hygric influences, leads to the introduction of pollutants in its capacity as a solvent and transport agent and further promotes the loosening of the structure through dissolution processes (Goretzki et al., 1987; Malaga-Starzec et al., 2002; Ondrasina et al., 2002; Ruedrich and Siegesmund, 2001; Shushakova et al., 2013; Steiger et al., 2014; Tschegg et al., 1999; Weiss et al., 2001; Widhalm et al., 1999).

Simon, 2001 generally distinguishes between two processes: those on the surface and those affecting the inner grain structure. The surface processes are described below, as the loosening of the grain structure is largely responsible for the decay phenomenon of granular disintegration and is the focus of the following investigations.

Water as solvent and transport medium plays a fundamental role in most damage mechanisms. Depending on the extent of exposure, direct irrigation of marble can lead to dissolution processes on the calcite, which affects the surface in terms of roughness. This is an ideal foundation for the adhesion of foreign substances and gradually leads to the formation of a biofilm which, after the adhesion of nutrients, provides a nutrient medium for various microorganisms on which crusts can build up over time in the rain 
shadow areas. At a certain point, the resulting compaction of the surface causes dissolution processes and sulfation below the film. The formation of gypsum is associated with an increase in volume, which exerts pressure on the structure of the marble. According to Simon, 2001, this process is limited in terms of its depth. If a crust that has formed is partially broken up, ions from the stone can enter the crust area and promote sintering.

The crusts usually reduce the diffusion of water vapour, which makes it a moisture blockade that makes it difficult for water inside to escape. The resulting uneven environment leads to different moisture-drying properties which, coupled with the temperature, lead to stresses in the structure. As a result of this, the structure will be disrupted if the processes are repeated frequently, which can lead to the detachment of a compacted surface.

\section{Methodology}

\subsection{Basic concept and Objectives}

The ultrasonic velocity is a non-destructive tool to determine the weathering state of marble. This is of particular importance with regard to marble monuments that are part of the cultural heritage. As those monuments are often irreplaceable evidences of history, an in-depth knowledge of their weathering state is preferred. Besides the transmission measurements, the application of ultrasonic tomography is a tool for a detailed insight into the internal structure of those objects. Main problem in this context, is the interpretation of those tomograms, which is not trivial, due to the different intrinsic and extrinsic influences on the ultrasonic wave velocity. Main aim of this thesis is in this context to analyse the main influencing parameters of different, often used marble varieties on the ultrasonic wave velocities to improve the interpretation of ultrasonic tomograms. Besides laboratory analyses, different measurement campaigns have been performed to receive data under environmental conditions and compare them to the experimental data. 


\subsection{Sample preparation and orientation}

As the rock properties of marble show a pronounced anisotropy, all marble samples have been prepared according to a reference coordinate system. Therefore, the former marble blocks have been orientated according to a X, Y and Z- system, related to visible fabric elements as the foliation plane (see Figure 4) All later samples have been manufactured according to this established system, to ensure the comparability of all results. The XY-plane marks the metamorphic foliation, while the $\mathrm{X}$-direction is parallel to the lineation. The Z-direction is perpendicular to the foliation plane. An arbitrary coordinate system was defined, if the specimens did not show any macroscopically visible fabric elements. All pole figures and stereographic projections depicted in this work show an uniform orientation according to the reference system and represent the lower hemisphere (see Figure 4b)
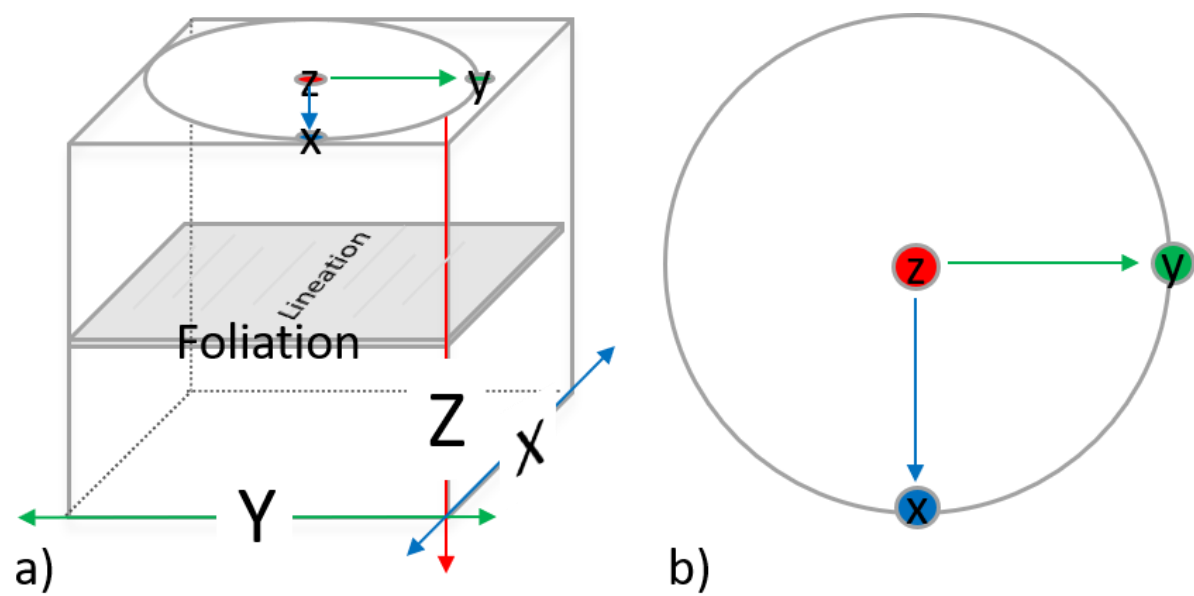

b)

Figure 4 a) Reference coordinate system according to macroscopic visible fabric elements as foliation and lineation. b) orientation according to the pole figures (lower hemisphere).

\subsection{Petrographic and fabric analyses}

\subsubsection{Quantitative fabric analyses}

The microfabric has been analysed on thin sections with $30 \mu \mathrm{m}$ thickness, as well as particularly on ultra-thin sections by polarisation microscopy. The analyses have been performed in three directions parallel to the $\mathrm{XY}-, \mathrm{XZ}$ - and $\mathrm{YZ}$-plane to investigate possible directional dependencies. The quantitative fabric analyses were conducted with a Fabric 
Analyzer Microscope G60 (Russel-Head Instruments) and converted by the support software uniaxial v1.2. The MATLAB-based software FAME 2.1 (for further information see Hammes and Peternell, 2016) was used for the evaluation of the grain shape parameters.

\subsubsection{CL}

The capability of a mineral to emit visible light, when exposed to an electron beam, is called cathodoluminescence $(\mathrm{CL})$. The observations were obtained by using a hot cathode electron gun on carbon-coated polished thin sections. Besides the acquisition of a CL-image, a crossed polarized image of the same region can also be produced since the electron gun is mounted on an optical microscope. This allows for a comparison of both results. In carbonates such as marble, the intensity of luminescence is mostly controlled by the ratio of manganese and iron, where $\mathrm{Mn}^{2+}$ acts as an activator and $\mathrm{Fe}^{2+}$ as a quencher ion. With this method late-stage crack fillings, sector zoned growth fabrics or fluid influences in marbles can be discerned. Furthermore, distinctions between calcite and dolomite can be made, which are the main components of marble (see Gross et al., 1999; Marshall, 1991).

\subsubsection{X-Ray Goniometer, EBSD measurements}

The crystallographic preferred orientation (CPO) or lattice preferred orientation of the minerals (LPO) was determined on a X-Ray texture goniometer (PAN analytical X'pert System). The analyses have been performed on polished samples with a size of $5 \times 5-$ $8 \times 8 \mathrm{~cm}$, parallel to the $X Y-, X Z$ - und $Y Z$-plane. Each sample was analysed with a beam size of $10 \times 10 \mathrm{~mm}$ for 9 measuring points per plane to receive an adequate number of data and avoid wrong results caused by single crystal effects (Leiss and Ullemeyer, 2006). The calculation of the pole figures was performed with the software TexCor as well as with the MATLAB based software MTEX (Bachmann et al., 2010; Mainprice et al., 2015), which was used to calculate the ODF data and the anisotropic physical properties (Mainprice et al., 2011; Mainprice et al., 1990). 
Another used technic was the electronic backscatter diffraction (EBSD) to determine the texture. EBSD is a texture analysing technique using scanning electron microscopy (SEM), where the SEM is equipped with an EBSD detector (for further information see Maitland and Sitzman, 2007; Wenk and van Houtte, 2004). This technique was used for the sculpture of an o site measurement due to the small sample size of $20 * 15 \mathrm{~mm}$.

\subsection{Petrophysical properties}

\subsubsection{Porosity}

Following DIN 52102 the effective porosity (porosity accessible from the outside) was investigated by determining the different weight states, dry weight (md), wet weight (mw) and buoyancy weight $(\mathrm{mb})$ using demineralised water as the pore-saturating medium. After the samples have been dried at $40^{\circ} \mathrm{C}$ to mass consistency, the saturation of the accessible pore space was achieved by 24 -hour storage in vacuum and subsequent water storage for 48 hours. The buoyancy weight was measured by submerging the samples in a water bath with simultaneous weight-measurement by an under-floor balance. The measurements were carried out on cubic samples with an edge length of approx. 65 $\mathrm{mm}$. The porosity results from the equation:

$$
\Phi=\frac{m_{w}-m_{d}}{m_{w}-m_{b}} * 100
$$

Whereas

$$
\begin{aligned}
& \Phi[\%]=\text { Porosity } \\
& m_{d}[g]=\text { Dry weight } \\
& m_{w}[g]=\text { wet weight } \\
& m_{b}[g]=\text { buoyancy weight }
\end{aligned}
$$

Furthermore, the bulk density ( $\rho r o h$ ) and the matrix density ( $\rho$ mat) can be determined on the basis of these data.
Bulk density:

$$
\rho_{\text {roh }}=\frac{m_{d}}{m_{w}-m_{b}} \quad\left[\mathrm{~kg} / \mathrm{m}^{3}\right]
$$
Matrix density:

$$
\rho_{\text {mat }}=\frac{m_{d}}{m_{d}-m_{b}} \quad\left[\mathrm{~kg} / \mathrm{m}^{3}\right]
$$


The pore space is of decisive importance for the weathering behaviour of natural stone, as the mechanical and physical properties (e.g. water transport mechanisms) of a rock are controlled by the type, shape, size, distribution and cross-linking of the pores.

\subsubsection{Ultrasonic measurements}

\subsubsection{Transmission}

Ultrasonic data are calculated by the measured ultrasonic travel time determined for the respective measuring distance, considering the longitudinal wave, following the equation:

$$
V_{p}=\frac{l \times 10^{3}}{t_{l}-t_{0}}
$$

With the compressional wave velocity $V_{p}[\mathrm{~m} / \mathrm{s}]$, the measured distance $I$ in $\mathrm{mm}$, the measured travel time $t_{1}[\mu s]$ and the probe specific travel time $t_{0}$.

This type of wave correlates especially well with the structural properties of marble (Dürrast et al., 1999; Köhler, 1991; Ruedrich et al., 2001; Ruedrich and Siegesmund, 2001; Weiss et al., 2001) and depends on the mineralogical, physical and mechanical properties of the stone, its degree of water saturation and its level of deterioration.

Generally, for ultrasonic measurements lower frequencies are used to measure opposite positions in transmission. Mostly applied in cases where the reflection method will give qualitative insufficient results. The reasons for the insufficient quality can be found in the specific material characteristics. For example, the acoustic attenuation and sound scattering is very high for heterogeneous material as natural stone and concrete. Therefore, low frequencies between 20 and $350 \mathrm{kHz}$ are used for these materials, whereby the sound radiation is more or less unfocused, with an aperture angle of $180^{\circ}$. Ahmad et al., 2009 gives a more detailed overview regarding ultrasonic testing. 


\subsubsection{2 $360^{\circ}$ measurements}

To determine the 3-Dimensional velocity distribution spherical samples with diameter of $50 \mathrm{~mm}$ have been measured with a frequency of $1 \mathrm{MHz}$ under dry and water saturated conditions. A measuring equipment allows the determination of the compressive wave velocity $(V p)$ in transmission in 192 directions in an immersion bath. The equipment allows a $360^{\circ}$ rotation of the sphere, while the submersible transducers rotate horizontally stepwise in $10^{\circ}$ until $75^{\circ}$ (see Figure 5). Based on these data the spatial distribution of Vp can be calculated and be depicted as an isoline plot (Schmidt-Net). Detailed information can be found at Jahns, 1995.
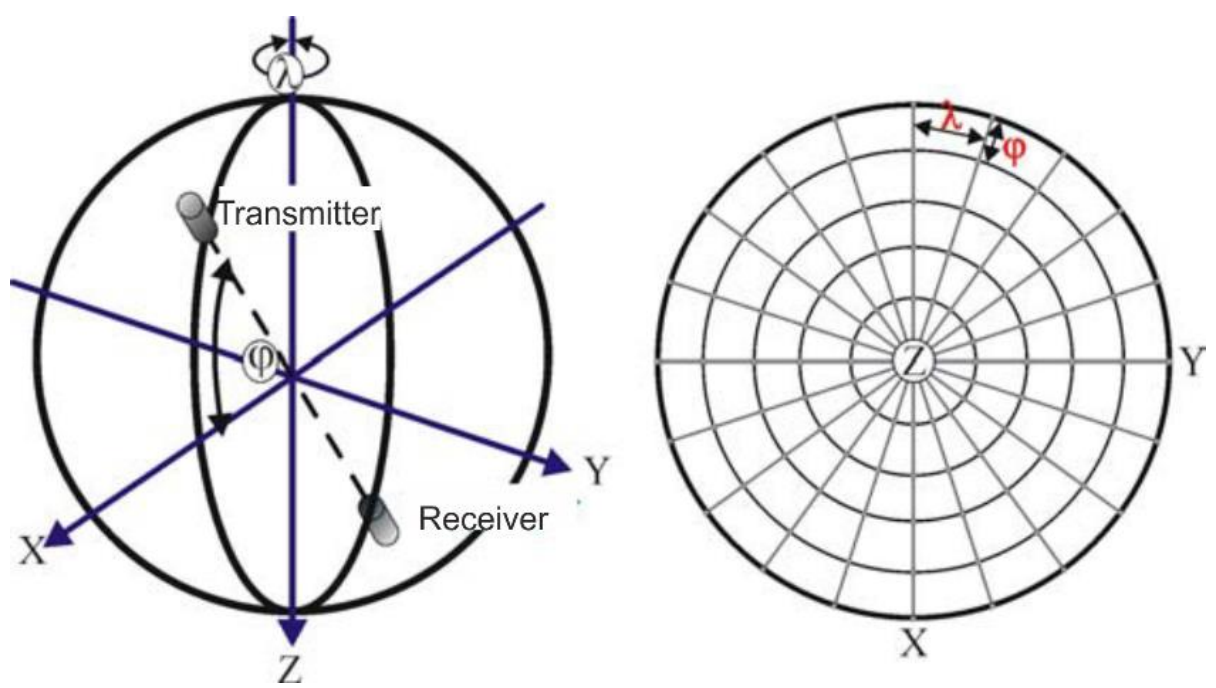

Figure 5 Schematic representation of the measurement equipment and the applied measurement grid (modified after Ruedrich, 2003).

\subsubsection{Tomographic inversion}

To determine the weathering state of important cultural and historical objects made of marble, the method of ultrasonic measurements is well established and ensures a nondestructive examination method (e.g. Dürrast et al., 1999; Köhler, 1991, 2014; Ruedrich et al., 2001; Ruedrich and Siegesmund, 2001; Siegesmund et al., 2010; Snethlage, 2014; Weiss et al., 2001). The transmission method has been established as an often used monitoring examination, whereas the tomographic approach is less often used (Capizzi et al., 2013; Cardarelli and Nardis, 2001; Menningen et al., 2018b; Ruedrich et al., 2001; Siegesmund et al., 2010). The main reason that the conventional method is favoured is the very time-consuming tomographic measurement process and the non-trivial interpretation. While the transmission method considers the mean ultrasound travel time 
for one distance and gives no detailed information about the internal structure, the tomography allows the determination of the velocities in a cross-sectional plane. With an optimal ray coverage, the plane can be spatially resolved, and corresponding weakness zones can be detected.

Ultrasonic tomography assumes that a longitudinal wave crosses on its way through an object the weathered surface followed by the intact core, depending on the weathering depth, and then again, the weathered surface on the other side. Assuming an equal weathering depth, the transit time of the P-wave will increase less than proportionately to the total thickness of the investigated object, so the average velocity will increase (see Blum and Rahm, 1998). For an ultrasonic tomography on a predefined cross-section, different measurement points are defined and marked. The transmitter is positioned at one defined point of measurement, while the receiver is placed at each other defined point on that cross-section. After completion of that array, the transmitter position is changed to the following defined point and the receiver is again positioned at each circumferential point, until the cross-section is measured.

Measuring ultrasonic velocities alone does not provide a spatial velocity distribution inside the rock, i.e. zones of high or low velocities, therefore, further processing of the data is needed. The travel time of each ray only represents the mean velocity over the distance it covered, hence, a grid of intersecting ray paths needs to be generated. By performing a 2D tomographic analysis of the source-to-receiver travel times using the software GeoTomCG, it is possible to calculate velocities at predefined points inside this grid (GeoTom, LLC 2017).

GeoTomCG calculates its inversions with a technique called SIRT or simultaneous iterative reconstruction technique (Lehmann, 2007). This method uses a starting (or initial) velocity model and modifies it, until it converges into a solution (for detailed information see Jackson and Tweeton, 1994). The calculations consist of a repeating cycle of three steps. The initial velocity model is used to calculate a set of model travel times, so called forward computation. These calculated model travel times are subtracted from the measured travel times, generating a set of residuals, which allow the calculation of a set of correction factors, which are then applied to the grid points in the initial model. In GeoTomCG, the correction factors per point are weighted, corresponding to the number 
of rays that passed that point. The programme repeats this cycle of steps through a user specified number of iterations.

\subsubsection{Dynamic E-modulus}

The modulus of elasticity (Edyn) or Young's Modulus can be calculated on basis of the compressive ultrasonic wave following the equation:

$$
E d y n=V_{P}^{2} \frac{(1+\mu)(1-2 * \mu)}{1-\mu} * \rho
$$

Where:

$\begin{array}{lll}\mathrm{Vp}[\mathrm{m} / \mathrm{s}] & = & \mathrm{P} \text {-wave velocity } \\ \rho & = & \text { the density } \\ \mu & = & \text { the Poisson's ratio. }\end{array}$

The Poisson's ratio can be calculated by:

$$
\mu=\frac{V_{p}^{2}-2 V_{s}^{2}}{2\left(V_{p}^{2}-V_{s}^{2}\right)}
$$

To calculate the Poisson's ratio it is necessary to know the transversal wave velocity $\left(\mathrm{V}_{\mathrm{s} .}\right)$, as well as the compressional wave velocity (P-wave) (Fleischer, 2002; Siegesmund and Dürrast, 2014).

\subsubsection{Thermal expansion}

The thermal expansion behaviour of the marbles examined was determined on rock cylinders with a length of $50 \mathrm{~mm}$ and a diameter of $15 \mathrm{~mm}$, which were taken parallel to the orthogonal microstructure directions $(X, Y, Z)$ and the intermediate directions $X Y, X Z$ and YZ. The directional dependence of thermal dilatation was determined as a function of temperature.

Dilatation data is usually represented by calculating the coefficient of expansion $\alpha$, which is calculated using the formula:

$$
\alpha=\frac{\Delta \mathrm{l}}{\mathrm{l} * \Delta \mathrm{T}}
$$


$\alpha$ is determined from the slope of a portion of the strain curve, where:

$\begin{array}{lll}\alpha[\mathrm{K}-1] & = & \text { expansion coefficient } \\ \Delta \mathrm{I}[\mathrm{mm}] & = & \text { length change } \\ \Delta \mathrm{T}[\mathrm{K}-1] & = & \text { temperature change } \\ \mathrm{I}[\mathrm{mm}] & = & \text { sample length }\end{array}$

For better illustration, the value $\varepsilon$, representing the absolute length change is given by the formula:

With:

$$
\varepsilon=\frac{\Delta \mathrm{l}}{\mathrm{l}}
$$

$\begin{array}{lll}\varepsilon[\mathrm{mm} / \mathrm{m}] & = & \text { length change per meter } \\ \Delta l[\mathrm{~mm}] & = & \text { length change } \\ I[\mathrm{~m}] & = & \text { sample length }\end{array}$

\subsubsection{Resistance of marble to thermal and moisture cycles}

The resistance of marble to thermal and moisture cycles, also known as bowing, was tested according to the DIN EN 16306. Therefore, marble slabs with a size of $400 * 100 * 30 \mathrm{~mm}$ were analysed in different directions, according to the reference system. The slabs are placed in a box, where a heating mat irradiates the samples from above, while their bottom is placed on a wet fleece with a $5 \mathrm{~mm}$ high water film.

One cycle includes a heating phase of 6 hours, where the temperature increases from ambient temperature up to $80^{\circ} \mathrm{C}$ and a cooling phase of 18 hours, back to ambient temperature. The bowing behaviour was investigated by a measuring bridge with an accuracy of $\pm 1 \mu \mathrm{m} / 35 \mathrm{~cm}$. The calibration of the dial gauge was performed with a reference cylinder made of quartz glass.

According to the equation:

$$
B=\frac{H}{L} * L_{N}
$$

With:

$\begin{array}{lll}\mathrm{B}[\mathrm{mm} / \mathrm{m}] & = & \text { bowing } \\ \mathrm{H}[\mathrm{mm}] & = & \text { measured expansion } \\ \mathrm{L}[\mathrm{m}] & = & \text { measuring distance }[\mathrm{m}] \text { and } \\ \mathrm{L}_{\mathrm{N}}[\mathrm{m}] & = & \text { standardized measuring distance }\end{array}$

the bowing intensity was calculated. 


\subsection{Moisture characteristics}

\subsubsection{Capillary water uptake}

The capillary water uptake was measured following DIN EN 13755:2008-08, to determine the cross-linking of the pore space and the intensity of the capillary water transport. The latter is of great importance for the weathering of marble due to the high solubility of the calcite crystal.

The capillary water absorption was, measured in 3 directions ( $X, Y$ and $Z)$. Therefore. dry rock cubes (edge length $=65 \mathrm{~mm}$ ) were used as test material and fixed on a under floor balance upon a water basin filled with demineralised water. Approximately $10 \mathrm{~mm}$ of the lower part of the sample was placed in the water, while the weight gain was measured every 10 seconds with a connected software.

The water absorption coefficient (w-value) is determined by the relationship of the capillary water absorption $\left(m_{w}\left[\mathrm{~kg} / \mathrm{m}^{2}\right]\right.$ ) versus time $(\mathrm{t}[\mathrm{h}])$ following the equation:

$$
w=\frac{m_{w}}{\sqrt{t}} \quad\left[\mathrm{~kg} / \mathrm{m}^{2 *} \sqrt{\mathrm{t}}\right]
$$

The $w$-value provides information on how much water can be absorbed by the rock over a certain area by capillary suction.

A further important parameter for characterising the water absorption capacity of rocks is the degree of saturation, which describes the ratio of the maximum water absorption (accessible pore space under vacuum $\mathrm{W}_{\mathrm{vac}}$ ) and the voluntary water absorption under normal conditions (atmospheric pressure $W_{\text {atm }}$ ) of a rock. The S-value is calculated using the following equation:

$$
S=\frac{w_{a t m}}{W_{v a c}}
$$




\subsection{Artificial Alteration}

All samples were artificially alterated within this work, to analyse the weathering characteristics and their influences on the rock properties. Therefore, all samples were stepwise alterated by thermal load. To ensure that the samples have no prior thermal influences, they weren't dried above $40^{\circ} \mathrm{C}$.

The first step was to place the samples in an oven and increase the temperature up to $60^{\circ} \mathrm{C}$. The samples were left there for 4 hours, to ensure an uniform heating of the samples, before they were placed in a cooled bucket with water, where the temperature was about $4^{\circ} \mathrm{C}$. Afterwards they were dried again at $40^{\circ} \mathrm{C}$ until mass constancy.

After all measurements have been performed, the next weathering cycle was induced, with a temperature of $90^{\circ} \mathrm{C}$. Following the described procedure, the next steps included heating up to $120^{\circ} \mathrm{C}, 150^{\circ} \mathrm{C}$ and $200^{\circ} \mathrm{C}$. After these steps, a final alteration step was initiated where the samples were warmed up to $200^{\circ} \mathrm{C}$, placed in cooled water and finally were stored for 24 hours in a fridge. After this time, they were again heated up to $200^{\circ} \mathrm{C}$ for 4 hours and cooled down in cool water. After this procedure, the samples were dried and analysed. For this work the roman numbers $0-\mathrm{VI}$ are used to abbreviate the weathering steps with 0 as initial state, $160^{\circ} \mathrm{C}, \| 90^{\circ} \mathrm{C}$, III $120^{\circ} \mathrm{C}$, IV $150^{\circ} \mathrm{C}, \mathrm{V} 200^{\circ} \mathrm{C}$ and $\mathrm{VI}$ for the combination of heating and freezing. 


\section{The Estremoz Marbles}

The non-destructive evaluation of marble by means of ultrasonic velocities has proven its usability within the last decades. The application of ultrasonic tomography is less often performed due to its time-consuming approach and non-trivial interpretation. One important aspect for the best possible interpretation is an in-depth knowledge of the specific marble properties, particularly with regard to their rock physical properties. As an example of possible variations within the same marble type, the Portuguese Estremoz marbles were analysed systematically. Their rock physical properties were determined and used to quantify their anisotropy. Especially the thermal expansion behaviour was investigated to evaluate their weathering vulnerability. This type of marble shows a great diversity in colour and fabric, even if each sample comes from the same anticline. To see if these differences influence its weathering behaviour and thus possible ultrasonic investigations, a systematic study on representative types has been performed.

\subsection{Introduction}

The application of marble for the creation of buildings, monuments and art is known since antiquity as they are special and valuable natural dimensional stones. These stones show properties of high compactness and high mechanical resistance. They are easy to polish, exhibit aesthetical properties such as translucency and great colour diversity. Wherever deposits were available as a nearby resource architects, artists and sculptors used this rock material. Therefore, this material was used for important historical works of art, and thus are an expression of the national identity. The Taj Mahal, for example, attracts millions of tourists from all over the world every year. Made from Makrana marble (Sanchit Garg et al., 2019) and in combination with an exquisite ornamentation and precious gemstones, this building is part of the world heritage and the national landmark of India. The Alhambra in Granada (Spain) is one of the most visited tourist attractions in Europe. At this locality, twelve precious lions, made from the white Macael marble, can be found (Navarro et al., 2017). 
The use of marble can also be traced back to the beginnings of Greek culture. The marble from Paros, Pentelian marble, or those from Naxos and Thassos were already used for the construction of high-quality residential buildings, baths, kitchens, temples and as material for artistic purposes. The most famous statue or antique building made of Parian marble is probably the Venus of Milo or the Apollo temple in Delphi.

The well-known Greek marble was displaced by the marble found in the Alpe Apuane Region throughout Roman domination. In the Italian province of Massa-Carrara in Tuscany, the famous Carrara marble has been mined since time of the Roman Republic. The Renaissance sculptor Michelangelo created his artworks, like the David in Florence, by using the white marble. Carrara marble has not only been used for magnificent sculptures, imposing temples, palaces and monuments, but also everyday objects like baths and whole streets were made of this marble. This marble is traded with many different names, i.e. Ordinario, Venato, Nuvplato, Calacatta, Arabescato etc. (Meccheri et al., 2007).

Besides those famous marble varieties, the Portuguese Estremoz marble is another example of an important heritage stone. In the construction of 200 national monuments, it has been used verifiable (IP - IHRU) and there is no city in Portugal where Estremoz Marble has not, somehow, been used in both, small works of art or utilitarian objects as public monuments and in private homes. Historically documented usage dates to the fourth century BC (Cabral et al., 1992) and extends to the current global commercial trade, where Estremoz Marble can be found all over the world.

This long-time usage constitutes an indicator of the marble's importance in the history of Portugal and certifies its value as a Global Heritage Stone Resource to be preserved. Nowadays business associations and Portuguese dimension stone companies have made a huge effort towards the promotion and marketing by enhancing high levels of quality, certification, verification and management of Estremoz Marble (Lopes and Martins, 2015).

On the other hand, numerous damages on sculptures, ancient or historical buildings and monuments, as well as modern facades made from marble, have shown that this unique rock material also shows signs of deterioration when used as building stone. Macroscopic damages of marbles are very complex and originate mainly by chemical, biological and physical as well as anthropogenic impacts. A pronounced surface roughness can be 
traced back to chemical solution processes. Black crust formation and the development of gypsum is also well-known, probably resulting from the high traffic volume. Gaseous compounds, solid dirt particles, such as soot, fine particles, rubber particles and microbiological colonisation are the main causes of the soiling and pollution on the surfaces of the statues (Steiger et al., 2014).

Those damages can be observed as networking cracks like craquelure. Areas of strong fabric decay, macrocracks and material breakouts are also common. Sporadically, a sugar-like crumbling can be observed or even flaking and scaling phenomena (Fitzner and Heinrichs, 2004; Siedel and Siegesmund, 2014).

This deterioration can not only be observed for ancient objects made of marble. The usage of stone panels as cladding material for facades has undergone a considerable increase in the last decades. The observed durability problem, for example their bowing behaviour, as the most spectacular deterioration feature of some marble panels, has given a negative image to these materials. The reasons for the observed deformation are still under discussion (Kessler, 1919; Koch and Siegesmund, 2004; Luque et al., 2011; Ruedrich, 2003; Siegesmund et al., 1999; Siegesmund et al., 2000a; Siegesmund et al., 2008; Weiss et al., 2002b; Weiss et al., 2002a; Zeisig et al., 2002). Length changes of approximately $1 \mathrm{~mm} / \mathrm{m}$ upon repeated heating and cooling cycles have been reported, which consequently leads to a loss of cohesion along the grain boundaries.

As the Portuguese Estremoz marble is one example of the important marble varieties used as building stone, intensive analyses have been performed to analyse their potential weathering behaviour. The name Estremoz is used for many of the varieties, exploited and sold from the region. To demonstrate the possible differences within one anticline and the importance of the mineralogical composition and the rock fabrics on the potential physical weathering, a large collection of selected varieties of the Estremoz marbles were investigated. Representative marble varieties were chosen for analysis with regard to their mineralogical composition and microfabric. Emphasis is placed on the ultrasonic velocities, thermal and thermohygric expansion, bowing behaviour and the residual strain to characterise the effect of stone decay. 


\subsection{Regional geology and tectonic setting}

The Estremoz Anticline (Gonçalves, 1972) is a $45 \mathrm{~km} \mathrm{NW-SE} \mathrm{structure} \mathrm{with} \mathrm{a} \mathrm{maximum}$ $10 \mathrm{~km}$ width near Estremoz, Portugal (Figure 6).

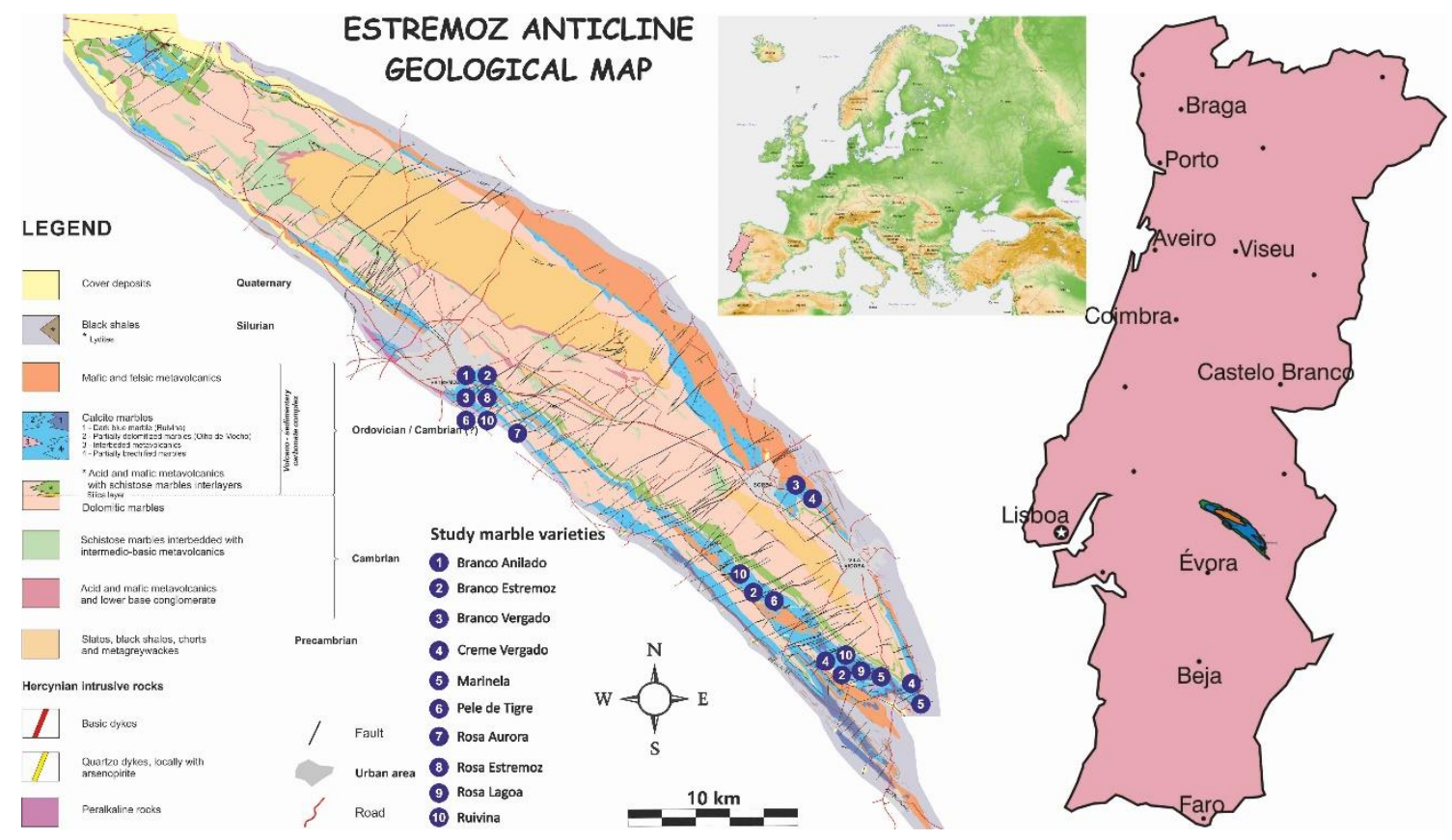

Figure 6 Geological map of the Estremoz Anticline, Portugal (Moreira and Vintém, 1997). Sample locations: 1) Branco Anilado, 2) Branco Vergado, 3) Rosa Aurora, 4) Pele deTigre, 5) Ruivina, 6) Creme Vergado, 7) Marinela, 8) Rosa Estremoz, 9) Rosa Lagoa, and 10) Branco Estremoz.

First described by da Silva and Camarinhas, 1957, the stratigraphic sequence of the Estremoz Anticline includes the following units (Gonçalves, 1972; Gonçalves, 1974; Gonçalves and Oliveira, 1986; Oliveira et al., 1991; Lopes, 2003; Lopes, 2007; Pereira et al., 2012) (Figure 7):

(1) Precambrian Ediacaran greywackes, shales and black cherts (Mares Formation, Série Negra succession), which crop out in two separate elongated NW-SE trending ribbons in the core of the Estremoz Anticline;

(2) Cambrian arkosic sandstones at the base (which unconformably overlie the Serie Negra rocks) and dolomitic limestones (400 m thick) towards the top (Dolomitic Formation); 
(3) A 5-50 m-thick silica-rich layer atop the dolomitic limestones (quartz and iron-rich, pyrite at depth, which is transformed into iron oxide pseudomorph crystals at the surface). The intersection of this layer was the criterion used to stop the drilling carried out in past projects to define the thickness of the marble (Lopes, 2003);

(4) Thick-bedded Cambrian-Ordovician (?) limestones (originally 70-100 m thick) with interbedded basalts, rhyolites and shales (this succession is known as the Volcanic-Sedimentary Complex of Estremoz, which includes the Estremoz Marbles with ornamental interest). The shales, black shales and black cherts, younger rocks aged Silurian-Devonian (d'Almeida, 2000; Lopes, 2003; Lopes, 2007) surround the Estremoz Anticline.

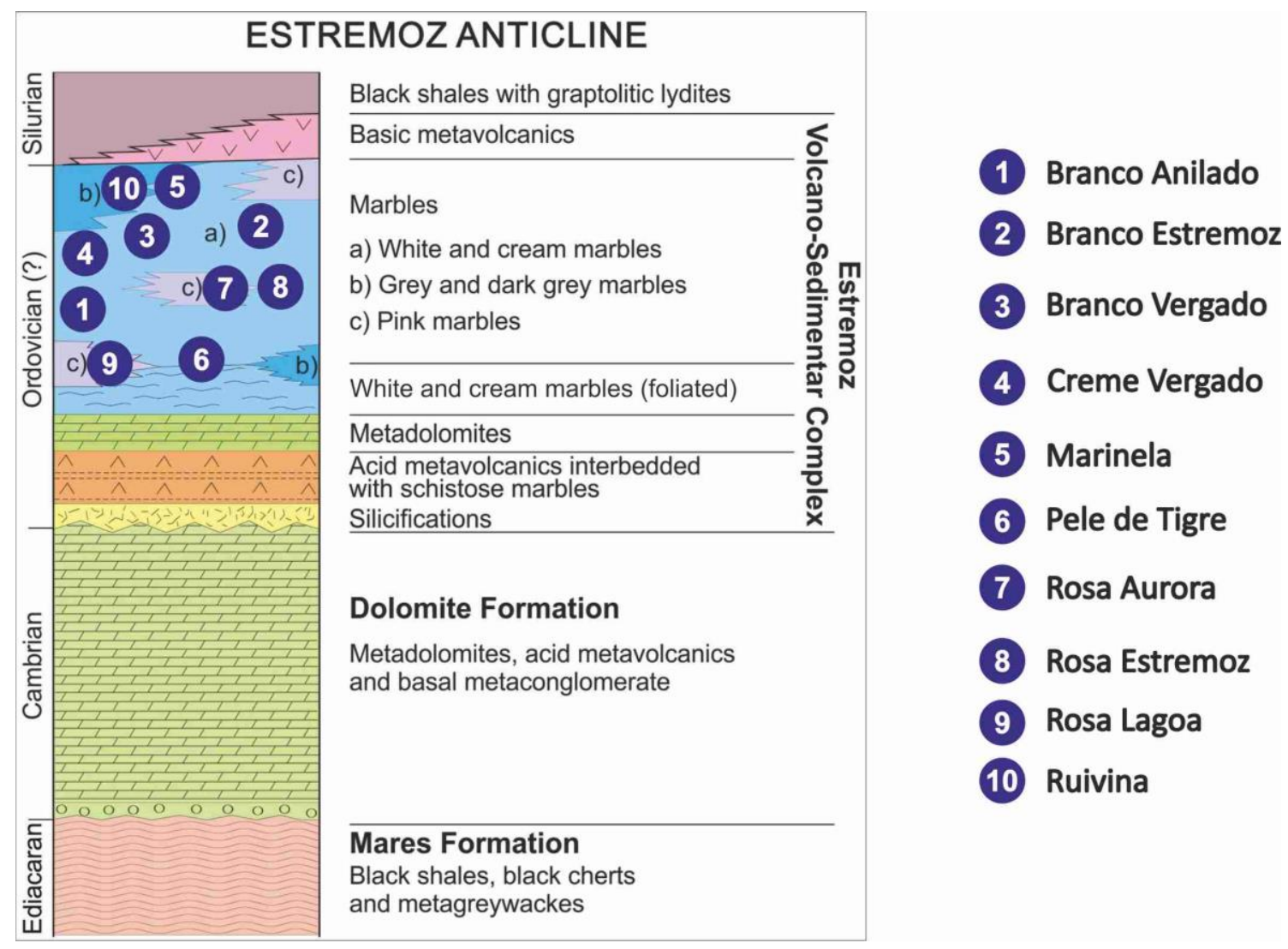

Figure 7 Tectonostratigraphic sequence of the Estremoz Anticline (Carvalho, 2008).

Caused by regional tectonic processes, overlapping by faults and thickening of the marble layers by folding along hinge zones, the marbles can attain a thickness of over $400 \mathrm{~m}$. The stratigraphic sequence of the Estremoz Anticline was deformed and metamorphosed under greenschist to lower amphibolite metamorphic conditions during the Variscan Orogeny (Carboniferous). Variscan deformation and metamorphism in the Ossa- 
Morena Zone was responsible for the development of $110^{\circ}-170^{\circ}$ - trending folds and ductile to brittle-ductile shear zones (Lopes, 2003; Pereira et al., 2012).

The Estremoz Anticline resulted from the interference of two Variscan folding phases of wrenching. D1 folds are associated with development of extensional shear zones and boudinage. Mylonitic foliation and stretching lineation parallel to the maximum elongation direction (170-180 ) and shear criteria (asymmetrical tails of porphyroclasts, $\mathrm{C}-\mathrm{S}$ planes, Figure 8) are consistent with movement with top-to-the-north.

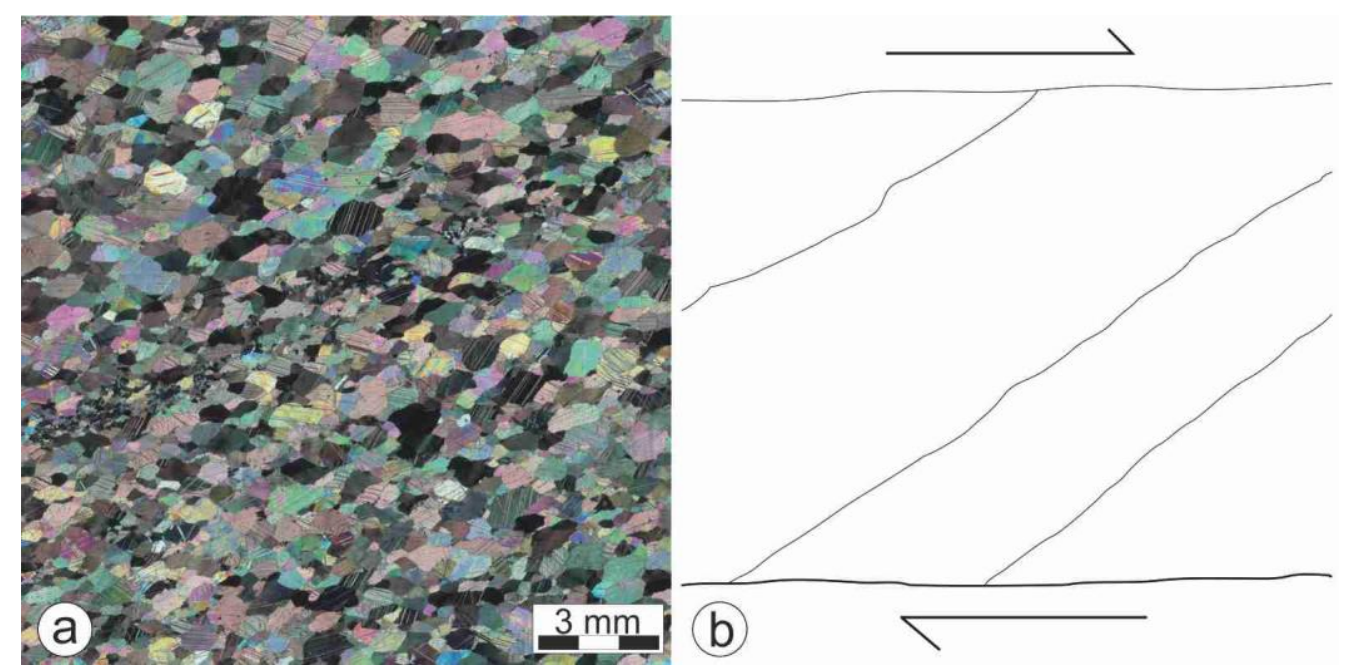

Figure 8 Example of SC-fabric observed in the Rosa Lagoa marble: a) thin section image, perpendicular to the foliation plane, b) sketch and interpretation of the SC fabric.

The Estremoz Anticline is characterised by $110-130^{\circ}$ striking, tight to close D2 folds with vergence to the NE. D2 folding is associated with slaty cleavage and discrete brittle-ductile shear zones along the reverse and stretched limbs of tight folds. These shear zones strike $110-130^{\circ}$ and have a gently $\left(<10^{\circ}\right) \mathrm{NW}$ - or SE-plunging mineral lineation parallel to the D2 fold axis (Boudani et al., 2015; Lopes, 2003; Lopes, 2007; Pereira et al., 2012). The Late Variscan fragile deformation is also presented in two sets of arrays. The first is closely related with the D2 folds and consists of subvertical NNE-SSW and ENE-WSW trending conjugated faults, frequently associated with NE-SW, subvertical tension cracks. The second fault set is characterised by sub-vertical NNW-SSE and NE-SW trending faults. 


\subsection{Estremoz Marble: heritage, commercial varieties,} applications and economy

\subsubsection{Historical aspects}

The marble from the Portuguese region Alentejo is used as an ornamental stone and has been appreciated since time immemorial (Figure 9). The different chromatic aspects and the odd quality make it unique, and thus has been exploited since antiquity as a valuable geological resource.

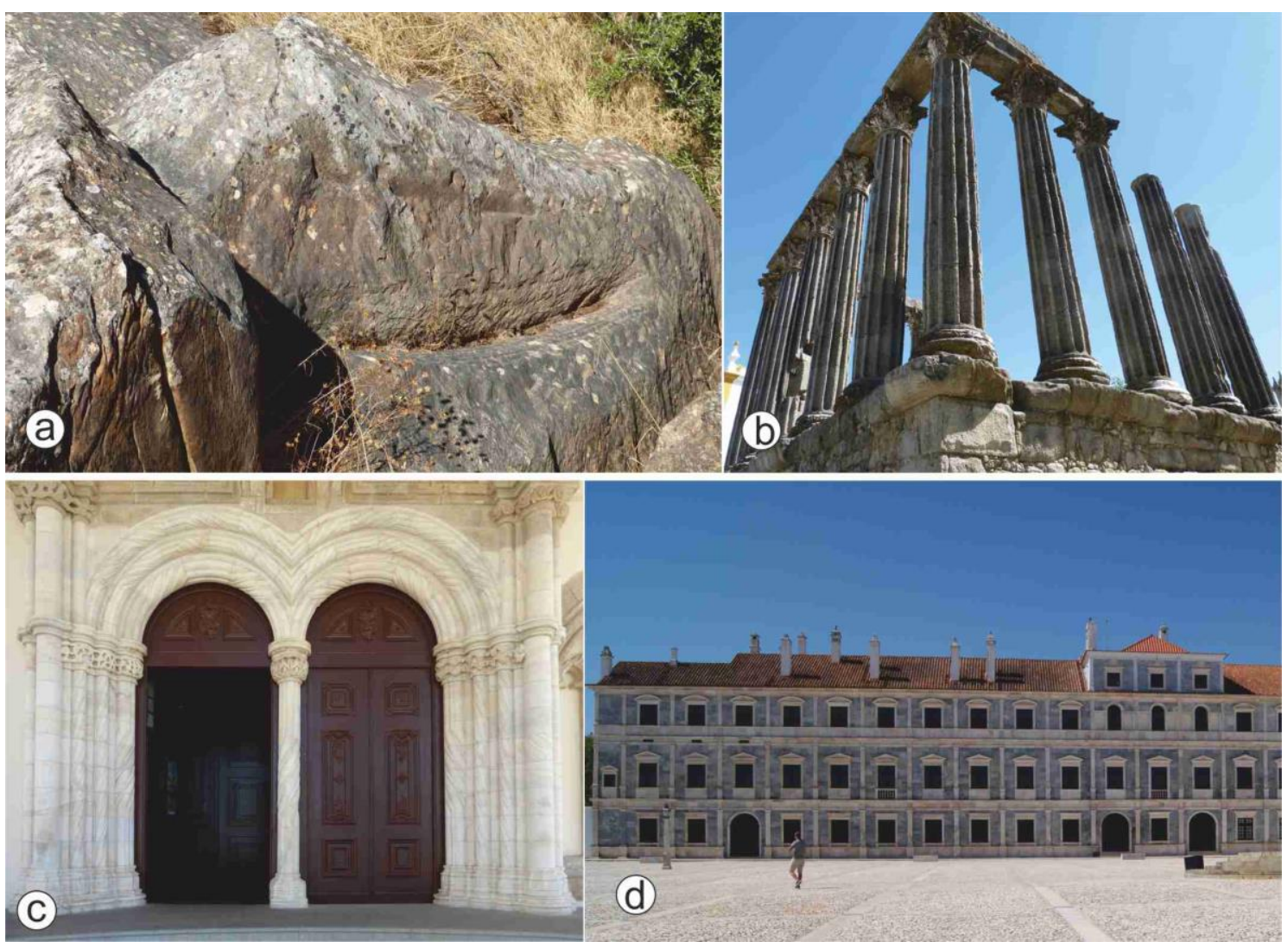

Figure 9 Use of Estremoz marble in architectural monuments from ancient Roman times to the historical period: a) Traces of Roman marble quarrying, b) Roman Temple in Evora, c) Portal of Igreja Sāo Francisco in Evora, and d) Ducal Palace of Vila Viçosa.

Many traces of Roman marble quarrying were found during the exploitation of quarries in the $20^{\text {th }}$ century (Figure 9a). Some of these were lost due to neglect and a lack in recognizing their historical value. Nevertheless, it was still possible to gather pieces that attest to the intense activity in the Roman Period. These objects include columns, unfin- 
ished sculptures, or pieces damaged during the process of sculpting sarcophagi, structural elements for buildings, and containers to preserve meat and fish, etc. Many belong to private owners, but they can also be seen in several museums. Moreover, in the Roman Period, the Estremoz Marble was widely used for structural and decorative features in buildings that today are extraordinary architectural monuments. For example, the Roman Temple in Évora (Figure 9b), the Roman Theatre in Mérida (Spain) and the Roman Towns of Ammaia (Taelman et al., 2013) and Volubillis, Morocco, where they used the 'Portuguese pink'. This pale pink marble was exploited by the Romans near Vila Viçosa in the Lusitania which, till now, has not yet been identified outside Iberia' (Antonelli et al., 2009). Over the centuries Portuguese marbles were used in castles, palaces, churches and other buildings (Figure 9, d). They were sought for ornamental purposes and appeared inlaid with various polychromatic associations in several national and international monuments, for example, the Cathedral of Évora and Geronimo's Monastery (Portugal), the Escorial Monastery (Spain), several monuments in Rome (Italy), as well as the Louvre and Versailles (France) (Moura and Carvalho, 2007).

Marble exploration has always been characterised by the development of open pits, by right steps, due to the morphological characteristics of the Alentejo lowland terrain. Underground quarries are scarce, not proving to be the most effective option to preserve the cultural and natural landscape.

Portugal's entry into the European Economic Community in 1986 enabled the industry to have access to community funds for modernization. This allowed economic convergence with European countries and Portugal becoming more competitive.

\subsubsection{Economical background}

In statistical terms (see Figure 10), the available dimension stone export and import data from Portugal before 2000 , does not allow a precise estimation of the production between marbles and limestones or other stone types. However, an investigation by Luz, Luís Miguel Nunes Barata de, 2005 shows the trade relationships in the dimensional stone sector. 


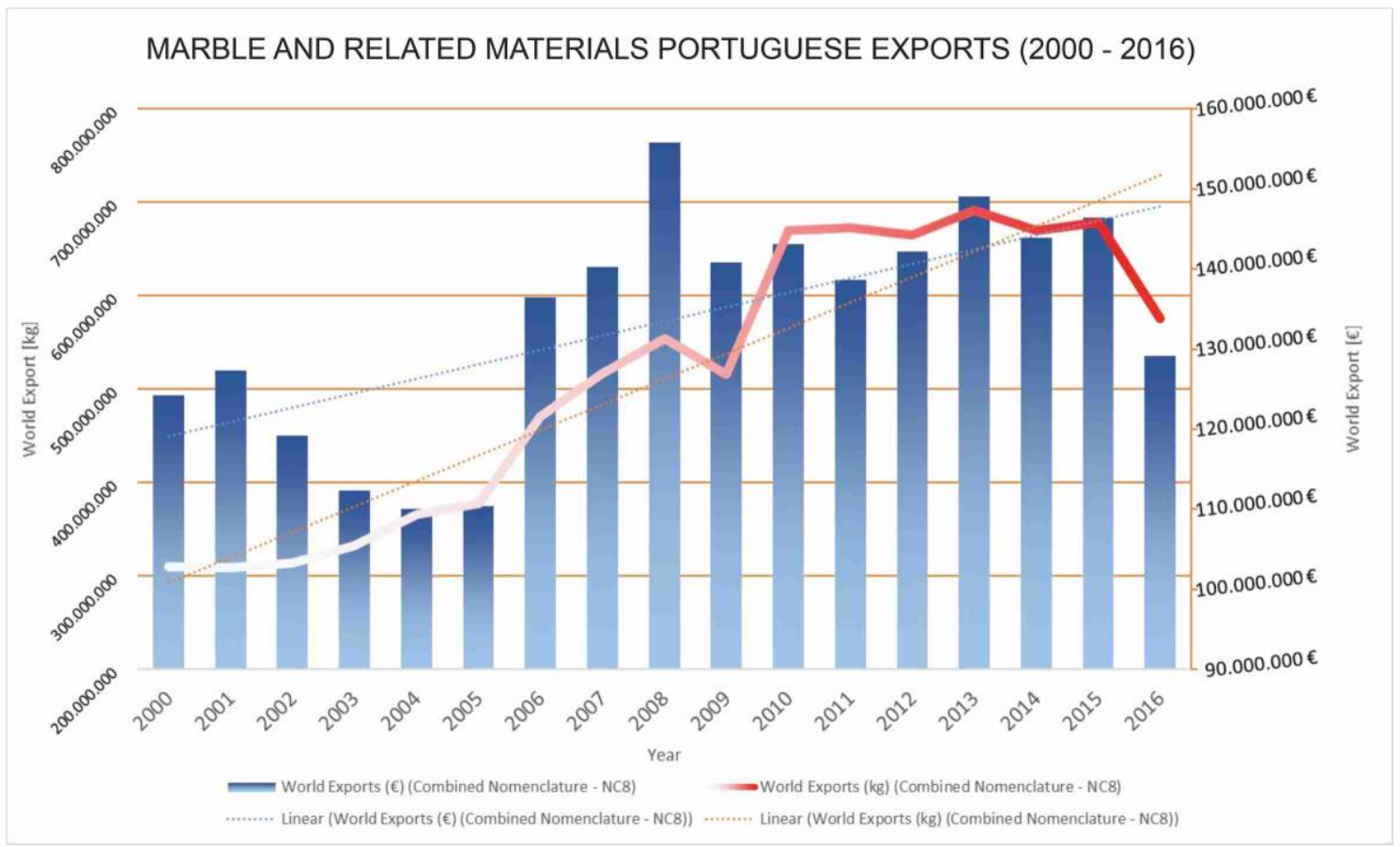

Figure 10 Export of Portuguese marble in quantity and value from 2000 to 2016. Data complete from 2000 to 2014, provisional in 2015 and preliminary in 2016. (Last update of this data: February 09, 2017; Table drawn on October 2017).

Until the end of the $1980^{\text {th }}$, France and Switzerland were the countries that showed the greatest interest in Portuguese marble (e.g. blocks and also pre-processed material). In the $1990^{\text {th }}$ trade with Italy and Spain increased. At the end of the $20^{\text {th }}$ century, countries like Norway, Morocco and Vietnam, with whom Portugal rarely traded with, became new trading partners.

Germany, France and Spain were the main partners for Portugal until 1987 in regard to cut stone, but after a decline in demand on the German market, Italy replaced Germany as main trading partner. Exports to the Netherlands and Greece also occurred. In 2000, India, Brazil, Vietnam, and Egypt were sporadically Portugal's trading partners in sawed material. They also became the main protagonists of Portugal's foreign trade in cut stone.

The longest, uninterrupted business relationship (import and export) for finished pieces of Portuguese marble exists between Italy (since 1983) and Spain (since 1984). Other member states of the European Union are also important trading partners, e.g. France, Belgium, Luxembourg, Germany, United Kingdom, the Netherlands and Greece (Luz, Luís Miguel Nunes Barata de, 2005). 
The quality of Portuguese marble as a finished product has become more interesting for other non-European countries. For example, at the turn of the $20^{\text {th }}$ century, China has become the main economic trading partner, but also relevant trade is being conducted with Brazil, Egypt and Taiwan.

Primary stone processing (block dimensioning) is done in or nearby the 67 active quarries. In the so-called "Marble Triangle" there are about 30 medium to large processing plants, that transform the blocks into slabs and tiles. In Alentejo 174 small and microfactories exist, half of them are found in the Estremoz region. Other processing centres are located in Pêro Pinheiro (150 km away; northwest of Lisbon) and in the Maciço Calcário Estremenho (200 km away, in the Leiria and Santarém districts, about 150 km north of Lisbon). In 1987 there were more than 260 active quarries in the Estremoz Anticline, although the dimension of these quarries was much lower in size than today, where the deepest extraction occurs at $150 \mathrm{~m}$ (Figure 11).
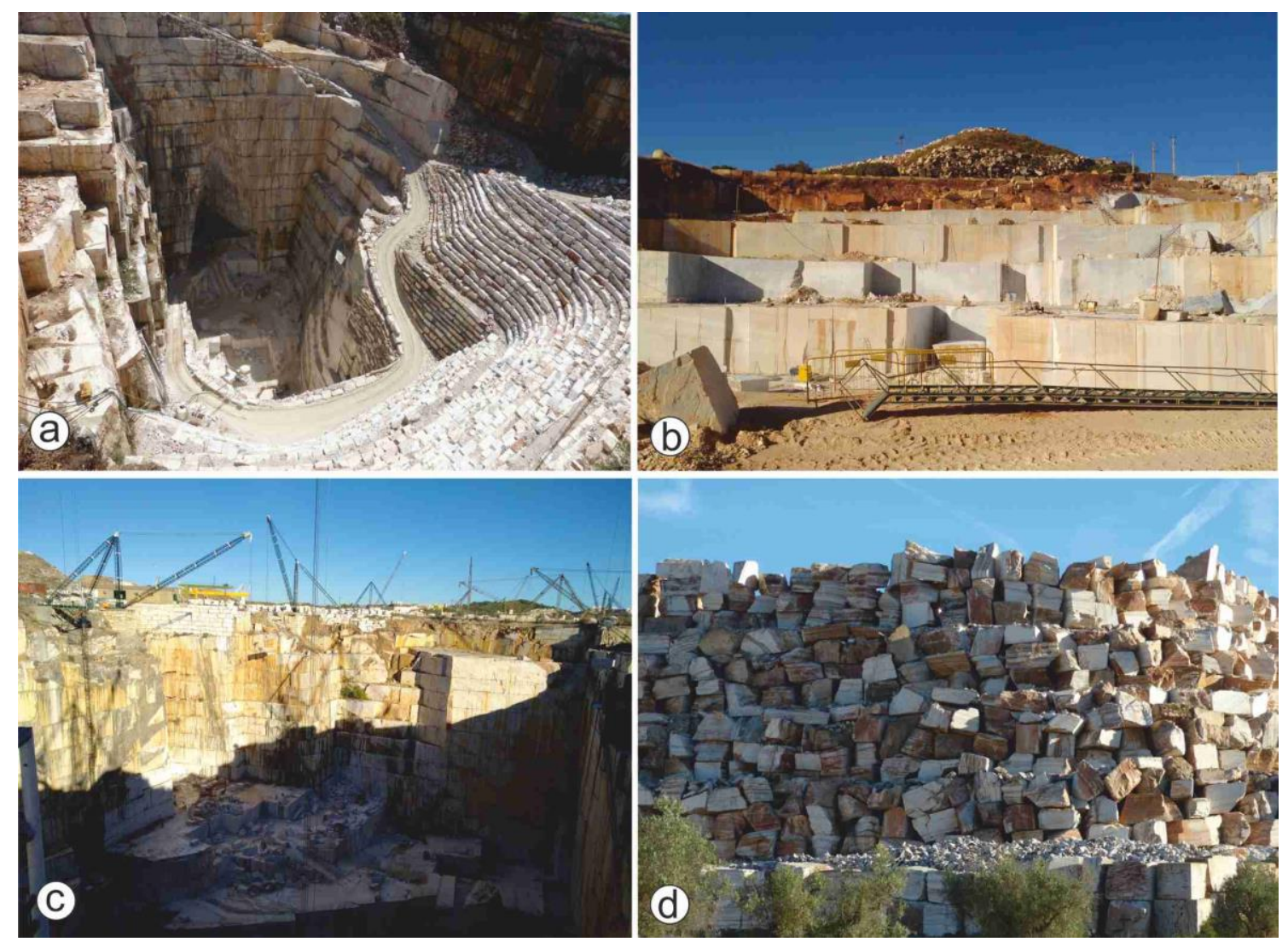

Figure 11 a) A marble quarry in Portugal, b) large dimensional marble blocks and exploitation in the quarry, c) huge derricks for extracting marble blocks along the perimeter of the quarry, and d) very large piles of extracted marble can be seen all around the quarries. 
Colours vary from white, cream, pink, grey to black and streaks with hues in any combination of these colours are possible (e.g. white with pink streaks). The pink marble varieties are internationally in great demand, while locally, white or cream-coloured blocks are also used in statue manufacturing. As was stated before, the marble decor expresses the deformation undergone during the Variscan Orogeny.

The high quality of the Alentejo's marble makes it a very versatile stone. The stone can be used for terraces, interior floor coverings and exterior cladding and for interior decoration (fireplaces, floors, tables, staircases, kitchen countertops, etc., Figure 12 a-f). It is often used in the urban landscape for park and city benches, garden tables and fountains (Fig. 4.7a), in funerary art, as masonry in engineering works, as structural elements in buildings and for paving of sidewalks and roads (Figure $12 \mathrm{~b}$ ). 

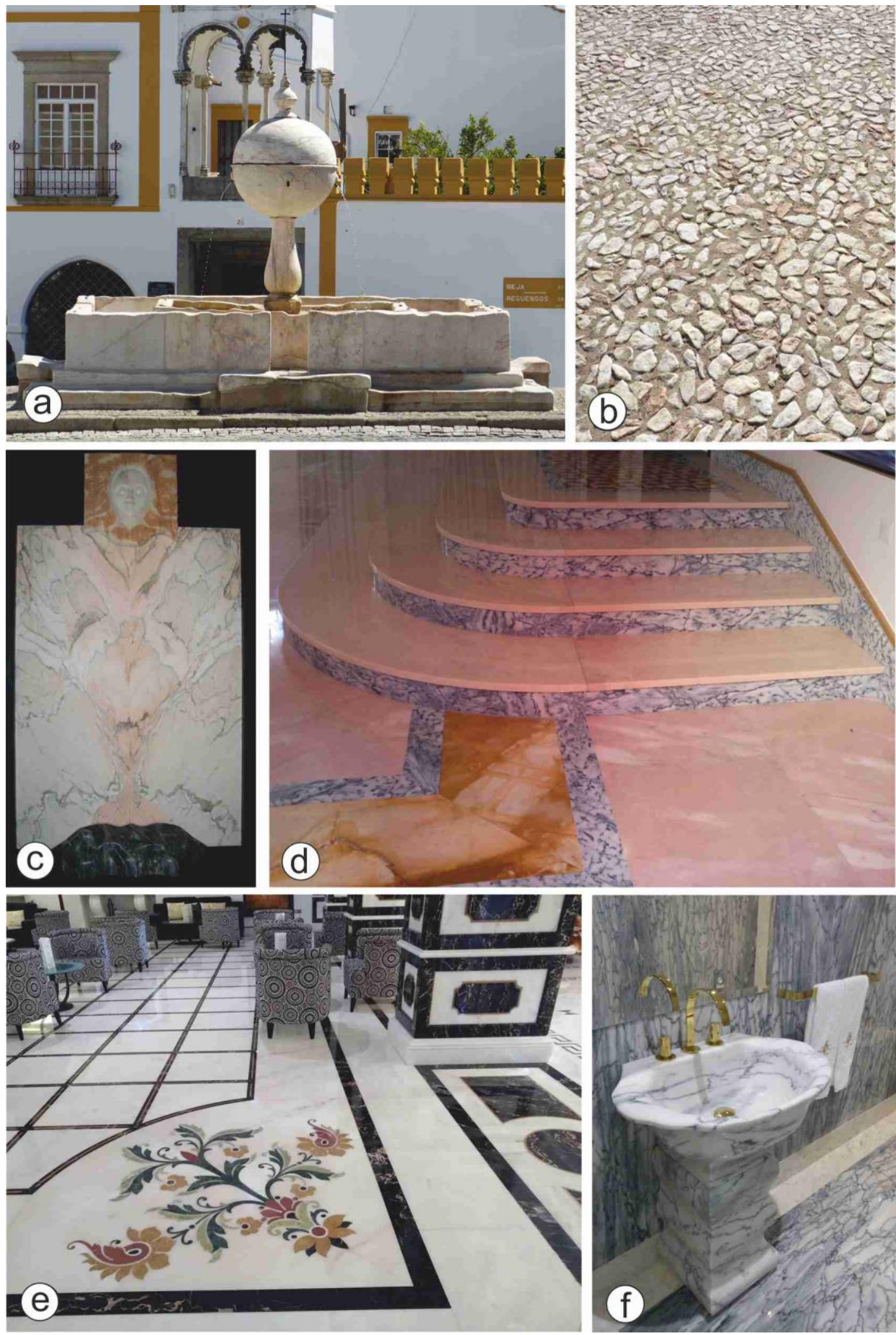

Figure 12 Examples of different colours and decors combined to enhance the aesthetical qualities of the marble: a) fountain in Evora, b) paving stones, c) marble wall decoration with a geometric décor obtained by preparing marble slabs in the way called "open book", d) decorative staircase made by combining different marble colours, e) pilasters and floor with geometric décor made from differently coloured marbles; in the foreground a floral ornament of different stone types, and f) bathroom cladded with marble panels and a solid washbasin. 


\subsection{Characterisation of representative marble samples}

The name "Estremoz marble" is used for commercial purposes and is an ambiguous designation. This designation can only have a geographical meaning, since under this name several marble varieties are commercialized (Figure 13). In the Estremoz-Borba-Vila Viçosa Anticline, marbles with different macro and micro characteristics are quarried. These marbles are fine- to coarse-grained, coloured from white to grey with intermediate beige and pinkish varieties. They are rarely homogeneous and frequently reddishbrownish-greyish spots and veins are distributed randomly. Textural variations are very frequent, whereby obtaining large volumes of stone with the same characteristics is very difficult. This structural variability can be observed at the quarries and in the extracted blocks (Figure 12, Figure 13, Figure 14).

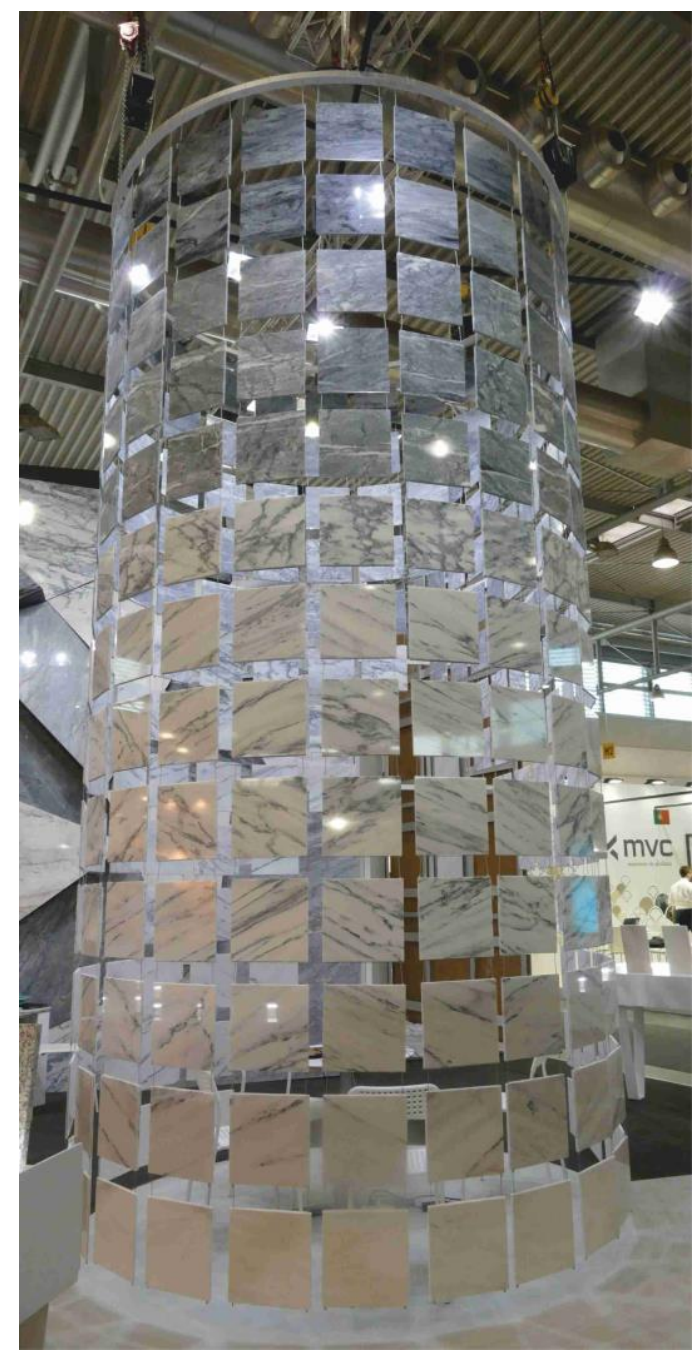

Figure 13 The different colours of the Estremoz marbles. The colours can range from darkish grey, to pinkish and white, with many variations created by veins and spots in several colours. 


\subsubsection{Macroscopic description}

The most representative commercial marble varieties exploited in the Estremoz region were selected: Branco Vergado, Branco Estremoz, Branco Anilado, Creme Vergado, Marinela, Pele de Tigre, Rosa Aurora, Rosa Lagoa, Rosa Estremoz and Ruivina (Figure 14).

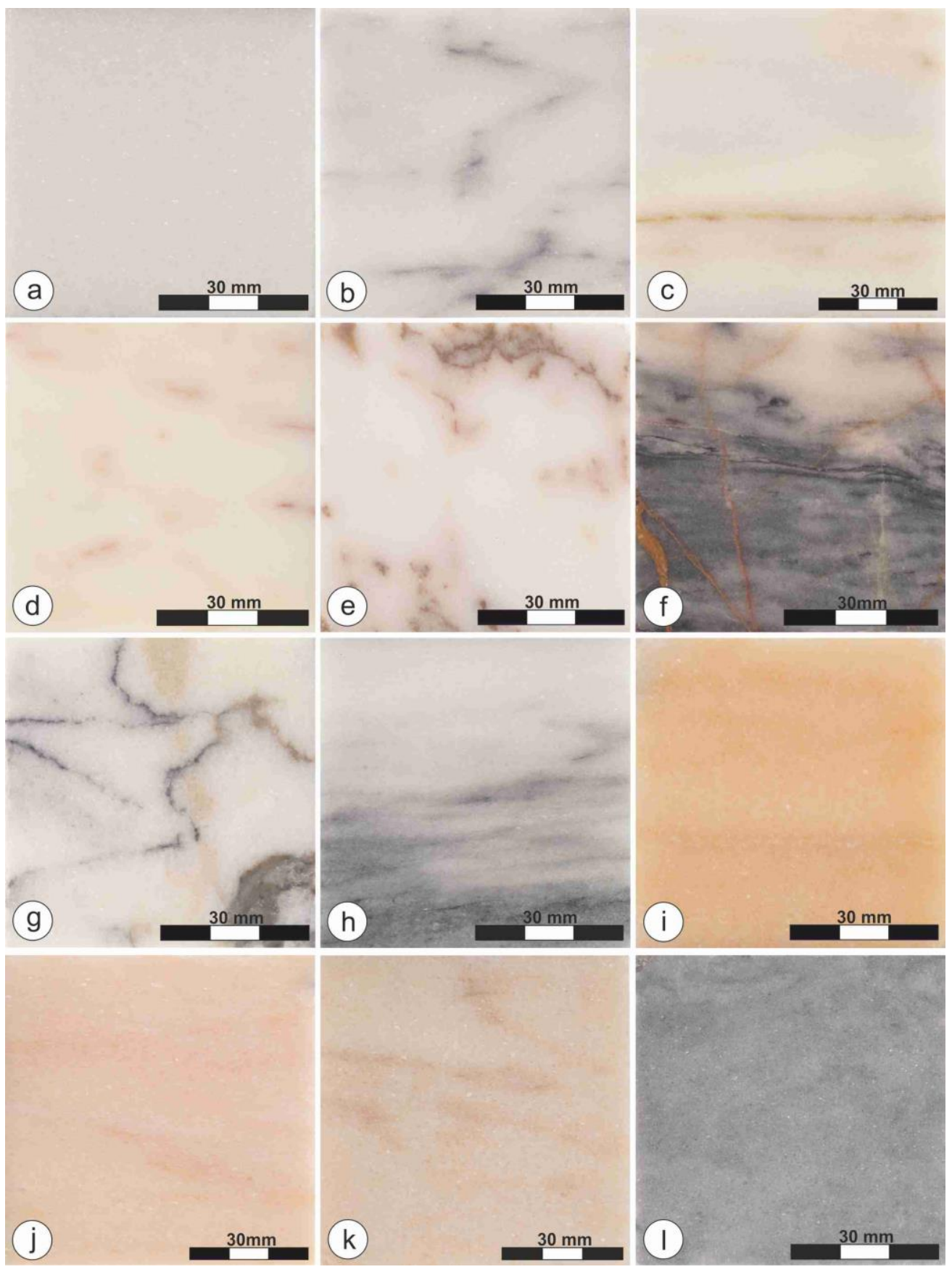

Figure 14 Macroscopic images of different Estremoz varieties: a) Branco, b) Branco Vergado, c) Branco Estremoz, d) Branco Anilado, e) Creme Vergado, f) Marinela, g) Pele de Tigre, h) Pele de Tigre, i) Rosa Aurora, j) Rosa Lagoa, k) Rosa Estremoz, and I) Ruivina. 
These varieties, whose commercial name can be different according to the companies providing the stone, were supplied by the quarry owners. The colour and textural variations cover the typical span of the Estremoz marbles as shown in Figure 13. Branco Vergado (Figure $14 \mathrm{~b}$ ) is a finer grained white marble, with reddish spots and reddish to brownish veins. Branco Estremoz (Figure $14 \mathrm{c}$ ) is a white crystalline stone and shows light yellowish spots, this marble is a coarse-grained variety, with brownish, greyish or reddish veins, constituted by a mosaic of calcite crystals. The medium-grained Branco Anilado (d) is whitish and shows small greyish veins with an irregular distribution. Creme Vergado (e) is characterised by reddish to brownish veins, irregularly distributed throughout the fine- to medium-grained white marble. Marinela $(f)$ is greyish to whitish, fine-grained and shows reddish and brownish to yellowish irregular veins. Alternating greyish to whitish layering can also be observed. Pele de Tigre ( $\mathrm{\&} h$ ) is a mediumgrained white variety characterised by light brownish or greyish veins, with an irregular distribution. The Rosa Aurora (i) variety is coarse-grained, rosy-white in colour and occasionally shows darker rose shades. Rosa Lagoa (j) is whitish rose, coarse-grained, with brownish to reddish veins. Rosa Estremoz $(\mathrm{k})$ is a coarse-grained variety, whitish pink in colour and shows pinkish banding and sporadic greyish veins. Ruivina (I) is medium- to fine-grained and has a dark grey appearance with lighter greyish zones and some whitish veins.

\subsubsection{Chemical analyses}

If marbles show any colours, they raise some curiosity. The reasons for the variety of colours were described by Lopes and Martins, 2015 and give chemically, in terms of the major elements, no differences to justify their different colours. They assume that some trace elements called chromophores may be responsible for the differences in marble colouration. The pink marble, which has higher levels of Ti, $\mathrm{Mn}$ and Fe, is the only variety showing significant differences. Lopes and Martins, 2015 described a close relationship between pink marbles and the presence of muscovite-sericite-rich layers and quartzbearing green layers. The thicker the layer, the greater is the pink colouration of the marble. Further away from these layers, the marble gently loses the pinkish colour and becomes white or cream. The darker grey and bluish shades are due to the presence of 
organic matter, which sometimes occurs concentrated in layers' sub-parallel to the regional second-phase foliation (Lopes and Martins, 2015).

The main petrographic characteristics of the Estremoz marble have been described as very diverse, with medium grain sizes and heteroblastic textures (Taelman et al., 2013). Calcite is the main component, generally more than 90 mass percent (m-\%)(Moura and Carvalho, 2007; Taelman et al., 2013). In 36 samples of Estremoz marble, Moura and Carvalho, 2007 found 27 samples with $>99 \mathrm{~m}$-\% calcite and only six samples with $<10 \mathrm{~m}$ - \% dolomite. Quartz is a common accessory, muscovite is present in about half of the samples and iron oxides rarely occur (Moura and Carvalho, 2007; Taelman et al., 2013). Bands with fine-grained green phyllosilicates, are observed occasionally (Lopes and Martins, 2015; Taelman et al., 2013). Related to the heteroblastic texture, the calcite crystals display curved-embayed or sutured grain boundaries, whereas the equigranular marbles show straight grain boundaries (Taelman et al., 2013).

The studied marbles show comparable characteristics. With $87-98 \mathrm{~m}-\%$ calcite is also the main component of the studied marbles; white micas and quartz occur in low quantities; feldspars are only vestigial. In all the varieties analysed, a very low amount of dolomite occurs ranging 1-2 m-\%. For two samples a quantity of 3 and 11 mass percent dolomite could be determined (Table 1), which is similar to the data published by Moura and Carvalho, 2007.

Table 1 Mass percent of chemical compounds and calculated amount of calcite and dolomite.

\begin{tabular}{|c|c|c|c|c|c|c|c|c|c|c|}
\hline $\begin{array}{l}\text { Chemical } \\
\text { compound }\end{array}$ & $\begin{array}{c}\text { Branco } \\
\text { Anilado } \\
(\%)\end{array}$ & $\begin{array}{c}\text { Creme } \\
\text { Vergado } \\
(\%)\end{array}$ & $\begin{array}{c}\text { Branco } \\
\text { Vergado } \\
(\%)\end{array}$ & $\begin{array}{l}\text { Rosa Au- } \\
\text { rora (\%) }\end{array}$ & $\begin{array}{c}\text { Ruivina } \\
\text { (\%) }\end{array}$ & $\begin{array}{l}\text { Rosa La- } \\
\text { goa (\%) }\end{array}$ & $\begin{array}{c}\text { Rosa Es- } \\
\text { tremoz } \\
(\%)\end{array}$ & $\begin{array}{c}\text { Branco Es- } \\
\text { tremoz } \\
(\%)\end{array}$ & $\begin{array}{l}\text { Pele de ti- } \\
\text { gre } \\
(\%)\end{array}$ & $\begin{array}{c}\text { Marinela } \\
\text { (\%) }\end{array}$ \\
\hline $\mathrm{CaCO}_{3}$ & 98.48 & 93.02 & 97.8 & 97.34 & 98.12 & 96.78 & 95.16 & 98.3 & 96.82 & 96.32 \\
\hline $\mathrm{MgCO}_{3}$ & 0.63 & 4.87 & 0.61 & 0.77 & 0.84 & 0.98 & 1.55 & 0.71 & 0.96 & 0.73 \\
\hline $\mathrm{CaO}$ & 55.17 & 52.11 & 54.79 & 54.53 & 54.97 & 54.22 & 53.31 & 55.07 & 54.24 & 53.96 \\
\hline $\mathrm{MgO}$ & 0.3 & 2.33 & 0.29 & 0.37 & 0.4 & 0.47 & 0.74 & 0.34 & 0.46 & 0.35 \\
\hline $\mathrm{SiO}_{2}$ & 0.39 & 1.11 & 0.98 & 0.9 & 0.41 & 1.26 & 2.41 & 0.53 & 1.49 & 2.08 \\
\hline $\mathrm{Fe}_{2} \mathrm{O}_{3}$ & 0.04 & 0.18 & 0.08 & 0.19 & 0.08 & 0.2 & 0.28 & 0.05 & 0.09 & 0.15 \\
\hline $\mathrm{Al}_{2} \mathrm{O}_{3}$ & 0.06 & 0.17 & 0.13 & 0.18 & 0.09 & 0.29 & 0.16 & 0.09 & 0.15 & 0.26 \\
\hline $\mathrm{K}_{2} \mathrm{O}$ & 0.02 & 0.06 & 0.06 & 0.1 & 0.02 & 0.19 & 0.07 & 0.04 & 0.09 & 0.07 \\
\hline $\mathrm{Mn}_{2} \mathrm{O}_{3}$ & 0.01 & 0.03 & 0.01 & 0.02 & 0.01 & 0.02 & 0.02 & 0.01 & 0.02 & 0.03 \\
\hline $\mathrm{Na}_{2} \mathrm{O}$ & 0 & 0 & 0 & 0.01 & 0 & 0.01 & 0 & 0.01 & 0 & 0 \\
\hline $\mathrm{SO}_{3}$ & 0.026 & 0.011 & 0.027 & 0.017 & 0.02 & 0.009 & 0.017 & 0.021 & 0.009 & 0.012 \\
\hline $\mathrm{CO}_{2}$ & 43.58 & 43.05 & 43.27 & 43.14 & 43.51 & 42.99 & 42.51 & 43.53 & 42.99 & 42.67 \\
\hline b. $\mathrm{H}_{2} \mathrm{O}$ & 0.15 & 0.34 & 0.11 & 0.27 & 0.22 & 0.06 & 0.14 & 0.03 & 0.17 & 0.15 \\
\hline \multicolumn{11}{|l|}{ Mineral } \\
\hline Calcite & 97.68 & 87.18 & 97.03 & 96.37 & 97.08 & 95.57 & 93.27 & 97.40 & 95.63 & 95.40 \\
\hline Dolomite & 1.37 & 10.66 & 1.33 & 1.69 & 1.83 & 2.15 & 3.39 & 1.56 & 2.10 & 1.60 \\
\hline
\end{tabular}




\subsubsection{Microstructures}

The microstructures of all marble varieties have been analysed in 3 directions, according to the reference coordinate system as described in 3.2 Sample preparation and orientation. The XY-plane marks the metamorphic foliation, while the $\mathrm{X}$-direction is parallel to the lineation. The Z-direction is perpendicular to the foliation plane. An arbitrary coordinate system was defined, if the specimens did not show any macroscopically visible fabric elements.

The microfabric of the studied marbles are quite different. A pronounced grain size variation is evident (Figure 15) with equigranular to seriate grain boundaries. Grain boundaries are not straight, and the contacts are usually interlobate. The varieties Branco Estremoz, with some polygonal contacts, and Marinela, with amoeboid contacts, are the extreme cases. A preferred grain shape orientation can be observed in all the varieties, less pronounced in Branco Estremoz and more evident in Marinela. Undulose extension is observed in Ruivina and subgrain formation is extensive in Marinela. The dark veins and spots are rich in oxides and opaque minerals, and also richer in chromophore elements. In some varieties veins contain more opaque minerals.

In almost all oriented thin sections, perpendicular to the foliation plane and cut along the stretching lineation, a well-defined S-C-fabric is often observable (Figure 8). Even at the microscopic level, strain deformation partitioning can be seen defining shear bands with SC-fabric development. In general, dynamic recrystallization caused the preferential arrangement and shape preferred orientation. Recrystallization of the calcite was controlled by the prevailing tensile field. Also, the crystallization of quartz, often with fluid inclusions, occurs preferentially between the calcite crystals, principally when they exhibit well-defined grain boundaries or well-developed granoblastic fabric. 


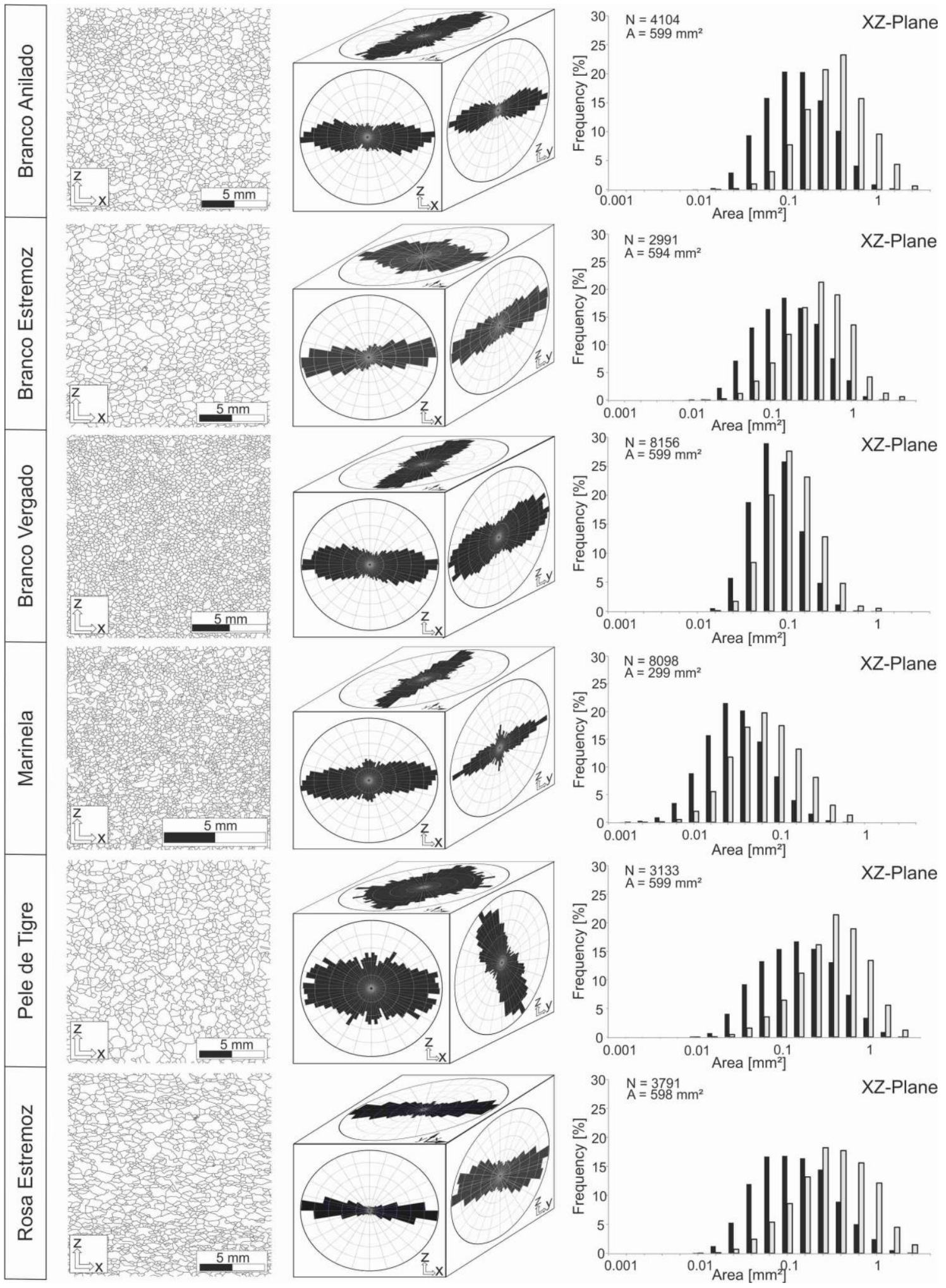

Figure 15 From left to the right: Characteristic line drawing of a microscope image, shape preferred orientation and grain size (relative frequency of specific area class has been calculated with respect to the total area (grey bars; $\mathrm{A}=$ total area) and total number of grains (black bars; $\mathrm{N}=$ total number of grains)) of Branco Anilado, Branco Estremoz, Branco Vergado, Marinela, Pele de Tigre and Rosa Estremoz. 


\subsubsection{Quantitative shape fabric}

The quantitative shape fabric was analysed for all investigated marbles on the basis of three thin sections parallel to the $X Y-, X Z$ - and YZ-planes. According to the reference system (3.2 Sample preparation and orientation), those thin sections were prepared and digitized with a Fabric Analyser Microscope and converted by the support software uniaxial v1.2 (see 3.3.1 Quantitative fabric analyses). The MATLAB based software FAME 2.1 (Hammes and Peternell, 2016) was used for the evaluation of the shape parameters. The results are given in more detail for the following marbles: Branco Anilado, Branco Estremoz, Branco Vergado, Marinela, Pele de Tigre, and Rosa Estremoz (Figure 15)

The grain sizes of the Marinela range between $40 \mu \mathrm{m}$ and $1.3 \mathrm{~mm}$, with an average grain size of $197 \mu \mathrm{m}$ and can be described as a fine-grained marble. In all thin sections, two distinct shape preferred orientations can be observed, which is most pronounced for the ZY-plane, with grain sizes between $100 \mu \mathrm{m}$ and $2.2 \mathrm{~mm}$. They differ in a larger scale for the Pele de Tigre. An average grain size of $401 \mu \mathrm{m}$ classified this marble also as finegrained, with a random distribution of the shape preferred orientation in the XY-plane. Most significant is this orientation within the XZ-plane that shows a clear diagonal alignment. Similar to this marble, Branco Anilado shows a distribution of grain sizes from 103 $\mu \mathrm{m}$ up to $1.75 \mathrm{~mm}$, and an average value of $423 \mu \mathrm{m}$. The shape preferred orientation is pronounced in every section and parallel to the foliation plane (XY). The grain sizes of the almost equigranular Branco Vergado range between $53 \mu \mathrm{m}$ and $670 \mu \mathrm{m}$, with an average grain size of $314 \mu \mathrm{m}$. The fine-grained marble consists of grains between 300

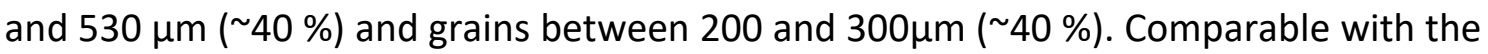
Branco Anilado, the shape preferred orientation is observable in all three sections, whereby it is less pronounced and slightly oblique in the XY- and YZ-plane. The grain sizes for the Branco Estremoz show larger grains and vary between $103 \mu \mathrm{m}$ and $2.1 \mathrm{~mm}$ with an average of $453 \mu \mathrm{m}$, which is comparable to the Rosa Estremoz that shows a distribution between $108 \mu \mathrm{m}$ and $2.5 \mathrm{~mm}$ and an average grain size of $435 \mu \mathrm{m}$. Even if those values give the impression, that both types of marble have a similar fabric, there are differences that can be observed by the shape preferred orientation. Along the XYplane, the Branco Estremoz shows a weak preferred orientation, with an almost random 
distribution, while the Rosa Estremoz exhibits a preferred orientation in all sections, which is most pronounced along the XZ-plane.

The average grain size calculated for the results of all three thin sections per variety, ranges between $197 \mu \mathrm{m}$ (Marinela) up to $453 \mu \mathrm{m}$ (Branco Estremoz), whereby the results hardly differ between the investigated marble types, as can be seen in Table 2 . Differences in the grain size distribution are more obvious, in comparison with each plane, but just in a small range. All samples show a more or less pronounced shape preferred orientation in every section, whereas the Marinela has two distinct preferred orientations of grain boundaries in every section. Only the Pele de Tigre and Branco Estremoz indicate in one plane $(\mathrm{XY})$ a random distribution.

Table 2 Mean grain size [mm], grain size distribution and grain boundary geometry of Branco Anilado, Branco Estremoz, Branco Vergado, Marinela, Pele de Tigre and Rosa Estremoz.

\begin{tabular}{lcll}
\hline Marble & Grain size [mm] & Grain size distribution & Grain boundary geometry \\
\hline Branco Anilado & 0.42 & Equigranular - inequigranular & Interlobate \\
Branco Estremoz & 0.45 & Equigranular - inequigranular & Polygonal - interlobate \\
Branco Vergado & 0.31 & Inequigranular & Interlobate \\
Marinela & 0.20 & Seriate & Interlobate - amoeboid \\
Pele de Tigre & 0.40 & Inequigranular & Interlobate - amoeboid \\
Rosa Estremoz & 0.43 & Inequigranular & Interlobate - polygonal \\
\hline
\end{tabular}




\subsubsection{Cathodoluminescence}

The capability of a mineral to emit visible light, when exposed to an electron beam, is called cathodoluminescence $(C L)$ (see 3.3.2 CL).

The investigated marbles show essentially a reddish to brownish luminescence. The $\mathrm{CL}$ results for the samples Branco Anilado, Creme Vergado, Rosa Estremoz and Marinela in the XZ-plane are shown in Figure 16 and compared to their complimentary polarized light images. The Branco Anilado shows a uniform red luminescence, where small local areas, partly along grain boundaries and calcite twins display a brighter luminescence. In contrast, the Creme Vergado shows extremely low luminescence, which can be interpreted as an iron-rich carbonate stone. As already described $11 \%$ dolomite was detected in this marble and around $0.18 \%$ iron oxide (Table 1 ). Different calcite generations could be found for the Rosa Estremoz, with a brighter older core and a darker, younger area. The younger area shows growth zonation's.

The inhomogeneous Marinela shows several post-deformation veins consisting of calcite. Different generations of grains are detectable, where the youngest grains can be distinguished from the older by their degree of luminescence. The varying darker colour of the other grains can be explained by the amount of Fe. The whole fabric is strongly characterised by deformation and alteration due to fluids. All the analysed marbles show a similar, homogenous luminescence where different grain generations can be differentiated. The only exceptions are the Marinela, with a very inhomogeneous luminescence and the weak to non-luminescing Creme Vergado. 


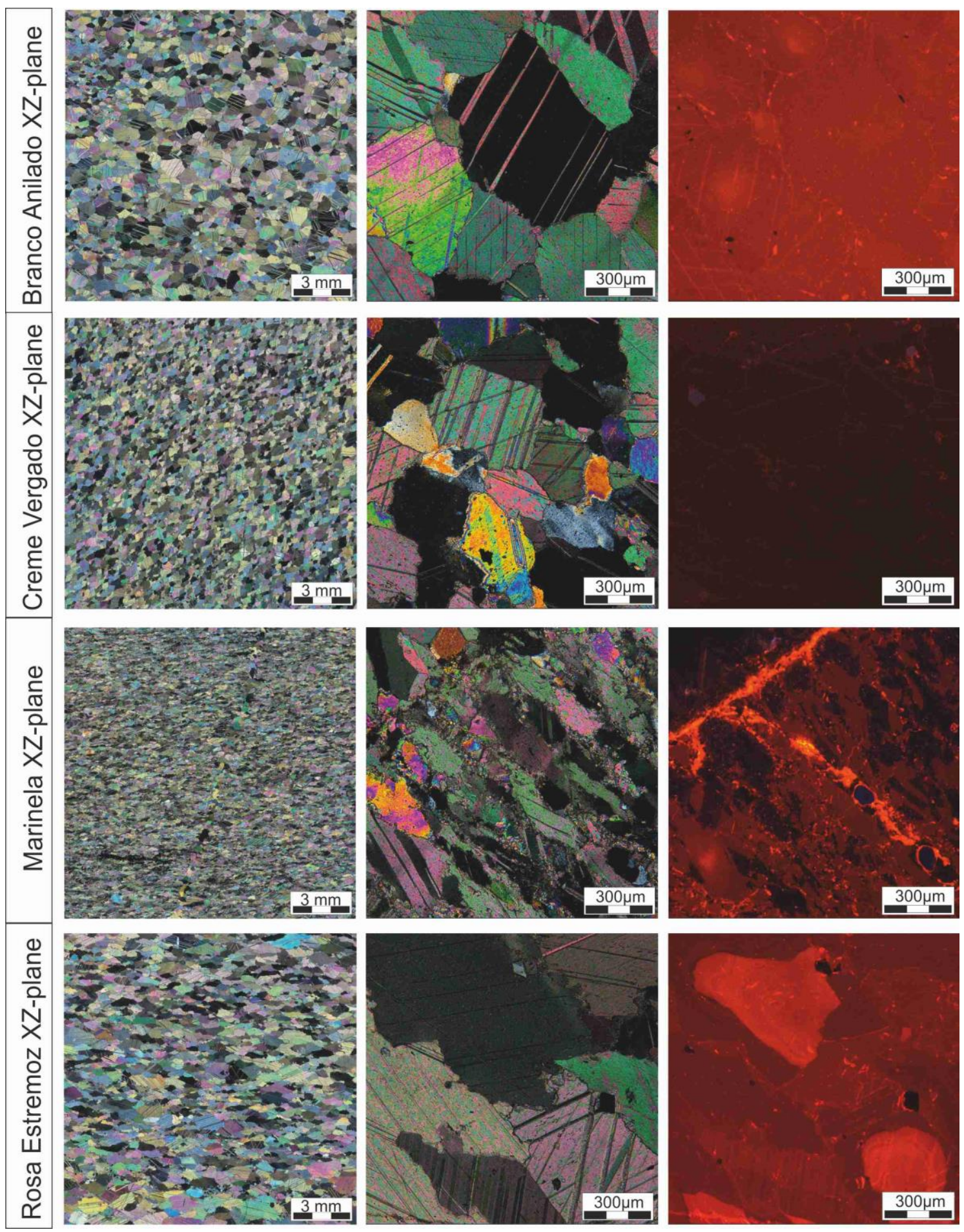

Figure 16 From left to the right: Thin section scan showing the microstructure, detailed thin section images, crossed polars (middle) and cathodoluminescence (right) of the same region for Branco Anilado, Creme Vergado, Marinela and Rosa Estremoz (XZ-plane). 


\subsubsection{Lattice preferred orientation}

The lattice preferred orientation was measured by means of X-Ray diffraction (see Chapter 3.3.3 X-Ray Goniometer, EBSD measurements). For all samples, the c-, a-, r-, and $f$-planes were measured ( $r$ and $f$ not shown here) and plotted with regard to the other fabric elements, i.e. the foliation and lineation if it was observable (Figure 17, right plots).

The c-axis and a-axis pole figures of Branco Anilado, Branco Estremoz, Branco Vergado, Marinela, Pele de Tigre and Rosa Estremoz are displayed in Figure 17. Most of the investigated marbles show the characteristics of a c-axis fibre type (according to the classification proposed by Leiss and Ullemeyer, 1999), with a single c-axis maximum (006), while the a-axes (110) show a great-circle distribution.

The crystallographic preferred orientation of the Branco Anilado is strongly pronounced with a c-axis maximum of $2.7 \mathrm{mrd}$ ( $\mathrm{mrd}=$ multiples of random distribution), which is slightly elongated along the XZ-plane. The a-axis distribution surrounds the c-axis density circularly and shows a maximum of $1.6 \mathrm{mrd}$. The Branco Estremoz represents a caxis fibre type, with a strongly pronounced maximum of $2.8 \mathrm{mrd}$ which is perpendicularly orientated to the foliation plane and slightly elongated. Accordingly, the a-axis are orientated as a girdle parallel to the $\mathrm{XY}$-plane, with a maximum of $1.9 \mathrm{mrd}$. The lattice preferred orientation for the Branco Vergado is similar to the Branco Estremoz and Branco Anilado, with a less pronounced c-axis maximum of $2.1 \mathrm{mrd}$. It is also slightly elongated along the XZ-plane and surrounded by a girdle-like a-axis distribution with a maximum of $1.5 \mathrm{mrd}$. A very strong pronounced c-axis maximum of $3.6 \mathrm{mrd}$ is found in the Marinela, the highest value for all Estremoz samples. A pronounced single maximum of the c-axis parallel to the Z-direction is weakly elongated within the XZ-plane. The circularly arranged a-axis density shows a strongly pronounced a-axis maximum, that has with $2.2 \mathrm{mrd}$, the highest intensity for all varieties. The distribution of the c-axis is strongly elongated in the YZ-plane for the Pele de Tigre. Parallel to the YX-plane lies the girdle-like a-axis distribution with a distinct a-axis maximum of $1.6 \mathrm{mrd}$. The Rosa Estremoz shows a c-axis maximum of $2.5 \mathrm{mrd}$, which is elongated to the YZ-plane and a circularly arranged a-axis density with a maximum of $1.7 \mathrm{mrd}$. 

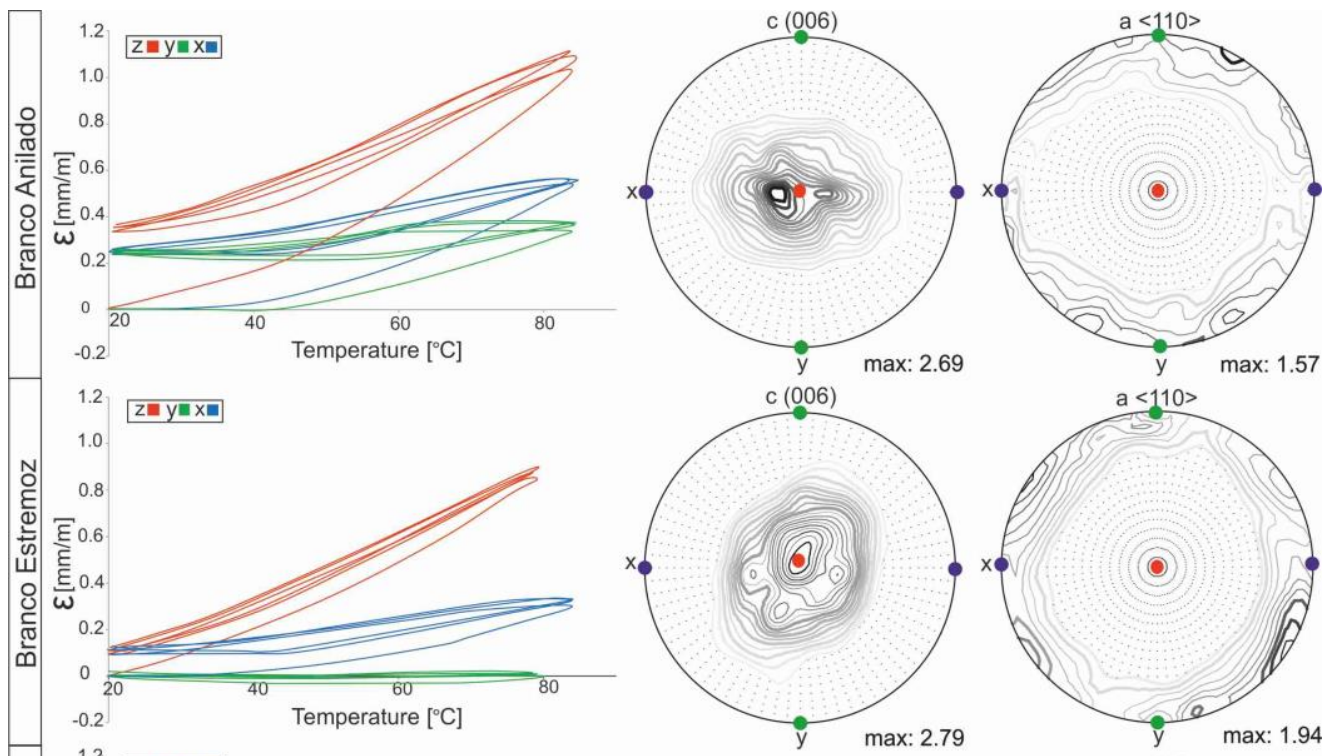

$\mathrm{z} \square \mathrm{y}=\mathrm{x}$
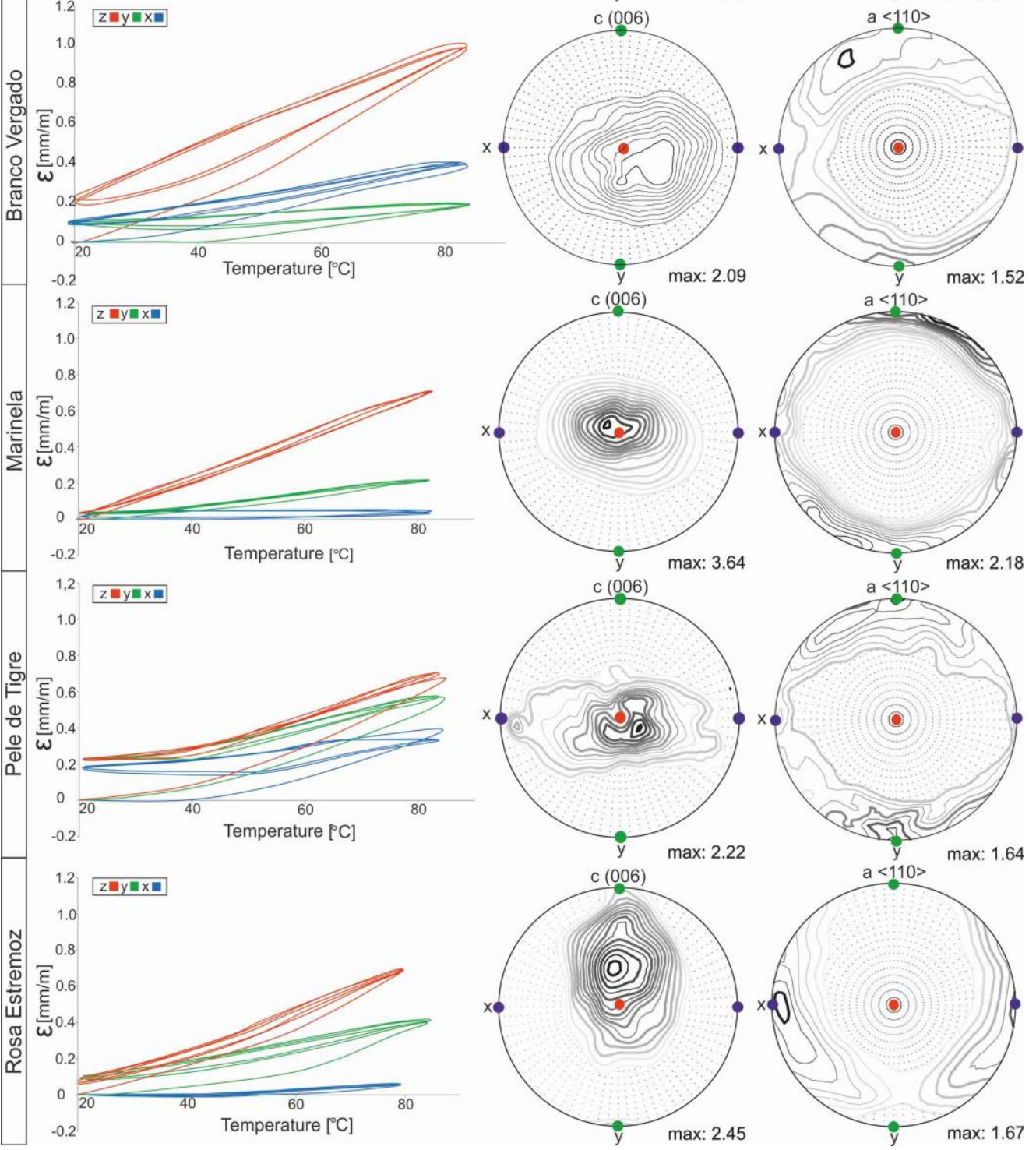

Figure 17 Thermal dilatation $\varepsilon[\mathrm{mm} / \mathrm{m}]$ shown as a loop of hysteresis with directional dependence (left graphs) and pole figures of the lattice preferred orientation for $\mathrm{c}$ - and a-axis (right plots), for the specimens: Branco Anilado, Branco Estremoz, Branco Vergado, Marinela, Pele de Tigre and Rosa Estremoz. 
To summarise, the maximum c-axis densities of all investigated marbles are similar and moderately to strongly pronounced. The results for those maxima vary between 3.64 mrd for Marinela and 2.09 mrd for Branco Vergado. Almost all marbles show a single c-axis maximum, which is more or less elongated and, in some cases, a weakly to moderate girdle-like shape of the intensity distribution can be observed. The Rosa Estremoz is an example for a well pronounced c-axis maximum of $2.45 \mathrm{mrd}$, which is strongly elongated along the YZ-plane. In contrast, the received maximum of $2.69 \mathrm{mrd}$ for Branco Anilado is slightly elongated along the XZ-plane. Almost all a-axis pole figures represent a girdle, with the highest maximum of $2.18 \mathrm{mrd}$ for Marinela and the lowest with 1.52 mrd for Branco Vergado. An exception represents the Pele de Tigre, which shows almost a belt-like distribution of the c-axis maximum of $2.22 \mathrm{mrd}$ and an a-axis maximum of $1.62 \mathrm{mrd}$.

\subsubsection{Ultrasonic velocities}

Ultrasonic velocities have been determined for 22 cubic samples $(6.5 * 6.5 * 6.5 \mathrm{~cm})$. The transmission measurements were performed in 3 directions $(X, Y, Z)$, using $350 \mathrm{kHz}$ transmitter (for further information see Chapter 3.4.2.1 Transmission). The analyses were conducted under normal ambient conditions (around $20^{\circ} \mathrm{C}$ and about 65 $70 \%$ rel. humidity), dried to constant mass $\left(40^{\circ} \mathrm{C}\right)$ and water saturated.

In Table 3, velocities [km/s] are given for all samples, classified by their marble colour. Independent of the sample conditions, all marble types show a distinct preferred velocity distribution, while mostly all show the lowest velocity according to the z-direction. The velocities range between 3.13 and $6.28 \mathrm{~km} / \mathrm{s}$ under dry conditions, 3.28 and $6.17 \mathrm{~km} / \mathrm{s}$ under ambient conditions and 4.03 and $6.76 \mathrm{~km} / \mathrm{s}$ water saturated. Compared to the ambient measurements, the velocities mainly slowed down or didn't change under dry conditions. The water saturation led to an significant velocity increase, while the distribution pattern, according to the measured direction, stays the same, expect for the sample MB, MgRV, GRsV and PSRA. 
Table 3 Ultrasonic velocities [km/s] in $X-, Y$-, and Z-direction under dry, ambient and water saturated conditions.

\begin{tabular}{|c|c|c|c|c|c|c|c|c|c|c|}
\hline \multirow[t]{2}{*}{$\begin{array}{l}\text { Marble } \\
\text { category }\end{array}$} & \multirow[t]{2}{*}{ Sample } & \multicolumn{3}{|c|}{ Dry samples } & \multicolumn{3}{|c|}{$\begin{array}{l}\text { Samples under labora- } \\
\text { tory conditions }\end{array}$} & \multicolumn{3}{|c|}{ Water saturated } \\
\hline & & $x$ & Y & Z & $\mathrm{x}$ & Y & Z & $x$ & Y & Z \\
\hline \multirow{4}{*}{ Branco } & MgBA & 3.91 & 4.43 & 3.37 & 4.06 & 4.43 & 3.48 & 4.78 & 5.12 & 4.04 \\
\hline & GBsV & 4.36 & 4.51 & 4.24 & 4.48 & 4.64 & 4.35 & 5.64 & 5.61 & 5,38 \\
\hline & $\mathrm{MB}$ & 5.44 & 5.13 & 5.23 & 5.35 & 4.97 & 4.99 & 6.04 & 6.58 & 6.61 \\
\hline & MgB & 4.08 & 3.13 & 3.77 & 4.22 & 4.08 & 3.44 & 4.85 & 4.03 & 4.83 \\
\hline \multirow{4}{*}{$\begin{array}{r}\text { Branco } \\
\text { Vergado }\end{array}$} & BBBV & 5.57 & 5.67 & 5.01 & 5.66 & 5.78 & 5.01 & 5.77 & 5.88 & 5.70 \\
\hline & MgBV & 4.31 & 4.64 & 3.54 & 4.31 & 4.64 & 4.42 & 5.58 & 5.77 & 5.05 \\
\hline & EBV & 4.26 & 4.49 & 3.78 & 4.26 & 4.49 & 3.87 & 4.96 & 5.05 & 4.39 \\
\hline & BVCV & 4.7 & 4.57 & 4.47 & 4.83 & 4.84 & 4.59 & 5.66 & 5.58 & 5.42 \\
\hline \multirow{5}{*}{$\begin{array}{l}\text { Cremes } \\
\text { Vergado }\end{array}$} & ECV & 5.08 & 5.46 & 4.89 & 5.08 & 5.46 & 5.04 & 5.70 & 5.86 & 5.56 \\
\hline & $\mathrm{MgCV}$ & 4.85 & 4.92 & 4.08 & 4.85 & 4.92 & 4.18 & 6.62 & 6.40 & 5.12 \\
\hline & PSCV & 4.05 & 4.23 & 3.87 & 4.20 & 4.28 & 3.87 & 5.55 & 5.55 & 5.21 \\
\hline & MR & 4.85 & 5.2 & 4.95 & 4.99 & 5.2 & 5.11 & 5.68 & 5.74 & 6.83 \\
\hline & MgRV & 4.76 & 5.18 & 4.65 & 4.76 & 4.87 & 4.72 & 5.21 & 5.53 & 5.52 \\
\hline \multirow[t]{3}{*}{ Rosa } & GRsV & 4.86 & 5.75 & 4.80 & 4.52 & 4.36 & 4.6 & 5.62 & 5.65 & 5.64 \\
\hline & BBR & 3.71 & 4.08 & 3.32 & 3.75 & 4.14 & 3.28 & 6.75 & 6.75 & 4.77 \\
\hline & PSRA & 5.16 & 4.64 & 4.52 & 5.08 & 4.46 & 4.52 & 5.60 & 5.15 & 5.23 \\
\hline \multirow{3}{*}{$\begin{array}{l}\text { Pele de } \\
\text { Tigre }\end{array}$} & PSPT & 3.62 & 4.60 & 4.11 & 3.84 & 4.54 & 4.21 & 5.05 & 5.47 & 4.99 \\
\hline & BVPT & 5.23 & 5.53 & 4.82 & 5.23 & 5.44 & 4.89 & 5.97 & 5.83 & 5.55 \\
\hline & BVR & 4.42 & 4.5 & 4.01 & 4.66 & 4.76 & 4.27 & 5.51 & 5.87 & 5.45 \\
\hline \multirow[t]{2}{*}{ Ruivina } & PSR & 4.54 & 5.3 & 4.59 & 4.54 & 5.3 & 4.59 & 5.72 & 5.99 & 5.53 \\
\hline & GR & 4.55 & 5.04 & 4.11 & 4.61 & 4.89 & 4.27 & 5.86 & 5.75 & 5.40 \\
\hline Marinela & MAR & 5.72 & 6.28 & 5.37 & 5.43 & 6.17 & 5.27 & 5.83 & 6.40 & 5.37 \\
\hline
\end{tabular}

\subsection{Thermal dilatation}

The thermal dilatation $\varepsilon[\mathrm{mm} / \mathrm{m}]$, as a function of temperature, is an important property to characterise dimension stones. It describes the expansion behaviour during thermal exposure and was analysed using a pushrod dilatometer (Chapter 3.4.5 Thermal expansion).

For this investigations, 3 specimens in $\mathrm{X}-, \mathrm{Y}$ - and Z-direction, according to the reference system, were measured for each marble type, to identify $\varepsilon$ and possible directional dependences. The specimens were heated from $20^{\circ} \mathrm{C}$ up to $90^{\circ} \mathrm{C}$ and subsequently cooled down to $20^{\circ} \mathrm{C}$. To ensure the equilibration of the samples, heating and cooling was performed with a velocity of $1^{\circ} \mathrm{C} / \mathrm{min}$ while the maximum and minimum temperature was hold for 6 hours. This cycle was performed for 4 times and used to calculate the thermal 
dilatation coefficient $\alpha$ (for further information see Koch and Siegesmund, 2004; Strohmeyer, 2003).

The results are exemplaric plotted for six samples (Branco Anilado, Branco Estremoz, Branco Vergado, Marinela, Pele de Tigre and Rosa Estremoz) in Figure 17. The plots show for all investigated marble samples basically in the first cycle a successive increase of the slope until the maximum heating temperature, while the slope is straighter for the second to fourth cycle. According to this, the first cycle shows for all samples the highest $\alpha$ coefficients, defined by the gradient of the slope, whereas they are lower in the second cycle and remain approximately constant for the following cycles. The smallest value in the first cycle was measured for the Marinela $\left(0.8 \times 10^{-6} \mathrm{~K}^{-1}\right.$ in X-direction) and the highest for Branco Anilado (16.12 $\times 10^{-6} \mathrm{~K}^{-1}$ in Z-direction). Cycle two to four shows a range between $0.16 \times 10^{-6} \mathrm{~K}^{-1}$ (Y-direction) and $13.1 \times 10^{-6} \mathrm{~K}^{-1}$ (Z-direction) both determined for the Branco Estremoz.

As shown in Table 4, the average thermal dilatation coefficient $\alpha$, determined for the $2^{\text {nd }}$ to $4^{\text {th }}$ cycle, varies for all samples in Z-direction between $7.80 \times 10^{-6} \mathrm{~K}^{-1}$ (Pele de Tigre) and $12.97 \times 10^{-6} \mathrm{~K}^{-1}$ (Branco Estremoz), in the Y-direction between $0.16 \times 10^{-6} \mathrm{~K}^{-1}$ (Branco Estremoz) and $5.57 \times 10^{-6} \mathrm{~K}^{-1}$ (Pele de Tigre) and in the X-direction between $0.37 \times 10^{-6} \mathrm{~K}^{-}$ ${ }^{1}$ for Marinela up to $9.53 \times 10^{-6} \mathrm{~K}^{-1}$ for Rosa Aurora. According to Fig. 12, the highest expansion values $\varepsilon$ for all marbles were determined in Z-direction. The amount of variation in every direction for one sample represents an anisotropic rock property and shows with $A_{\alpha} 69.7 \%\left(A_{\alpha}=\alpha_{\max }-\alpha_{\min }\right) / \alpha_{\max } * 100$ [\%]) the weakest anisotropy for Pele de Tigre, whereas the highest anisotropy was measured for the Branco Estremoz with $A_{\alpha} 98.8 \%$ (Tab. 4.3).

All investigated varieties show a directional dependence in their degree of thermal expansion, which is most pronounced for all samples in the Z-direction and mainly influenced by the texture of the whole rock. Due to the pronounced lattice preferred orientations (Fig. 4.12), the anisotropic thermal single crystal properties of calcite (parallel to the c-axis a thermal expansion coefficient $\alpha$ of $26 \times 10^{-6} \mathrm{~K}^{-1}$ and perpendicular to the crystallographic c-axis a negative coefficient of $-6 \times 10^{-6} \mathrm{~K}^{-1}$, (Kleber et al., 2010), affect the properties of the whole rock. Corresponding to this, the samples with a pronounced LPO show a stronger expansion parallel to the adjusted c-axes (Z-direction), whereas it 
is parallel to the a-axes low or not pronounced (X-Y-direction). According to the almost girdle like c-axis distribution of the Pele de Tigre, the directional dependence is weaker pronounced for this variety.

Table 4 Thermal dilatation coefficient $\alpha\left[10^{-6} \mathrm{~K}^{-1}\right]$ under dry and wet conditions. Displayed are the average values for the $2^{\text {nd }}$ to $4^{\text {th }}$ cycle under dry conditions and the average of all 5 cycles under wet conditions for every direction, calculated from the increasing part of every cycle. Furthermore, the Min and Max $\alpha$-values for the dry and wet cycles as well as the calculated anisotropy [\%].

\begin{tabular}{|c|c|c|c|c|c|c|c|}
\hline \multicolumn{8}{|c|}{ Thermal dilatation coefficient $\alpha$ under dry and wet conditions } \\
\hline \multirow[b]{2}{*}{ Marble } & \multirow[b]{2}{*}{ conditions } & \multicolumn{3}{|c|}{ Average $\alpha \times 10^{-6} \mathrm{~K}^{-1}$} & \multicolumn{2}{|c|}{$\alpha \times 10^{-6} \mathrm{~K}^{-1}$} & \multirow[b]{2}{*}{ Anisotropy [\%] } \\
\hline & & $\mathrm{x}$ & $\mathrm{y}$ & z & Min & Max & \\
\hline \multirow[t]{2}{*}{ Branco Anilado } & wet & 5.12 & 3.45 & 11.93 & $3.36(y)$ & $12.01(z)$ & 72.02 \\
\hline & dry & 4.74 & 2.05 & 11.90 & $1.9(\mathrm{y})$ & $11.93(z)$ & 84.07 \\
\hline \multirow[t]{2}{*}{ Branco Estremoz } & wet & 4.39 & 0.35 & 13.05 & $0.15(y)$ & $13.66(z)$ & 98.9 \\
\hline & dry & 3.57 & 0.16 & 12.97 & $0.16(y)$ & $13.1(z)$ & 98.78 \\
\hline \multirow[t]{2}{*}{ Branco Vergado } & wet & 4.35 & 1.76 & 13.18 & $1.54(\mathrm{y})$ & $13.79(z)$ & 88.83 \\
\hline & dry & 4.69 & 1.48 & 12.34 & $1.43(y)$ & $12.57(z)$ & 88.62 \\
\hline \multirow[t]{2}{*}{ Creme Vergado } & wet & 8.85 & 2.71 & 8.48 & $2.6(y)$ & $9.71(z)$ & 73.22 \\
\hline & dry & 7.62 & 2.07 & 8.32 & $1.91(y)$ & $8.44(z)$ & 77.37 \\
\hline \multirow[t]{2}{*}{ Marinela } & wet & 11.48 & 4.37 & 10.17 & $4.13(y)$ & $12.51(x)$ & 66.99 \\
\hline & dry & 0.37 & 2.99 & 10.82 & $0.32(x)$ & $10.93(y)$ & 97.07 \\
\hline \multirow[t]{2}{*}{ Pele de Tigre } & wet & 3.41 & 6.47 & 7.52 & $3.16(x)$ & $7.78(z)$ & 59.38 \\
\hline & dry & 2.78 & 5.57 & 7.80 & $2.4(x)$ & $7.92(z)$ & 69.7 \\
\hline \multirow[t]{2}{*}{ Rosa Aurora } & wet & 10.2 & 4.38 & 11.61 & $4.13(y)$ & $12.61(z)$ & 67.25 \\
\hline & dry & 9.53 & 2.50 & 10.62 & $2.38(y)$ & $10.83(z)$ & 78.02 \\
\hline \multirow[t]{2}{*}{ Rosa Estremoz } & wet & 1.37 & 5.0 & 10.98 & $1.07(x)$ & $12.02(z)$ & 91.1 \\
\hline & dry & 0.95 & 4.94 & 10.51 & $0.95(x)$ & $10.64(z)$ & 91.07 \\
\hline \multirow[t]{2}{*}{ Rosa Lagoa } & wet & 2.38 & 5.12 & 11.77 & $2.25(x)$ & $12.49(\mathrm{z})$ & 81.99 \\
\hline & dry & 1.90 & 4.20 & 11.48 & $1.9(x)$ & $11.53(z)$ & 83.52 \\
\hline \multirow[t]{2}{*}{ Ruivina } & wet & 7.0 & 2.68 & 10.46 & $2.16(y)$ & $10.76(z)$ & 79.93 \\
\hline & dry & 6.27 & 1.94 & 10.83 & $1.88(y)$ & $11.05(z)$ & 82.99 \\
\hline
\end{tabular}

\subsubsection{Residual strain $\left(\varepsilon_{\mathrm{RS}}\right)$ under dry conditions}

Apart from the thermal dilatation, the residual strain, describing the irreversible expansion caused by thermal load, can also vary in magnitude and direction. The samples Branco Estremoz, Branco Anilado, Branco Vergado, Rosa Estremoz, Pele de Tigre and Marinela (Figure 17) represent all investigated variations of residual strain and show more or less a pronounced directional dependence of the residual strain.

In Table 5 the total amount of residual strain after four cycles in each direction is displayed. The investigated residual strains vary between almost $0 \mathrm{~mm} / \mathrm{m}$ in the X-direction 
(Marinela and Rosa Estremoz) and reaches a maximum of $0.36 \mathrm{~mm} / \mathrm{m}$ in the Z-direction (Branco Anilado). In general, the lowest value for the X-direction was measured for Rosa Estremoz and Marinela, the highest for Branco Anilado $(0.26 \mathrm{~mm} / \mathrm{m})$. The values in the Y-direction differ between $0.01 \mathrm{~mm} / \mathrm{m}$ (Branco Estremoz) and $0.26 \mathrm{~mm} / \mathrm{m}$ (Branco Anilado). The lowest residual strain in the Z-direction was measured for the Marinela (0.04 $\mathrm{mm} / \mathrm{m}$ ). The marbles show different phenomena regarding the residual strain.

All of them show a directional dependence, except the almost isotropic Marinela and Pele de Tigre (Table 5). For Branco Estremoz and Rosa Estremoz, the residual strain is less pronounced, with higher, comparable values in the X- and Z-direction (Branco Estremoz) and Y-and Z-direction (Rosa Estremoz). A different pattern can be observed for Branco Anilado and Branco Vergado, that show a higher residual strain in the Z-direction, while the $\mathrm{X}$ - and $\mathrm{Y}$ - direction are similar in their irreversible expansion. In general, almost all investigated samples show the highest amount of residual strain after the first cycle and the following cycles show only weak influences on the total amount of irreversible expansion.

Table 5 Residual strain for the samples Pele de Tigre, Branco Anilado, Marinela, Branco Vergado, Branco Estremoz and Rosa Estremoz under dry and wet conditions for each direction and anisotropy of total Residual strain [\%].

\begin{tabular}{c|c|cccc}
\multicolumn{7}{c}{ RESIDUAL STRAIN ERS DRY AND WET [MM/M] } \\
\hline \multicolumn{2}{c}{ MARBLE TYPE } & Conditions & \multicolumn{4}{c}{$E_{\text {RS }}[\mathrm{mm} / \mathrm{m}]$} & Anisotropy [\%] \\
BRANCO ANILADO & wet & 0.07 & 0.08 & 0.09 & 26.67 \\
& dry & 0.26 & 0.26 & 0.36 & \\
BRANCO ESTREMOZ & wet & 0.09 & 0.11 & 0.17 & 57.14 \\
& dry & 0.13 & 0.01 & 0.11 & \\
BRANCO VERGADO & wet & 0.10 & 0.05 & 0.36 & 76.27 \\
& dry & 0.12 & 0.09 & 0.23 & \\
MARINELA & wet & 0.20 & 0.10 & 0.16 & 36.36 \\
& dry & 0.02 & 0.04 & 0.04 & \\
PELE DE TIGRE & wet & 0.00 & 0.04 & 0.01 & 37.04 \\
& dry & 0.17 & 0.23 & 0.22 & \\
ROSA ESTREMOZ & wet & 0.05 & 0.09 & 0.19 & 80.77 \\
& dry & 0.00 & 0.11 & 0.07 & \\
\hline
\end{tabular}

\subsubsection{Thermal dilatation and residual strain}

The directional dependence of $\alpha$ does not automatically lead to the same directional dependence of $\varepsilon_{\mathrm{RS}}$, regarding the amount of change in the $\mathrm{X}-, \mathrm{Y}$ - and Z-direction. Basi- 
cally, the samples Branco Anilado and Branco Vergado show the highest $\alpha$ - and $\varepsilon_{\mathrm{RS}}$-values in the Z-direction. Pele de Tigre shows a small variation in a combined with a small variation in $\varepsilon_{\text {RS. }}$ Rosa Estremoz and Branco Estremoz show the highest $\alpha$ value in the Zdirection, while the largest amount of residual strain was measured in the Y- (Rosa Estremoz) and X-direction (Branco Estremoz). Marinela shows a strongly pronounced $\alpha$ value in the Z-direction, but no clear preferred direction of residual strain.

In addition to the directional dependence of $\alpha$ and $\varepsilon_{\mathrm{RS}}$, Siegesmund and Dürrast, 2014 described, that thermal dilatation can be divided into four different types.

Type I shows an isotropic thermal dilatation $\alpha$, and no residual strain $\varepsilon_{\mathrm{RS}}$.

Type II shows an isotropic thermal dilatation $\alpha$, and residual strain $\varepsilon_{\mathrm{RS}}$.

Type III is characterised by an anisotropic $\alpha$ and no residual strain $\varepsilon_{\mathrm{RS}}$.

Type IV exhibits an anisotropic $\alpha$ value and residual strain $\varepsilon_{\text {RS. }}$

All investigated marble varieties show a pronounced directional dependence of $\alpha$ and the residual strain, thus they can be assigned to Type IV. Exceptions are the Pele de Tigre with an anisotropic $\alpha$ coefficient and an isotropic residual strain which can be categorized as Type II. The Marinela shows properties of Type III with an anisotropic $\alpha$ coefficient and almost no residual strain $\varepsilon_{\mathrm{RS}}$.

\subsubsection{Thermohygric dilatation}

After four dry cycles, all samples have been measured for five cycles under wet conditions. The specimen chamber was tilted at an angle of around $25^{\circ}$ and was filled with demineralised water. The cycle procedure was the same as under dry conditions, whereas after every heating cycle, the evaporated water was refilled. The refilling of the water with ambient temperature was performed in the middle of the $20^{\circ} \mathrm{C}$ period, to avoid a cooling induced by the water (for details see Koch and Siegesmund, 2004; Strohmeyer, 2003).

The thermal dilatation coefficient $\alpha$, shows for all investigated marbles no strong difference between the first and the following cycles. All investigated values range between $0.15 \times 10^{-6} \mathrm{~K}^{-1}$ for Branco Estremoz in the Y-direction and $13.79 \times 10^{-6} \mathrm{~K}^{-1}$ for Branco 
Vergado in the Z-direction. For all samples, the directional dependence is even observable under wet conditions and varies in the X-direction between $1.37 \times 10^{-6} \mathrm{~K}^{-1}$ for Rosa Estremoz and $11.48 \times 10^{-6} \mathrm{~K}^{-1}$ for Marinela, in the $\mathrm{Y}$-direction between $0.35 \times 10^{-6} \mathrm{~K}^{-1}$ for Branco Estremoz and $6.47 \times 10^{-6} \mathrm{~K}^{-1}$ for Pele de Tigre. The values for the Z-direction differ between $7.52 \times 10^{-6} \mathrm{~K}^{-1}$ for Pele de Tigre and $13.05 \times 10^{-6} \mathrm{~K}^{-1}$ for Branco Estremoz. The anisotropy of $\alpha$ ranges between $59.38 \%$ for the Pele de Tigre and $98.9 \%$ for Branco Estremoz (Table 4).

Compared to the dry values, it can be observed, that the $\alpha$-values under wet conditions are higher than the dry values. All investigated marble varieties show a higher dilatation coefficient, except Branco Vergado in the X-direction and Marinela, Ruivina and Pele de Tigre in the Z-direction. On the other hand, the anisotropy $A_{\alpha}$ is a bit lower under wet conditions, apart from Branco Estremoz, Rosa Estremoz and Branco Vergado, where they are a bit higher compared to dry conditions. The largest difference can be observed for the Marinela, whose dilatation coefficient in the X-direction increases from $0.37 \mathrm{x}$ $10^{-6} \mathrm{~K}^{-1}$ to $11.48 \times 10^{-6} \mathrm{~K}^{-1}$ and has a big influence on the amount of anisotropy, which reduces from $97.07 \%$ down to $66.99 \%$ (Table 4).

\subsubsection{Residual strain under wet and dry conditions}

Repeating temperature cycles under dry conditions produce a strong increase of irreversible residual strain, but only for the first cycle. Under wet conditions the marbles show a different expansion behaviour, which means they start to expand continuously. The residual strain increases significantly if water is present, whereas Siegesmund et al., 2008 , observed, that the amount of residual strain under dry conditions does not necessarily directly correlate with the amount of residual strain under wet conditions. The highest residual strain after five wet cycles can be observed with $0.36 \mathrm{~mm} / \mathrm{m}$ for the Branco Vergado in the Z-direction, the lowest with $0.00 \mathrm{~mm} / \mathrm{m}$ was measured for the Pele de Tigre in X-direction. The anisotropy of $\varepsilon_{\text {RS }}$ differs between $22.22 \%$ for the Branco Anilado up to $100 \%$ for Pele de Tigre.

The effect of moisture is more pronounced in terms of residual strain: exemplified by, Branco Anilado, Branco Vergado, Pele de Tigre, Marinela, Branco Estremoz and Rosa Estremoz under dry and wet conditions (Figure 18). The first part of the graph (red 
shaded) represents the amount of residual strain under dry conditions, and the second part of the graph (blue shaded) represents the residual strain under wet conditions. Whereas under dry conditions, none of the samples shows a significant increase of the residual strain after the first cycle, it starts to rise again under wet conditions. According to Siegesmund et al., 2008, the amount of residual strain under wet conditions exhibits phenomena, which differ from tendencies under dry conditions.
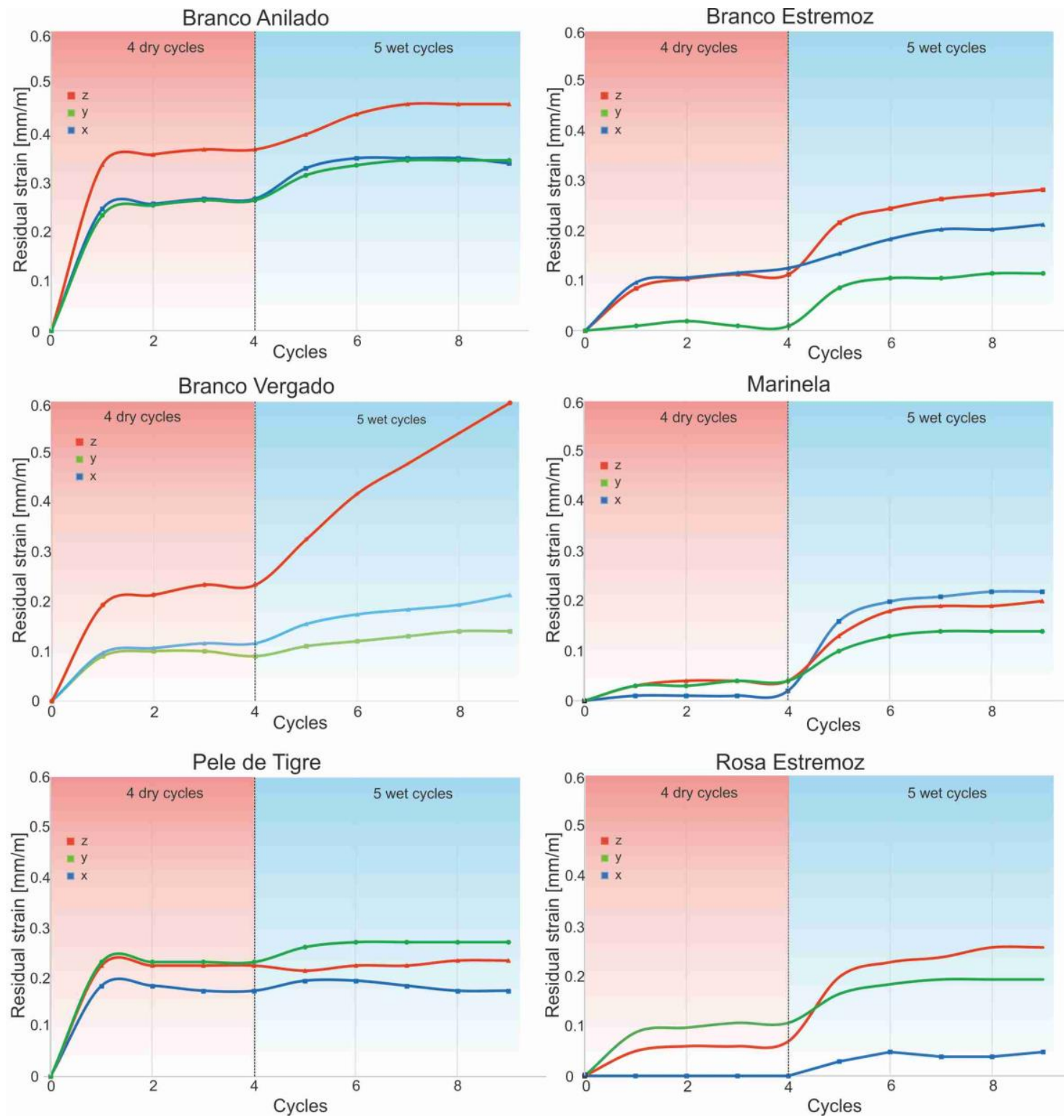

Figure 18 Residual strain $\varepsilon_{\text {RS }}[\mathrm{mm} / \mathrm{m}]$, curves indicate X- (blue), Y- (green) and Z- (red) direction. Progressive increase of residual strain of the Branco Anilado, Branco Estremoz, Branco Vergado, Marinela, Pele de Tigre and Rosa Estremoz, investigated as a function of the number of heating cycles under dry ( 4 cycles, red background) and wet ( 5 cycles, blue background) conditions. 
The Branco Anilado has a high residual strain under dry conditions, that increases again under wet conditions. After two wet cycles, the increase slows down, whereas the tendencies of the directional dependence and anisotropy stay the same as under dry conditions. The residual strain of the Branco Vergado also exhibits a slight, but constant increase in the $\mathrm{Y}$ - and $\mathrm{X}$ - direction, while the anisotropy of directional dependence increases, which can be observed in the higher difference between the $\mathrm{Y}$-/X-direction and Z-direction. While the Pele de Tigre does not show any changes compared to the expansion under dry conditions, the Marinela, which showed only a very low, residual strain, shows an increase for the first two wet cycles and is weakening afterwards under wet conditions. Directional dependence is barely pronounced. The Branco Estremoz shows an anisotropic residual strain, that increases under wet conditions. The directional dependence is more pronounced than under dry conditions and the residual strain increases in every direction. For the Rosa Estremoz, the residual strain increases under wet conditions, even in the $\mathrm{X}$-direction, that did not show any residual strain under dry conditions. The amount of increase differs from the results under dry conditions, where the Y-direction had the highest residual strain. Under wet conditions the largest increase can be observed in the Z-direction.

The total irreversible change of length after dry and wet cycles differs between 0.05 $\mathrm{mm} / \mathrm{m}$ in the X-direction for the Rosa Estremoz and $0.6 \mathrm{~mm} / \mathrm{m}$ for the Branco Vergado in the Z-direction. For all samples, a directional dependence can be recognized, while the Rosa Estremoz shows the highest anisotropy of $80.77 \%$ and the Branco Anilado the smallest with $26.67 \%$ (Table 5). 


\subsection{Application of the Estremoz marble:}

\section{The State Theatre of Darmstadt}

The State Theatre of Darmstadt (STD,) was built in 1972. The eight-story building has a length of $180 \mathrm{~m}$ in the east-west direction and a width of $95 \mathrm{~m}$ in the north-south direction. The façade is ventilated and thermally isolated. The theatre is cladded with panels of Estremoz marble. Different panel dimensions are used, but the thickness of $3 \mathrm{~cm}$ applies to all panels. The most frequent panel height is $160 \mathrm{~cm}$; the common width is 60-70 cm. In total, about 2,200 marble panels were used as cladding on the building. The material is a fine- to medium grained marble, decorated by a network of greyish to brownish layers, defining the foliation. The foliation is an important property because it is a mechanical zone of weakness and has a considerable influence on the rock's properties.
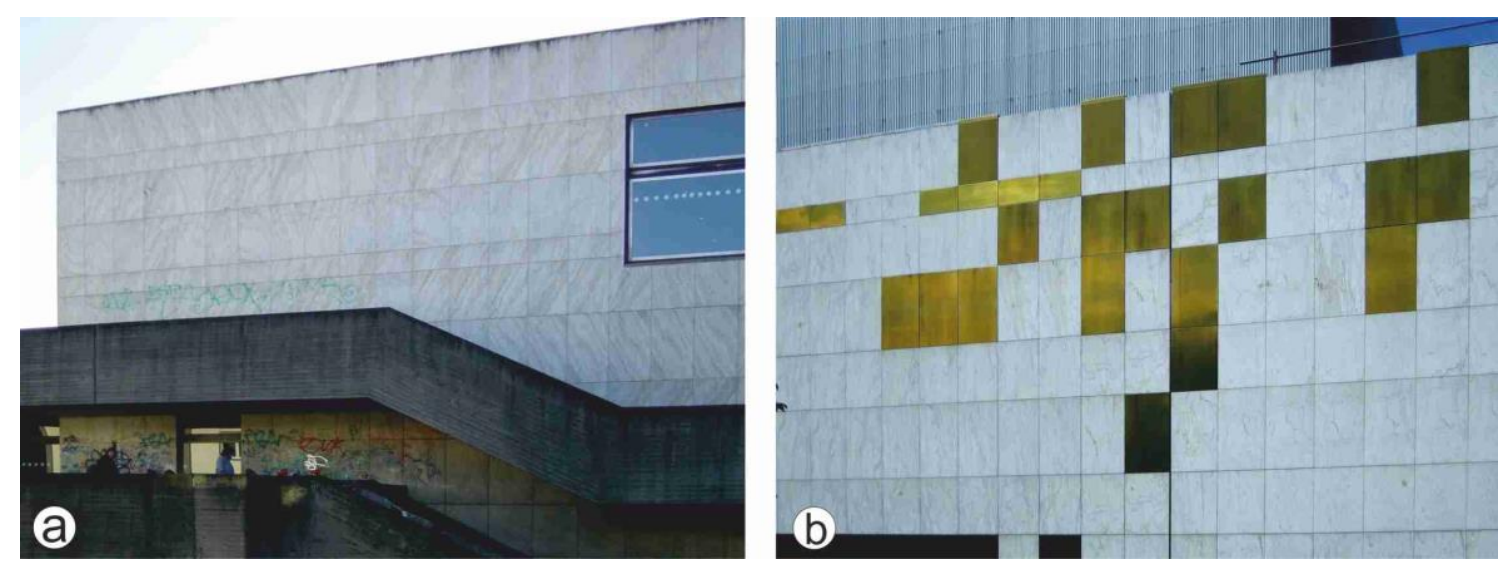

Figure 19 a) Marble façade of the State Theatre in Darmstadt before renovation in 2002. b) Detailed view of the façade cladded with Estremoz marble and replaced panels made of brass. 

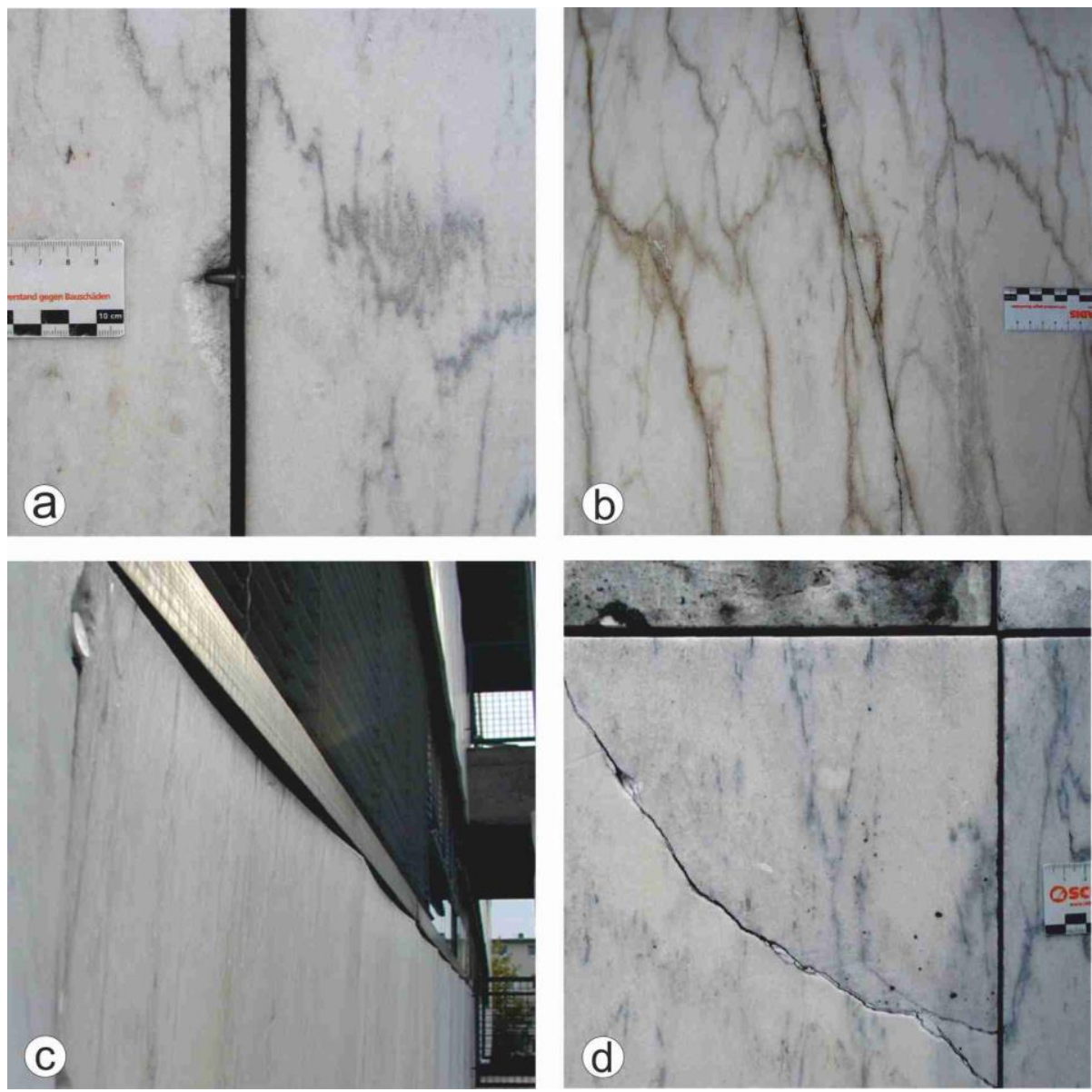

Figure 20 Damages observed in marble cladding at the State Theatre: a) outburst at a support dowl in a vertical panel joint, b) deteriorated panel with strong back weathering, c) example of concave bowing, and d) crack at a panel corner.

For all façade panels, the foliation shows a relatively equal orientation, i.e. vertical to the panel surfaces, but oriented parallel to the panel long axes (see Figure 20, Figure 21). $1-2 \mathrm{~cm}$ thick coarse-grained layers, that are also oriented parallel to the foliation, can be observed. Healed cracks occur on many panels up to a decimetre in length. Sporadically, single calcite crystals of up to $1 \mathrm{~cm}$ in diameter can be found in coarse-grained layers, which are oriented parallel to the foliation. Furthermore, individual decimetrethick bands, consisting of pure calcite matrix can be observed. They are often crosscut by open fractures, which are oriented approximately perpendicular to the foliation and whose length usually extends over the entire width of these bands (Figure 20, Figure 21). 

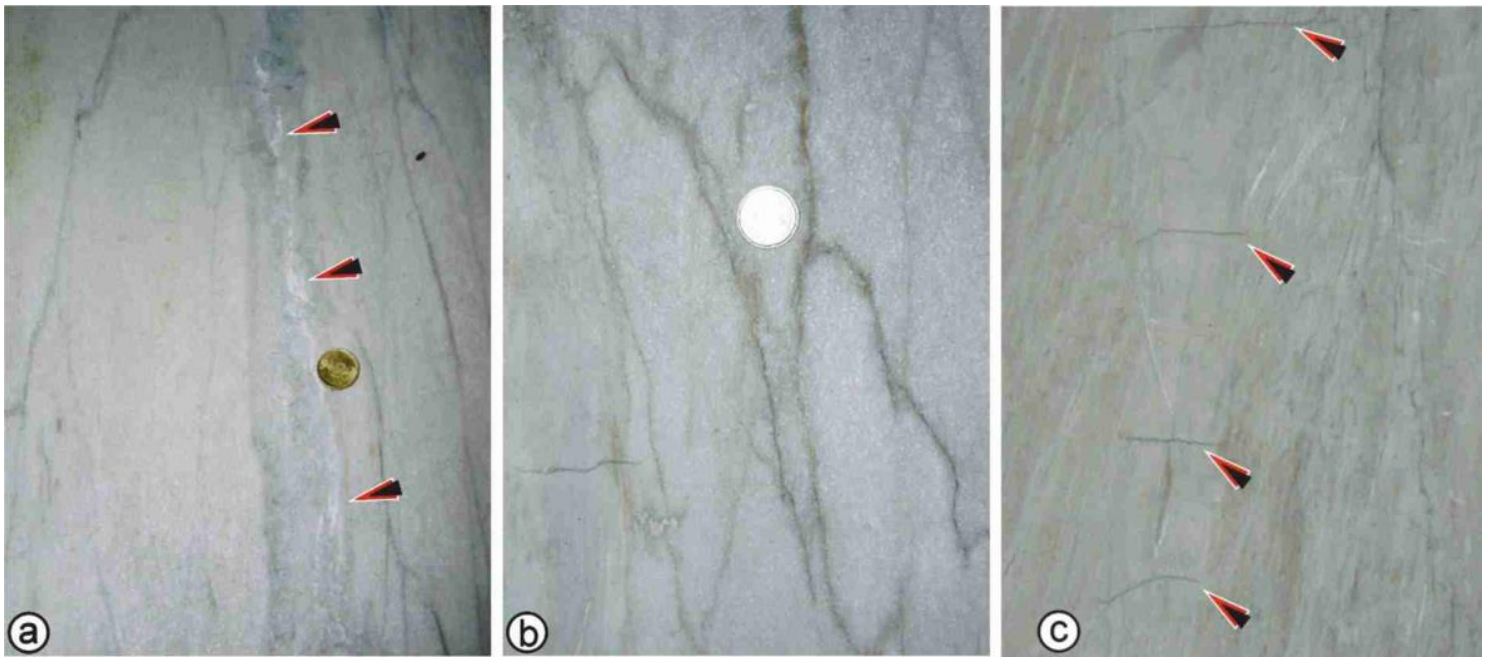

Figure 21 a) Streaks and coarse-grained calcite layer (arrows) delineate the foliation, b) further fracture system, parallel to the foliation and decorated with brownish phyllosilicates and c) fine-grained calcite band with transverse cracks.

A further fracture system is observed in some façade panels parallel to the foliation (Figure 21, Figure 22). Occasionally, they reach a decimetre in length and are decorated with a fine-grained whitish or brownish phyllosilicate-rich material (Figure 21 b). Very often, the crack filling shows different degrees of back-weathering. Cracks also run transversely to the (longitudinal) light to dark coloured foliation-parallel fractures. These will be referred to as "Cracks, cross cutting the foliation" (Figure 21c, Figure 22c). Another type of cracks can be observed at the edges of the panels, i.e. defined as open cracks, which are longer than $3 \mathrm{~cm}$ and running over the whole thickness of the panel (Figure $20 \mathrm{~d}$, Figure 22d). Breakouts and broken panels are also observable. 


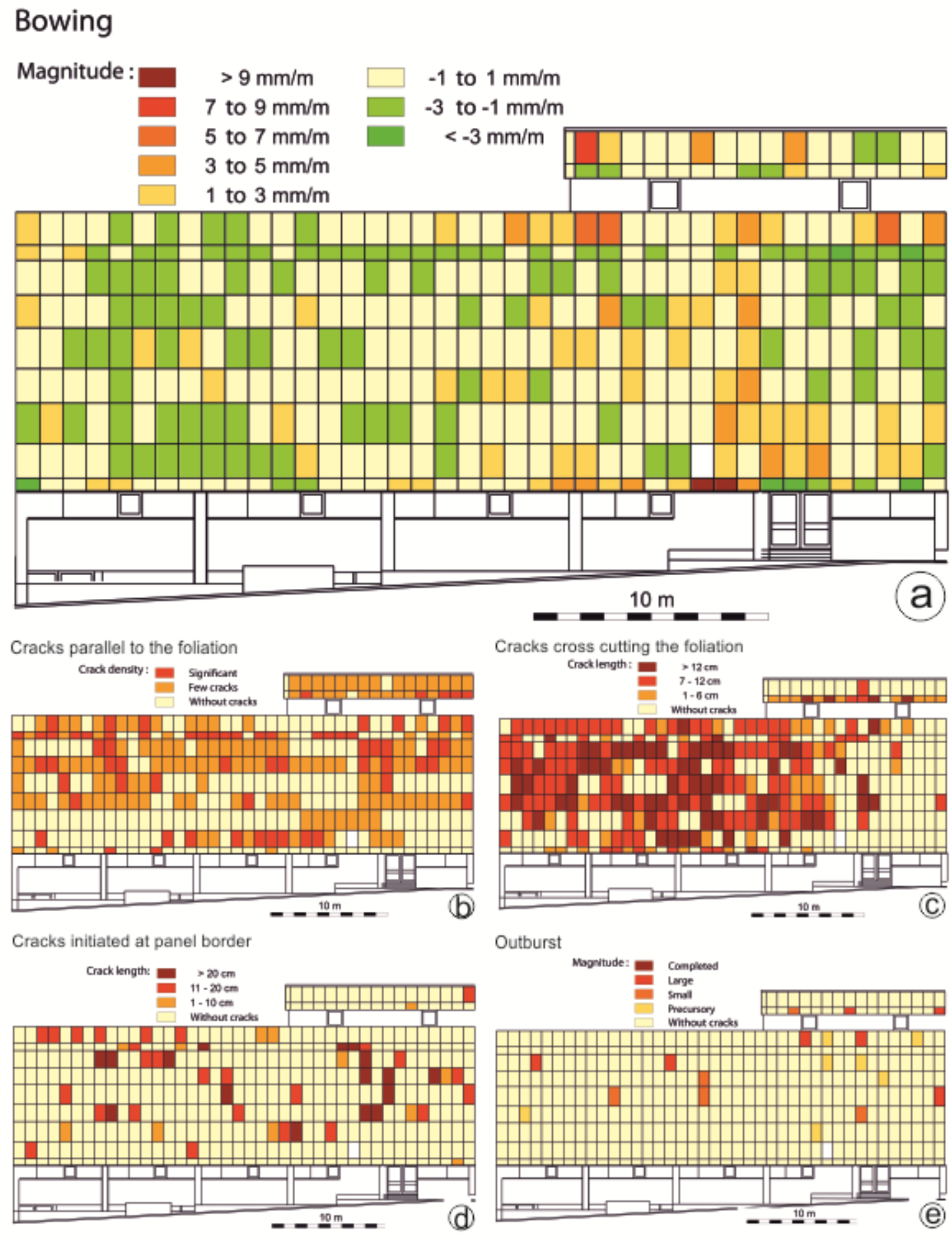

Figure 22 Decay mapping of the STD façade (south): a) amount of bowing, b) cracks parallel to the foliation, c) cracks cross cutting the foliation, d) cracks initiated at panel borders, and e) outburst.

The panels of the State Theatre of Darmstadt are characterised by concave and convex bowing, whereas convex bowing is predominant, as shown exemplaric for the south fa- 
çade in Figure 22a. The intensity of bowing is low pronounced at the STD and the magnitude is less than $3 \mathrm{~mm} / \mathrm{m}$ for most of the panels. Very rarely the degree in bowing is higher than $5 \mathrm{~mm} / \mathrm{m}$. Convex bowing seems to be more homogeneously distributed for the varying façade orientations and for the different rows. Conspicuously the bowing at the north and south façades show a contrary behaviour. At the north façade, the lower rows exhibit stronger convex bowing, whereas the upper rows show a less pronounced deformation. For the south façade, this relationship is inverted (Figure 22). The concave bowing of panels at the State Theatre is more complex. For example, the highest bowing values at the north and south façades are observable in row 6 and 10 exceeding $4 \mathrm{~mm} / \mathrm{m}$. A lot of these panels are below the window rows. This observation suggests that the bowing and its degree is also controlled by the building physics.

\subsubsection{Bowing behaviour}

The bowing test (see Chapter 3.4.6 Resistance of marble to thermal and moisture cycles) simulates the weather conditions on the building, which ultimately leads to the thermally-induced deformation and the bowing of the marble façade (see Figure 22 for façade mapping results). For this purpose, samples with a size of $400 \times 100 \times 30 \mathrm{~mm}$ in two different directions (parallel and perpendicular to the foliation) were prepared and tested. The test specimens were placed on a mm-thick water film during the test run and were cyclically irradiated from above with a heating mat at a distance of $3 \mathrm{~cm}$. One cycle consisted of a heating phase of 6 hours, in which the temperature on the plate surface rose from room temperature $\left(21-24^{\circ} \mathrm{C}\right)$ to $80^{\circ} \mathrm{C}$ and a cooling phase of about 18 hours so that one heating cycle could be run per day. Seventy cycles in total were performed.

Panels from Branco Estremoz (BE), Rosa Estremoz (RE) and Rosa Lagoa (RL) were used for the bowing test (Figure 23). All samples show comparable bowing behaviour, except sample RE-05 and less pronounced for RE-06 (Figure 23 a). For sample RE-05, parallel to the foliation, a maximum of around $0.5 \mathrm{~mm} / \mathrm{m}$ can be observed. This value is already determined after the first ten cycles and remains more or less constant throughout the testing. The direction perpendicular to the foliation shows a less pronounce bowing behaviour with a maximum of round $0.1 \mathrm{~mm} / \mathrm{m}$. Koch, 2006 reported on a sample from 
Ruivina comparable or even higher values, i.e. parallel to the foliation a maximum bowing of $0.36 \mathrm{~mm} / \mathrm{m}$ and perpendicular a maximum bowing of around $1.01 \mathrm{~mm} / \mathrm{m}$.
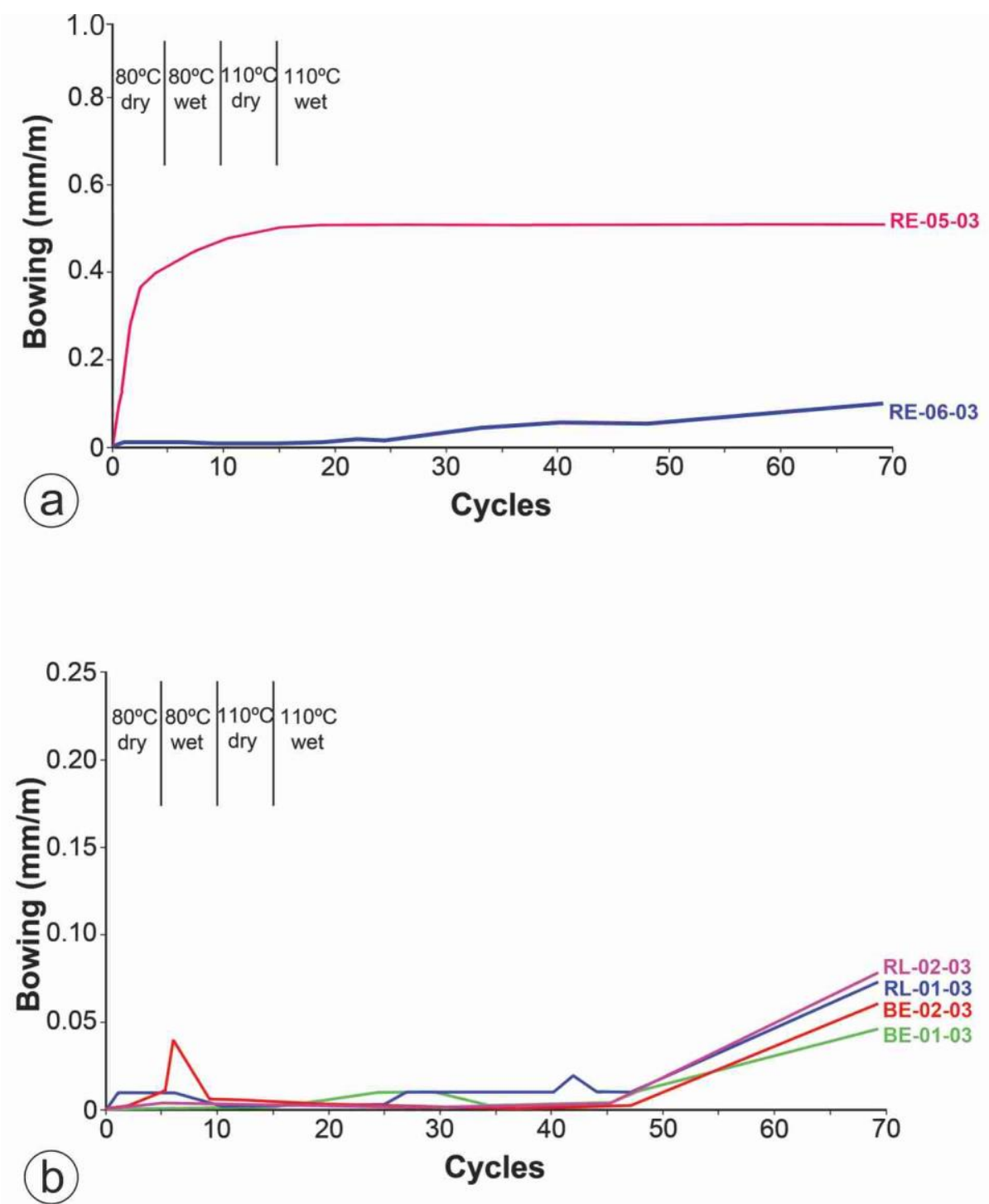

Figure 23 Increase of bowing $[\mathrm{mm} / \mathrm{m}]$ investigated as a function of the number of cycles: a) bowing of Rosa Estremoz (RE) and b) bowing of Rosa Lagoa (RL) and Branco Estremoz (BE).

Laboratory determination of the bowing potential was also conducted on several sets of marble prepared from removed panels of the State Theatre in Darmstadt. These panels show a different degree in bowing on-site at the theatre, i.e. from $0.7 \mathrm{~mm} / \mathrm{m}(P 1)$ to $5.4 \mathrm{~mm} / \mathrm{m}$ (P3) and $12.2 \mathrm{~mm} / \mathrm{m}$ for panel P6. As specimens in the bowing test usually curve convexly, regardless of the bending tendency on the building, their convex side, i.e. the former back side of the panel (the façade panels are concavely bent), was turned. The curves of the bowing behaviour of the individual specimens are shown in Figure 
24 a-c. The deterioration rate detected in the bowing test differs widely between the three selected demounted samples. For example, sample P1 exhibits in laboratory tests the smallest bowing value after 40 cycles with around $0.5 \mathrm{~mm} / \mathrm{m}$ (Figure 24 a), a value comparable to the RE-sample shown in Figure 23 a. The highest change after 30 cycles (more than $6.5 \mathrm{~mm} / \mathrm{m}$ ) occurs in sample P6 (Figure $24 \mathrm{c}$ ). This panel already had the highest value of bowing at the building.
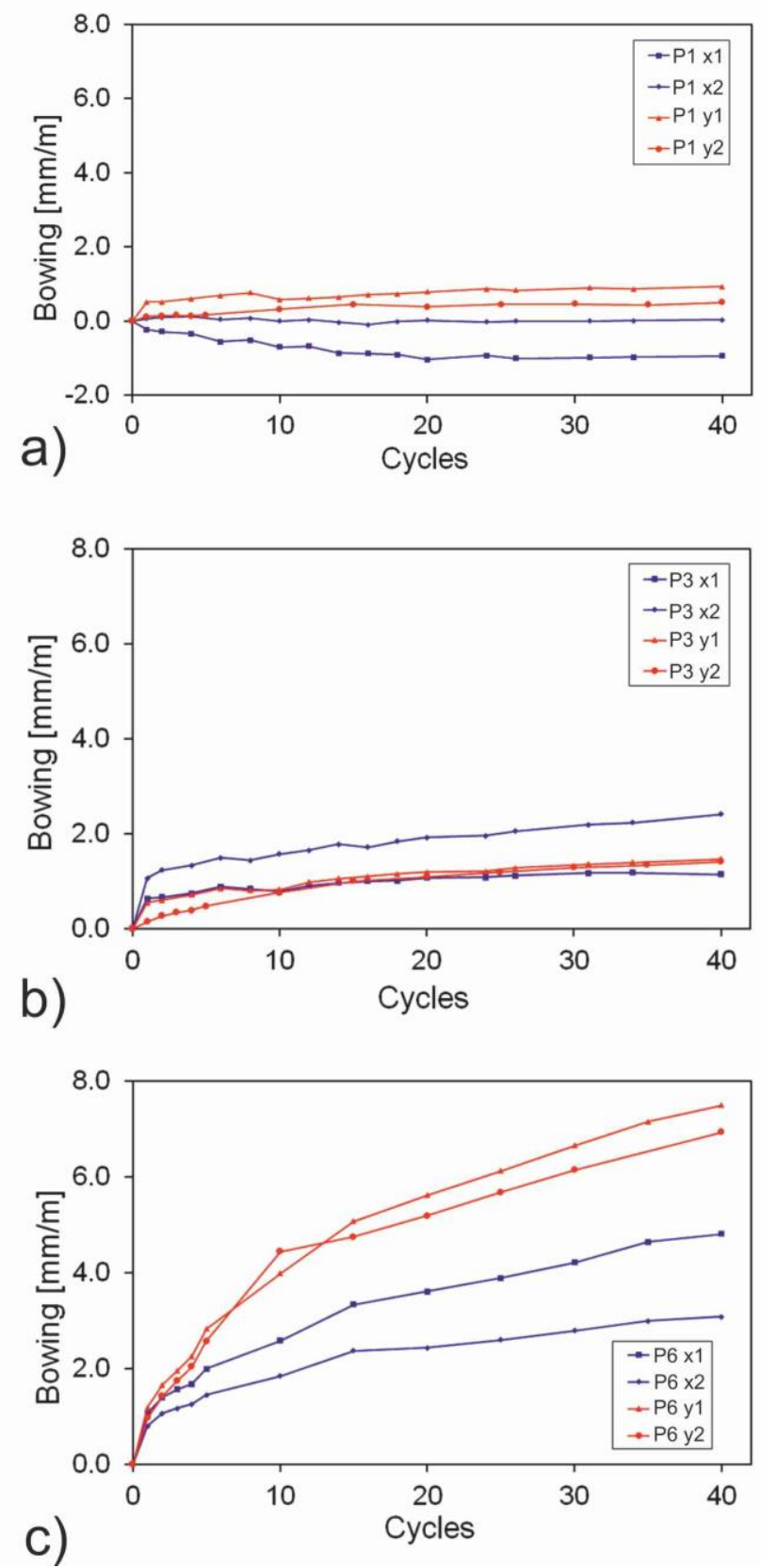

Figure 24 Increase of bowing $[\mathrm{mm} / \mathrm{m}]$ investigated as a function of the number of cycles: a) bowing of P1 in the $\mathrm{X}$ - and $\mathrm{Y}$-direction, $\mathrm{b}$ ) bowing of $\mathrm{P} 3$ in the $\mathrm{X}$ - and $\mathrm{Y}$-direction, and c) bowing of $\mathrm{P} 6$ in the $\mathrm{X}$ - and $\mathrm{Y}$ direction. 
Three essential observations were derived. Except for panel P3, the test bodies whose longitudinal axis is oriented parallel to the $\mathrm{Y}$-direction (perpendicular to the foliation) show a higher bowing than in the X-direction. This difference in direction is particularly pronounced in specimen P6 (Figure 24c), which shows a strong bending behaviour. In panel P1 (bowing of $0.7 \mathrm{~mm} / \mathrm{m}$ ), the test specimens are even slightly concave in the Xdirection (Figure 24 a). This observation is consistent with investigations on other types of marble with comparable texture and grain shape orientation, where the strongest bowing always occurred in specimens oriented perpendicular to the foliation. Thus, the tendency observed in the laboratory, has also been seen on the building.
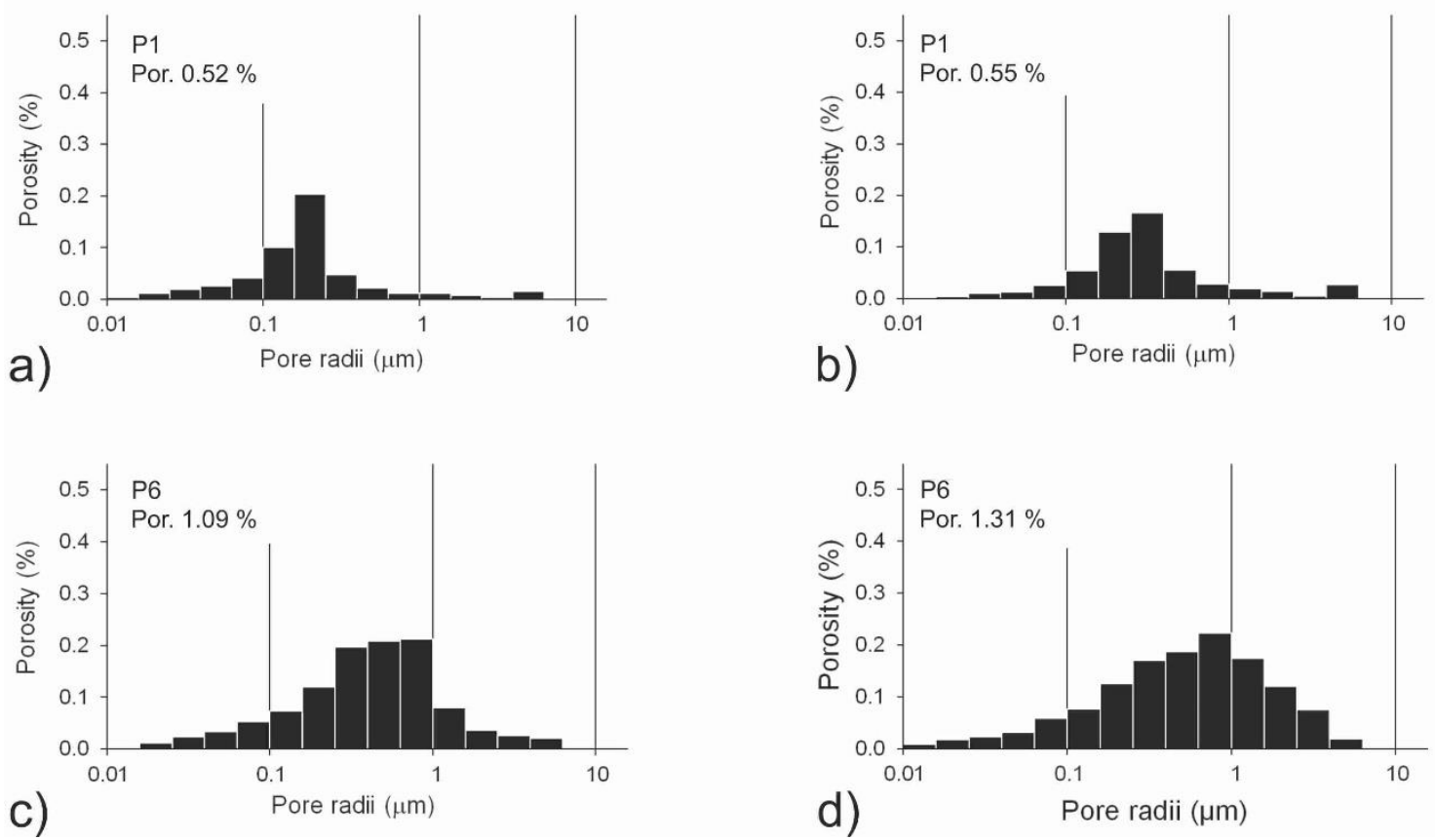

Figure 25 Porosity (Por) as a function of pore radii $[\mu \mathrm{m}]$, a) P1 pore radii distribution determined with a porosity of 0.52 vol.- $\%$, b) pore size distribution for sample P1 after the porosity was increased to 0.55 vol.-\%, c) sample P6 with a porosity of 1.09 vol.-\%, and d) P6 shows a different pore radii distribution after a porosity increase to $1.31 \mathrm{Vol} .-\%$.

For all samples, the porosity and pore size distribution has been determined by using mercury porosimetry. Fig. 4.20 demonstrates the relationship between the porosity and pore size distribution and the degree in bowing. Sample P1 (Figure 25 a) exhibits an initial porosity of around 0.52 vol.- \%, while the sample P6 (Figure $25 \mathrm{c}$ ) shows a total porosity of around 1.09 vol-\%. These higher values reflect an extreme increase in the porosity due to progressive bowing. Moreover, the pore size maximum moves towards 
larger pore radii as a function of the bowing. For both samples, the porosity and pore size distribution were measured again, i.e. after artificial aging in the laboratory. As expected, the sample P6 (Figure $25 \mathrm{~d}$ ) shows a significant higher increase in the porosity and a shift towards larger pores with a maximum pore diameter of around $1 \mu \mathrm{m}$.

The Rosa Estremoz façade marble from Darmstadt has a distinctive lattice preferred orientation (Figure 26). For the c-axes, a point-shaped maximum was determined with an intensity of $3.8 \mathrm{mrd}$, which is oriented perpendicular to the foliation (Figure 26a). Correspondingly, the a-axes show a girdle distribution parallel to the foliation plane. The thermal expansion coefficient $\alpha$ of calcite is extremely anisotropic (Kleber et al., 2010): $\alpha_{11}=26 \times 10^{-6} \mathrm{~K}^{-1}$ parallel and $\alpha_{22}=-6 \times 10^{-6} \mathrm{~K}^{-1}$ perpendicular to the crystallographic $\mathrm{c}-$ axis (Figure 26 b), i.e. calcite contracts normal to the c-axis and expands parallel to the c-axis. As a result, a very anisotropic material behaviour is to be expected.

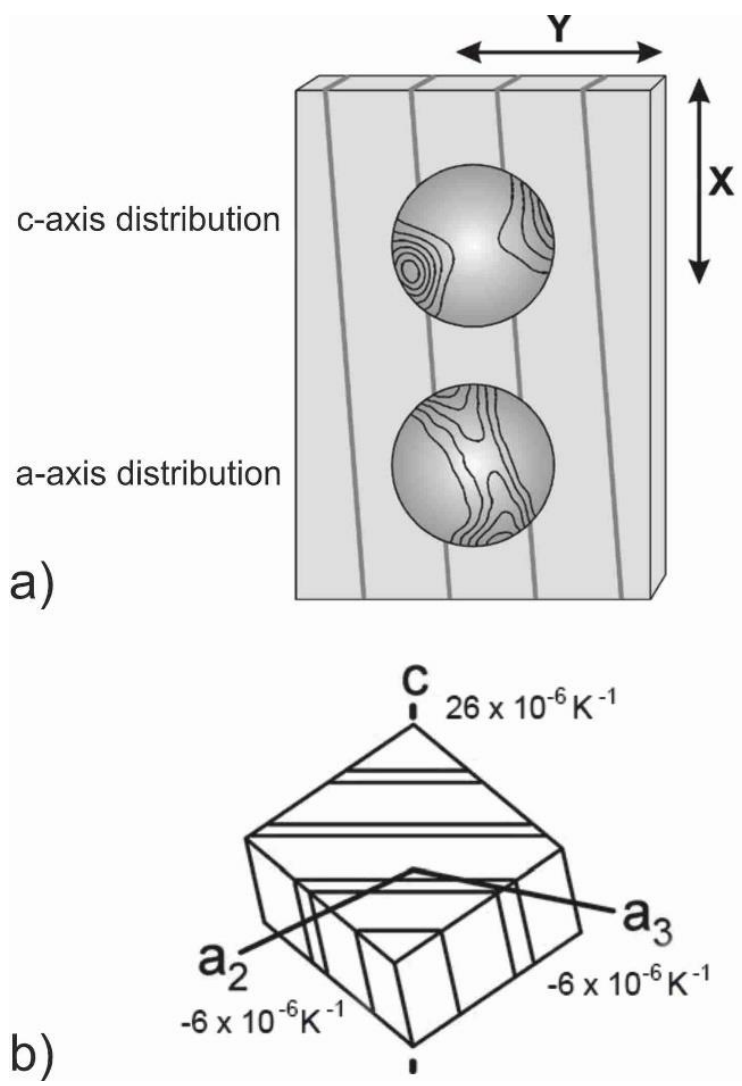

Figure 26 a) Preferred orientation of the crystallographic c- and a-axis transferred to the panel geometry and foliation found at the STD, which are in this case almost perpendicular to the front of the panel $b$ ) Anisotropy of thermal dilatation coefficient $\alpha$ for a calcite single crystal. The positive value for the c-axis means an expansion under heating conditions, while the negative value for the a-axis means, that contraction will occur under heating conditions. 
The thermal expansion measurements on the demounted panels are given in Figure 27. The façade marble exhibits a pronounced anisotropy in the length change under thermal stress. In panel P1, when the temperature is raised to $90^{\circ} \mathrm{C}$, the change in length in the Y-direction is more than twice as high as compared to the X-direction $(0.5 \mathrm{~mm} / \mathrm{m})$. In panel P6, the difference in the $X$ direction is negligible. When the laboratory results are applied on the building, this means that the marble will show a length change of $0.4 \mathrm{~mm}$ caused by expansion on a warm summer day and contraction in the winter. While this happens in one direction, the total length in the other direction of the panel remains unchanged. These can be easily explained by the single crystal data of calcite, the lattice preferred orientation of the crystallographic c- and a-axis and the panel geometry (see Figure 27 a). For sample P1 furthermore in Y-direction (Figure 27 b), a significant increase in the curve can be seen at approximately $55^{\circ} \mathrm{C}$. This can activate a buffering effect originated by pre-existing microcracks, which decreases with increasing temperature, and thus leads to a gradual increase in the curve. The expansion of the calcite crystals is initially buffered by these pre-existing cracks, so that only a reduced stress transfer within the rock occurs. In the higher temperature range of about $40-60{ }^{\circ} \mathrm{C}$, this process is replaced by the formation of thermally induced microcracks. These newly formed microcracks are only partially closed because the cracks are offset during contraction. Subsequent cooling causes an irreversible residual strain of about $0.2 \mathrm{~mm} / \mathrm{m}$. For comparison, the residual strain in the strongly deformed panel P6 in the Y-direction is less pronounced (Figure 27d). The higher pre-stressing (bowing) of panel P6 leads to the buffer effect, having a control on the high temperature range, so the formation of new and more thermal-induced microcracks is less intense, which consequently results in a lower residual strain. 

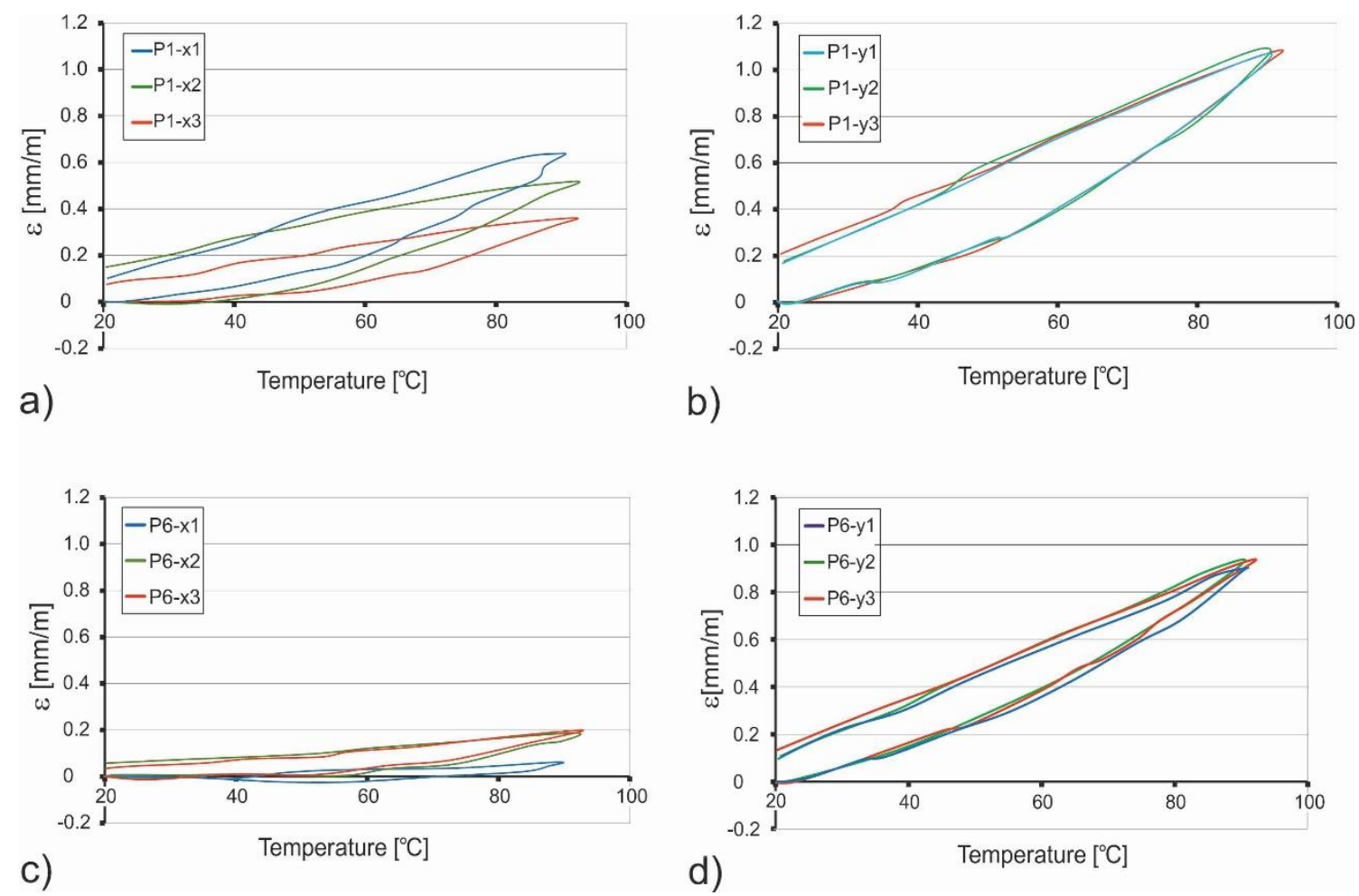

Figure 27 Thermal expansion as function of temperature shown for 3 cycles $\left(20-90-20^{\circ} \mathrm{C}\right)$, a) P1 in the $X$ direction, b) P1 in the Y-direction, c) P6 in the X-direction and d) P6 in the Y-direction.

\subsection{Summary}

The Estremoz marbles have been exploited from the Estremoz Anticline in Portugal since antiquity to the present-day for various purposes. In a commercial context, the name Estremoz is used for all of the stone varieties, even though the marbles differ strongly in their appearance. The colours range from white, to pinkish and dark grey, whereby a monochromatic colour is seldom. More often randomly distributed veins and spots in different colours determine the aesthetic properties and allow for versatile applications.

Mineralogical and rock physical analyses have been carried out on 10 different, mostly representative marble varieties. One goal of the study is not only to compare the macroscopic appearance, but to demonstrate the importance of the mineralogical composition and the rock fabrics on the potential physical weathering behaviour.

Calcite is the main component in all the investigated marble samples. Only Rosa Estremoz and Creme Vergado show a low amount of dolomite ( $3 \%$ and $11 \%$ ). The miner- 
alogical composition of the marbles exhibits no differences to justify the colour variations. The low amount of altered pyrite, found in some samples, cannot be responsible for the colourful appearance of the different varieties.

The microfabric of the studied marbles shows several differences, that reflects the geological conditions. The grain boundaries observed are equigranular to seriate in most varieties, however, in Branco Estremoz they are polygonal and in Marinela interlocking amoeboid, and thus the extreme cases. The grain sizes vary between fine- to mediumgrained, whereby a shape preferred orientation can be observed in all varieties. It is less pronounced in Branco Estremoz and more evident in Marinela.

For all samples, the cathodoluminescence showed a similar, homogenous luminescence, where different grain generations are differentiated. The only exceptions are the Marinela, with a very inhomogeneous luminescence and the weak to non-luminescing Creme Vergado.

The lattice preferred orientation shows for all samples similar and moderately to strongly pronounced c-axis maxima with the highest values determined for the Marinela and the lowest for Branco Vergado. Almost all marbles show a single c-axis maximum, which is more or less elongated and surrounded by a girdle of the a-axis maxima. An exception is the Pele de Tigre, which shows a belt-like distribution of the c-axis maxima.

The weathering behaviour of marbles is an important process to be investigated, especially when these stones are used for exterior applications. For this reason, the thermal expansion under dry and thermohygric conditions was determined, regarding the residual strain, as an important value for irreversible length change.

The thermal expansion under dry conditions shows for all investigated marble variations a preferred direction, which is obviously distinct to the lattice preferred orientation. All determined marbles show the highest expansion parallel to the c-axis in the Z-direction, while the expansion is lower parallel to the a-axis. The Pele de Tigre shows almost no directional dependence, which can be explained by the almost girdle-like distribution of the c-axis maxima. The irreversible change of length is evident for all varieties, except the Marinela, and most pronounced for the Branco Anilado. 
All investigated marble varieties show a pronounced directional dependence of $\alpha$ and residual strain $\varepsilon_{\mathrm{RS}}$, except the Marinela and the Pele de Tigre. According to Siegesmund and Dürrast, 2014, these marbles can be assigned to Type IV. The Marinela can be categorized as Type III with an anisotropic $\alpha$ and almost no residual strain and the Pele de Tigre as Type II with an almost isotropic thermal dilatation and residual strain. The irreversible change of length due to heating cycles almost stops after the first dry cycle. Thermal expansion under thermohygric conditions was also determined, considering that the influence of humidity is important in all exterior applications. Repeated heating cycles under wet conditions show for almost all varieties a rising length change. This is similar to dry conditions and most evident in the first cycle. With the exception of Branco Vergado, where growth is continuous in the Z-direction, all marbles stay more or less constant at least after 2 wet cycles. The Pele de Tigre does not even show further length change. All marble varieties show an irreversible change in length under thermohygric conditions, but apart from the Branco Vergado, it does not increase after 2 cycles.

The bowing test, determined for 3 varieties, showed a maximum amount of bowing for the Rosa Estremoz $(0.5 \mathrm{~mm} / \mathrm{m})$. Similar to the thermohygric expansion, the maximum value was reached after 5 cycles and did not increase in the continuing cycles. Bowing behaviour shows a directional dependence, according to the lattice preferred orientation and the grain shape orientation. A comparison of the laboratory values and the onsite measurements at the State Theatre in Darmstadt for the Estremoz marble showed a similar directional dependence but different intensities of bowing. At the State Theatre of Darmstadt, not only the rock physical properties influence the bowing behaviour, but also the building physics seems to be an important factor. However, the rock fabric needs to be considered when the rock is cut for specific applications.

Changes in temperature and the presence of humidity are the controlling factors for deterioration with regard to the anisotropic single crystal properties of calcite. All investigated varieties show anisotropic properties, with preferred orientations of grain shape and crystallography. The residual permanent length change is a measure of the vulnerability to thermal weathering. Even if marble has a very simple mineralogical composition, the thermal sensitivity and anisotropic rock properties have to be considered for the manufacturing processes, particularly with regard to specific applications. 


\section{Marble varieties and the effect of alteration}

Marble is an often used heritage stone ( see Chapter 4 The Estremoz Marbles) and especially famous sculptures were made by this material. To get an insight into their weathering state, a non-destructive analysis of them is desired. Ultrasonic tomography is one possibility to receive the desired insight, while a good interpretation depends on the knowledge regarding the specific material.

Systematic analyses were performed on 6 marble types, which were often used as an heritage stone. The Spanish Blanco Macael, the Italian Carrara Gioia and Lasa, the Polish Großkunzendorf and Prieborner and the less common German Wunsiedel marble which is primarily used regionally. To relate their weathering state to an ultrasonic velocity, a successive artificial weathering has been performed, analysing important rockphysical changes within the alteration.

\subsection{Provenance, macroscopic description and decay phenomena}

\section{Blanco Macael marble}
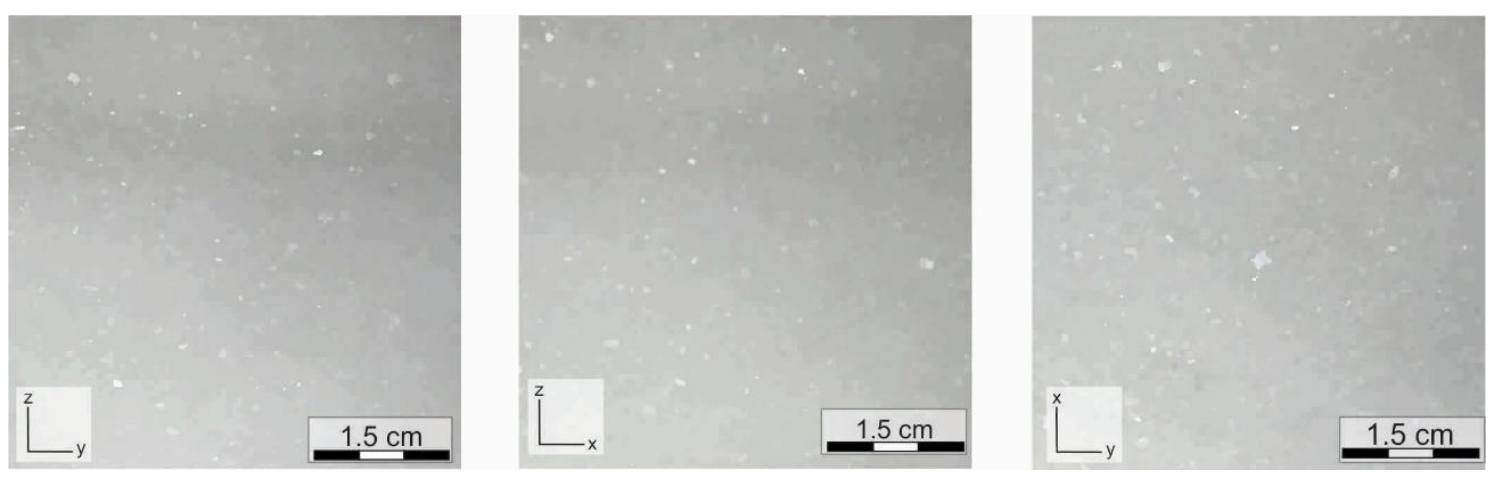

Figure 28 Macroscopic image of the Blanco Macael. 
The Blanco Macael is a Spanish marble variety, which is exploited near the municipality of Macael, in the southern Spanish province Almeria in Andalusia. Geologically, this marble is a late Triassic variety belonging to the Nevado-Filabride complex, located at the so called Betic Internal Zone. This is the lowest tectonic unit of the Alboran Domain (Luque Aranda, 2011). Macroscopically, this variety is characterized by a white colour, sporadically interspersed with bands varying from light to dark grey. The banding of the analysed blocks has a thickness up to $1 \mathrm{~cm}$ and is primarily found parallel to the foliation. The artificial alteration led to a strongly pronounced sugaring of this marble variety, indicating a progressive granular disintegration.

\section{Carrara marble}
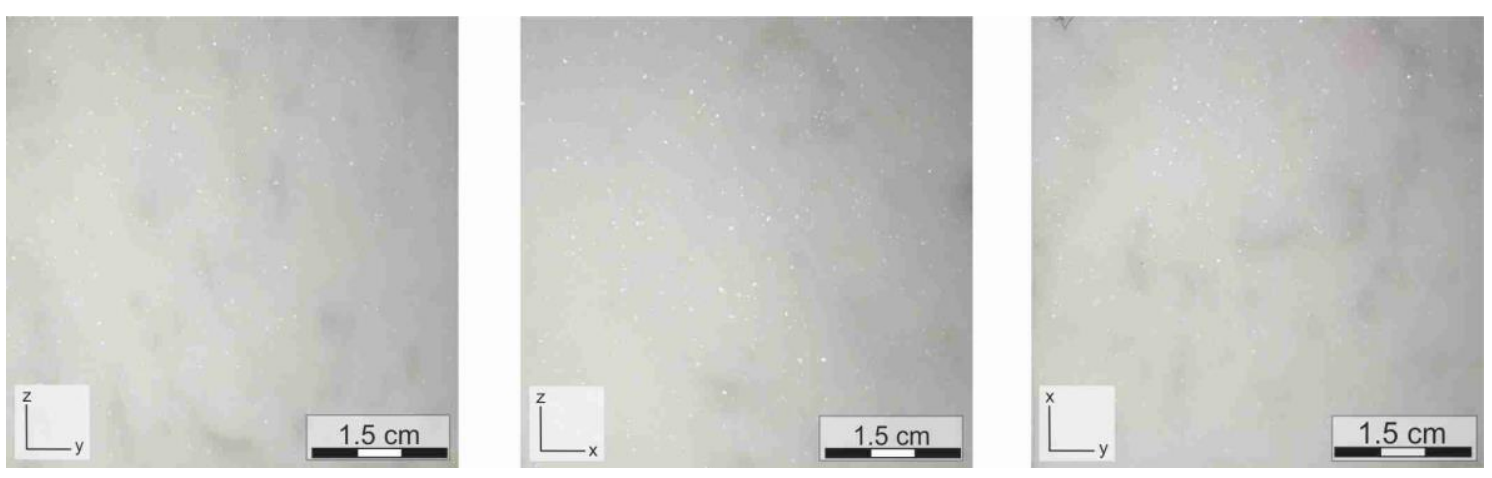

Figure 29 Macroscopic image of the Carrara Gioia.

The Carrara marble is quarried in the Apuan Alps of the province of Massa-Carrara, a Tuscany region of Central Italy. This variety is sold by different names like Bianco Carrara C, Statuario, Ordinario, Gioia, depending on the colour shades and quality. Geologically, these marbles are located at the lower part of the Apennine nappe, a metamorphic complex, outcropping in a tectonic window (Carmignani et al., 1978). Two synmetamorphic phases of deformation during the alpine orogeny led to the overprint of the marble (Carmignani and Kligfield, 1990). The analysed marble samples belong to the so called Gioia variety, a whitish marble with irregularly streaked dark grey bands. Typical decay phenomenon of this marble is a back weathering of the surface caused by granular disintegration. This disintegration process shows an penetrating progress to the depth of the marble. 


\section{Lasa marble}
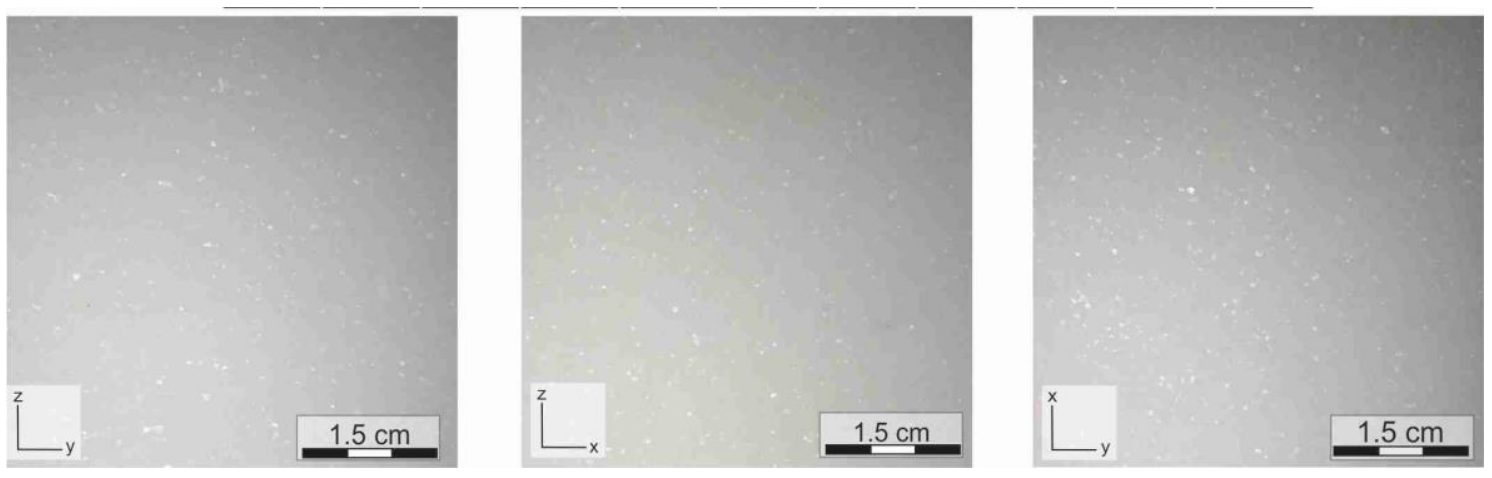

Figure 30 Macroscopic image of the Lasa marble.

Lasa Marble is quarried at the Vinschgau-Ultenvalley, south of Lasa in South Tyrol (Italy). Geologically it is located within the tectonic Laas Unit in the Ortler-Campo Crystalline (Nappe). It is part of the Scharl-Campo Crystalline Complex, located south of the Vinschgau Valley between Töll (near the city of Meran) and Laas and has been over thrusted by the Stubai-Ötztal Crystalline. The Laas Unit is one of three tectonic units and the lowest part within the Ortler-Campo Crystalline (Unterwurzacher and Obojes, 2012). The macroscopic appearance of the analysed material is mainly white, only isolated foliation parallel dark bands could be observed. Ruedrich, 2003 described back weathering of the surface as the main decay phenomena on a naturally weathered gravestone made of Lasa marble. He could not observe any cracks or in-depth granular disintegration, which correlates with the observations made for artificially alterated material.

\section{Großkunzendorf marble}
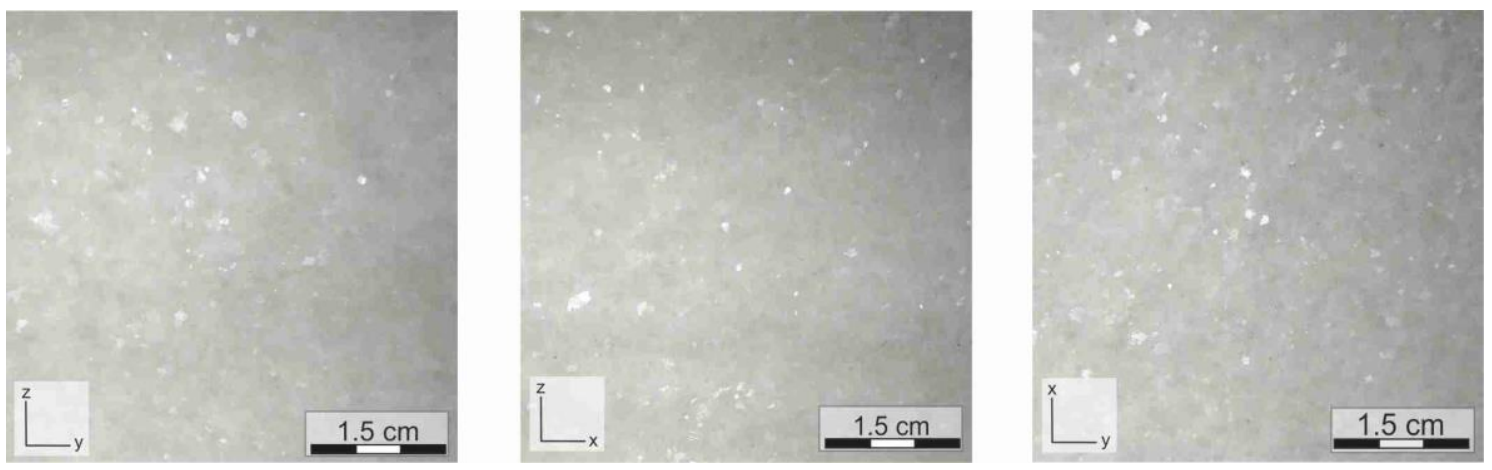

Figure 31 Macroscopic image of the Großkunzendorf marble. 
In the south-western part of Poland, a few kilometres south of Nysa, is the quarry of the Großkunzendorf marble located. This marble is exploited in the eastern Sudeten Mountains and part of the Desna Formation. The deformation history includes pre-Variscan and Variscan overprinting (Ruedrich, 2003). The marble is predominantly light grey, but is occasionally characterised by dark grey mica layers parallel to the foliation. The decay phenomena of this marble are characterized by a distinct back weathering of the original surface and parallel, open macrocracks. Locally, the loss of individual grains can be observed.

\section{Prieborn marble}
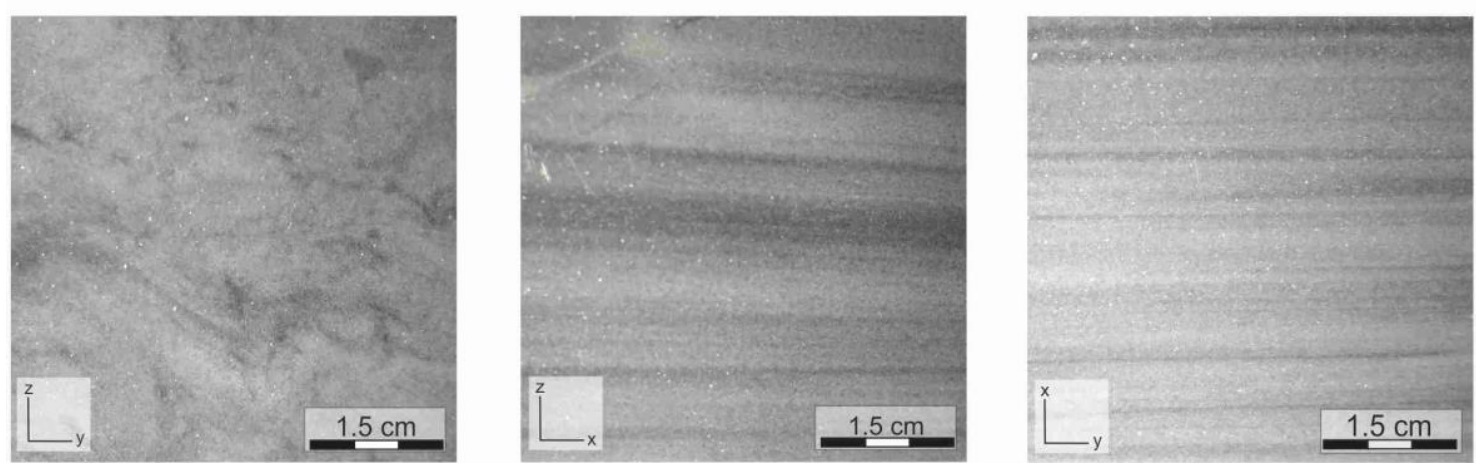

Figure 32 Macroscopic image of the Prieborn marble.

The Prieborn marble is located southeast of Strzelin and about one kilometre east of the eponymous village Przeworno (Prieborn) in Poland. This marble is located in the western Sudeten Mountains and part of a Proterozoic metamorphic complex (Ruedrich, 2003). The exploitation of the Prieborn marble was historically carried out within a limited framework and is not caved today. Macroscopically the strong banding of alternating light and dark grey narrow layers is characteristically for this marble. The thickness of these layers ranges within a scale of millimetres, whereby according to Ruedrich, 2003 a dominance of $5 \mathrm{~mm}$ can be determined. The macroscopic visible crack systems are conspicuously mineralized and sealed, crosscutting the fabric. The analysed material is excavated marble from the marble palais and therefore already weathered. 


\section{Wunsiedel marble}
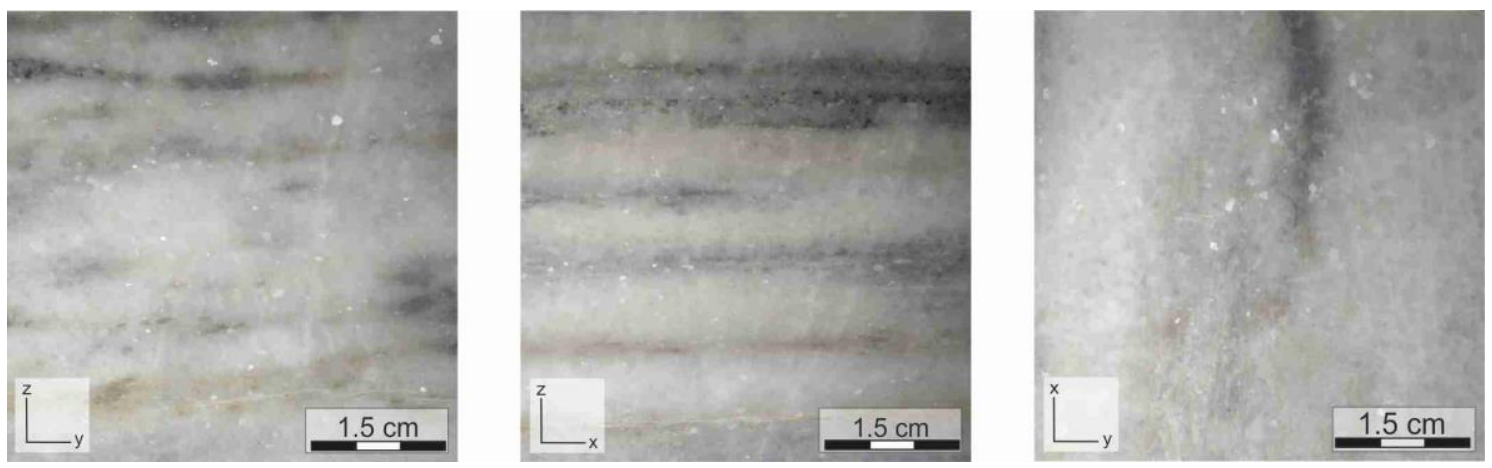

Figure 33 Macroscopic image of the Wunsiedel marble.

The Wunsiedel marble is exploited in the Fichtelgebirge, in the north-east of Bavaria (Germany) where it is formed in two bands (Grimm, 2018), while only the southern part was used for mainly tombstones and ashlars. It is embedded in the so-called "Wunsiedel Formation", a carbonate bearing sequence of Lower and Middle Cambrian age within the Fichtelgebirge Anticline, which belongs to the Variscan basement. The appearance of this marble is very heterogeneous and occasionally characterized by a strong banding due to the layered enrichment of graphite, as well as enrichments of calcium silicates or layered silicates. The colours of the bands range from black and grey to green and red. The weathering behaviour of this marble is dominated by cracks, while granular disintegration is less common. 


\subsection{Microfabric}

\section{- Blanco Macael marble}

The Blanco Macael has a calcite content of $96.82 \mathrm{~m} .-\%$ and is therefore classified as a calcite marble. The grain structure is inequigranular polygonal with straight to slightly curved, occasionally also lobate grain boundaries. Most calcite grains have twin lamellae, whereby no traces of deformation are visible. Quartz could be detected accessory, while Sáez-Pérez, 2009 also reported the presence of muscovite and albite. The average grain size is $495 \mu \mathrm{m}$ with a minimum of $105 \mu \mathrm{m}$ and a maximum size of $2600 \mu \mathrm{m}$, determined in three orthogonal cut planes.

A preferred grain boundary orientation could be detected in all cutting planes, whereby it is clearly formed foliation-parallel in the YZ-plane and weaker in the XZ-plane. The XYplane accordingly a preferred orientation in Y-direction.

The texture of the Blanco Macael shows a strong c-axis point maximum with an intensity of $2.9 \mathrm{mrd}$ (multiple random distribution), which is accordingly surrounded by an a-axes belt, with an equally strong intensity of $2.45 \mathrm{mrd}$. 


\begin{tabular}{|c|c|}
\hline $\begin{array}{l}\text { Grainfabric } \\
\quad \text {-equigranular polygonal }\end{array}$ & $\begin{array}{l}\text { Preferred grain shape orientation } \\
\text { - in ZY-plane elongation in } \\
\text { Y-direction }\end{array}$ \\
\hline \multirow{2}{*}{$\begin{array}{l}\text { Medium grain size } \\
-495 \mu \mathrm{m}\end{array}$} & \multirow{3}{*}{$\begin{array}{l}\text { Texture } \\
\text { - c-axis fibre type } \\
\text { medium intensity }\end{array}$} \\
\hline & \\
\hline $\begin{array}{c}\text { Grain boundary geometry } \\
\text {-straight to lobate }\end{array}$ & \\
\hline
\end{tabular}

\section{Grain fabric}
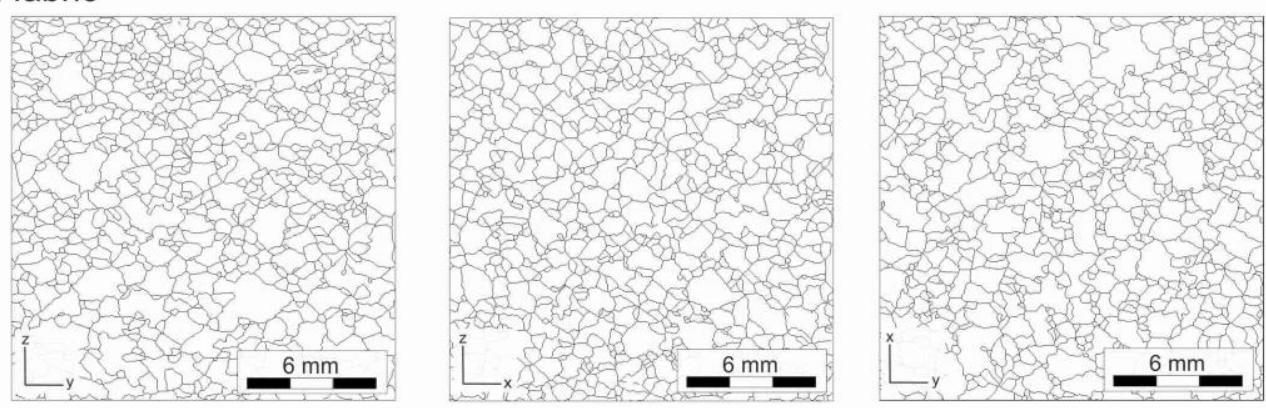

Grain area distribution
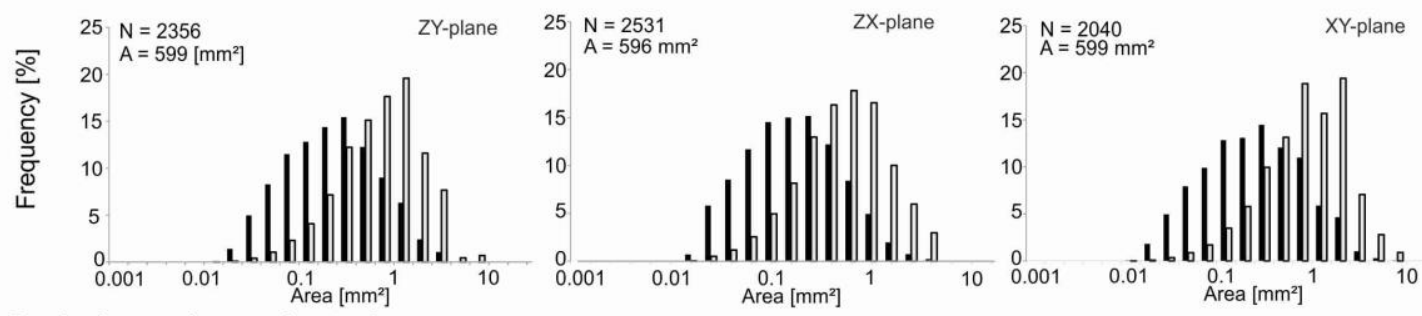

Grain boundary orientation
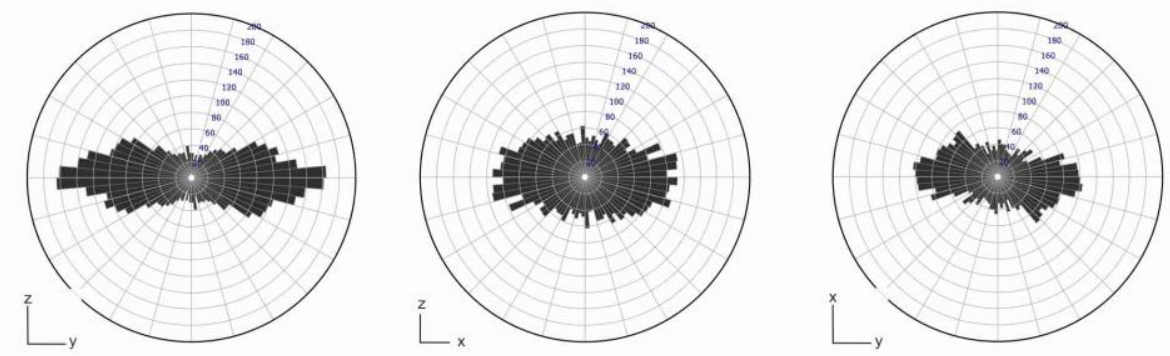

Texture:
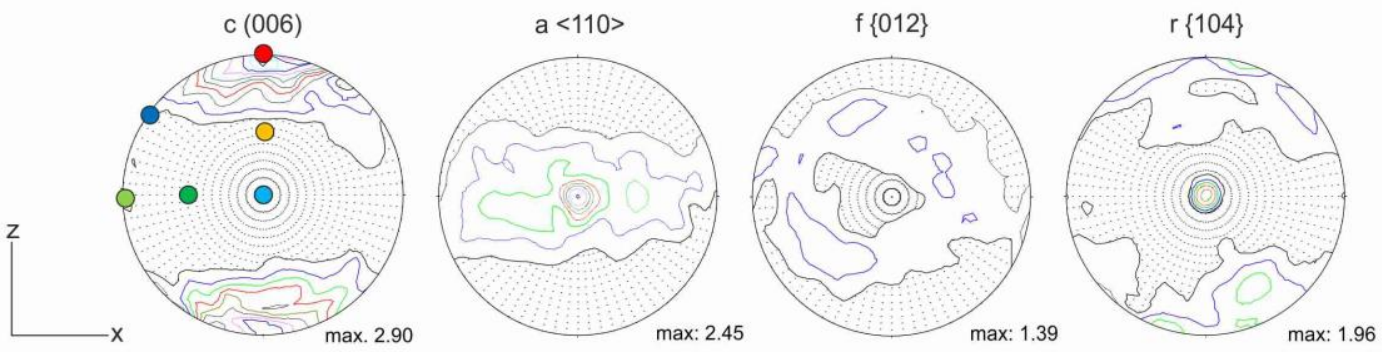

Figure 34 Main fabric characteristics of the Blanco Macael. Characteristic line drawing of a microscope image, grain size (relative frequency of specific area class has been calculated with respect to the total area (grey bars; $\mathrm{A}=$ total area) and total number of grains (black bars; $\mathrm{N}=$ total number of grains)), shape preferred orientation and texture. 


\section{- Carrara marble}

The Carrara Gioia marble is a calcite marble, with a calcium carbonate content of $95.52 \mathrm{~m}-\%$. The microstructure has a characteristic granoblastic grain shape, whereby static recrystallization can be mentioned as an essential process for the formation of the structure. The grain boundaries are straight to interlobate, with an equigranular grain aggregate with predominantly polygonal grain contacts. The grain size of the marble in the investigated cut layers is at a minimum of $99 \mu \mathrm{m}$ and at a maximum of $1350 \mu \mathrm{m}$ with an average grain size of $284 \mu \mathrm{m}$. The grain boundaries are sporadically dark decorated with graphite. Twin lamellae are quite frequently formed, whereby no deformation traces are observed.

A grain shape preferred orientation can be observed for the ZX-plane in X-direction, whereas the ZY-plane only shows a discreet and slightly sloping adjustment. In the XYplane, grain shape preference can be determined in both $\mathrm{X}$ and $\mathrm{Y}$-direction. The texture is in the intermediate range with a maximum intensity of $2.35 \mathrm{mrd}$ of the c-axes and shows the pattern of a c-axis fibre type (Leiss and Ullemeyer, 1999). The a-axes surround this maximum in a belt-like manner with a weak maximum of $1.6 \mathrm{mrd}$. 


\begin{tabular}{|c|c|}
\hline $\begin{array}{c}\text { Grain fabric } \\
\text {-equigranular polygonal }\end{array}$ & $\begin{array}{c}\text { Preferred grain shape orientation } \\
- \text { in ZX-plane elongation in } \\
\text { X-direction }\end{array}$ \\
\cline { 1 - 1 } $\begin{array}{c}\text { Medium grain size } \\
284 \mu \mathrm{m}\end{array}$ & $\begin{array}{c}\text { Texture } \\
\text { - c-axis fibre type with medium } \\
\text { intensity }\end{array}$ \\
\hline $\begin{array}{c}\text { Grain boundary geometry } \\
\text { straight to interlobate }\end{array}$ & \\
\hline
\end{tabular}
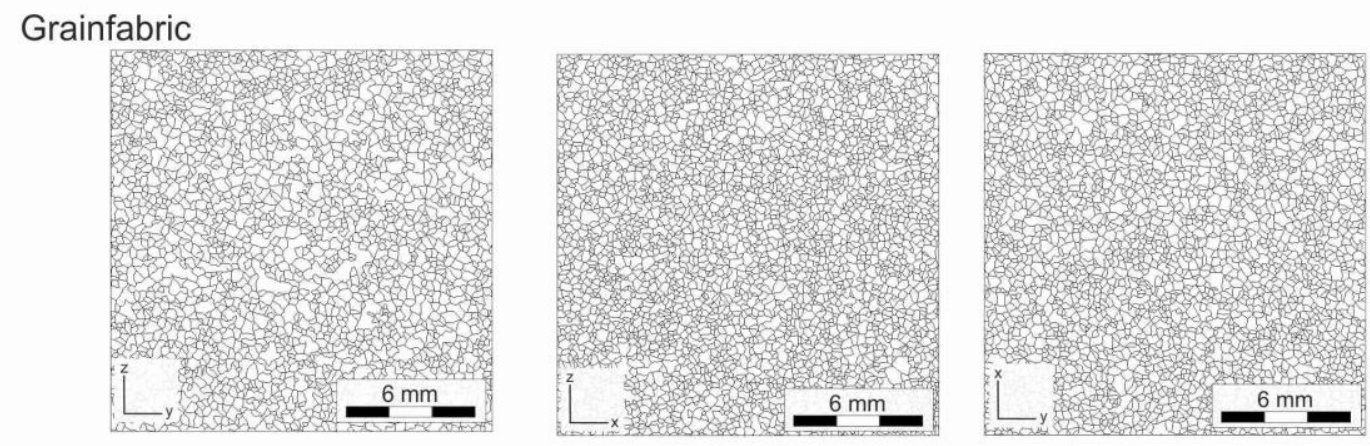

Grain area distribution
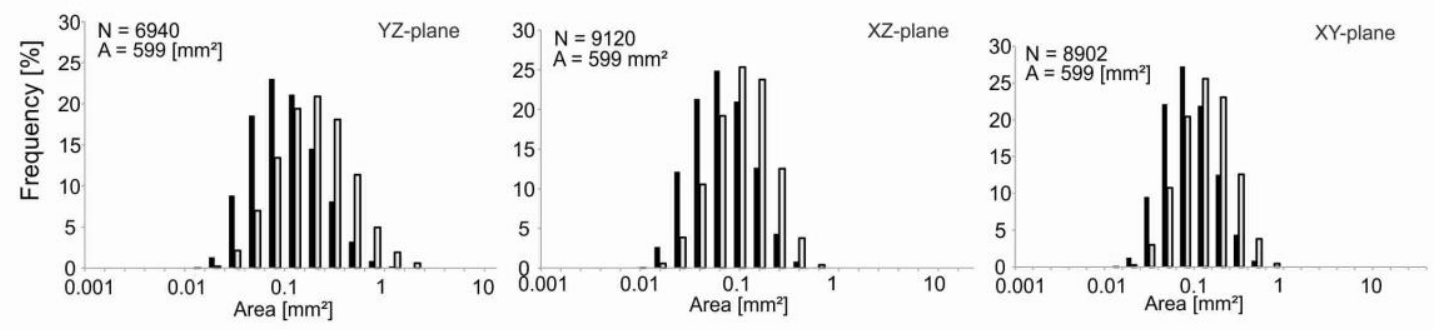

Grain boundary orientation
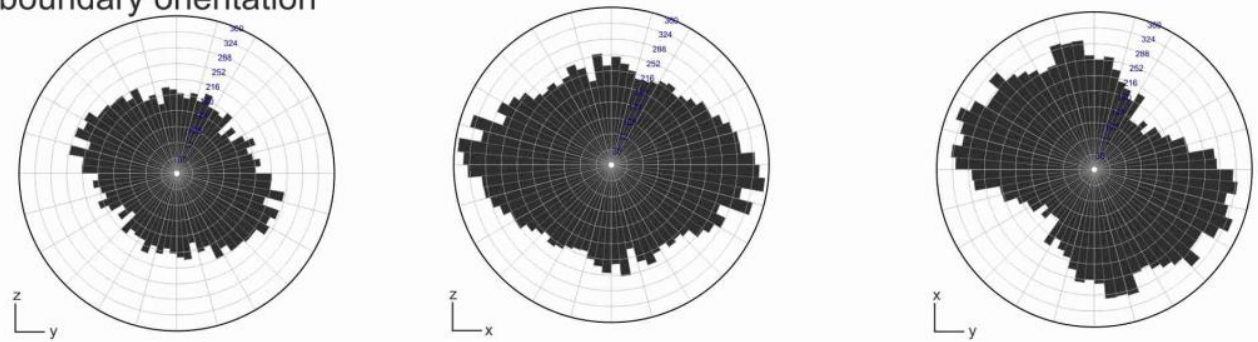

Texture:
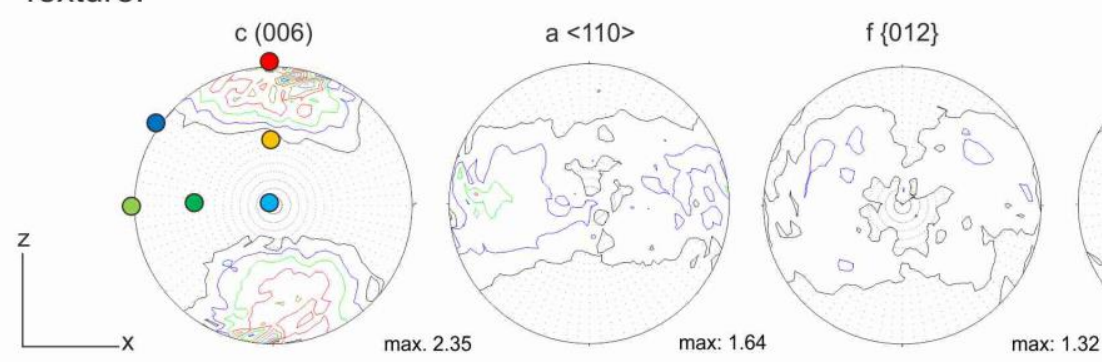

$r\{104\}$

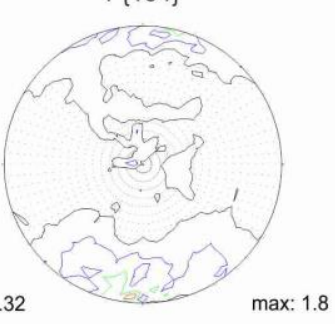

Figure 35 Main fabric characteristic of the Carrara Gioia. Characteristic line drawing of a microscope image, grain size (relative frequency of specific area class has been calculated with respect to the total area (grey bars; $\mathrm{A}=$ total area) and total number of grains (black bars; $\mathrm{N}=$ total number of grains)), shape preferred orientation and texture. 


\section{- Lasa marble}

Lasa marble can be counted among the granoblastic marble varieties. With a calcite content of $97.35 \mathrm{~m}-\%$, it is a pure calcite marble, which contains quartz as an accessory mineral.

The grain structure of the marble is predominantly equigranular with locally occurring areas with more distinct grain size differences. The grain boundaries are mostly curved to slightly bended, while partially interlocked grain boundaries can also be observed. The average grain size of Lasa marble is $419 \mu \mathrm{m}$, with grain sizes varying between $100 \mu \mathrm{m}$ in the smallest and $1400 \mu \mathrm{m}$ in the largest diameter. Twin lamellae are very strongly represented, whereby only occasionally a deformation of these can be observed. A preferred grain boundary orientation is observed in the YZ-plane parallel to the Z-direction perpendicular to the foliation and in the ZX-plane foliation parallel to the X-direction.

The texture of Lasa marble represents an a-axis fibre type in which the c-axis intensities surround the a-axes in circularly. The maximum c-axis intensity of $2.06 \mathrm{mrd}$ is in the intermediate range and a weak a-axes intensity of $1.66 \mathrm{mrd}$. 


\begin{tabular}{|c|c|}
\hline $\begin{array}{c}\text { Grain fabric } \\
\text {-equigranular polygonal }\end{array}$ & $\begin{array}{c}\text { Preferred grain shape orientation } \\
- \text { ZY-plane elongation in } \\
\text { Z-direction }\end{array}$ \\
\cline { 1 - 1 } $\begin{array}{c}\text { Medium grain size } \\
-419 \mu m\end{array}$ & $\begin{array}{c}\text { Texture } \\
- \text { a-axis fibre type with medium } \\
\text { intensity }\end{array}$ \\
\hline $\begin{array}{c}\text { Grain boundary geometry } \\
\text {-straight to interlobate }\end{array}$ & \\
\hline
\end{tabular}

\section{Grain fabric}
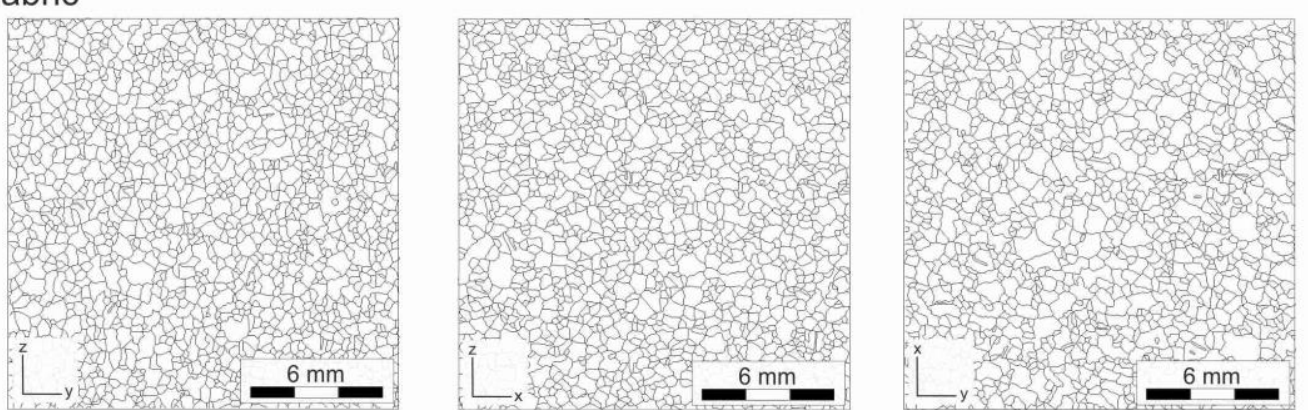

Grain area distribution
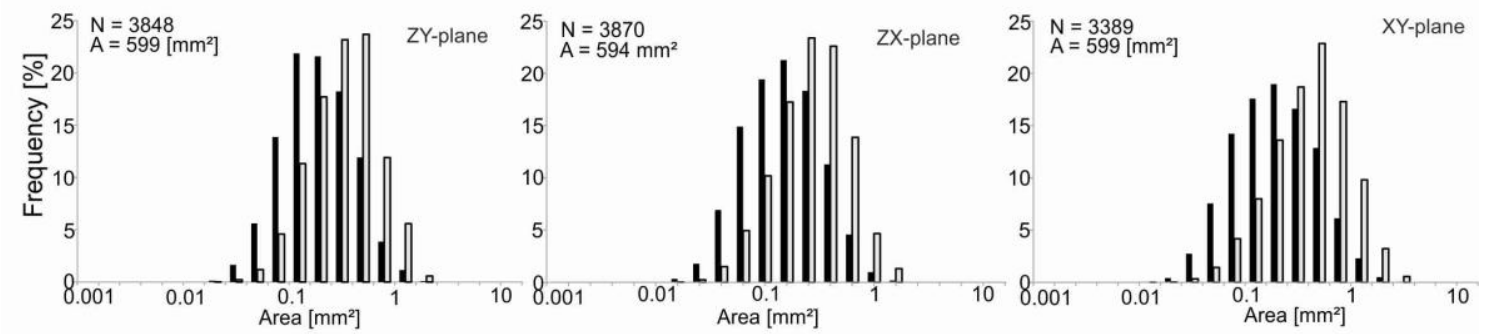

Grain boundary orientation
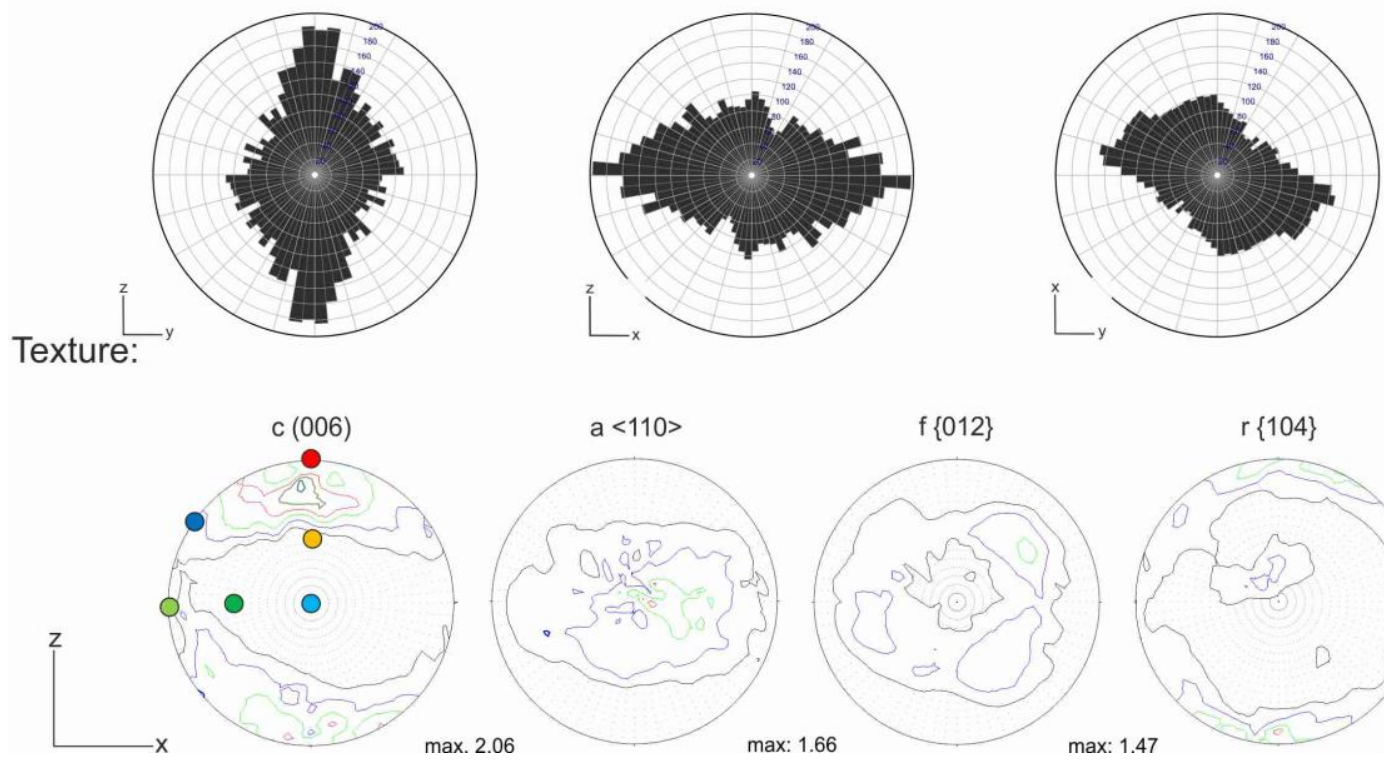

$\mathrm{f}\{012\}$

$r\{104\}$

Figure 36 Main fabric characteristics of the Lasa marble. Characteristic line drawing of a microscope image, grain size (relative frequency of specific area class has been calculated with respect to the total area (grey bars; $\mathrm{A}=$ total area) and total number of grains (black bars; $\mathrm{N}=$ total number of grains)), shape preferred orientation and texture. 


\section{- Großkunzendorf marble}

Großkunzendorf marble is a coarse-grained marble with a calcite content of $95.99 \mathrm{~m}-\%$. Its microstructure is characterized by a post-metamorphic cold plastic deformation and can be described as slightly cataclastic (Ruedrich, 2003). Accessory quartz and biotite are present, but their content can also be significantly higher contributing the fabric of the Großkunzendorf marble (Weiss et al., 1999).

The microstructure of the rock is characterised by a seriate grain size distribution with an average grain size about $545 \mu \mathrm{m}$, whereby the grain sizes range between 102 and $2800 \mu \mathrm{m}$. The grain boundary geometry, in particular of the large grains reaching almost $3 \mathrm{~mm}$, is strongly bended to interlocked. This results in an interlobate grain shape, which indicates grain boundary migration as a deformation mechanism shaping the microstructure.

A large number of the calcite crystals show a pronounced twin formation, which occasionally show signs of deformation due to later deformation processes. A preferential orientation of the grain boundaries can be observed in the XZ- and XY-plane, foliation parallel to the $\mathrm{X}$-direction. The texture of the marble shows an almost belt-like distribution of the c-axes with a low c-axis maximum of $1.6 \mathrm{mrd}$, whereas the a-axes in the $\mathrm{Y}$ direction show almost a point maximum with an intensity of $1.4 \mathrm{mrd}$. 


\begin{tabular}{|c|c|}
\hline $\begin{array}{l}\text { Grain fabric } \\
\text {-seriate-interlobate }\end{array}$ & $\begin{array}{c}\text { Preferred grain shape orientation } \\
\text { - in } Z X \text { - and } X Y \text {-plane elongation in } \\
\text { X-direction, foliation parallel }\end{array}$ \\
\hline $\begin{array}{c}\text { Medium grain size } \\
-545 \mu \mathrm{m}\end{array}$ & \multirow{2}{*}{$\begin{array}{l}\text { Texture } \\
\text { - c-axis fibre type with low } \\
\text { intensity }\end{array}$} \\
\hline $\begin{array}{c}\text { Grain boundary geometry } \\
\text {-curved to interlocking }\end{array}$ & \\
\hline
\end{tabular}

\section{Grain fabric}
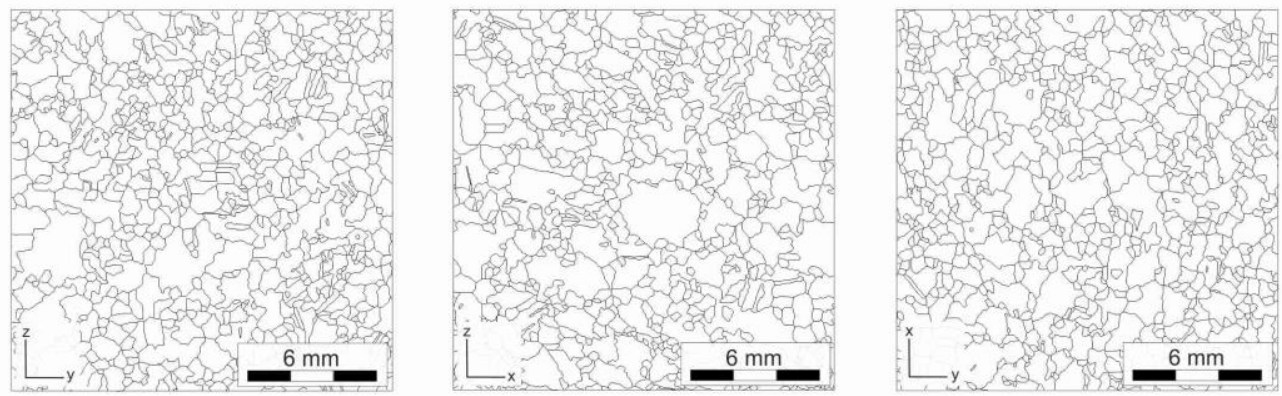

Grain area distribution

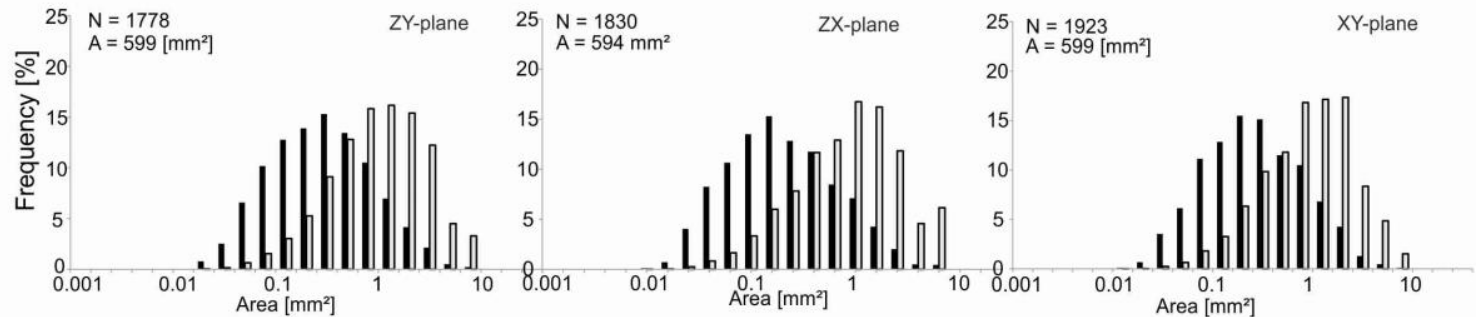

\section{Grain boundary orientation}
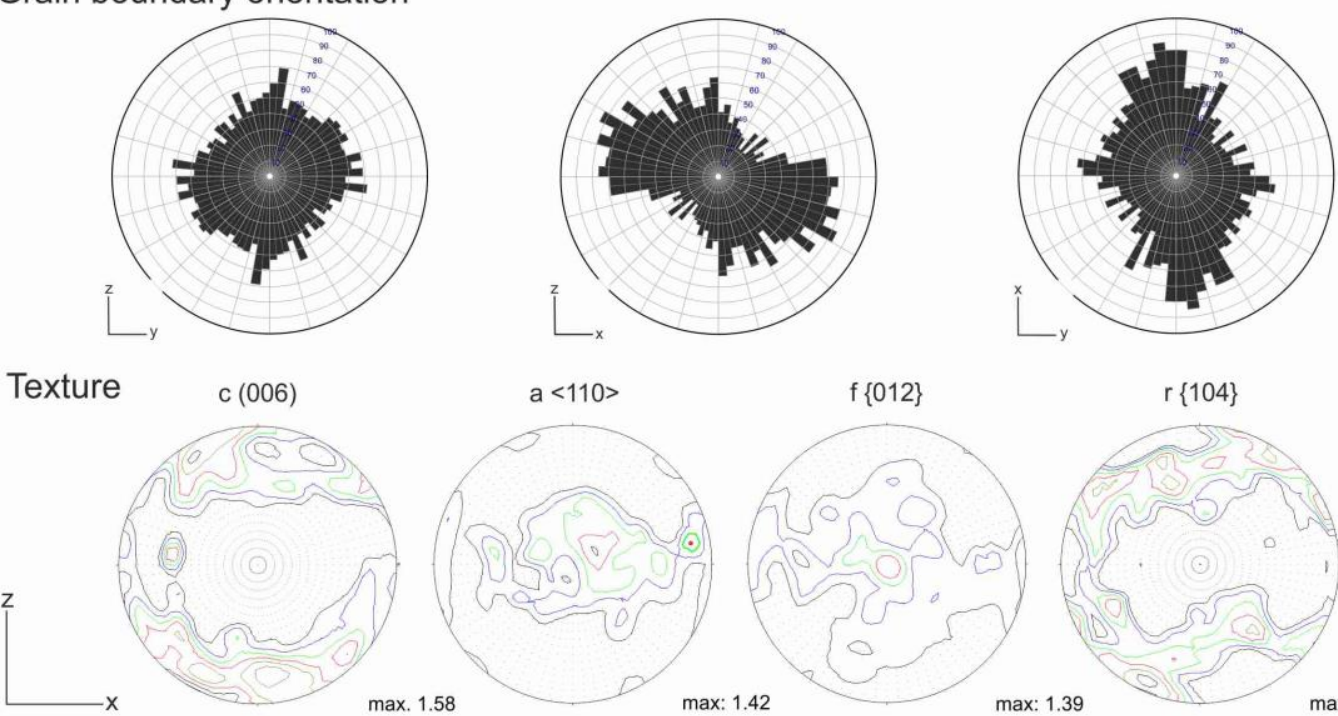

$\mathrm{a}<110>$

f $\{012\}$

$r\{104\}$
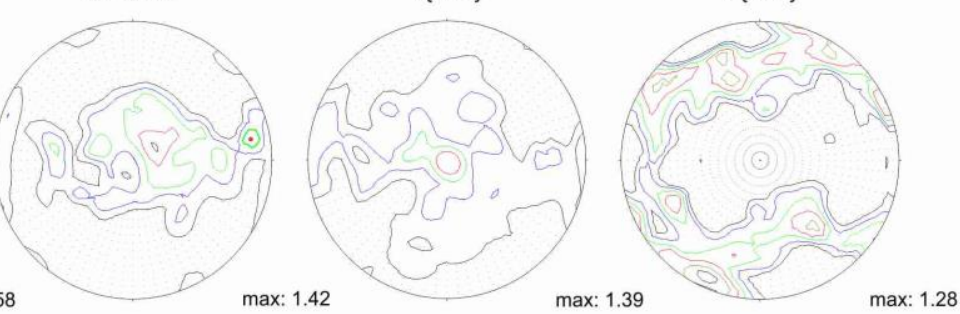

Figure 37 Main fabric characteristics of the Großkunzendorf marble. Characteristic line drawing of a microscope image, grain size (relative frequency of specific area class has been calculated with respect to the total area (grey bars; $\mathrm{A}=$ total area) and total number of grains (black bars; $\mathrm{N}=$ total number of grains)), shape preferred orientation and texture. 


\section{- Prieborn marble}

The Prieborn marble is characterized by a relatively homogeneous structure, sporadically alternating with very fine-grained bands. It is a pure calcite marble with a calcite content of $97.3 \mathrm{~m}-\%$, which contains accessory pyrite and quartz.

The microstructure of Prieborn marble has an equigranular grain structure with polygonal grain shapes and curved grain boundaries. In addition, locally equilibrated grain boundary structures with straight grain edges can also be observed. The static recrystallization of the calcite crystals is an essential process for the formation of the microstructure.

The average grain size is $242 \mu \mathrm{m}$, whereby the grain sizes vary from a minimum of $72 \mu \mathrm{m}$ to a maximum of $1220 \mu \mathrm{m}$. Twinning can be observed, whereby the twin lamellae have a straight and parallel course and cross sometimes the whole calcite grain. Preferred grain boundary orientation is clearly visible perpendicular to the foliation in the YZplane, in the Z-direction, and parallel to the Y-direction in the XY-plane.

The texture of the analysed sample is characterised as a strongly pronounced c-axis fibre type, with an c-axis maximum of $3.3 \mathrm{mrd}$, whereby a clear extension of the point maximum parallel to the Y-direction can be observed. The formed a-axis belt shows with 2.2 mrd also a distinct submaximum in intensity.

The sample of the Prieborn marble was made available to us by the Stiftung Preussische Schlösser und Gärten (SPSG) Potsdam within the scope of a measuring campaign at the obelisk (see Chapter 6. The marble Obelisk at the Neuen Garten, Potsdam) for further investigations. The material is an already weathered quarry stone, which was replaced within a restoration measure. 


\begin{tabular}{|c|c|}
\hline $\begin{array}{l}\text { Grain fabric } \\
\quad \text {-equigranular polygonal }\end{array}$ & $\begin{array}{l}\text { Preferred grain boundary orientation } \\
\text { - in XY- and YZ-plane elongation } \\
\text { perpendicular to the foliation }\end{array}$ \\
\hline $\begin{array}{c}\text { Medium grain size } \\
-242 \mu \mathrm{m}\end{array}$ & \multirow{2}{*}{$\begin{array}{l}\text { Texture } \\
\text { - c-axis fibre type with a } \\
\text { strong intensity }\end{array}$} \\
\hline $\begin{array}{c}\text { Grain boundary geometry } \\
\text {-straight to lobate }\end{array}$ & \\
\hline
\end{tabular}

\section{Grain fabric}
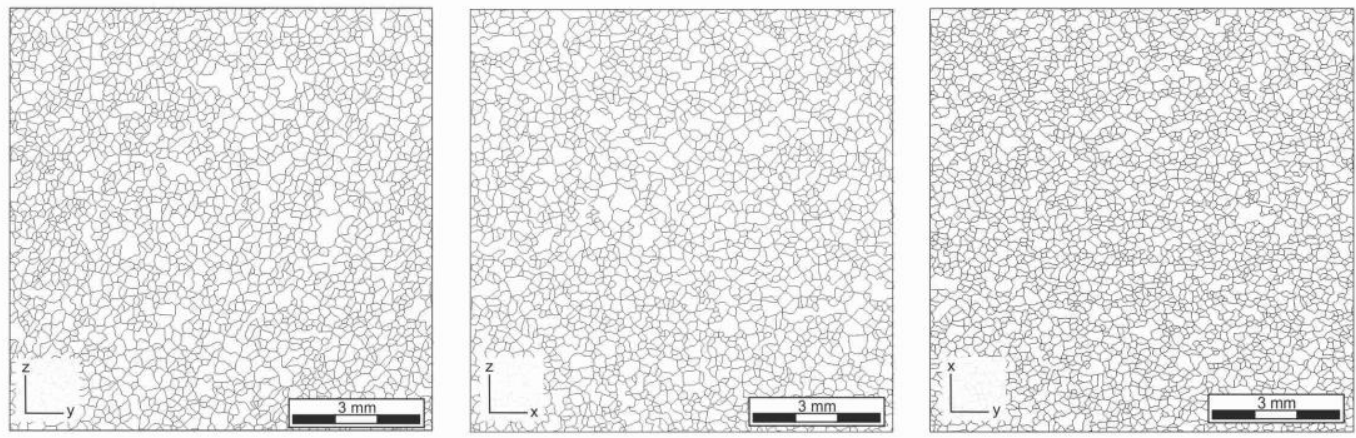

Grain area distribution

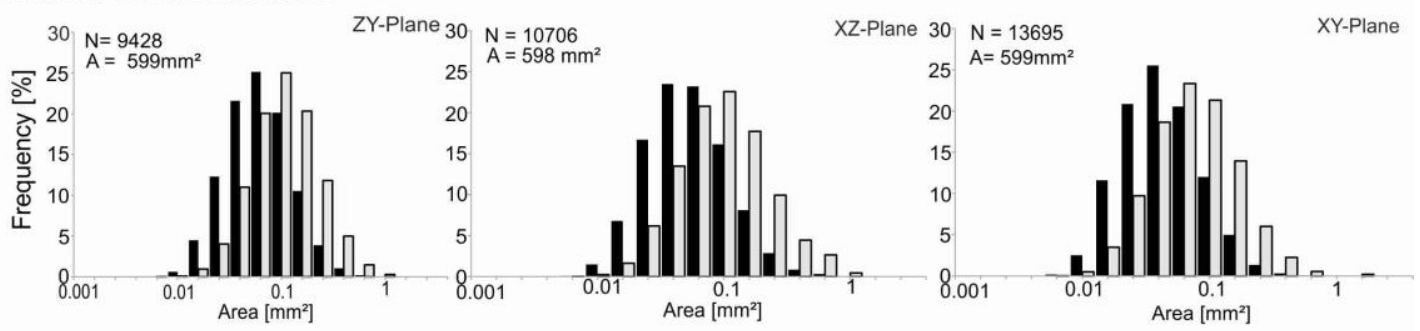

Grain boundary orientation

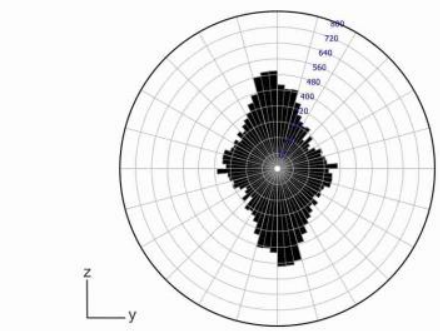

Texture:
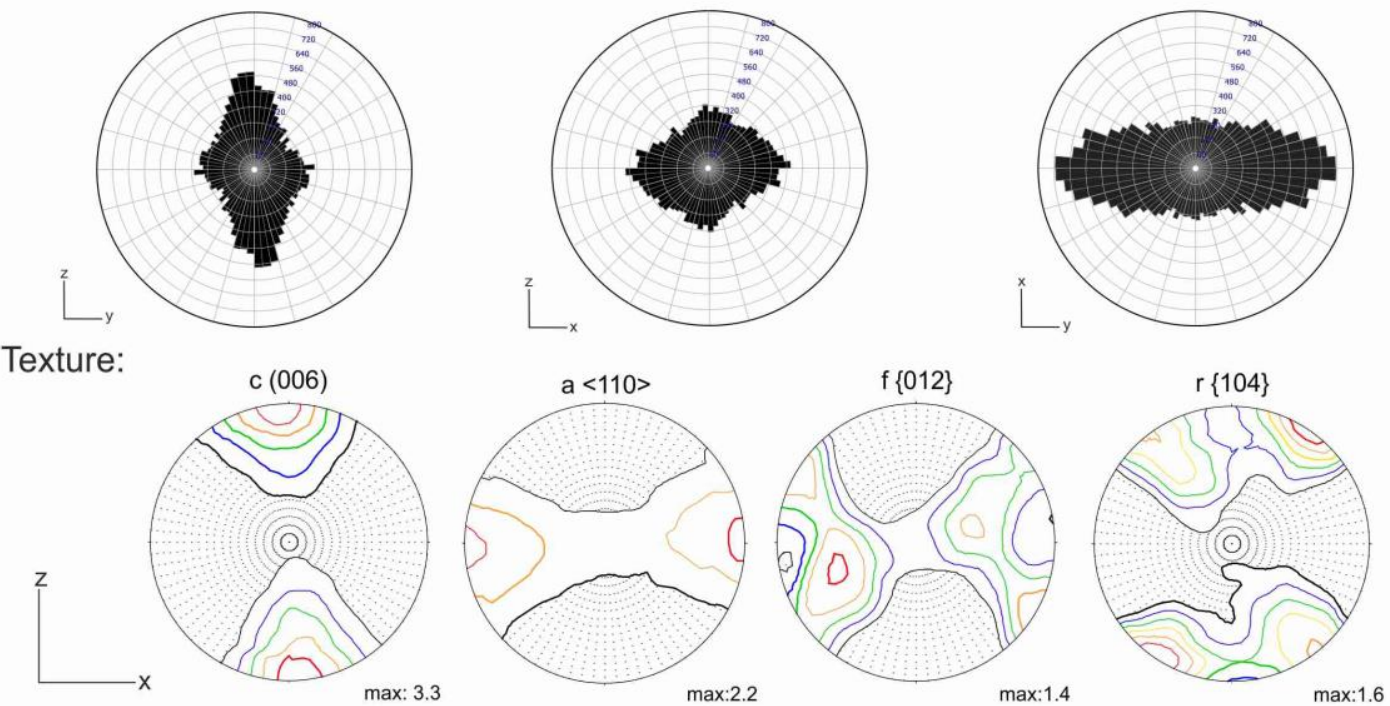

Figure 38 Main fabric characteristics of the Prieborn marble. Characteristic line drawing of a microscope image, grain size (relative frequency of specific area class has been calculated with respect to the total area (grey bars; $\mathrm{A}=$ total area) and total number of grains (black bars; $\mathrm{N}=$ total number of grains)), shape preferred orientation and texture. 


\section{- Wunsiedel marble}

The Wunsiedel marble has with $44.4 \mathrm{~m}$-\% the lowest calcium carbonate content of all examined varieties and includes $53.9 \mathrm{~m}$-\% magnesium carbonate. The microstructure of this marble is, just like the macroscopic structure, characterized by its heterogeneity. The seriate grain size distribution shows an average grain size of $434 \mu \mathrm{m}$, whereby the determined grain sizes of all three cutting layers are between 100 and $2850 \mu \mathrm{m}$. The grain boundary geometry varies strongly, depending on the layer horizon, and alternates between layers with curved grain shapes up to amoeboid. The grains often have twin lamellae, whereby their characteristics vary in relation to the respective horizon within the thin section. The samples show a distinct preferred orientation of their grain boundaries, which are foliation-parallel at the ZY- and ZX-planes, whereas the XY-plane originates from a band of very fine calcite grains, which is not necessarily representative for the other two cut layers.

The texture of Wunsiedel marble shows a c-axis point maximum in Z-direction, elongated in Y-direction with a high intensity of $3.1 \mathrm{mrd}$. The belt-like arrangement of the aaxis distribution shows the strongest maximum intensity of all examined varieties, with $2.9 \mathrm{mrd}$. 


\begin{tabular}{|c|c|}
\hline $\begin{array}{l}\text { Grainfabric } \\
\quad \text {-seriate-interlobate }\end{array}$ & $\begin{array}{l}\text { Preferred grain shape orientation } \\
\text { - in ZX- and ZY-plane elongation } \\
\text { perpendicular to the foliation }\end{array}$ \\
\hline $\begin{array}{c}\text { Medium grain size } \\
-419 \mu \mathrm{m}\end{array}$ & \multirow{2}{*}{$\begin{array}{l}\text { Texture } \\
\text { - pronounced c-axis fibre type } \\
\text { with a high intensity }\end{array}$} \\
\hline $\begin{array}{l}\text { Grain boundary geometry } \\
\text {-curved to interlocking }\end{array}$ & \\
\hline
\end{tabular}

\section{Grain fabric}
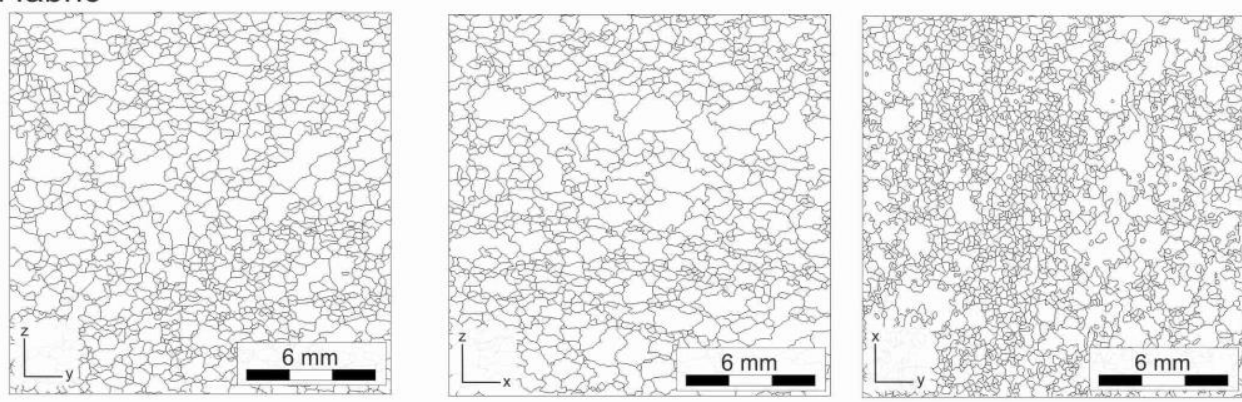

Grain area distribution
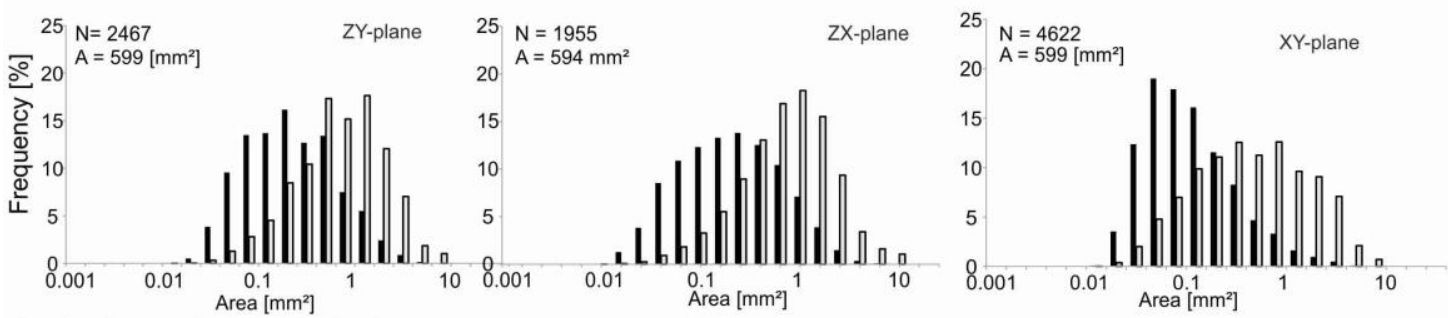

Grain boundary orientation
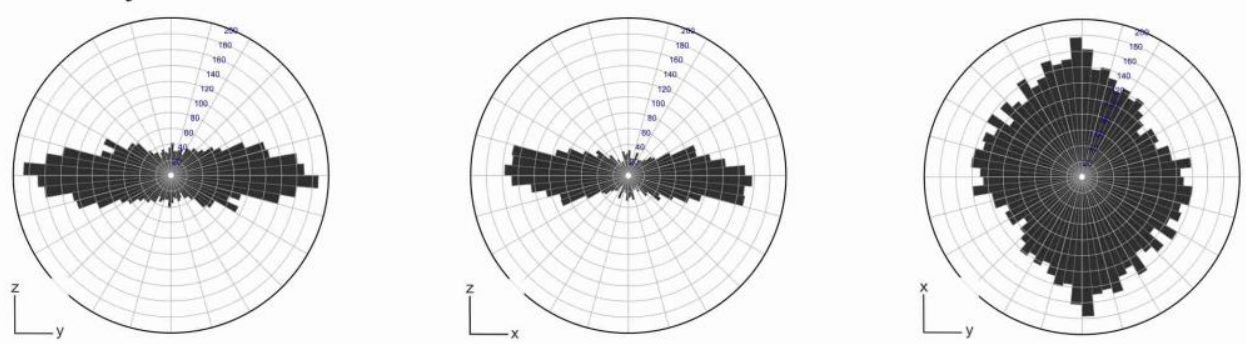

Texture:
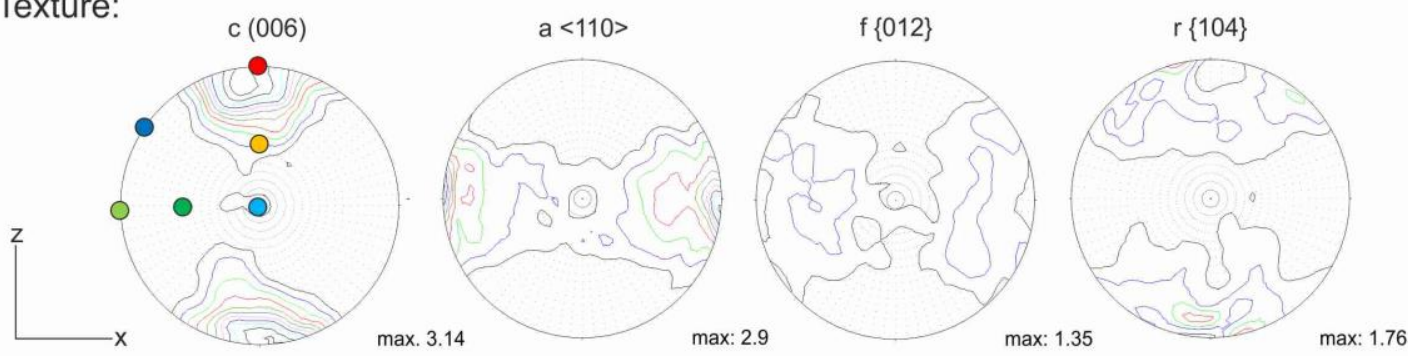

Figure 39 Main fabric characteristics of the Wunsiedel marble. Characteristic line drawing of a microscope image, grain size (relative frequency of specific area class has been calculated with respect to the total area (grey bars; $\mathrm{A}=$ total area) and total number of grains (black bars; $\mathrm{N}=$ total number of grains)), shape preferred orientation and texture. 


\subsection{Petrophysical properties}

The alteration of marble leads to a significant porosity increase and change of the pore space properties. Generally the porosity has a direct and indirect effect on most physical rock properties and is the most important rock parameter (Siegesmund and Dürrast, 2014). An increasing porosity has often an unfavourable influence on the weathering behaviour, especially if the pore radii shift to the pore classes of $0.1-1.0 \mu \mathrm{m}$, the socalled capillary pores (Klopfer 1985). Those pore sizes change the water transport mechanisms of crystalline marble significantly and increase the weathering process.

\subsubsection{Porosity}

The quarry fresh effective porosity of crystalline marble analysed by hydrostatic weighing is very low ranging about $0.1-0.46$ vol.-\% (Koch, 2006),0.2 - 0.3 vol.-\% (Ruedrich, 2003; Ruedrich et al., 2013) up to 0.57 vol.-\% (Poschlod, 1990). The alteration of marble causes an increase of this porosity which is still very low and ranging between 0.4 and 0.7 up to 2.33 vol.-\% reported for a Carrara marble by Ruedrich et al., 2013, but effective regarding the resulting modifications of the rock properties. Therefore, the change of porosity within the stepwise artificial alteration was determined for 7 samples (Table 6).

Table 6 Effective porosity $(\varphi)$ in volume percent for each weathering state (fresh to $200^{\circ} \mathrm{C}+$ an additional freeze-heat cycle) based on the analyses of 10 cubic samples (fresh) down to 5 samples $\left(200^{\circ} \mathrm{C}\right)$.

\begin{tabular}{llllllll}
\hline & FRESH [\%] & $60^{\circ} \mathrm{C}[\%]$ & $90^{\circ} \mathrm{C}[\%]$ & $120^{\circ} \mathrm{C}[\%]$ & $150^{\circ} \mathrm{C}[\%]$ & $200^{\circ} \mathrm{C}[\%]$ & $200^{\circ} \mathrm{C}+[\%]$ \\
\hline BLANCO MACAEL & $0.18 \pm 0.02$ & $0.23 \pm 0.03$ & $0.25 \pm 0.02$ & $0.33 \pm 0.03$ & $0.38 \pm 0.01$ & $0.72 \pm 0.13$ & $0.77 \pm 0.08$ \\
CARRARA GIOIA & $0.37 \pm 0.05$ & $0.44 \pm 0.04$ & $0.43 \pm 0.03$ & $0.50 \pm 0.05$ & $0.50 \pm 0.04$ & $0.54 \pm 0.02$ & $0.80 \pm 0.01$ \\
LASA & $0.41 \pm 0.01$ & $0.49 \pm 0.02$ & $0.48 \pm 0.02$ & $0.53 \pm 0.03$ & $0.56 \pm 0.02$ & $0.63 \pm 0.05$ & $0.79 \pm 0.02$ \\
GROßKUNZENDORF & $0.12 \pm 0.01$ & $0.16 \pm 0.01$ & $0.23 \pm 0.02$ & $0.26 \pm 0.02$ & $0.36 \pm 0.02$ & $0.41 \pm 0.01$ & $0.75 \pm 0.03$ \\
PRIEBORN & $0.44 \pm 0.02$ & 0.58 & 0.59 & - & 0.62 & 0.62 & - \\
WUNSIEDEL & $0.32 \pm 0.14$ & $0.32 \pm 0.15$ & $0.36 \pm 0.16$ & $0.41 \pm 0.16$ & $0.45 \pm 0.17$ & $0.53 \pm 0.18$ & $0.58 \pm 0.19$ \\
ROSA ESTREMOZ & 0.2 & 0.2 & 0.26 & 0.29 & 0.31 & 0.67 & - \\
\hline
\end{tabular}

The measured porosities $(\phi)$ range between 0.12 vol.- $\%$ and 0.41 vol.- $\%$ for the quarry fresh marble samples, while the varieties Prieborn with $\phi=0.44$ vol.- $\%$ as well as Carrara Gioia with $\phi=0.37$ vol.- $\%$ were already weathered at their 'fresh' state. Over the weathering course the Rosa Estremoz and the Wunsiedel marble show no porosity increase 
caused by the first heating up to $60^{\circ} \mathrm{C}$, while all the other varieties, even the preweathered samples show an increase of $\phi$. The next heating step up to $90^{\circ} \mathrm{C}$ shows a furthermore slightly porosity increase. For the next weathering steps, a constant increase can be observed for all samples until $150^{\circ} \mathrm{C}$. While all marbles continue their slightly porosity increase up to $200^{\circ} \mathrm{C}$, the Blanco Macael and the Rosa Estremoz show a significant increase of about 0.35 vol.- $\%$ up to almost 0.7 vol.- $\%$ after heating to $200^{\circ} \mathrm{C}$. At this point they differ strongly from the other samples, which need the additional freeze cycle to increase their porosity up to 0.7 vol.- $\%$. This last heating-freeze cycle finally increases the porosity to $0.75-0.8$ vol.-\% for all varieties, while the effect is only small for the Blanco Macael. The Wunsiedel marble shows a different behaviour within the whole artificial alteration. The porosity increase is low and even the last cycle did not show any significant increasing effect, but this marble shows a comparatively high standard deviation (0.14 -0.19 vol.-\%), which increases after each weathering step. This reflects the macro- and microscopic visible heterogeneity and shows that the crack growth is not uniform for this marble and depends on specific conditions.

\subsubsection{Capillary water uptake}

Almost all weathering processes as freeze-thaw cycles, solution processes, salt-related weathering and thermo-hygric processes are determined by the presence of water. The pore space and pore system relates to the amount of water absorption, the nature of water transport, and the size of the surface area available for chemical interactions (Siegesmund and Dürrast, 2014). Capillary water uptake is an important parameter for materials with pore diameters within the range of the so-called capillary pores (see Chapter 5.3 Petrophysical properties). To determine the transformation within the artificial alteration, the capillary water uptake was analysed for all marble varieties. The capillary water absorption coefficient $\left[\mathrm{km} / \mathrm{m}^{2 *} \mathrm{Vh}\right]$ given in Table 7 was analysed for one cubic sample in the unweathered state and after heating cycles up to $200^{\circ} \mathrm{C}$. The $\mathrm{w}$ value is given for 3 directions, as well as the water absorption $\left(W_{\text {cap }}\right)$ in weight and volume percent. The porosity can also be found in Table 7. The given water absorption value in weight percent is given as mean value of all analysed cubes under the specific conditions (10 samples at the fresh state, 5 samples for the $200^{\circ} \mathrm{C}$ state). The $w$-value can be used to classify rocks into three types: (1) slightly absorbing ( $w<0.5 \mathrm{~kg} / \mathrm{m}^{2} \mathrm{~h}_{0.5}$ ), 
(2) medium absorbing ( $w 0.5-3.0 \mathrm{~kg} / \mathrm{m}^{2} \mathrm{~h}_{0.5}$ ), and (3) highly absorbing ( $w>3.0 \mathrm{~kg} /$ $\mathrm{m}^{2} \mathrm{~h}_{0.5}$ ) (Snethlage, 2008). According to this classification, all analysed marble varieties are slightly absorbing, regardless if they are quarry fresh (w-values between 0.02 and $\left.0.17 \mathrm{~kg} / \mathrm{m}^{2} \mathrm{~h}_{0.5}\right)$ or artificially weathered $\left(0.09-0.45 \mathrm{~kg} / \mathrm{m}^{2} \mathrm{~h}_{0.5}\right)$, but all of them increase according to the weathering intensity. Only the strongly weathered Großkunzendorf shows a slightly higher w-value of $0.55 . \mathrm{kg} / \mathrm{m}^{2} \mathrm{~h}_{0.5}$ in X-direction. The thermal induced deterioration of all marble types shows an increasing capillary water uptake capability, which is connected to the increasing porosity (see Siegesmund and Dürrast, 2014). Regardless of the weathering state, it should be noted that the capillary water uptake occurs relatively fast and is finished within the first 60 - 180 minutes. The saturation coefficient $\mathrm{S}$ describes how much of the total pore space is accessible to water absorption and helps to determine the frost resistance. Siegesmund and Dürrast, 2014 describe that for metamorphic rocks the saturation coefficient has limited significance due to the very small water absorption values under atmospheric and under vacuum conditions. They are influenced by the measurement procedure, the standard deviation of different samples and the resolution limit. According to the classification of Hirschwald, 1912, S values below 0.75 stand for a weather and frost resistant rock, while values below 0.9 indicate a rock, which is not frost and weather resistant. For any rock type with a saturation coefficient between 0.75 and 0.9 further investigations are recommended.

The analysed marble varieties represent the entire spectrum of the S-value with 0.57 for the Blanco Macael up to 0.93 for the Carrara Gioia, whereby most of the samples are assigned to the group of rocks, where further investigations are recommended. 
Table 7 w-value, capillary water uptake, porosity and saturation coefficient for the investigated marble varieties under fresh and weathered conditions.

\begin{tabular}{|c|c|c|c|c|c|c|c|c|}
\hline Marble & $\begin{array}{l}\text { Weathering } \\
\text { state }\end{array}$ & Direction & $\begin{array}{l}\text { w-value } \\
\left(\mathrm{kg} / \mathrm{m}^{2 *} \mathrm{vh}\right)\end{array}$ & $\begin{array}{l}W_{\text {(cap) }} \\
\text { (weight \%) }\end{array}$ & $\begin{array}{l}\text { W }_{\text {(Cap) }} \\
\text { (Vol \%) }\end{array}$ & $\begin{array}{l}\text { Porosity } \\
{[\%]}\end{array}$ & $\begin{array}{l}\text { Water ab- } \\
\text { sorption } \\
\text { [Weight \%] }\end{array}$ & $\begin{array}{l}\text { Saturation } \\
\text { coefficient }\end{array}$ \\
\hline BM & Fresh & $\begin{array}{l}X \\
Y \\
Z\end{array}$ & $\begin{array}{l}0.09 \\
0.07 \\
0.09\end{array}$ & $\begin{array}{l}0.04 \\
0.04 \\
0.04\end{array}$ & $\begin{array}{l}0.12 \\
0.11 \\
0.12\end{array}$ & $\begin{array}{l}0.18 \\
\pm 0.02\end{array}$ & $\begin{array}{l}0.07 \text { (vac) } \\
0.04 \text { (atm) }\end{array}$ & 0.57 \\
\hline & $200^{\circ} \mathrm{C}$ & $\begin{array}{l}X \\
Y \\
Z\end{array}$ & $\begin{array}{l}0.32 \\
0.35 \\
0.32\end{array}$ & $\begin{array}{l}- \\
0.20 \\
0.17\end{array}$ & $\begin{array}{l}- \\
0.53 \\
0.47\end{array}$ & $\begin{array}{l}0.72 \\
\pm 0.13\end{array}$ & $\begin{array}{l}0.28 \text { (vac) } \\
0.19 \text { (atm) }\end{array}$ & 0.68 \\
\hline GI & Fresh & $\begin{array}{l}X \\
Y \\
Z\end{array}$ & $\begin{array}{l}0.09 \\
0.12 \\
0.16\end{array}$ & $\begin{array}{l}0.11 \\
0.12 \\
0.18\end{array}$ & $\begin{array}{l}0.29 \\
0.32 \\
0.49\end{array}$ & $\begin{array}{l}0.37 \\
\pm 0.05\end{array}$ & $\begin{array}{l}0.14 \text { (vac) } \\
0.13 \text { (atm) }\end{array}$ & 0.93 \\
\hline & $200^{\circ} \mathrm{C}$ & $\begin{array}{l}X \\
Y \\
Z\end{array}$ & $\begin{array}{l}0.45 \\
0.42 \\
0.42\end{array}$ & $\begin{array}{l}0.23 \\
0.23 \\
0.23\end{array}$ & $\begin{array}{l}0.62 \\
0.63 \\
0.63\end{array}$ & $\begin{array}{l}0.54 \\
\pm 0.02\end{array}$ & $\begin{array}{l}0.29 \text { (vac) } \\
0.23 \text { (atm) }\end{array}$ & 0.79 \\
\hline LA & Fresh & $\begin{array}{l}X \\
Y \\
Z\end{array}$ & $\begin{array}{l}0.09 \\
0.07 \\
0.16\end{array}$ & $\begin{array}{l}0.11 \\
0.10 \\
-\end{array}$ & $\begin{array}{l}0.30 \\
0.28 \\
-\end{array}$ & $\begin{array}{l}0.41 \\
\pm 0.01\end{array}$ & $\begin{array}{l}0.15 \text { (vac) } \\
0.11 \text { (atm) }\end{array}$ & 0.73 \\
\hline & $200^{\circ} \mathrm{C}$ & $\begin{array}{l}X \\
Y \\
Z\end{array}$ & $\begin{array}{l}0.09 \\
0.40 \\
0.39\end{array}$ & $\begin{array}{l}0.25 \\
0.26 \\
0.26\end{array}$ & $\begin{array}{l}0.68 \\
0.70 \\
0.71\end{array}$ & $\begin{array}{l}0.63 \\
\pm 0.05\end{array}$ & $\begin{array}{l}0.29 \text { (vac) } \\
0.26 \text { (atm) }\end{array}$ & 0.90 \\
\hline GK & Fresh & & $\begin{array}{l}0.05 \\
0.02 \\
0.04\end{array}$ & $\begin{array}{l}0.02 \\
0.04 \\
0.02\end{array}$ & $\begin{array}{l}0.05 \\
0.12 \\
0.06\end{array}$ & $\begin{array}{l}0.12 \\
\pm 0.01\end{array}$ & $\begin{array}{l}0.04 \text { (vac) } \\
0.03 \text { (atm) }\end{array}$ & 0.75 \\
\hline & $200^{\circ} \mathrm{C}$ & & $\begin{array}{l}0.55 \\
0.45 \\
0.29\end{array}$ & $\begin{array}{l}0.23 \\
0.24 \\
0.24\end{array}$ & $\begin{array}{l}0.62 \\
0.65 \\
0.66\end{array}$ & $\begin{array}{l}0.41 \\
\pm 0.01\end{array}$ & $\begin{array}{l}0.27 \text { (vac) } \\
0.24 \text { (atm) }\end{array}$ & 0.89 \\
\hline $\mathbf{P}$ & Fresh & $\begin{array}{l}X \\
Y \\
Z\end{array}$ & $\begin{array}{l}0.09 \\
0.17 \\
0.13\end{array}$ & $\begin{array}{l}0.16 \\
0.16 \\
0.16\end{array}$ & $\begin{array}{l}0.43 \\
0.42 \\
0.42\end{array}$ & $\begin{array}{l}0.44 \\
\pm 0.02\end{array}$ & $\begin{array}{l}0.21 \text { (vac) } \\
0.16 \text { (atm) }\end{array}$ & 0.76 \\
\hline $\mathbf{w}$ & Fresh & $\begin{array}{l}X \\
Y \\
Z\end{array}$ & $\begin{array}{l}0.09 \\
0.03 \\
0.14\end{array}$ & $\begin{array}{l}0.11 \\
0.06 \\
0.07\end{array}$ & $\begin{array}{l}0.29 \\
0.17 \\
0.18\end{array}$ & $\begin{array}{l}0.32 \\
\pm 0.14\end{array}$ & $\begin{array}{l}0.12 \text { (vac) } \\
0.09 \text { (atm) }\end{array}$ & 0.75 \\
\hline
\end{tabular}




\subsubsection{Ultrasonic measurements}

The correlation of the P-wave velocity determined by ultrasonic measurements and the weathering state of marble was confirmed by many scientific analyses (Ahmad et al., 2009; Babacan and Gelisli, 2015; Boudani et al., 2015; Dürrast et al., 1999; Fleischer, 2002; Köhler, 1991, 2014; Lindner et al., 1999; Ruedrich, 2003; Ruedrich et al., 2013; Siegesmund et al., 2000a; Siegesmund et al., 2004b; Weiss et al., 1999; Weiss et al., 2000; Weiss et al., 2002a). Whereas the P-wave velocity of a quarry fresh marble is relatively high (6-7 [km/s]), it decreases with increasing weathering state. This velocity decrease is connected to the formation of microcracks throughout the weathering process, which has a huge influence on the velocity reduction (e.g. Weiss et al., 2002a). Köhler, 1991, established a velocity-based classification for the weathering state of Carrara marble which helps to define the weathering state of objects made of marble (Table 8). The damage classes span from highly deteriorated rocks with small velocities below $1.5 \mathrm{~km} / \mathrm{s}$ to fresh and intact rock with $5 \mathrm{~km} / \mathrm{s}$ and above. As those measurements allow a nondestructive evaluation of the material, they are used for quality assurance as well as for preservation purposes in the context of heritage conservation.

Table 8 The Vp-structural damage classification for marbles (Köhler 1991, Köhler 2014).

\begin{tabular}{lcc}
\hline \multicolumn{1}{c}{ Weathering state } & Velocity $\mathbf{V}_{\mathbf{p}}[\mathrm{km} / \mathrm{s}]$ & Damage classes \\
\hline Fresh & $>5.0$ & 0 \\
Increasingly porous & $3.0-5.0$ & $\mathrm{I}$ \\
Granular disintegration & $2.0-3.0$ & $\mathrm{II}$ \\
Brittle & $1.5-2.0$ & $\mathrm{III}$ \\
Crumbling rock & $<1.5$ & $\mathrm{IV}$ \\
\hline
\end{tabular}




\subsubsection{Transmission measurements}

The distribution of elastic waves depends on the mineralogical composition, the fabric as well as the type and arrangement of cracks. Furthermore, the crack filling medium, water or air has a significant impact (e.g. Siegesmund, 1996; Weiss et al., 2002a). To assign a specific weathering state to an ultrasonic velocity, the systematic alteration of the marble samples was connected to repeated ultrasonic measurements. All cubic samples were analysed after each temperature cycle under dry and wet conditions. In Table 9, the mean dry ultrasonic velocities are given in three directions as well as the amount of anisotropy [\%].

The Blanco Macael shows the strongest and most distinct velocity decrease after almost every weathering cycle with a total reduction down to $1.60 \mathrm{~km} / \mathrm{s}$ which is a reduction of $65.58 \%$ in comparison to the unweathered velocity in Z-direction. The strongest impact is caused by the heating cycle up to $200^{\circ} \mathrm{C}$, with an average reduction of $27.4 \%$ in comparison to the $150^{\circ} \mathrm{C}$ cycle. The average velocity reduction per weathering step is $0.51 \mathrm{~km} / \mathrm{s}( \pm 0.23)$ and combined with a steadily increasing anisotropy up to $30.7 \%$. In comparison, the Lasa marble shows an alternating intensity of the velocity reduction. Here, every second weathering step shows a higher reduction and reaches its strongest influence at the combination of $200^{\circ} \mathrm{C}$ heating and freezing. That this combination has the biggest impact on the velocities can also be observed for the Großkunzendorf, Wunsiedel and the Lasa marble (see Figure 40). 
Table 9 Ultrasonic velocity [ $\mathrm{km} / \mathrm{s}$ ] measured on cubic samples after each weathering step (fresh- $200^{\circ} \mathrm{C}++$ ) according to the 3 main directions $X, Y$ and $Z$. $N=$ Number of cubes, each direction was measured on 5 positions. Anisotropy $A[\%]$ is given for each weathering step and refers to the respective mean value.

\begin{tabular}{|c|c|c|c|c|c|c|}
\hline $\begin{array}{l}\text { Weathering } \\
\text { step }\end{array}$ & Direction & $\begin{array}{l}\text { Blanco } \\
\text { Macael }\end{array}$ & Gioia & Lasa & $\begin{array}{l}\text { Groß- } \\
\text { kunzendorf }\end{array}$ & Wunsiedel \\
\hline \multirow{4}{*}{ Fresh $(n=10)$} & $x$ & $5.09 \pm 0.12$ & $3.82 \pm 0.21$ & $4.73 \pm 0.12$ & $6.00 \pm 0.06$ & $6.08 \pm 0.48$ \\
\hline & $\mathrm{Y}[\mathrm{km} / \mathrm{s}]$ & $5.28 \pm 0.15$ & $3.70 \pm 0.23$ & $4.83 \pm 0.09$ & $6.12 \pm 0.16$ & $6.09 \pm 0.26$ \\
\hline & z & $4.71 \pm 0.12$ & $3.59 \pm 0.20$ & $4.40 \pm 0.08$ & $5.76 \pm 0.11$ & $5.04 \pm 1.04$ \\
\hline & $A[\%]$ & 10.77 & 6.00 & 8.86 & 5.94 & 17.36 \\
\hline \multirow{4}{*}{$60^{\circ} \mathrm{C}(n=9)$} & $x$ & $4.37 \pm 0.14$ & $3.37 \pm 0.23$ & $4.52 \pm 0.09$ & $6.13 \pm 0.16$ & $5.93 \pm 0.35$ \\
\hline & $\mathrm{Y}[\mathrm{km} / \mathrm{s}]$ & $4.81 \pm 0.12$ & $3.37 \pm 0.20$ & $4.58 \pm 0.11$ & $6.00 \pm 0.04$ & $5.75 \pm 0.44$ \\
\hline & Z & $3.98 \pm 0.13$ & $3.19 \pm 0.23$ & $4.09 \pm 0.16$ & $5.83 \pm 0.12$ & $4.83 \pm 0.94$ \\
\hline & $A[\%]$ & 17.33 & 5.24 & 10.59 & 4.80 & 18.52 \\
\hline \multirow{4}{*}{$90^{\circ} \mathrm{C}(n=8)$} & $x$ & $4.08 \pm 0.23$ & $3.14 \pm 0.18$ & $3.96 \pm 0.17$ & $5.65 \pm 0.12$ & $6.16 \pm 0.54$ \\
\hline & $\mathrm{Y}[\mathrm{km} / \mathrm{s}]$ & $4.58 \pm 0.20$ & $3.13 \pm 0.15$ & $4.03 \pm 0.15$ & $5.59 \pm 0.12$ & $5.89 \pm 0.64$ \\
\hline & Z & $3.66 \pm 0.26$ & $2.97 \pm 0.18$ & $3.52 \pm 0.15$ & $5.40 \pm 0.07$ & $4.79 \pm 1.16$ \\
\hline & $A[\%]$ & 20.18 & 5.42 & 12.54 & 4.44 & 22.17 \\
\hline \multirow{4}{*}{$120^{\circ} \mathrm{C}(n=7)$} & $\mathrm{X}$ & $3.95 \pm 0.19$ & $2.76 \pm 0.18$ & $3.81 \pm 0.10$ & $5.30 \pm 0.17$ & $5.68 \pm 0.46$ \\
\hline & $\mathrm{Y}[\mathrm{km} / \mathrm{s}]$ & $4.14 \pm 0.18$ & $2.77 \pm 0.12$ & $3.89 \pm 0.09$ & $5.16 \pm 0.12$ & $5.41 \pm 0.58$ \\
\hline & Z & $3.14 \pm 0.21$ & $2.62 \pm 0.16$ & $3.35 \pm 0.08$ & $4.89 \pm 0.11$ & $4.61 \pm 0.98$ \\
\hline & $A[\%]$ & 24.11 & 5.42 & 13.73 & 7.71 & 18.84 \\
\hline \multirow{4}{*}{$150^{\circ} \mathrm{C}(n=6)$} & $\mathrm{X}$ & $3.00 \pm 0.17$ & $2.43 \pm 0.14$ & $3.27 \pm 0.13$ & $4.38 \pm 0.11$ & $5.30 \pm 0.46$ \\
\hline & $\mathrm{Y}[\mathrm{km} / \mathrm{s}]$ & $3.40 \pm 0.13$ & $2.45 \pm 0.12$ & $3.24 \pm 0.19$ & $4.16 \pm 0.08$ & $5.01 \pm 0.47$ \\
\hline & Z & $2.50 \pm 0.14$ & $2.29 \pm 0.14$ & $2.83 \pm 0.11$ & $3.96 \pm 0.15$ & $4.08 \pm 0.76$ \\
\hline & $A[\%]$ & 26.67 & 6.63 & 13.40 & 9.57 & 23.61 \\
\hline \multirow{4}{*}{$200^{\circ} \mathrm{C}(n=5)$} & $x$ & $2.12 \pm 0.21$ & $2.31 \pm 0.09$ & $2.89 \pm 0.12$ & $3.84 \pm 0.09$ & $4.92 \pm 0.44$ \\
\hline & $\mathrm{Y}[\mathrm{km} / \mathrm{s}]$ & $2.56 \pm 0.22$ & $2.28 \pm 0.06$ & $2.93 \pm 0.09$ & $3.63 \pm 0.05$ & $4.54 \pm 0.41$ \\
\hline & Z & $1.80 \pm 0.17$ & $2.11 \pm 0.09$ & $2.54 \pm 0.25$ & $3.42 \pm 0.19$ & $3.53 \pm 0.66$ \\
\hline & $A[\%]$ & 29.51 & 8.84 & 13.30 & 10.98 & 28.32 \\
\hline \multirow{4}{*}{$200^{\circ} \mathrm{C}+(n=4)$} & $x$ & $1.98 \pm 0.11$ & $2.13 \pm 0.05$ & $2.37 \pm 0.10$ & $3.23 \pm 0.05$ & $4.39 \pm 0.43$ \\
\hline & $\mathrm{Y}[\mathrm{km} / \mathrm{s}]$ & $2.34 \pm 0.12$ & $2.13 \pm 0.04$ & $2.44 \pm 0.07$ & $3.63 \pm 0.04$ & $3.94 \pm 0.32$ \\
\hline & Z & $1.62 \pm 0.05$ & $1.95 \pm 0.04$ & $1.97 \pm 0.03$ & $2.75 \pm 0.08$ & $2.90 \pm 0.53$ \\
\hline & $A[\%]$ & 30.71 & 8.38 & 19.27 & 14.83 & 34.05 \\
\hline \multirow{4}{*}{$200^{\circ}++(n=4)$} & $\mathrm{X}$ & & $1.83 \pm 0.02$ & & $2.73 \pm 0.08$ & \\
\hline & $\mathrm{Y}[\mathrm{km} / \mathrm{s}]$ & - & $1.82 \pm 0.03$ & - & $2.69 \pm 0.07$ & - \\
\hline & Z & & $1.68 \pm 0.04$ & & $2.65 \pm 0.06$ & \\
\hline & $A[\%]$ & & 8.05 & & 2.87 & \\
\hline
\end{tabular}




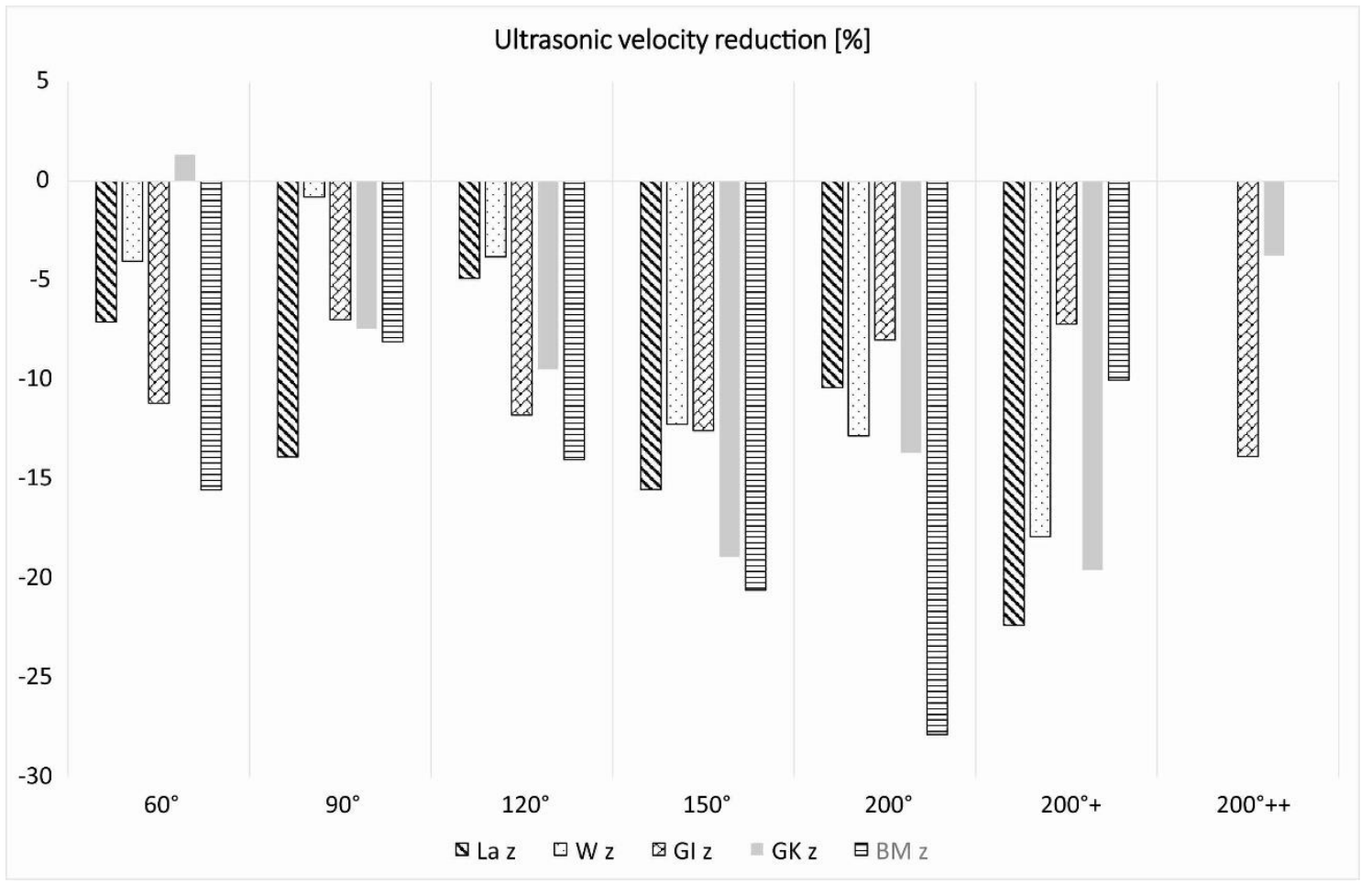

Figure 40 Velocity reduction (\%) for each weathering step with regard to the former velocity.

The amount of anisotropy increases with each weathering step. While the Carrara Gioia shows almost no changes and the anisotropy ranges between $5.24 \%$ and $8.84 \%$, the Wunsiedel marble shows the highest initial anisotropy of $17.36 \%$ and increases successive up to $34.05 \%$. It can be observed that the main velocity reduction for each sample takes place in Z-direction, whereas the Großkunzendorf shows an equalization after the second heating- freeze cycle. This may indicate a foliation parallel preferred crack formation.

\subsubsection{Influence of humidity and water saturation}

The weathering state of marble can be determined by ultrasonic measures, as long as the material is dry. The effect of an increasing porosity caused by cracks is reduced as soon as water penetrates the pore space and increases the velocities. This increase can reach almost intrinsic values for a fully saturated sample (Weiss et al., 2000).

The ultrasonic velocities for the water saturated samples after each heating cycle are given in Table 10. There are the mean values, out of 4 - 9 cubes and 5 measurements per direction displayed. 
Table 10 Ultrasonic velocity [ $\mathrm{km} / \mathrm{s}]$ measured on cubic samples under wet conditions after each weathering step $\left(f 60^{\circ} \mathrm{C}-200^{\circ} \mathrm{C}++\right)$ according to the 3 main directions $X, Y$ and $Z$. $n=$ Number of cubes, each direction was measured on 5 different positions. Anisotropy $A[\%]$ is given for each weathering step and refers to the respective mean value.

\begin{tabular}{llrrrrr}
\hline $\begin{array}{l}\text { Weathering } \\
\text { step }\end{array}$ & Direction & $\begin{array}{l}\text { Blanco } \\
\text { Macael }\end{array}$ & \multicolumn{1}{l}{ Gioia } & \multicolumn{1}{l}{ Lasa } & \multicolumn{1}{l}{$\begin{array}{l}\text { Groß- } \\
\text { kunzendorf }\end{array}$} & Wunsiedel \\
\hline & $\mathrm{X}$ & $6.65 \pm 0.08$ & $6.07 \pm 0.07$ & $6.12 \pm 0.05$ & $6.46 \pm 0.13$ & $6.62 \pm 0.11$ \\
$60^{\circ} \mathrm{C}(n=9)$ & $\mathrm{Y}[\mathrm{km} / \mathrm{s}]$ & $6.74 \pm 0.11$ & $6.04 \pm 0.12$ & $6.26 \pm 0.12$ & $6.38 \pm 0.09$ & $6.30 \pm 0.78$ \\
& $\mathrm{Z}$ & $6.35 \pm 0.06$ & $5.91 \pm 0.08$ & $6.07 \pm 0.10$ & $6.30 \pm 0.10$ & $5.88 \pm 0.20$ \\
& $\boldsymbol{A}[\%]$ & $\mathbf{5 . 7 9}$ & $\mathbf{2 . 6 4}$ & $\mathbf{3 . 0 4}$ & $\mathbf{2 . 9 4}$ & $\mathbf{1 1 . 1 8}$ \\
& $\mathrm{X}$ & $6.25 \pm 0.07$ & $5.97 \pm 0.10$ & $6.26 \pm 0.08$ & $6.41 \pm 0.15$ & $6.80 \pm 0.11$ \\
$90^{\circ} \mathrm{C}(n=8)$ & $\mathrm{Y}[\mathrm{km} / \mathrm{s}]$ & $6.27 \pm 0.11$ & $5.82 \pm 0.26$ & $6.33 \pm 0.08$ & $6.29 \pm 0.09$ & $6.56 \pm 0.11$ \\
& $\mathrm{Z}$ & $5.91 \pm 0.11$ & $5.73 \pm 0.12$ & $6.07 \pm 0.06$ & $6.21 \pm 0.17$ & $6.21 \pm 0.16$ \\
& $\boldsymbol{A}[\%]$ & $\mathbf{5 . 7 4}$ & $\mathbf{3 . 1 8}$ & $\mathbf{4 . 1 1}$ & $\mathbf{3 . 1 2}$ & $\mathbf{8 . 6 8}$ \\
& $\mathrm{X}$ & $6.39 \pm 0.03$ & $6.03 \pm 0.12$ & $6.11 \pm 0.07$ & $6.62 \pm 0.16$ & $6.67 \pm 0.41$ \\
$120^{\circ} \mathrm{C}(n=7)$ & $\mathrm{Y}[\mathrm{km} / \mathrm{s}]$ & $6.59 \pm 0.03$ & $5.92 \pm 0.14$ & $6.06 \pm 0.10$ & $6.54 \pm 0.07$ & $6.62 \pm 0.17$ \\
& $\mathrm{Z}$ & $6.17 \pm 0.02$ & $5.78 \pm 0.13$ & $5.81 \pm 0.09$ & $6.47 \pm 0.10$ & $6.31 \pm 0.17$ \\
& $\boldsymbol{A}[\%]$ & $\mathbf{6 . 3 7}$ & $\mathbf{4 . 1 5}$ & $\mathbf{4 . 9 1}$ & $\mathbf{2 . 2 7}$ & $\mathbf{5 . 4 0}$ \\
& $\mathrm{X}$ & $6.23 \pm 0.08$ & $6.13 \pm 0.05$ & $6.10 \pm 0.09$ & $6.43 \pm 0.12$ & $6.75 \pm 0.15$ \\
$150^{\circ} \mathrm{C}(n=6)$ & $\mathrm{Y}[\mathrm{km} / \mathrm{s}]$ & $6.30 \pm 0.09$ & $5.99 \pm 0.10$ & $6.22 \pm 0.11$ & $6.33 \pm 0.09$ & $6.56 \pm 0.12$ \\
& $\mathrm{Z}$ & $5.97 \pm 0.11$ & $5.97 \pm 0.13$ & $5.92 \pm 0.16$ & $6.17 \pm 0.14$ & $6.21 \pm 0.20$ \\
& $\boldsymbol{A}[\%]$ & $\mathbf{5 . 2 4}$ & $\mathbf{6 . 6 3}$ & $\mathbf{6 . 5 9}$ & $\mathbf{4 . 0 4}$ & $\mathbf{8 . 0 0}$ \\
& $\mathrm{X}$ & $5.87 \pm 0.13$ & $6.07 \pm 0.05$ & $6.00 \pm 0.06$ & $6.37 \pm 0.18$ & $5.38 \pm 0.77$ \\
& $\mathrm{Y}[\mathrm{km} / \mathrm{s}]$ & $5.95 \pm 0.13$ & $6.04 \pm 0.05$ & $6.07 \pm 0.07$ & $6.23 \pm 0.03$ & $5.07 \pm 0.94$ \\
& $\mathrm{Z}$ & $5.62 \pm 0.12$ & $5.67 \pm 0.44$ & $5.81 \pm 0.11$ & $6.21 \pm 0.12$ & $4.23 \pm 1.14$ \\
& $\boldsymbol{A}[\%]$ & $\mathbf{5 . 5 5}$ & $\mathbf{6 . 5 9}$ & $\mathbf{4 . 2 8}$ & $\mathbf{2 . 5 1}$ & $\mathbf{2 1 . 5 6}$
\end{tabular}

Independent of the weathering state, all cubes and varieties, show a significant increase of the compressional wave velocity, covering almost the span of velocities for a calcite single crystal $(5.7 \mathrm{~km} / \mathrm{s}$ parallel to the c-axis and $7.7 \mathrm{~km} / \mathrm{s}$ parallel to the a-axes according to Dandekar, D., P., 1968). Until a stress of $150^{\circ} \mathrm{C}$, the velocities range between 5.73 and $6.75 \mathrm{~km} / \mathrm{s}$, with a slightly fluctuation trend. After the next heating step up to $200^{\circ} \mathrm{C}$ these velocities are slowly but clearly reduced for all marble varieties, while the Großkunzendorf still keeps higher velocities. After the combination of heat and freezing temperatures, none of the marbles show higher velocities than $6.03 \mathrm{~km} / \mathrm{s}$. Ruedrich, $2003 \mathrm{ob}$ served the same for strongly weathered Carrara and Großkunzendorf marble and named the lower compressibility of water and/or the incomplete water saturation as the reason. As all samples show the same behaviour, the lower water compressibility seems to be more plausible, as the high number of cracks and therefore higher water proportion 
reduces the overall velocity. Regardless of this, the directional dependence of the wave velocity can still be observed for all samples and is consistent with the dry samples.

Besides the water saturation, the ultrasonic velocities have been measured under different air humidity's for the different weathering states. After 3 days in a specific relative air humidity the weight and the ultrasonic velocities have been determined. In Figure 41 the velocity evolution for the Blanco Macael is shown as an example. In dependence on the relative air humidity the velocities increase slightly, while the highest impact can be observed for the unweathered sample. With increasing weathering state, the influence of the humidity decreases. A comparable evolution can be observed for all marble varieties, while the Großkunzendorf shows a less clear trend.

Generally, the influence of the air humidity seems to be low, while as higher the weathering state of the marble as lower the influence, which can be observed in Figure 42. In Figure 42 the maximum velocity increase is given for all five marble types in Z-direction, according to the specific weathering state. This behaviour can be determined for all marble types. The Großkunzendorf shows no clear trend. Due to the long drying times of the Wunsiedel marble, the samples were not conclusively alterated and could not be considered for this examination. 


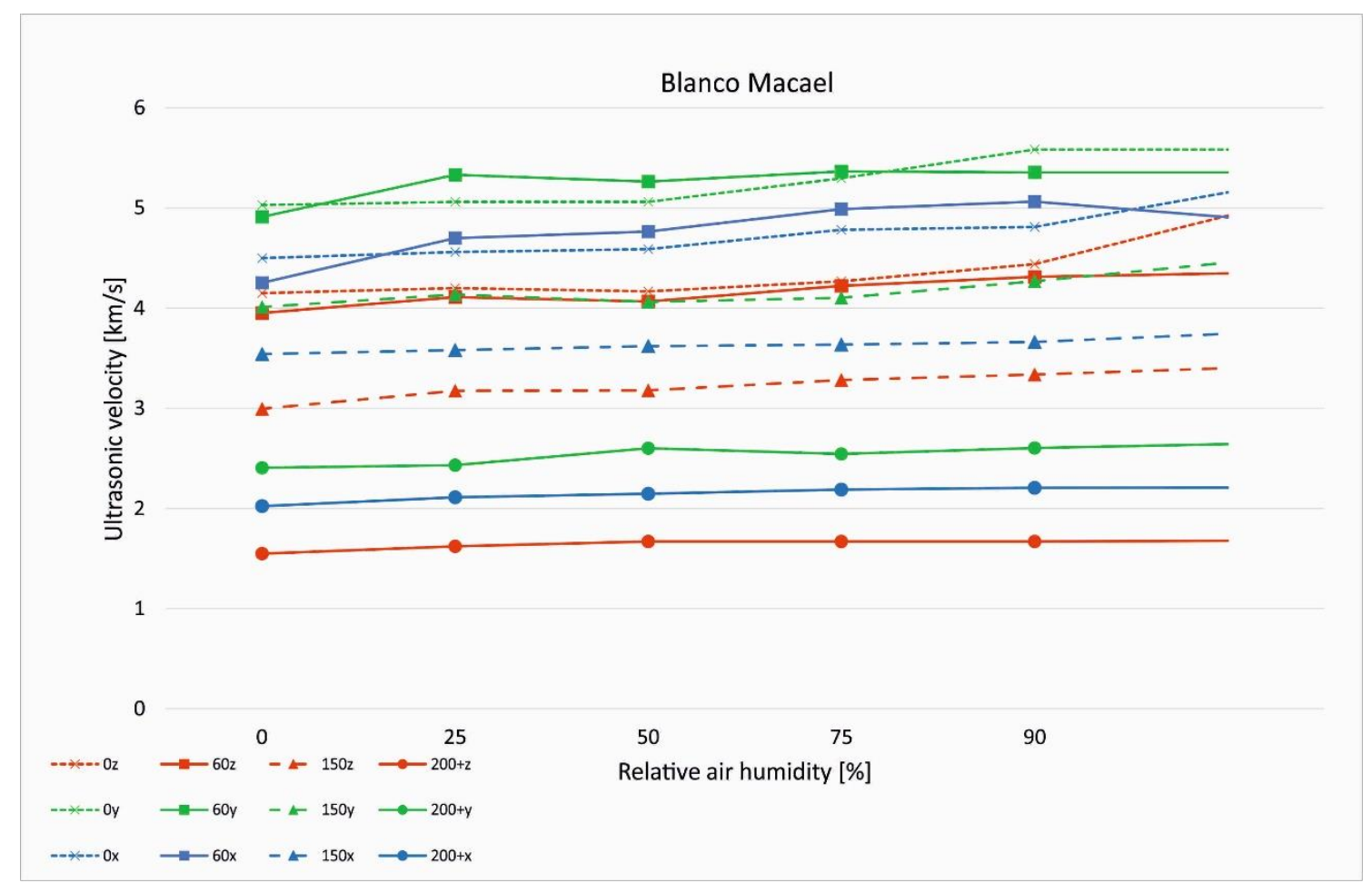

Figure 41 Velocity evolution in dependency of the relative humidity according to the different weathering states for the Blanco Macael. Given are the analysed three main directions $\mathrm{X}, \mathrm{Y}$ and $\mathrm{Z}$.

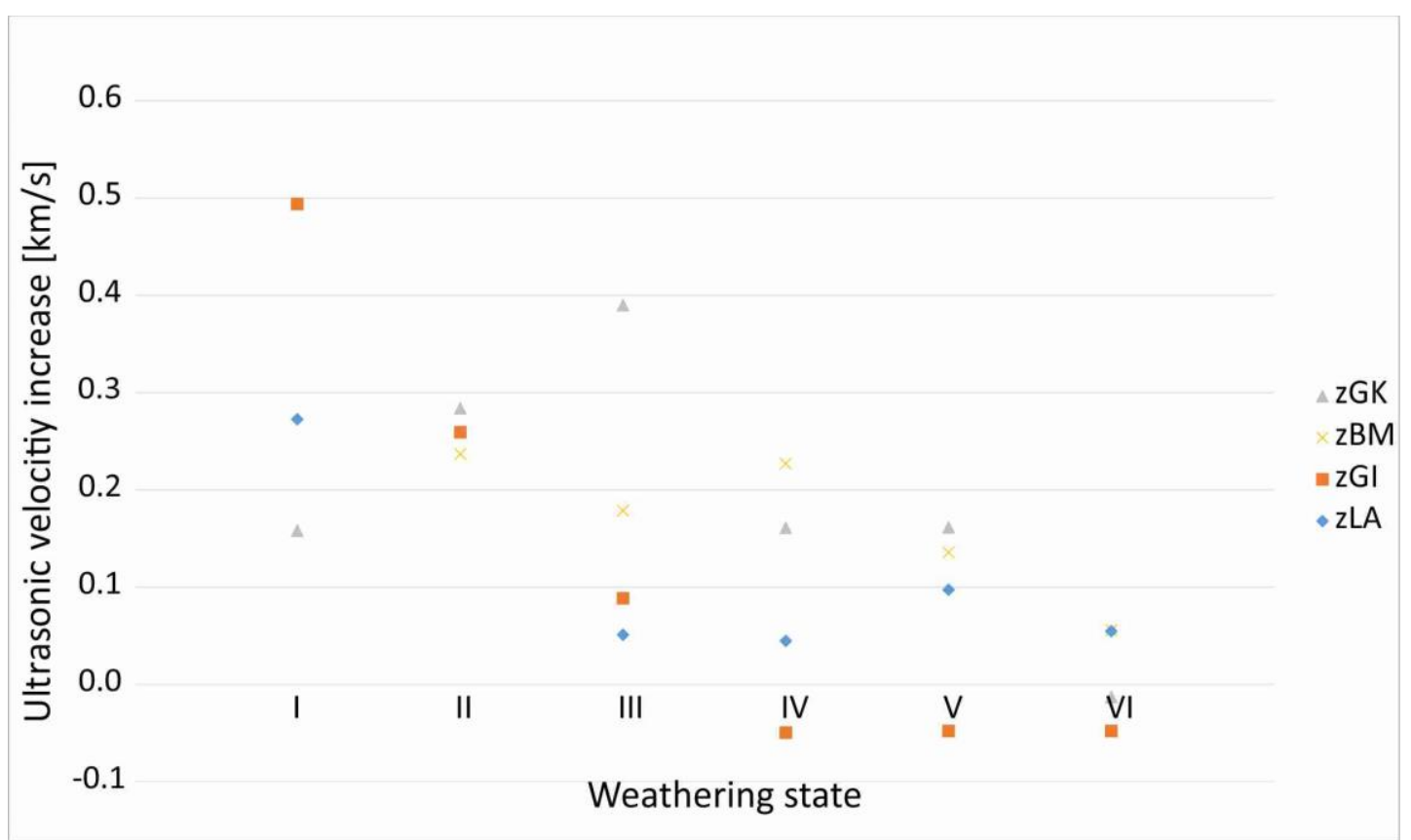

Figure 42 Maximum velocity increase $[\mathrm{km} / \mathrm{s}$ ] for the Großkunzendorf, Lasa, Blanco Macael and Carrara Gioia marble in Z-direction, according to the weathering state $\left(\mathrm{I}=\right.$ unweathered to $\left.\mathrm{VI}=200^{\circ} \mathrm{C}\right)$. 


\subsubsection{Intrinsic velocity distribution}

As already described, the water saturation of deteriorated marble can cause almost intrinsic velocity distributions. The intrinsic velocity distribution represents the crack-free compressive wave velocity, exclusively caused by the rock-forming minerals and their spatial arrangement. The P-wave velocities determined for a calcite single crystal are strongly anisotropic and differ with regard to the measured direction. A pronounced texture caused by the arrangement of those single crystals, leads to an overprint of the anisotropic properties of calcite on the whole rock properties. The variation of the maximum and minimum velocity is used to calculate the anisotropy.

$$
A[\%]=\left(V p_{\max }-V p_{\min }\right) / V p_{\max } * 100 \text { (Siegesmund and Dürrast, 2014). }
$$

Based on the textural data it was possible to calculate the polycrystal compressional wave velocity for each sample and to quantify their directional dependence, known as intrinsic anisotropy (Table 11).

Table 11 Intrinsic ultrasonic velocity [ $\mathrm{km} / \mathrm{s}]$ and the anisotropy [\%] calculated on basis of the texture.

\begin{tabular}{|c|c|c|c|c|c|c|c|}
\hline & $\begin{array}{l}\text { Blanco } \\
\text { Macael }\end{array}$ & Gioia & Lasa & $\begin{array}{l}\text { Großkun- } \\
\text { zendorf }\end{array}$ & $\begin{array}{l}\text { Wun- } \\
\text { siedel }\end{array}$ & $\begin{array}{l}\text { Rosa } \\
\text { Estremoz }\end{array}$ & Prieborn \\
\hline VP MIN [KM/S] & 6.8 & 6.8 & 6.8 & 6.8 & 6.9 & 6.8 & 6.96 \\
\hline$V P M A X[K M / S]$ & 6.4 & 6.5 & 6.5 & 6.6 & 6.4 & 6.4 & 6.32 \\
\hline$A[\%]$ & 5.88 & 4.41 & 4.41 & 2.94 & 7.25 & 5.88 & 9.2 \\
\hline
\end{tabular}

The calculated velocities range between 6.96 and $6.32 \mathrm{~km} / \mathrm{s}$, while the anisotropy varies between 2.94 and $9.2 \%$. As shown in Figure 43, the intrinsic anisotropy depends on the textural intensity. The Großkunzendorf, with a low texture of $1.57 \mathrm{mrd}$. shows only a low intrinsic anisotropy. On the other hand, the Prieborner with a strong texture of $3.3 \mathrm{mrd}$ has a high intrinsic anisotropy of $9.2 \%$. 


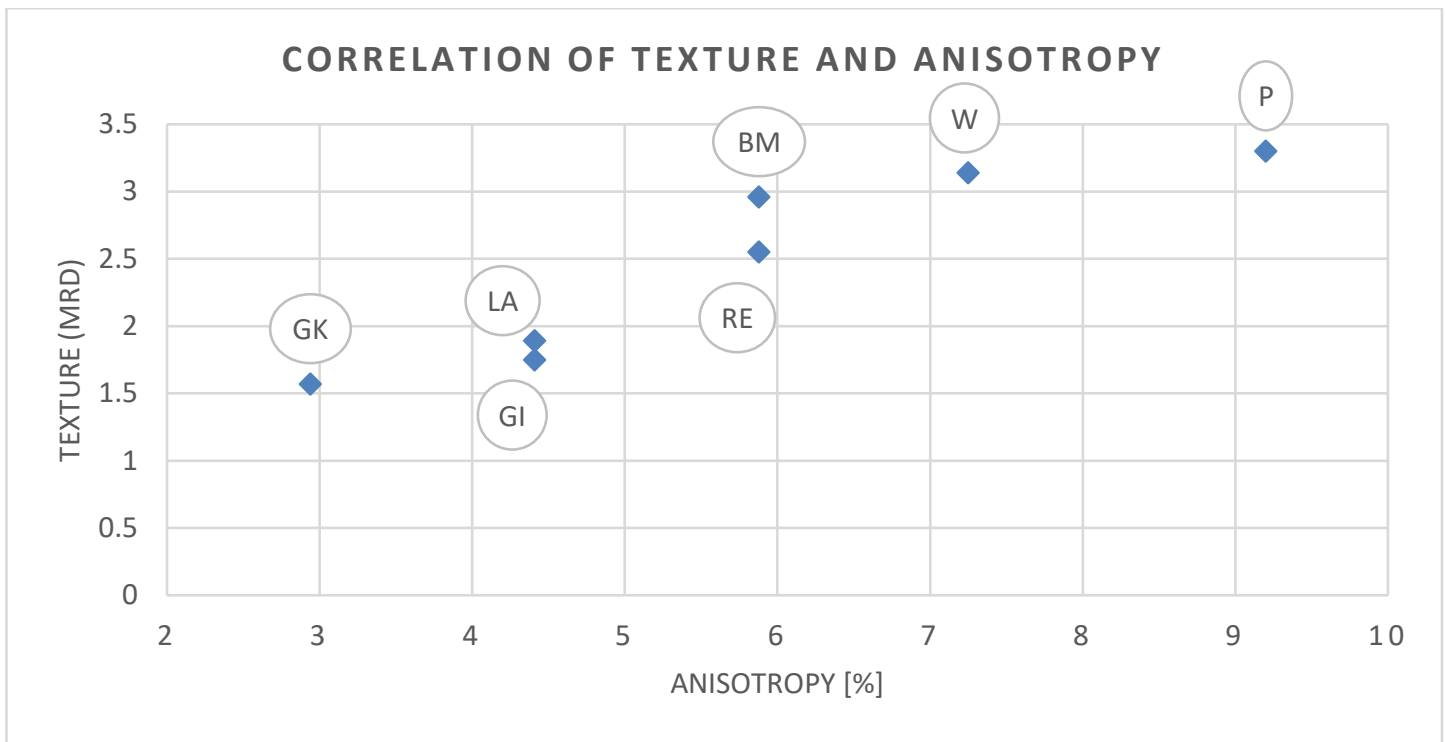

Figure 43 Correlation of texture [mrd] and anisotropy [\%] determined for seven analysed marble varieties.

\subsubsection{4 $\quad 360^{\circ}$ measurements}

In order to determine the spatial distribution of the velocity decrease, spherical samples were used to perform $360^{\circ}$ measurements (see Chapter 3.4.2.2 $360^{\circ}$ measurements). Those measurements were repeatedly executed for the same sample under dry and fully water saturated conditions after each weathering step.

\subsection{Crack related velocity reduction}

While the intrinsic velocity distribution is only influenced by rock forming minerals, the measured velocity will always be lower. This velocity reduction is caused by cracks forming throughout the exhumation, exploitation process, the further processing of the marble and finally it is affected by weathering processes.

As shown in Chapter 5.3.2.1 Transmission measurements, the alteration of marble significantly reduces the ultrasonic velocities due to the formation of cracks. To determine the specific crack evolution within the weathering process, spherical samples were analysed after each weathering step. The knowledge about an existing preferential orientation of microcracks and their influence on the intrinsic velocity distribution is of particular importance with regard to ultrasonic tomography (Ruedrich, 2003).

Therefore, the spherical samples were analysed under dry conditions and compared to the almost intrinsic, water saturated sample. The calculated $\Delta$-Vp-Plot is the difference 
between the water saturated and dry sample and allows an approximately determination of the preferred orientation. In Figure 44 and Figure 45 the results for all varieties after their alteration up to $200^{\circ} \mathrm{C}$ are given.

The comparison of the water saturated, weathered and calculated $\Delta$-Vp-Plot shows that the main crack pattern caused by artificial weathering increases the intrinsic anisotropy. The comparable distribution pattern of the water saturated and the calculated pole figure points on this conclusion. It can be observed that former high ultrasonic velocities show the lowest velocity reduction and on the other hand, the former low velocities show the highest reduction. While this general observation can be made, there are also several modifications between the different varieties. The samples Carrara Gioia and Wunsiedel show a crack pattern that is more comparable to the weathered distribution than to the water saturated. The pole figures of the varieties Blanco Macael, Lasa and Großkunzendorf show more or less the same distribution pattern, independent if they are water saturated or weathered. Therefore, the calculated distribution pattern is comparable to them. In contrast, the results for the Rosa Estremoz differ. Here we have a strong increase of the reduction parallel to the Z-direction, while the lowest increase can be observed in Y-direction.

All anisotropies increase due to the weathering process, while the anisotropy of the $\Delta$ Vp-Plot distinguishes between comparable anisotropies, as were found for the water saturated sample (Blanco Macael), medium intensities, ranging between the intrinsic, water saturated, low anisotropy and the high anisotropy of the weathered sample. The calculated Wunsiedel pole figure shows an anisotropy which is higher (54\%) than the weathered anisotropy of $50 \%$. This marble shows a strong foliation parallel preferred grain shape orientation, influencing the crack distribution pattern. 


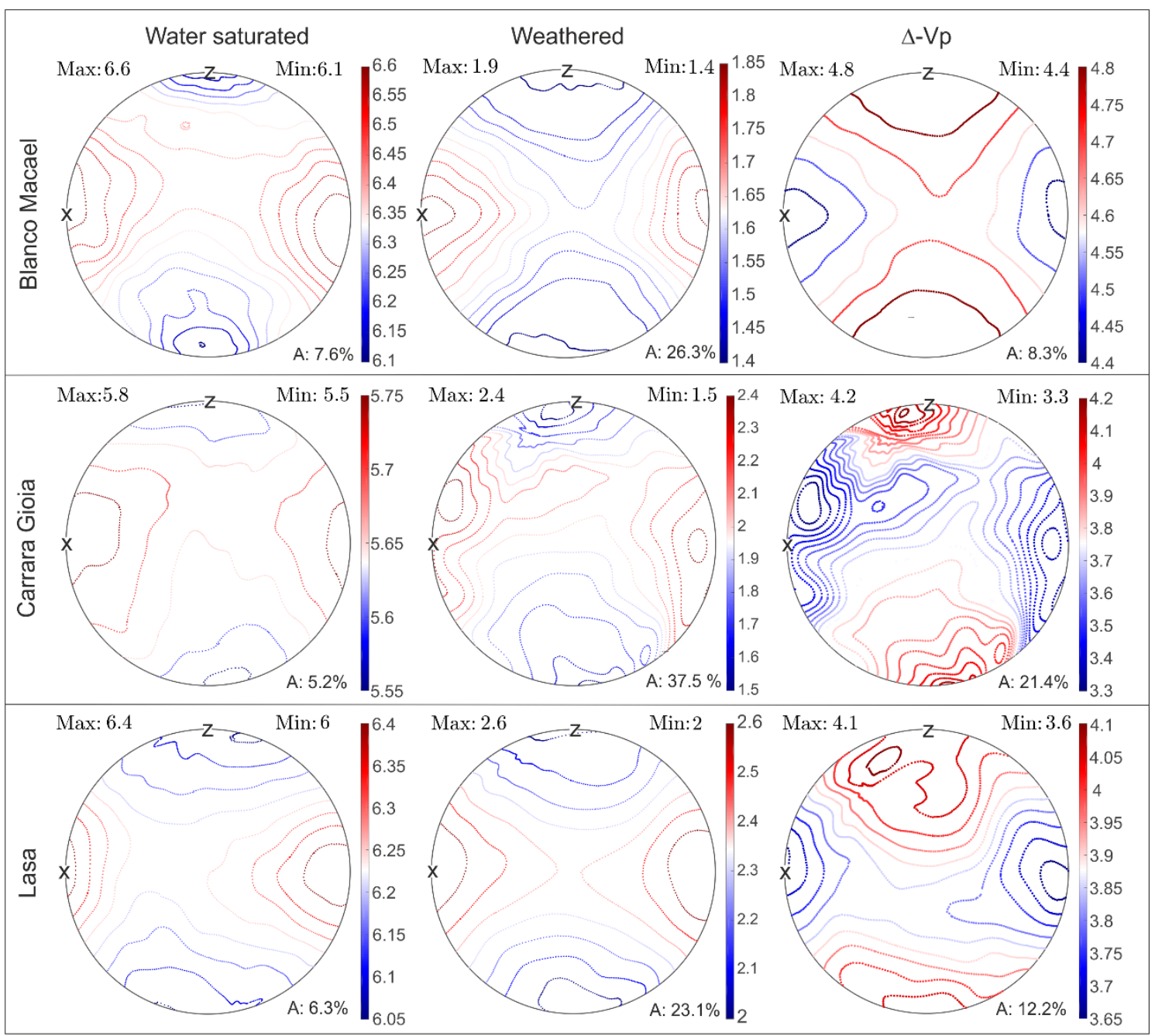

Figure 44 Velocity distribution Vp in $\mathrm{km} / \mathrm{s}$ for the marble varieties Blanco Macael, Carrara Gioia and Lasa. The plots show the distributions for the water saturated state (left side) the weathered, dry sample $\left(200^{\circ} \mathrm{C}\right)$ in the middle and $\Delta \mathrm{Vp}$, the calculated difference between saturated and weathered. 


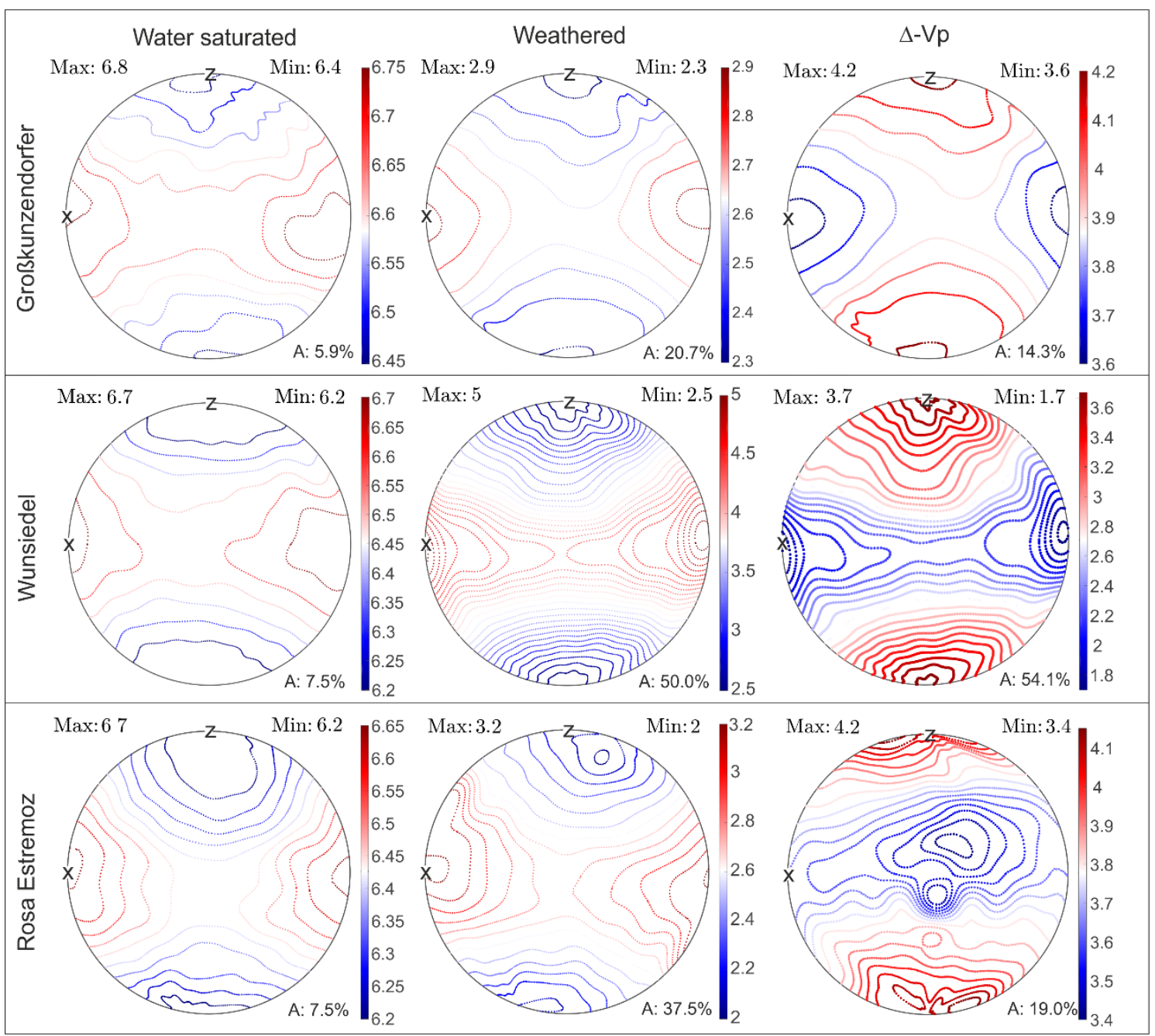

Figure 45 Velocity distribution Vp in km/s for the varieties Großkunzendorf, Wunsiedel and Rosa Estremoz. The plots show the distributions for the water saturated state (left side) the weathered, dry sample $\left(200^{\circ} \mathrm{C}\right)$ in the middle and $\Delta \mathrm{Vp}$, the calculated difference between saturated and weathered. 


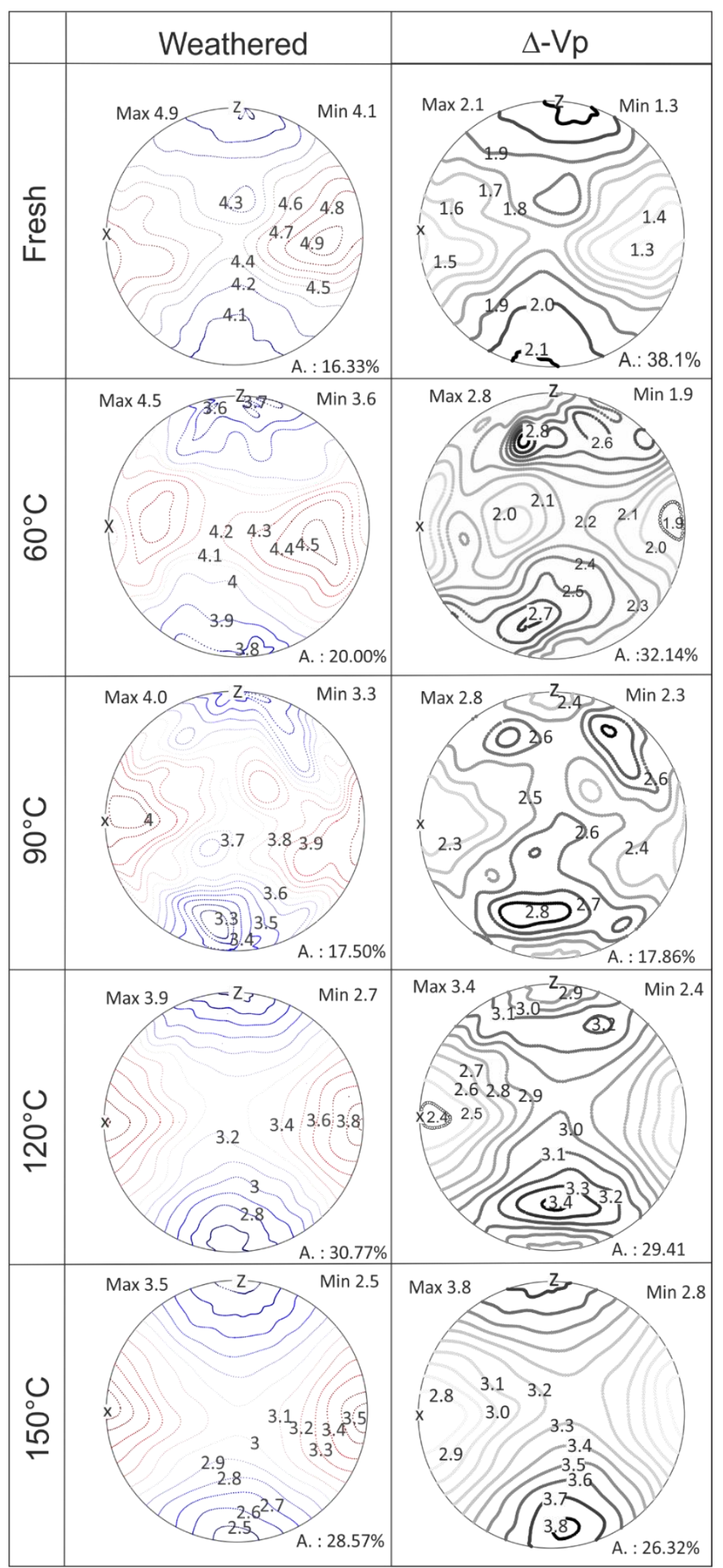

Figure 46 Development of the velocity distribution $\mathrm{Vp}[\mathrm{km} / \mathrm{s}]$ for each weathering step under dry conditions (left side) and the evolution of the $\Delta$-Vp-Plot in proportion to the water saturated state (right side) for the Blanco Macael. 
As an example, the weathering and crack evolution for the Blanco Macael is presented in Figure 46. The 'weathered' plots display the pole figures after each weathering step under dry conditions. The $\Delta$-Vp-Plot is the difference between the specific weathering degree and the water saturated sample, shown in Figure 44. The last alteration step up to $200^{\circ} \mathrm{C}$ is given in Figure 44 Velocity distribution $\mathrm{Vp}$ in $\mathrm{km} / \mathrm{s}$ for the marble varieties Blanco Macael, Carrara Gioia and Lasa. The plots show the distributions for the water saturated state (left side) the weathered, dry sample $\left(200^{\circ} \mathrm{C}\right)$ in the middle and $\Delta \mathrm{Vp}$, the calculated difference between saturated and weathered.

The fresh, unweathered sample shows velocities between $4.9 \mathrm{~km} / \mathrm{s}$ and $4.1 \mathrm{~km} / \mathrm{s}$, while the velocity distribution is primarily dominated by the texture, with a velocity minimum in Z-direction, slightly elongated in Y-direction and a maximum velocity in X-direction, slightly dipping into the Y-direction. Compared to the unweathered cubic samples the sphere has lower velocities, which can be explained by the sample preparation process. The $\Delta$ - $\mathrm{Vp}$-Plot indicates a crack distribution that increases the former intrinsic anisotropy. The first alteration step, heating up to $60^{\circ} \mathrm{C}$ and cooling down to $4^{\circ} \mathrm{C}$ seem to activate different mechanisms. The dry sample shows two velocity maxima with velocities between $4.4 \mathrm{~km} / \mathrm{s}$ and $4.5 \mathrm{~km} / \mathrm{s}$, following the axes belt, while the velocity minimum is still oriented perpendicular to the Z-direction. The $\Delta$-Vp-Plot shows a more diffuse crack distribution, with two minima caused by the velocity maxima and two maxima with $2.8 \mathrm{~km} / \mathrm{s}$ and $2.7 \mathrm{~km} / \mathrm{s}$. This pattern could be caused by the crystallographic r-planes, which show sub maxima in this area. Even if the temperature was only increased up to $60^{\circ} \mathrm{C}$ the velocities decrease down to $4.5 \mathrm{~km} / \mathrm{s}-3.6 \mathrm{~km} / \mathrm{s}$. The temperature step up to $90^{\circ} \mathrm{C}$ decreases the maximum velocity down to $4.0 \mathrm{~km} / \mathrm{s}$ and the minimum velocity down to $3.3 \mathrm{~km} / \mathrm{s}$, while the calculated difference between the maximum and minimum reduction decreases and lies between $2.8 \mathrm{~km} / \mathrm{s}$ and $2.3 \mathrm{~km} / \mathrm{s}$. The velocity maximum of $4.0 \mathrm{~km} / \mathrm{s}$ has now almost the same position oriented in X-direction, while the lower velocities are rearranged in Z-direction. The crack pattern shows that a small channel in $\mathrm{Y}$ Z-direction appears, decorated with spots of reductions between $2.8 \mathrm{~km} / \mathrm{s}$ and $2.6 \mathrm{~km} / \mathrm{s}$. Within the next heating cycle up to $120^{\circ} \mathrm{C}$, the main velocity reduction can be found in Z-direction. While the maximum velocity decreases from $4.0 \mathrm{~km} / \mathrm{s}$ to $3.9 \mathrm{~km} / \mathrm{s}$, the lower velocities decrease from $3.3 \mathrm{~km} / \mathrm{s}$ down to $2.7 \mathrm{~km} / \mathrm{s}$. This evolution can be observed by 
an increasing anisotropy, reaching values of $30.7 \%$. The crack distribution is concentrated on the areas of the highest and lowest velocities, following the texture induced velocity distribution, while the maxima are still arranged as two points within the Z-Ydirection. While the next heating cycle causes only moderate velocity reductions, the $\Delta$ Vp-pattern becomes more equal to the intrinsic distribution. The crack pattern develops more uniform, as the anisotropic influence has less preferred orientations than before. The last heating step was performed with an additional freeze thaw cycle, which can be recognized due to the significant velocity reduction down to $1.9 \mathrm{~km} / \mathrm{s}-1.4 \mathrm{~km} / \mathrm{s}$. As described before, the main crack pattern increases the intrinsic anisotropy.

This exemplaric crack evolution could be observed for almost all analysed samples. With increasing weathering state, the velocity distribution adapts to the intrinsic distribution and amplifies it.

\subsubsection{Relationship of velocity and porosity}

That a decreasing compressive wave velocity correlates with a porosity increase is known and was described by different authors (Mahmutoğlu, 2017; Ruedrich, 2003; Ruedrich et al., 2013; Siegesmund et al., 2010; Weiss et al., 2002a). The analysed marble varieties were examined with regard to this relationship. In Figure 47 the mean value for the different weathering states are given for the Blanco Macael (BM), Lasa (LA), Carrara Gioia (GI) and the Großkunzendorf (GK). The results for the Wunsiedel are not inserted, as they show a huge standard deviation and complicate the readability of the graph. Each weathering state is labelled with a roman number $(0-\mathrm{VI})$, while $(0)$ indicates the unweathered state, (I) the heating cycle up to $60^{\circ} \mathrm{C}$, (II) $90^{\circ} \mathrm{C}$, (III) $120^{\circ} \mathrm{C}$, (IV) $150^{\circ} \mathrm{C}$, (V) $200^{\circ} \mathrm{C}$ and $(\mathrm{VI})$ the heating up to $200^{\circ} \mathrm{C}$ and an additional freeze cycle. To improve the readability, each weathering cluster is labelled by a circle.

It can be observed that each weathering cycle causes a low porosity increase, starting around $0.1-0.2$ vol.- $\%$ and $4-6 \mathrm{~km} / \mathrm{s}$ and increases to almost 0.9 vol.-\% and velocities between 1 and $3 \mathrm{~km} / \mathrm{s}$. The Blanco Macael shows the biggest porosity increase by heating up to $200^{\circ} \mathrm{C}(\mathrm{V})$, while the following cycle (VI) causes a low further porosity increase. The combination of heating and freezing $(\mathrm{VI})$ has the biggest influence on the porosity of the GI and GK, while this effect is less distinct for the Lasa. The strongest impact can 
be stated for the Großkunzendorf marble, here every weathering step causes an increase of porosity, much higher than the one before, with a low range within each weathering group. Whereas the Carrara Gioia shows a clear influence of the combination heating and freeze (VI), the antecedent cycles cause relatively small changes between $4.1 \mathrm{~km} / \mathrm{s}-2.1 \mathrm{~km} / \mathrm{s}$ and a porosity between 0.32 vol.-\% and 0.59 vol.-\%.

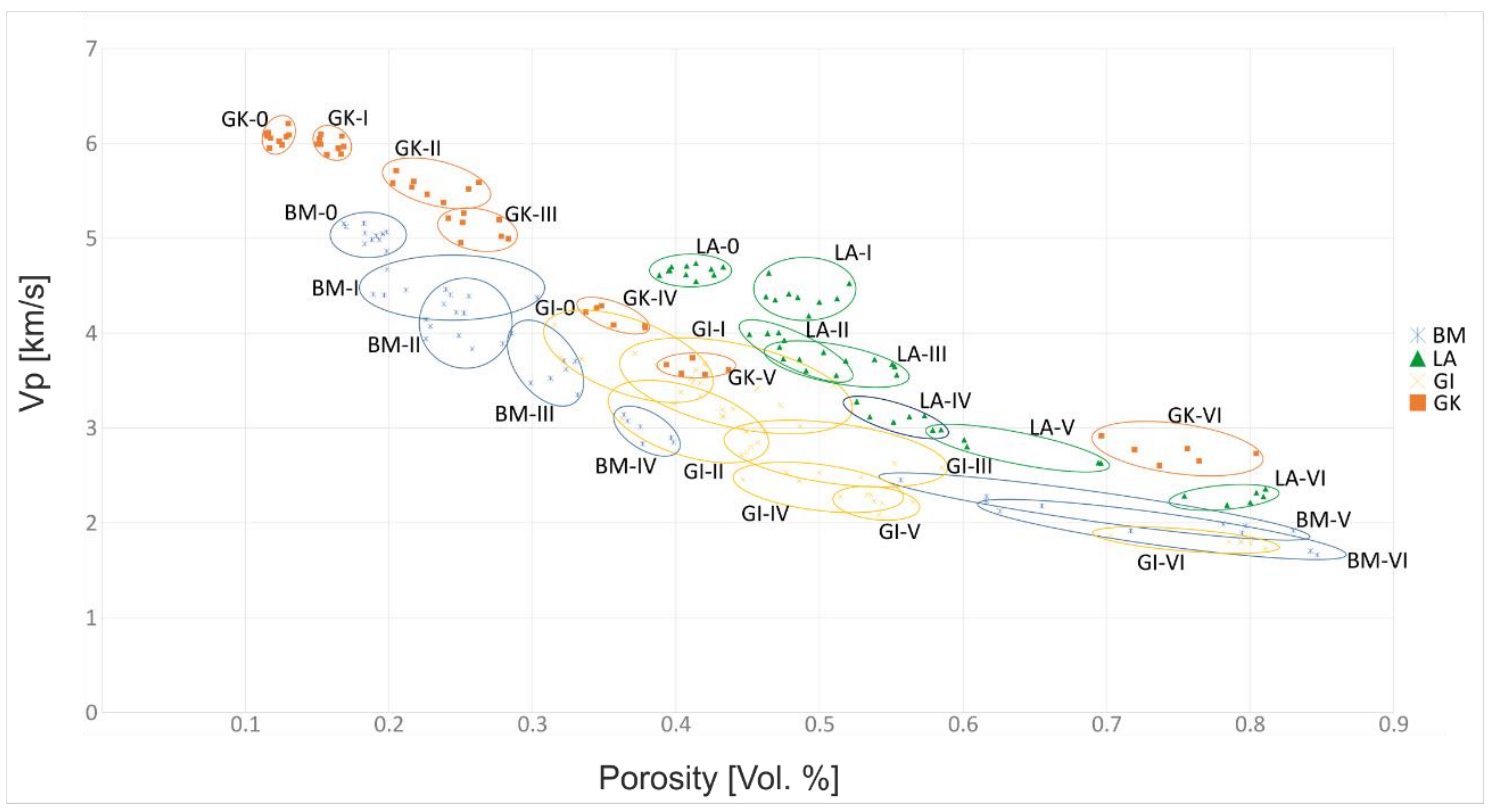

Figure 47 Correlation of the ultrasonic velocities and Porosity in the course of the velocity reduction caused by artificial alteration.

The relationship of the compressive wave velocity and the porosity was analysed by different authors. Köhler, 1991 developed a correlation function of velocity and porosity

$$
V_{P}=\sqrt{\frac{12}{\Phi}}
$$

which was based on experimental data, determined by numerous measurements on Carrara marble in different weathering states. Weiss et al., 2001 presented a model hypothesis based on the mathematical approach of O'Connell and Budiansky, 1974 and includes the principle that an existing porosity is formed by different ellipsoidal cracks. His approach considers possible crack geometries as pore aspect ratio defined by a length relationship. Ruedrich et al., 2013, used both approaches to test a data set of 123 marble samples. Their data ranged between 7.0 and $2.0 \mathrm{~km} / \mathrm{s}$ with very low porosities 
based on very flat cracks with an aspect ratio of 0.005 , which could be correlated to the approach of O'Connell and Budiansky, 1974. Two strongly weathered samples showed a modification of the crack geometry based on corrosion, what leads to a porosity increase, but has no distinct effect on the ultrasonic velocities. In those cases Ruedrich et al., 2013 received a correlation to the empirical correlation function of Köhler, 1991. They concluded that purely mechanical crack formation, follow the model approach of O'Connell and Budiansky, 1974 and thereby require a very small porosity increase with a strong velocity decrease. As soon as the fabric is affected by disintegration, solution processes can become active and modify the microcracks. They assume that in those cases, a strong porosity increase correlates to a relatively small velocity reduction. To see how the determined data should be interpreted within this context, Figure 48 shows the average compressional wave velocities for all analysed marble varieties within the artificial alteration under dry conditions. The correlation of velocity and porosity after Köhler, 1991 is given in red, the theoretical predictions according to the models of O'Connell and Budiansky, 1974 are given as black hatched lines

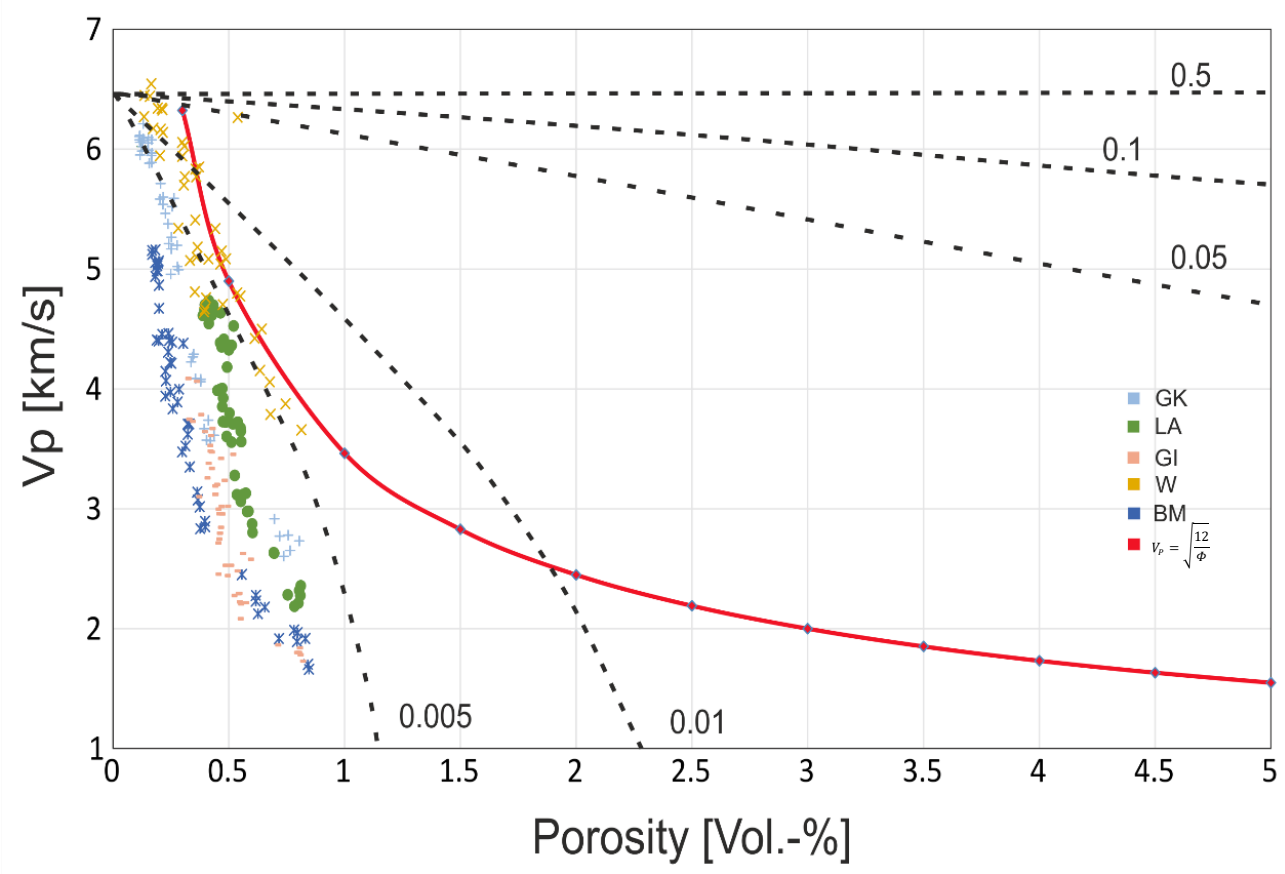

Figure 48 Average compressional wave velocities for different marble samples as a function of porosity and dry sample conditions. The velocity/porosity curve of Köhler, 1991 (bold line) and the theoretical predictions according to the models of O'Connell and Budiansky, 1974 (hatched lines) are added for comparison. The mean velocities of the compressive wave for the various marble samples in dependence of the porosity and sample state are shown (modified after Ruedrich et al., 2013; Siegesmund and Dürrast, 2014; Weiss et al., 2002a). 
According to the results of Ruedrich, 2003; Ruedrich et al., 2013; Weiss et al., 2001, all samples follow the model approach of O'Connell and Budiansky, 1974 with an aspect ratio of 0.005 . However, the Wunsiedel marble, with a partially high weathering resistance follows the porosity-velocity function of Köhler, 1991. The biggest difference between those marbles is that the Wunsiedel shows a relatively low weathering sensitivity which is associated to locally occurring macro cracks. These foliation parallel macro cracks, causing the high standard deviation (see Table 9), result in a comparable high porosity, combined with a high average velocity. Those results confirm the analyses of Ruedrich et al., 2013 in particular with regard to the mechanical crack formation. The high deterioration degree does not exclusively cause a high porosity, even if the f. e. strongly deteriorated Blanco Macael shows clear signs of total granular disintegration.

\subsubsection{Experimental tomography}

For an in-depth knowledge with regard to the development of a tomogram throughout an alteration, phantoms made of Blanco Macael, Carrara Gioia, Lasa, Großkunzendorf and Wunsiedel marble were manufactured. Those 5 samples were prepared according to the known spatial orientation of the fabric elements and transferred to the reference coordinate system. The phantoms were made out of the same block as all the other specimens to ensure comparable conditions, to determine the weathering behaviour by ultrasonic tomography with well-known material properties during the course of artificial weathering (Figure 49). 


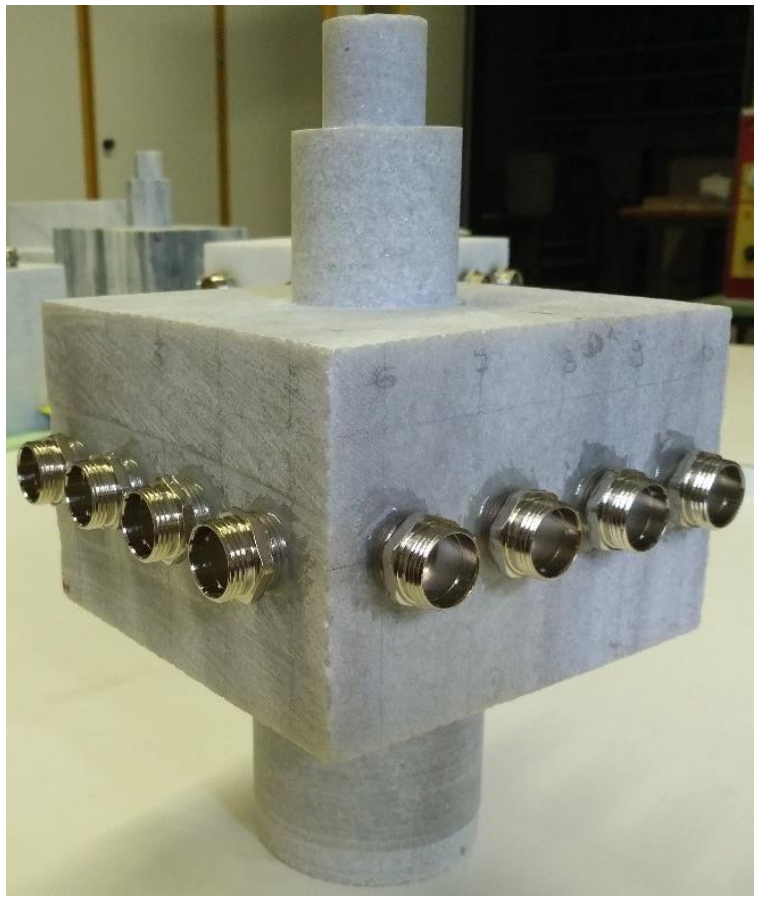

Figure 49 Phantom made of Großkunzendorf marble.

A methodical recording of the weathering behaviour needs constant test conditions. To ensure these conditions and the ultrasonic transducer was fixed on the surface. This required the use of numerous ultrasonic transducers, which have been developed with a frequency of $1 \mathrm{MHz}$. The transducers were connected to a multiplex which allowed the switching through the different probe positions (Figure 50). With this equipment, a repeatability under stable conditions was ensured.

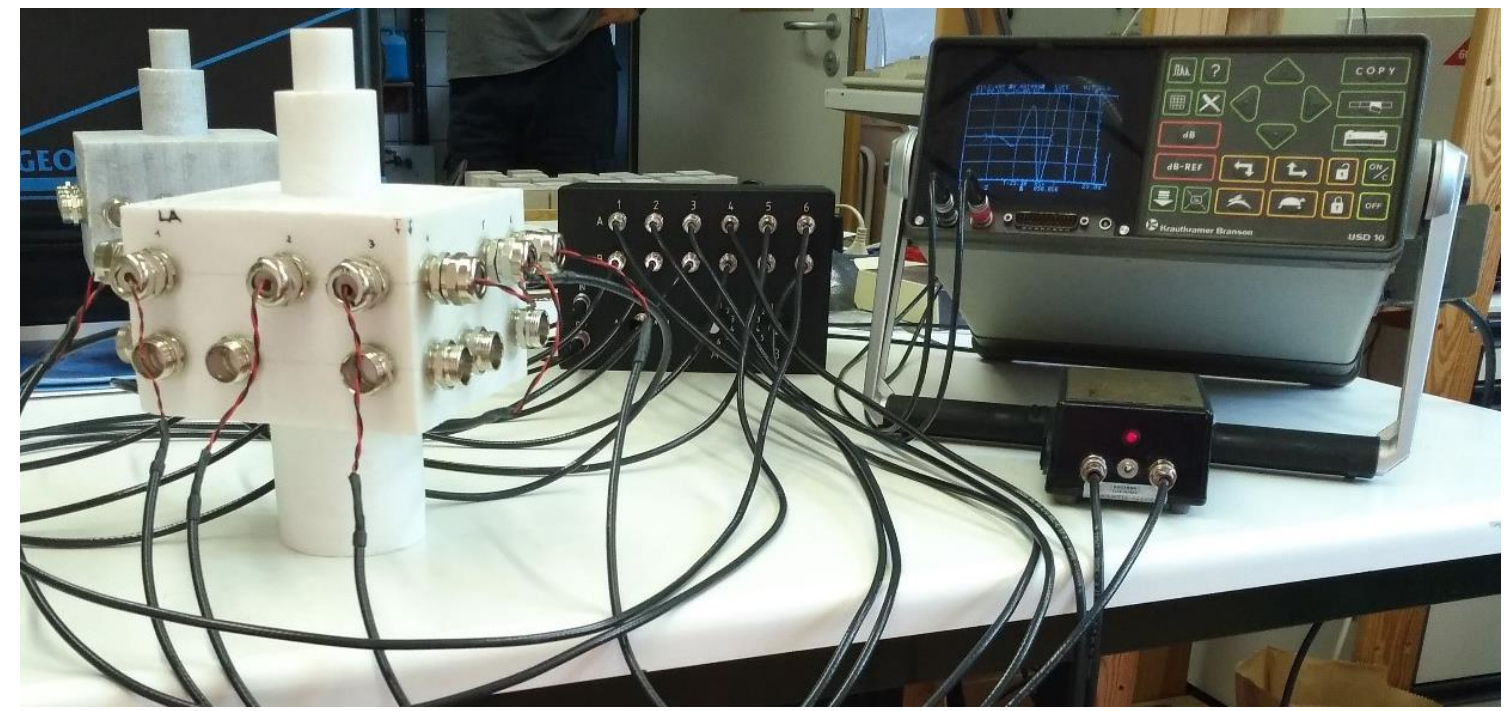

Figure 50 Marble phantom with the fixed different probe positions connected to the Krautkrämer ultrasound generator. 
Figure 51 shows the modelled tomograms of the marble phantoms in their previous state without consideration of the anisotropy and on the right considering the final percentage of anisotropy. It can be observed that for all samples a certain degree of anisotropy already has to be considered under unweathered conditions. This correlates very well with the data obtained from the systematic measurements of the cubes and spherical samples (see Table 9 and Table 10). Only the unweathered sample of Großkunzendorf (Figure 51), needs no consideration of anisotropy. This decision was made on basis of the distribution patterns for the root-mean-square (RMS) residuals, which are provided by the software GeoTomCG. Further descriptions can be found in Chapter 3.4.2.3

Tomographic inversion.

The velocities range between $3.8 \mathrm{~km} / \mathrm{s}$ for the Carrara Gioia and $6.5 \mathrm{~km} / \mathrm{s}$ for the Wunsiedel marble. The orientation of all tomograms is the same, while the direction of the lowest velocities correlates with the Z-direction. The anisotropy ranges between $0 \%$ (Großkunzendorf) and 20\% (Wunsiedel), causing relatively homogeneous tomograms. The irregularities that occur at the edges of the tomograms are triggered by the receiver positions and an increased number of rays and are not caused by the marble itself.

While all tomograms show elongated zones of higher velocities tending to the Z-direction, there is one area with lower velocities tending to the X-direction, which can be observed for the Wunsiedel marble. In this area, macroscopically visible healed cracks can be observed, influencing the velocity.

After the marble phantoms were recorded tomographically in their previous state, they were artificially alterated by thermal stress and then measured again. For all marble varieties, a higher degree of anisotropy results from an increasing weathering state, which corresponds with the systematic observations of the other samples. In Figure 53 and Figure 54 the tomogram evolution is given for the Blanco Macael and the Carrara Gioia. Exemplaric for the other samples. The Blanco Macael is depicted as a case where a high anisotropy (50\%) needs to be considered for the tomographic inversion. The Carrara Gioia still has a high anisotropy of $20 \%$, but was depicted to show the effect of the application of higher anisotropies than necessary. Furthermore, it is shown that by taking the anisotropy into account, previously occurring zoning is put into perspective. This is an important aspect that leads to misinterpretations if not considered. In particular Figure 
53 shows the large transformation for the velocity distribution of the Blanco Macael after recalculation of the weathered tomogram with $50 \%$ anisotropy (Figure 53).The previously occurring low velocity channels are relativised and bond to a considerably more homogeneous distribution, which also shows higher velocities than in the isotropic representation. A comparable evolution can be observed for the Carrara Gioia with an increasing homogeneity until the necessary amount of anisotropy was chosen with $20 \%$. As soon as this percentage becomes exceeded, a new channel of higher velocities appears (Figure 54). The shown tomograms demonstrate that the anisotropy has a large influence and definitely needs to be determined and well chosen as otherwise misinterpretations are possible.

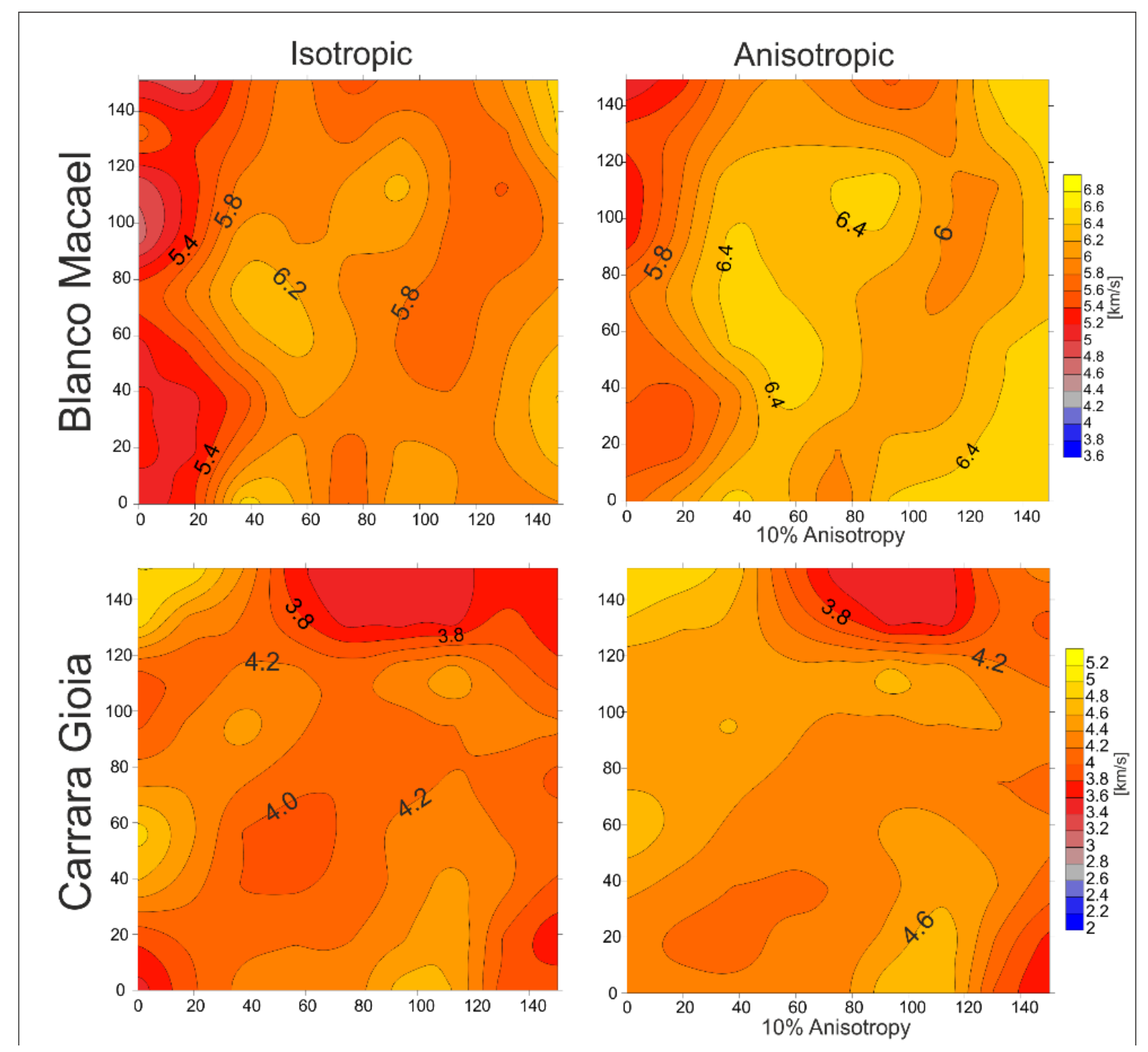

Figure 51 a) Tomograms investigated for the dummies in the unweathered state. The isotropic tomograms are given in the left Column, while the anisotropic tomograms are shown in the right column. The amount of anisotropy is given below the tomograms. Velocities are given in $\mathrm{km} / \mathrm{s}$. 


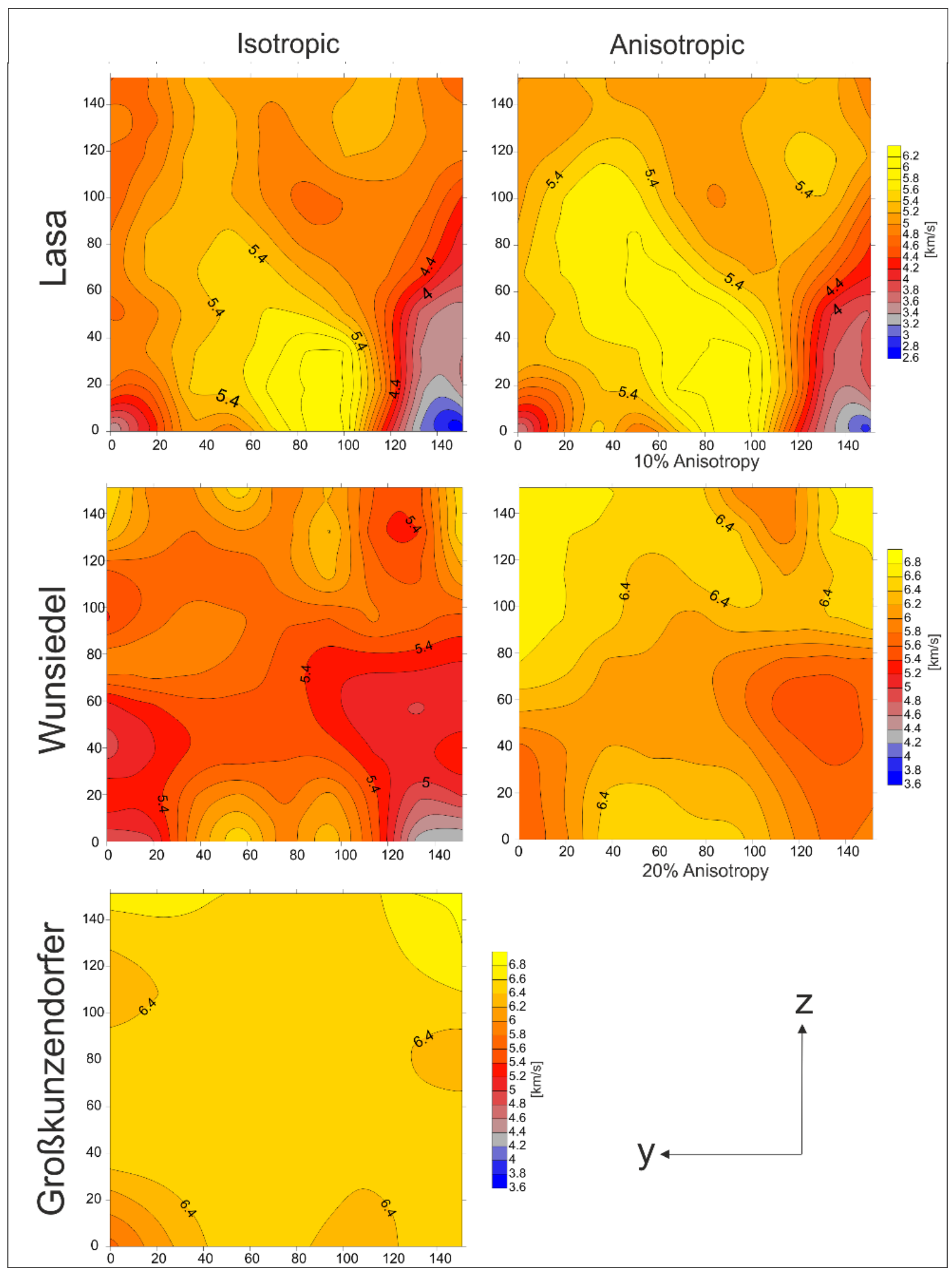

Figure 52 b) Tomograms investigated for the dummies in the unweathered state. The isotropic tomograms are given in the left Column, while the anisotropic tomograms are shown in the right column. The amount of anisotropy is given below the tomograms. Velocities are given in $\mathrm{km} / \mathrm{s}$. 


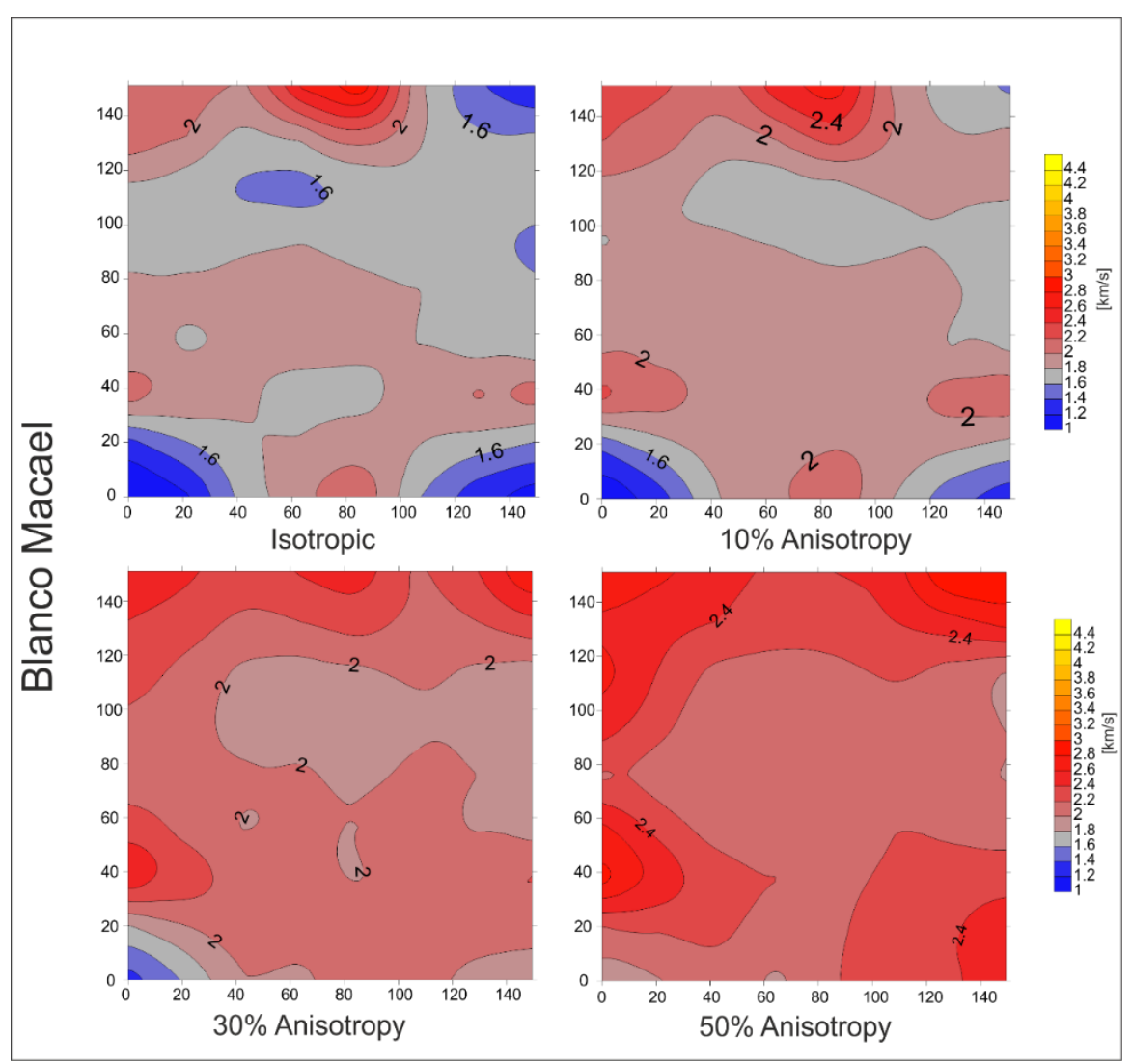

Figure 53 Tomograms for the weathered Blanco Macael with different amounts of anisotropy [\%].

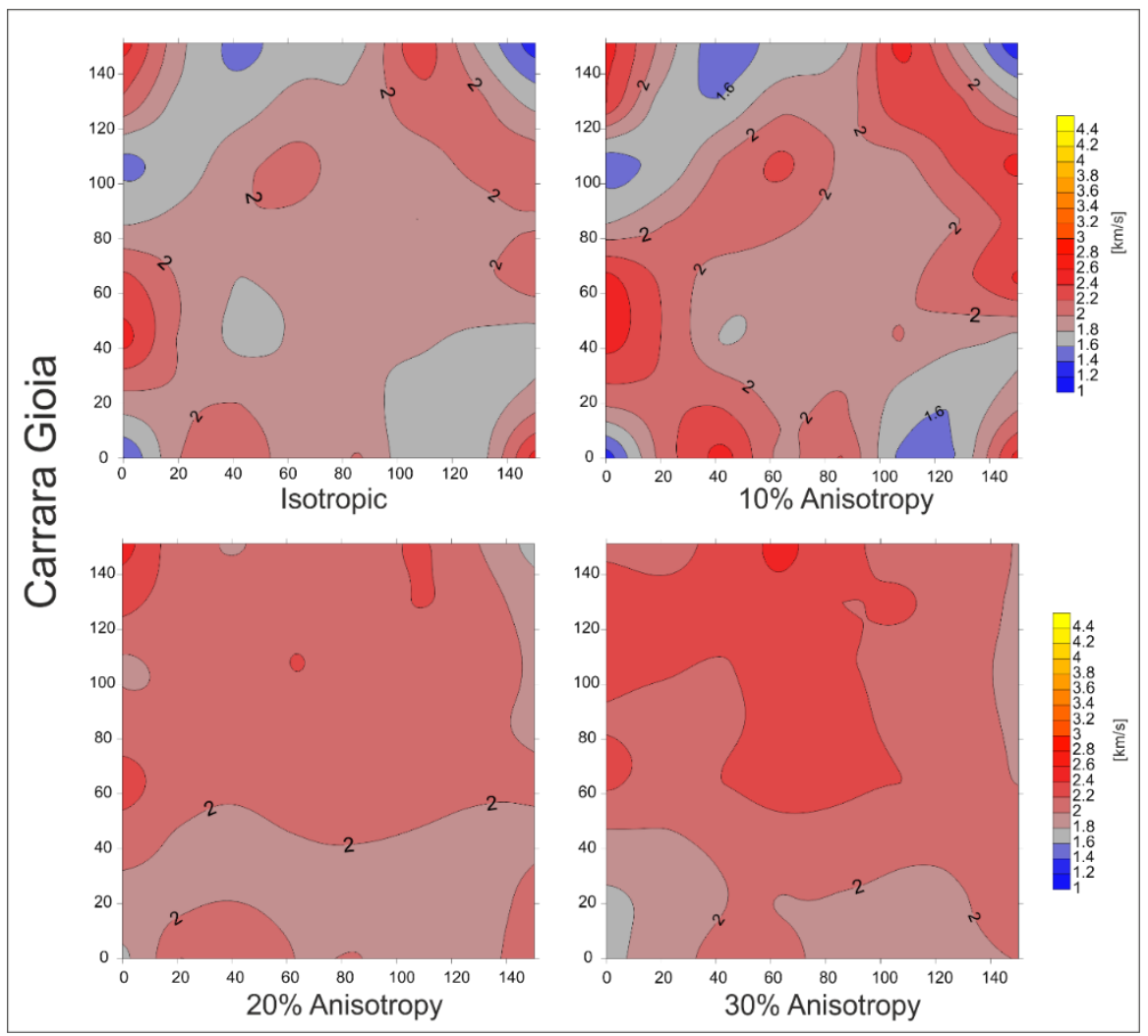

Figure 54 Tomograms for the weathered Carrara Gioia with different amounts of anisotropy [\%]. 


\subsubsection{Dynamic E-modulus}

The dynamic E-modulus $\left(E_{d y n}\right)$ was calculated according to the equation given in Chapter 3.4.4 Dynamic E-modulus and was determined based on the ultrasonic velocities for the cubes (Table 9) with a frequency of $350 \mathrm{kHz}$. The Poisson's ratio was calculated and ranged between 0.296 and 0.303 , while the shear wave data was determined on basis of the modelled textural velocities. The $E_{\text {dyn }}$ varies between $25.2 \pm 2.9 \mathrm{kN} / \mathrm{mm}^{2}$ for the Carrara Gioia and $71 \pm 1.6 \mathrm{kN} / \mathrm{mm}^{2}$ for the Großkunzendorf in the unweathered state (Figure 55). Each weathering step causes a clear reduction of the E-modulus and decreases to values between $6 \pm 0.3 \mathrm{kN} / \mathrm{mm}^{2}$ for the Carrara Gioia and $25 \pm 4.6 \mathrm{kN} / \mathrm{mm}^{2}$ for the Wunsiedel. The highest reduction can be observed for the Blanco Macael with $85.91 \%$ and the lowest for the Wunsiedel marble with $62.3 \%$ and is for all samples almost linear.

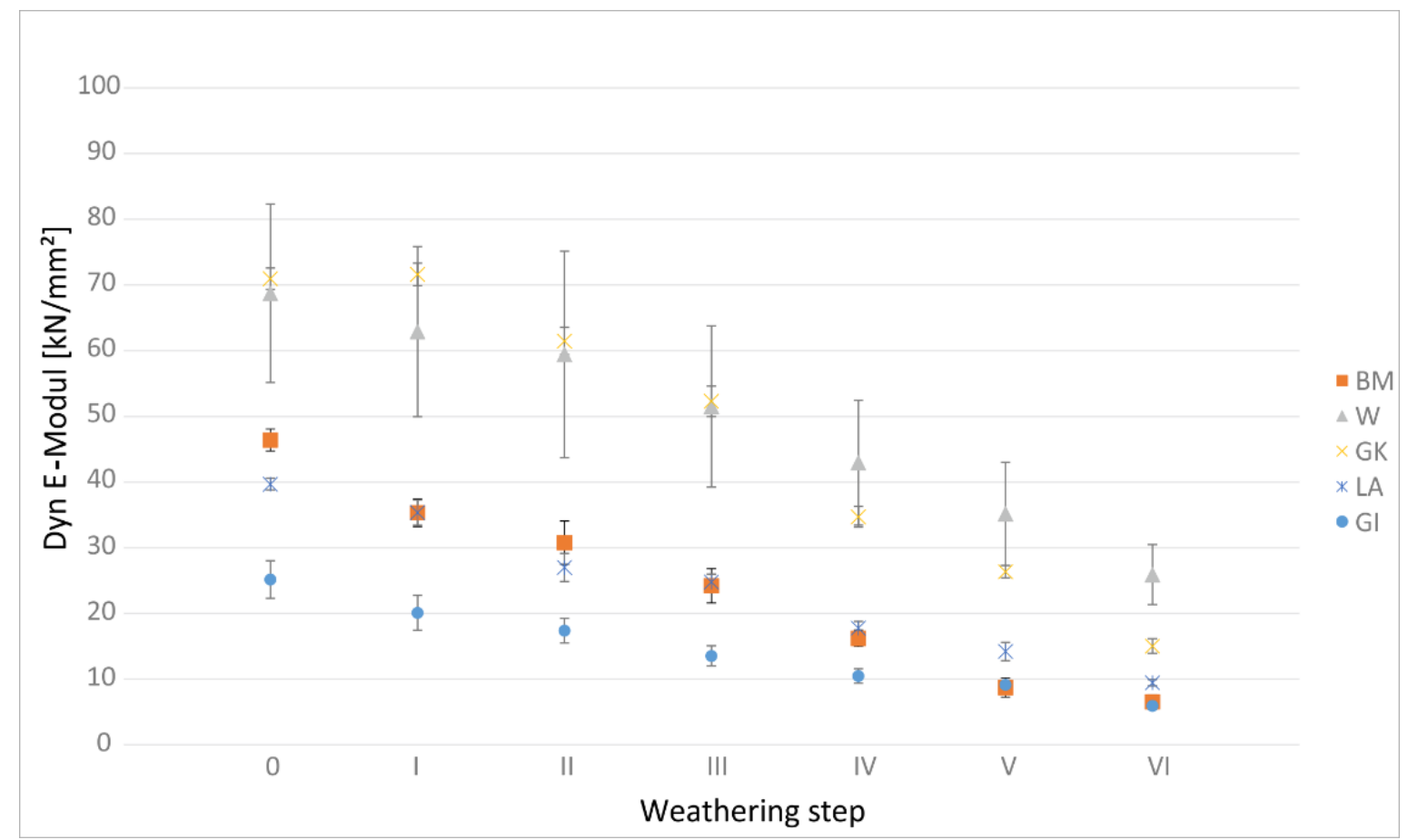

Figure 55 Evolution of the Dynamic E-modulus within the artificial alteration.

As the dynamic E-modulus describes the elasticity of a material and its resistance to deformation, all marble types show a strong decrease within this property. 


\subsubsection{Thermal dilatation}

The specific weathering behaviour of marble is based on the thermal properties of calcite. Main influencing parameter is the lattice preferred orientation where, according to a pronounced texture, the single crystal properties influence the properties of the whole rock. As described in Chapter 2. Marble, the calcite single crystal properties are not only anisotropic regarding to their ultrasonic wave velocities, but also for the thermal dilatation coefficient $\alpha$. While heating leads to an expansion parallel to the c-axis, it causes contraction parallel to the a-axes. A strong texture leads to an expansion of the marble sample according to the preferred orientation of the c-axis and a less intense expansion or contraction according to the preferred orientation of the a-axes. As the expansion and contraction effects the grain to grain contacts even within a small temperature range (Battaglia et al., 1993) and may cause an irreversible length change (Luque et al., 2010; Rüdrich et al., 2002; Ruedrich, 2003; Shushakova et al., 2013; Siegesmund et al., 2000b; Tschegg et al., 1999; Zeisig et al., 2002), the application of thermal cycles is a good instrument to determine the weathering vulnerability of marble.

The thermal dilatation $\varepsilon[\mathrm{mm} / \mathrm{m}]$, as a function of temperature, describes the expansion behaviour during thermal exposure and was analysed simultaneously for 6 specimens using a pushrod dilatometer.

For these investigations, 6 specimens in $\mathrm{X}-, \mathrm{Y}$ - and $\mathrm{Z}$-direction as well as in $\mathrm{XY}-, \mathrm{XZ}$ - and YZ-direction, according to the reference system, were measured for each marble type. The samples were heated from $20^{\circ} \mathrm{C}$ to $90^{\circ} \mathrm{C}$ and subsequently cooled down to $20^{\circ} \mathrm{C}$. To ensure the equilibration of the samples, heating and cooling was performed with a velocity of $1^{\circ} \mathrm{C} / \mathrm{min}$ while the maximum and minimum temperature was hold for 6 hours. This cycle was performed for 4 times and used to calculate the thermal dilatation coefficient $\alpha$ (see 3.4.5 Thermal expansion). The results are plotted in Figure 56 and shown for all investigated marble samples in context with their texture. It can be stated that the thermal expansion for all marble varieties shows a clear directional dependency according to the crystallographic preferred orientation, represented by the pole figures of the c- and a-axis distribution. 


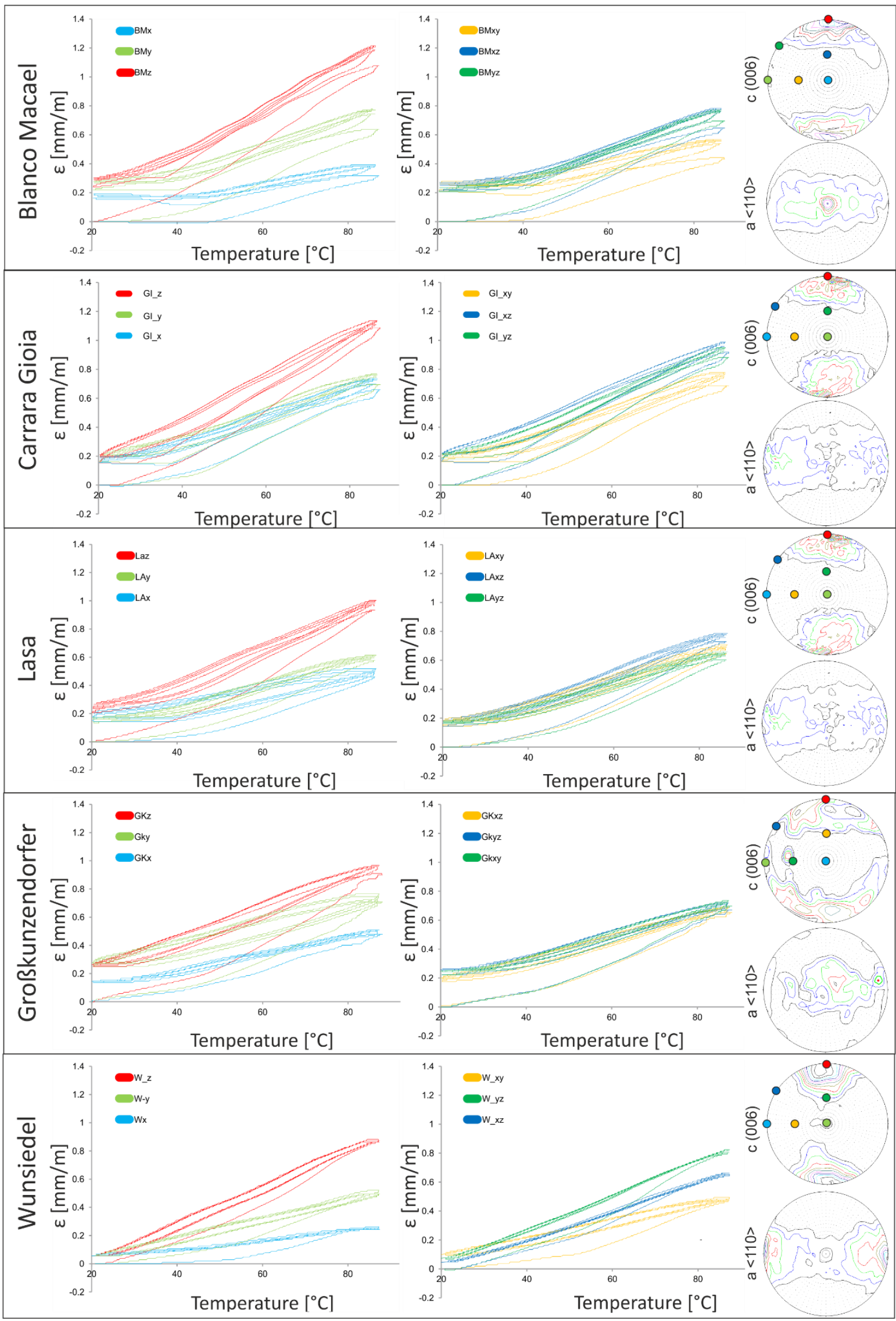

Figure 56 Thermal dilatation $\varepsilon[\mathrm{mm} / \mathrm{m}]$ shown as a loop of hysteresis with directional dependence (left graphs and middle) and pole figures of the lattice preferred orientation for c- and a-axis (right plots), for the specimens. 
Each sample shows the highest expansion in Z-direction, perpendicular to the foliation plane, which correlates with the direction of the highest intensity of the c-axis maxima, while the lowest expansions can be found along the a-axes in X-direction. All marbles show a more or less pronounced anisotropy of expansion in relation to the spatial position of the test specimens taken, which is primarily reflected in the main directions $(X, Y$ and Z). The minor directions show a significantly less pronounced anisotropy, depending on how close the specimen location is to the respective a- and c- axis maxima. The Wunsiedel marble shows the most obvious variation, with different expansion rates in all 6 sample directions. Basically, in the first cycle a successive increase of the slope until the maximum heating temperature can be observed for all samples and directions. Within this cycle, the slope of the hysteresis curve is flatter until a temperature of $40-60^{\circ}$. After this part, the curve starts to become steeper. As soon as the cooling phase is started, the curve declines almost linear until lower temperatures of about $40^{\circ} \mathrm{C}$ have been achieved. In this temperature range the temperature continues to decrease, while the contraction does not progress. This phenomenon can be clearly observed for the Blanco Macael and the Carrara Gioia and is less pronounced for the Großkunzendorf and the Lasa marble. The Wunsiedel shows the same phenomenon while it is only weakly pronounced. Comparable observations were made by Koch, 2006 and Leiss and Weiss, 2000. The latter explain the flatter increase in a lower temperature range with a buffering effect due to already existing microcracks. With increasing temperature this effect declines, and the coefficient increases. The result of this cycle is an irreversible length change; therefore, this phase seems to be the crack initializing. For the second to fourth cycle, the slope of the hysteresis curve is more linear, and the expansion and contraction shows almost the same temperature - dilatation rate. According to this, the first cycle shows the highest $\alpha$-coefficients (Table 12), defined by the gradient of the slope, whereas they are lower for the second cycle and remain approximately constant for the following cycles.

The smallest value in the first cycle was determined for the Wunsiedel $\left(3.82 \times 10^{-6} \mathrm{~K}^{-1}\right.$ in X-direction) and the highest for Blanco Macael (16.23 x $10^{-6} \mathrm{~K}^{-1}$ in Z-direction). Cycle two to four show a range between $2.87 \times 10^{-6} \mathrm{~K}^{-1}$ (X-direction Wunsiedel) and $14.2 \times 10^{-6} \mathrm{~K}^{-1}$ (Z-direction) determined for the Blanco Macael and Carrara Gioia. The $\alpha$-coefficients of the other directions are somewhere between the values of the Z- and X-directions, 
which can also be observed by the expansion intensity. The variation intensity in every direction for one sample represents an anisotropic rock property and shows with $A_{\alpha}$ $77.81 \%\left(\mathrm{~A}_{\alpha}=\alpha_{\max }-\alpha_{\min }\right) / \alpha_{\max } * 100$ [\%]) the highest anisotropy for the Blanco Macael, whereas the lowest anisotropy was measured for the Carrara Gioia with $A_{\alpha} 40.93 \%$ (Table 12).

Table 12 Thermal dilatation coefficient $\alpha\left[10^{-6} \mathrm{~K}^{-1}\right]$ under dry conditions. Displayed are the coefficients for the first cycle and the average values for the $2^{\text {nd }}$ to $4^{\text {th }}$ cycle under dry conditions for every direction, calculated from the increasing part of every $20^{\circ}-90^{\circ}-20^{\circ} \mathrm{C}$ cycle.

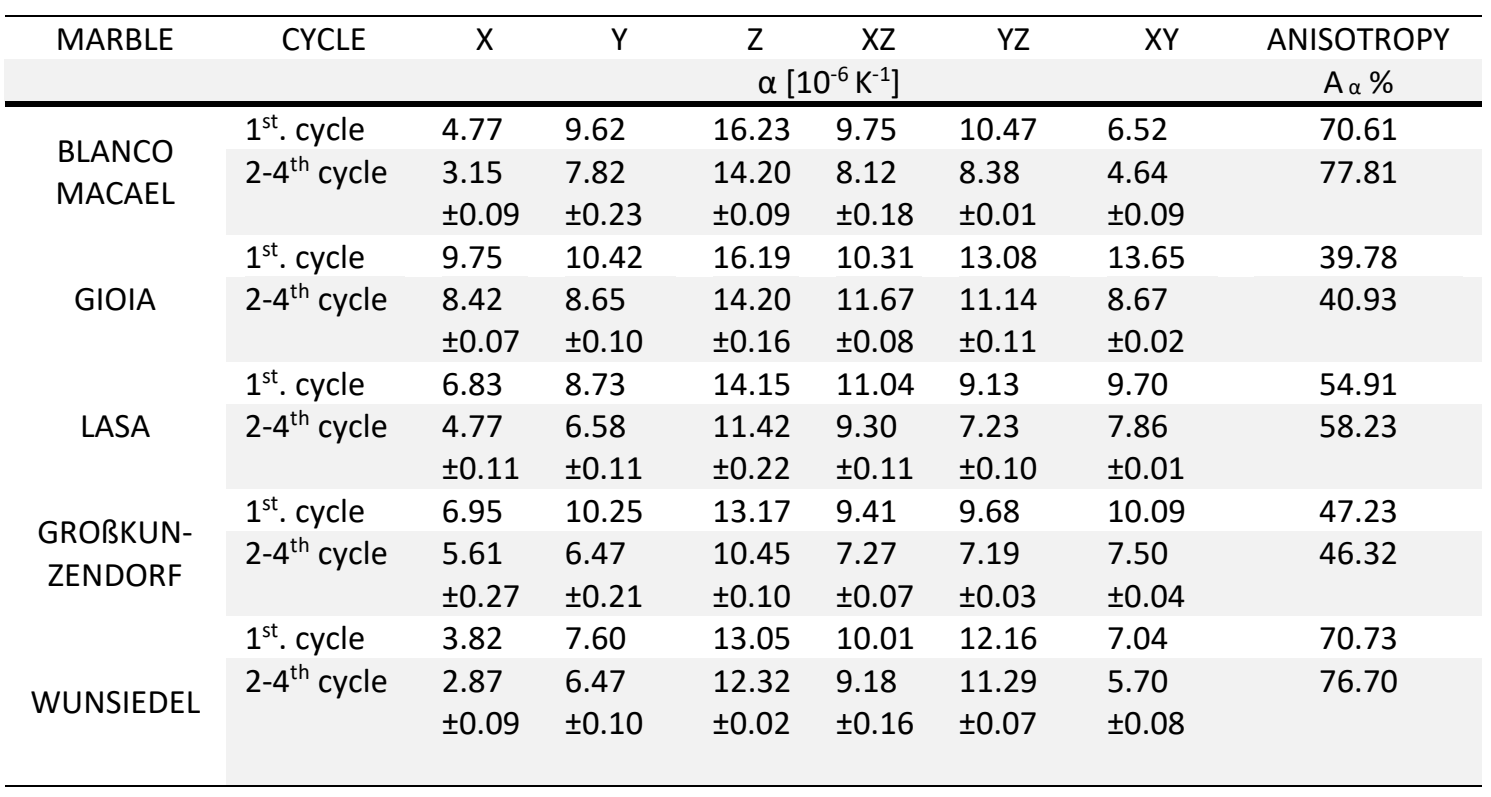

The directional dependence of the thermal dilatation is strongly influenced by the texture and the resulting amount of anisotropy can be correlated with the texture (see Figure 57). As stronger the intensity of the c-axis maximum, as higher the anisotropy. These findings agree with the results by Koch, 2006, who analysed an almost linear trend of the function anisotropy/texture. While there is a correlation between the amount of anisotropy and the texture, the amount of maximum expansion is independent from the texture intensity. 


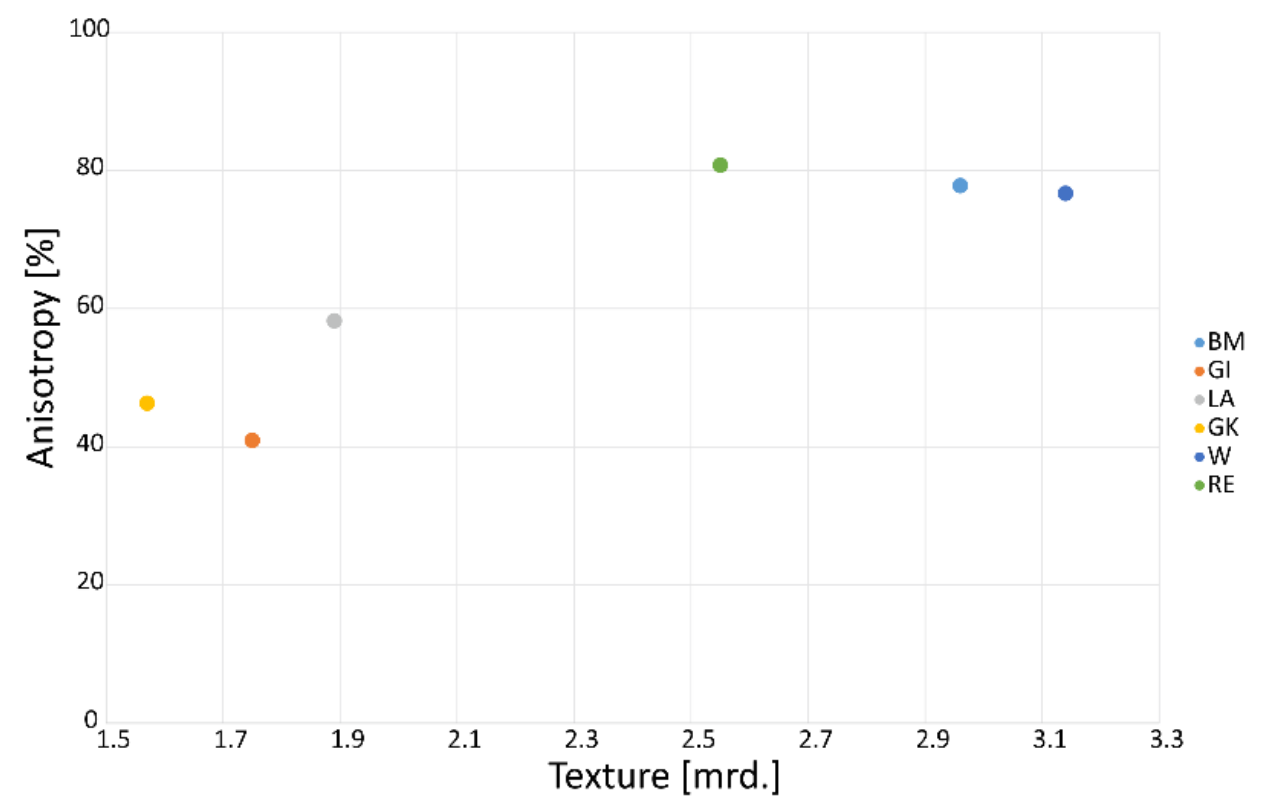

Figure 57 Correlation of the anisotropy for the thermal expansion and the texture.

A particularly weathering relevant aspect of the graphics in Figure 56 is the measure of the residual strain, the irreversible length change after the heating cycle. Here, all samples show a certain measure of the residual strain $(\varepsilon R S)$, whereby the Wunsiedel marble shows the lowest residual strain and the Großkunzendorf the highest. As described before, the first cycle leads to an irreversible length change, which hardly increases under dry conditions. Comparable data were obtained by Koch and Siegesmund, 2004, who also described that the same cycles under hygrothermal conditions can, however, reactivate and increase this irreversible expansion. Therefore, the samples were subsequently thermohygrically weathered for five further cycles. For this purpose, the samples were again cyclically heated from $20^{\circ} \mathrm{C}$ to $90^{\circ} \mathrm{C}$ and cooled down under implementation of water into the system at $20^{\circ} \mathrm{C}$. Figure 58 shows the results of the irreversible residual strain ( $\varepsilon R S)$ under thermal (red highlighted) and thermohygric (blue highlighted) load for all marbles in the 6 directions.

The graphs show that under dry conditions (highlighted in red) the greatest increase of $\varepsilon R S$ occurs in the first heating cycle and is then significantly lower or does not further increase. An exception is the Großkunzendorf, whose curve progression potentially indicates a further increase of $\varepsilon$ RS. In contrast, the Wunsiedel shows a very low degree of residual strain and also exclusively after the first heating cycle. Afterwards, no further 
increase can be observed. All varieties show an anisotropy of residual strain under dry conditions, which is most clearly developed for the Großkunzendorf and Blanco Macael.
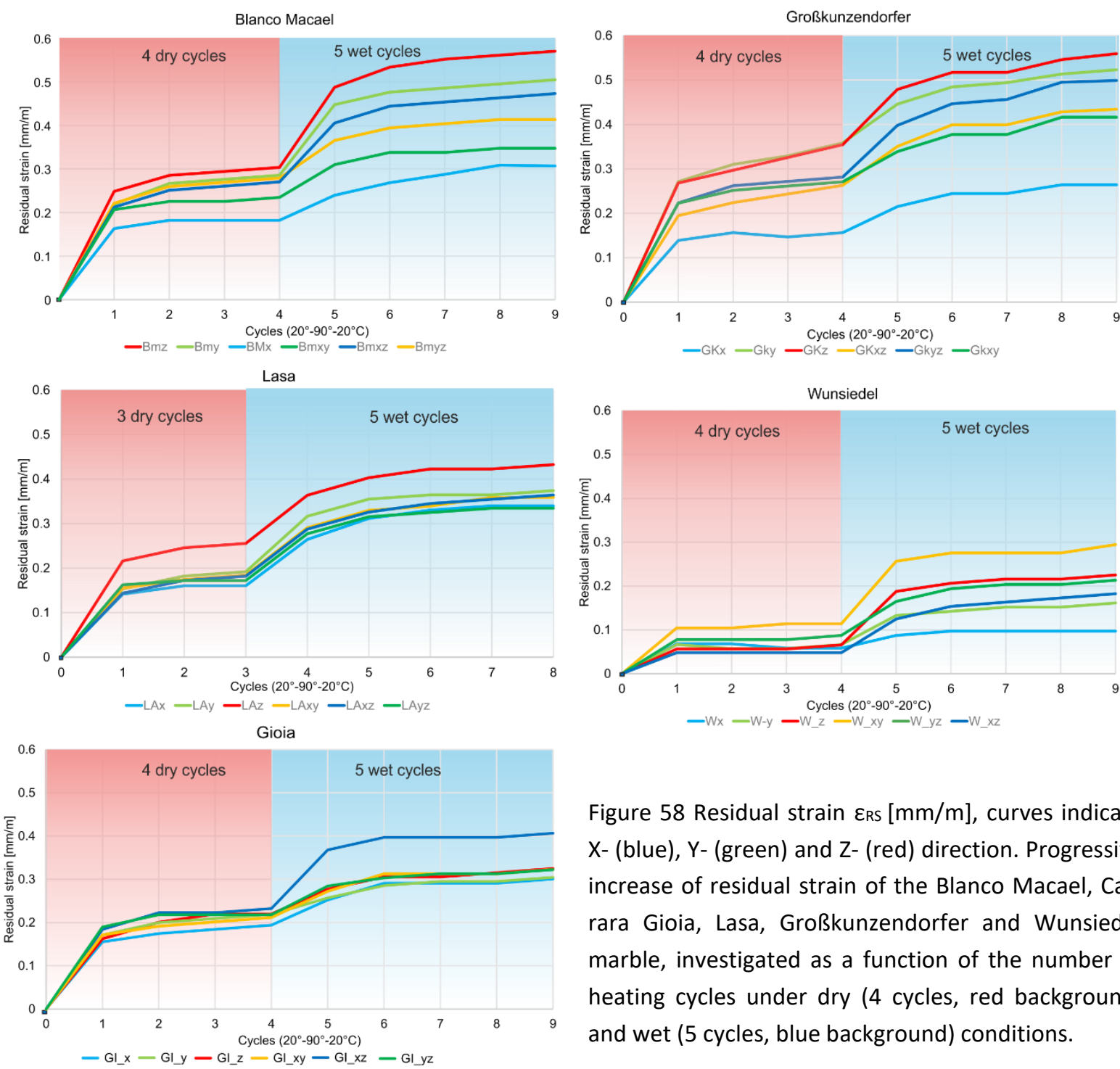

Figure 58 Residual strain $\varepsilon_{R S}[\mathrm{~mm} / \mathrm{m}]$, curves indicate $X$ - (blue), Y- (green) and Z- (red) direction. Progressive increase of residual strain of the Blanco Macael, Carrara Gioia, Lasa, Großkunzendorfer and Wunsiedel marble, investigated as a function of the number of heating cycles under dry (4 cycles, red background) and wet ( 5 cycles, blue background) conditions.

The thermohygric load (highlighted in blue) leads for all varieties to a further increase of the residual strain. It reaches a maximum value of $0.56 \mathrm{~mm} / \mathrm{m}$ for the Blanco Macael in the Z-direction and at $0.1 \mathrm{~mm} / \mathrm{m}$ in the X-direction of the Wunsiedel marble. The increase in residual strain also seems to have not yet been completed for the varieties Großkunzendorf, Blanco Macael and Lasa, therefore higher values of $\varepsilon$ RS can probably be reached. Apart from the varieties Gioia and Wunsiedel, all marbles show the highest residual strain in Z-direction and a more (Großkunzendorf, Blanco Macael) or less pronounced directional dependence (Gioia, Lasa). Since the residual strain is also influenced 
by other parameters, such as grain shape and grain boundaries, a simple correlation of the values with the results of the texture analysis is not possible.

According to the four types of thermal dilatation (Siegesmund and Dürrast, 2014) all tested samples belong to Type IV with an anisotropic $\alpha$ value and residual strain $\varepsilon_{\text {RS. }}$.

\subsubsection{Resistance of marble to thermal and thermohygric cycles}

The so called bowing test, analyses the resistance of marble to thermal and thermohygric cycles and is mainly controlled by the same parameters as the thermal and thermohygric expansion (see Chapter 5.3.3 Thermal dilatation). Therefore, the texture should have the same influence on the bowing direction as it was observed for the thermal expansion (Koch and Siegesmund, 2004). The marble varieties Blanco Macael, Carrara Gioia, Lasa and Großkunzendorf have been chosen for the bowing test, which was performed according to DIN EN 16306:2013-05. As the former marble block was not big enough, the Z-direction could not be investigated. Nevertheless, 3 samples of the $\mathrm{X}$ - and the $\mathrm{Y}$-direction of all samples have been cyclically heated up to $90^{\circ} \mathrm{C}$ and cooled down to ambient temperature about $20^{\circ} \mathrm{C}$ (see Chapter 3.4.6 Resistance of marble to thermal and moisture cycles).

In Figure 59, the results for all samples are depicted. The bowing intensity of the Blanco Macael ranges between $0.24-0.28 \mathrm{~mm} / \mathrm{m}$ in X-direction and $0.4-0.45 \mathrm{~mm} / \mathrm{m}$ in Y-direction, while the sample BMy3 shows lower intensities of $0.16 \mathrm{~mm} / \mathrm{m}$ than BMy1 and BMy2. Similar deviations in Y-direction can be observed for the Großkunzendorf and the Lasa. The Lasa marble reaches intensities between $0.34-0.38 \mathrm{~mm} / \mathrm{m}$ in Y-direction (Lay3 $-0.15 \mathrm{~mm} / \mathrm{m}$ ) and $0.26-0.31 \mathrm{~mm} / \mathrm{m}$ in X-direction. For the Carrara Gioia, the highest bowing intensity was achieved in Y-direction with $0.65-0.8 \mathrm{~mm} / \mathrm{m}$, which was generally the highest intensity. The X-direction shows values between $0.5-0.6 \mathrm{~mm} / \mathrm{m}$. 

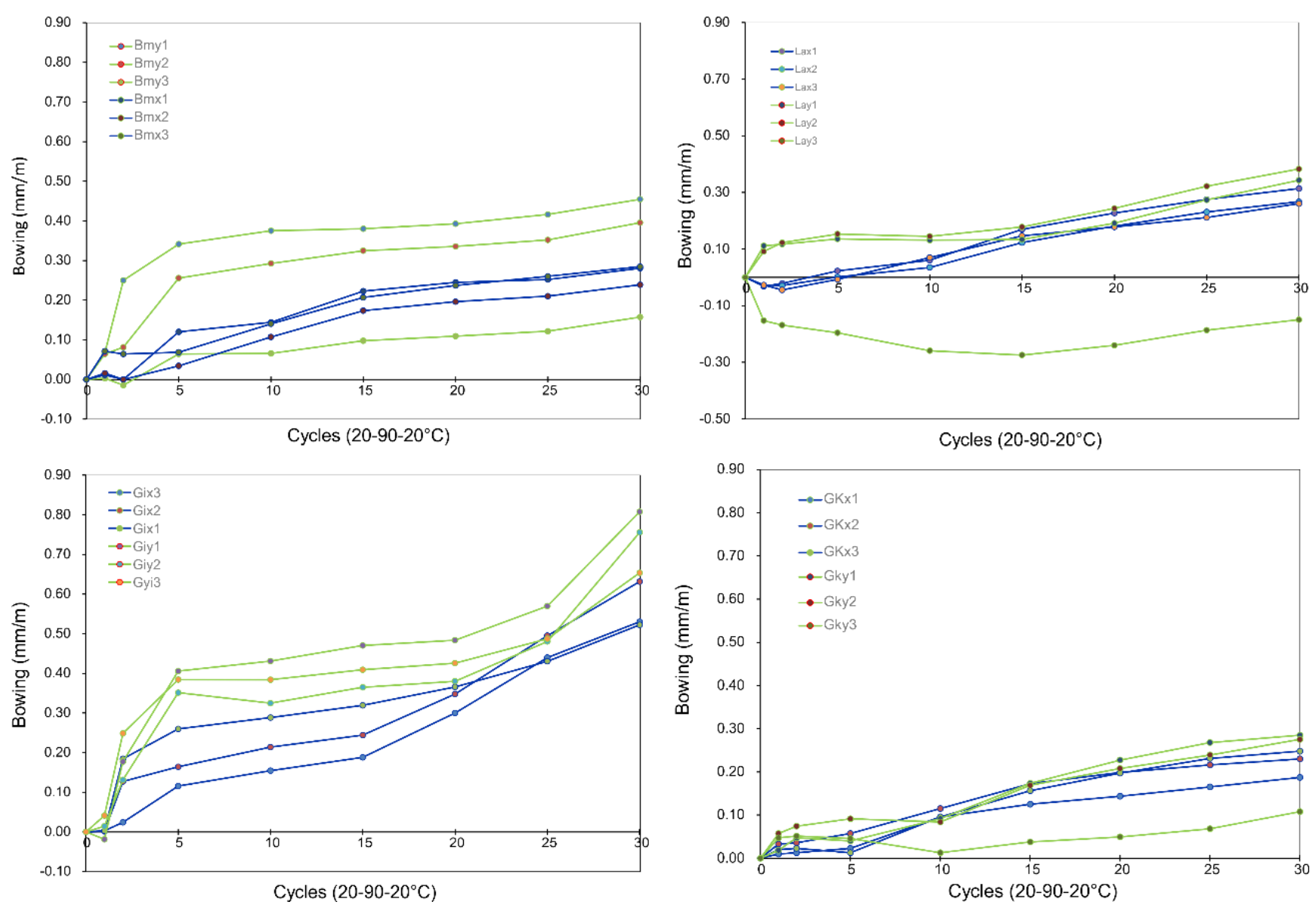

Figure 59 Increase of bowing $[\mathrm{mm} / \mathrm{m}]$ investigated as a function of the number of cycles for the Blanco Macael (BM), Lasa (LA), Gioia (GI) and Großkunzendorf (GK).

These data correlate well with the maximum values of residual strain for the thermohygric cycles, while the Carrara Gioia shows much higher values for the bowing test than for $\varepsilon_{\mathrm{RS}}$ and the Großkunzendorf achieved much higher values of about $0.5 \mathrm{~mm} / \mathrm{m} \varepsilon_{\mathrm{RS}}$ in Y-direction than for the bowing test. The reasons for the discrepancy of the Carrara Gioia cannot be clarified, especially as former studies have also shown that the Carrara marble achieves high expansion values (Koch and Siegesmund, 2004; Rüdrich et al., 2002). 


\section{On site case studies of ultrasonic measurements}

\section{The marble Obelisk at the Neuen Garten, Potsdam}

Close to the Marmorpalais in Potsdam (Germany) is an obelisk located made from Prieborn marble. After more than 200 years of exterior exposure this object was investigated with ultrasonic tomography along four different levels. Besides these measurements, a detailed decay mapping based on the macroscopically visible structures was performed as well. The results were compared to investigations carried out at a replaced, already weathered piece of Prieborn marble that was formerly used for another historic building in Potsdam and provided by the Stiftung preußische Schlösser and Gärten (SPSG). The analyses undertaken for this reference material included rock fabric analyses and ultrasonic measurements on a sphere under wet and dry conditions. Performed under laboratory conditions, this data was used to constrain the observed velocity values in terms of damage features on the obelisk. Laboratory velocity data and their anisotropies are the basic input data for the modelling of synthetic tomograms, and therefore an excellent database for quantifying the field measurements.

\subsection{The Obelisk, historic background and description}

The investigated freestanding obelisk (Figure 60) is located in the Neuer Garten in Potsdam (Germany), close to the lake Heiliger See and besides the southern wing of the Marmorpalais. It was built between 1793 and 1794, according to the plans of Carl Gotthard Langhans, who also designed the Marmorpalais between 1787 and 1792, in cooperation with Carl von Gonthard. The obelisk consists of three different marble varieties: Großkunzendorf from Poland, Carrara (Italy) and Prieborn (Poland), varieties that have also been used for the Marmorpalais (Ruedrich et al., 2001). 


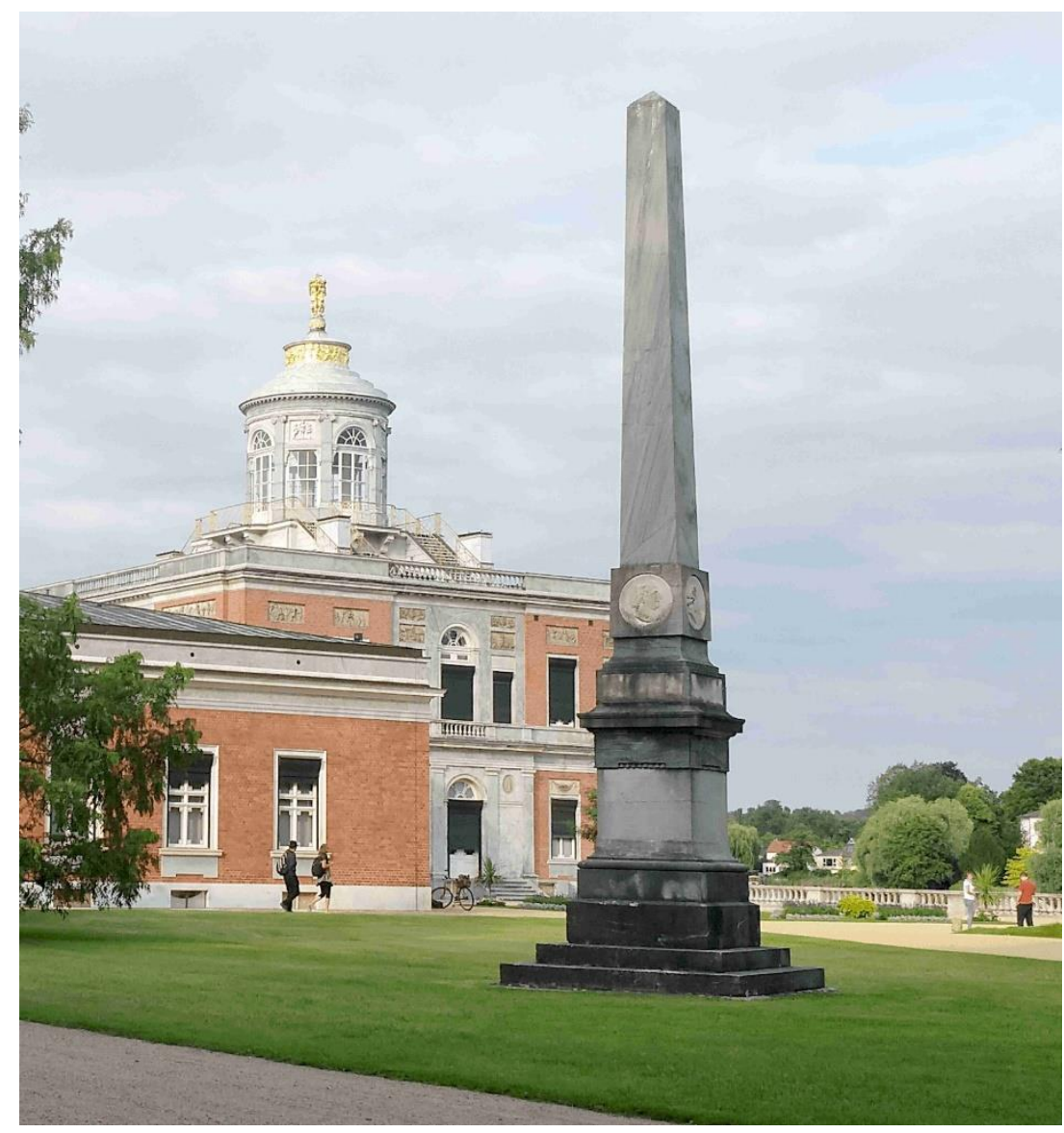

Figure 60 Obelisk in front of the Marmorpalais, Potsdam.

The obelisk has a total height of $9.1 \mathrm{~m}$, and consists of a pedestal, made of Großkunzendorf marble, followed by a part of Prieborn marble with a dentil ornament. Above that area, the contoured plinth is composed of Großkunzendorf, with a Prieborn plinth on top containing four slabs made of a white, probably Carrara marble. Four bas-relief medallions, showing male heads of different ages, representing the four seasons, are integrated into Prieborn marble and probably also made of Carrara marble. The monolithic upper part consists of Prieborn marble as well and has been closely examined in this study. It has a square ground plan and narrows from the bottom up with a width of $66.5 \mathrm{~cm}$ above the medallion to a width of $45.5 \mathrm{~cm}$ on top and a height of $5.2 \mathrm{~m}$. Thus, the faces of the profiled plinth are within 1.2 degrees off the vertical, which is significant when considering weathering from sun exposure. The spire on top is $21 \mathrm{~cm}$ high and made of a separate piece of Prieborn marble (Figure 61). 


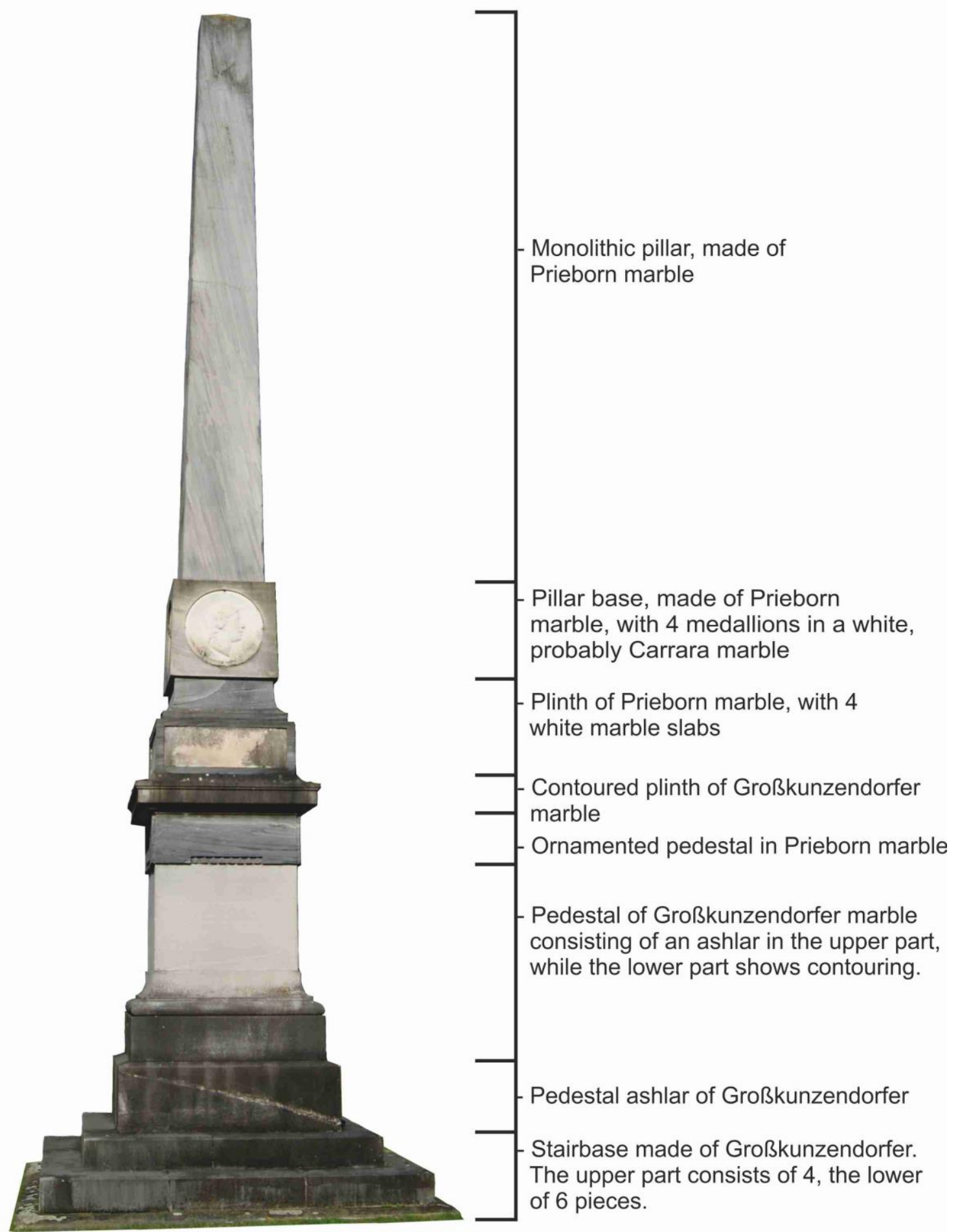

Figure 61 Detailed overview of the obelisk and the used marble varieties. The monolithic pillar was studied in detail. 
The surface of the monolithic upper part shows several decay phenomena like macroscopic visible open cracks (Figure 62a) and a strong relief (Figure 62b). This relief is caused by back weathered softer areas of the marble and can be observed all over the surface. Consequently, mineralised fractures are also more evident. These white lines, sealed cracks consisting of calcite, are distributed on the entire marble, crossing the rock fabric. They are mostly fine-grained (Figure 62c), whereas several are coarse-grained, with macroscopic visible crystals (Figure 62d). Due to their thickness and hardness they are more or less obvious and, in some areas, connected to an offset of the foliation. Besides the structural phenomena, indications for repairs could be found as three intersections (Figure 62e). Microbiological growth like lichens occurs especially at the top of the obelisk, as shown in Figure $62 \mathrm{f}$ and decreases toward the bottom.
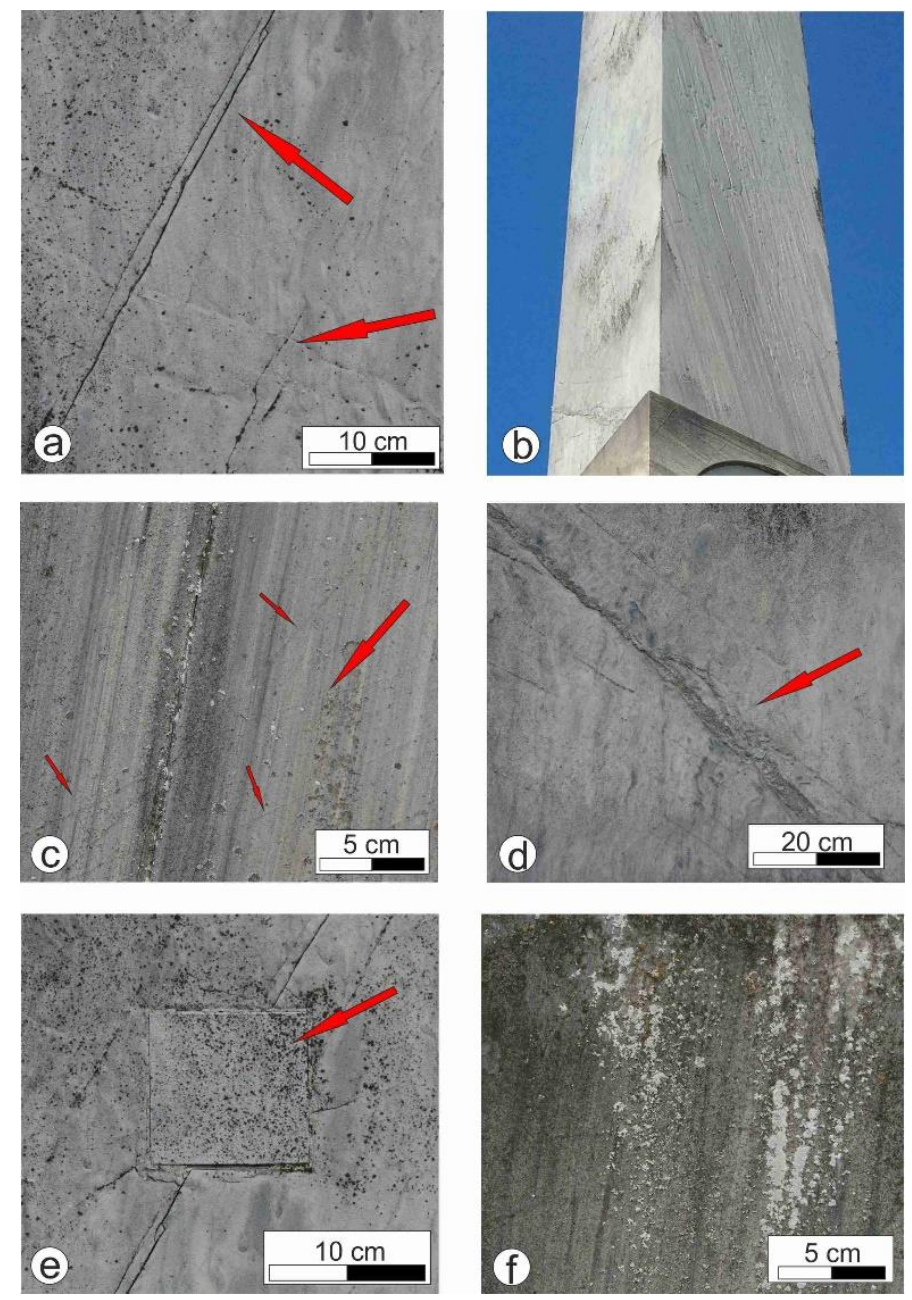

Figure 62 Phenomena of decay and structural elements found at the obelisk. a) open cracks, b) backweathering, c) fine-grained sealed cracks, d) coarse-grained sealed cracks, e) intersection, f) microbiological growth. 


\subsection{Decay mapping}

To characterize the decay features and the rock fabric elements of the investigated marble in more detail, onsite mapping was performed, considering the decay and structural phenomena as shown in Figure 62 a-e. The mapping was executed at a scale of 1:1 on a transparent foil, fixed on the surface of the obelisk. All the main fabric elements have been drawn on the foil to obtain a detailed map. Furthermore, the spatial orientation of the main elements, e.g. the foliation, has been investigated with a compass. Figure $63 \mathrm{a}$ presents a detail of this mapping, besides the original segment at the same scale, showing sealed cracks (Figure $63 \mathrm{~b}$ ). The results of all four mapped surfaces have been digitized to display the spatial distribution of all decay features and fabric elements and are illustrated in Figure 64 with respect to the geographic coordinates of the obelisk.

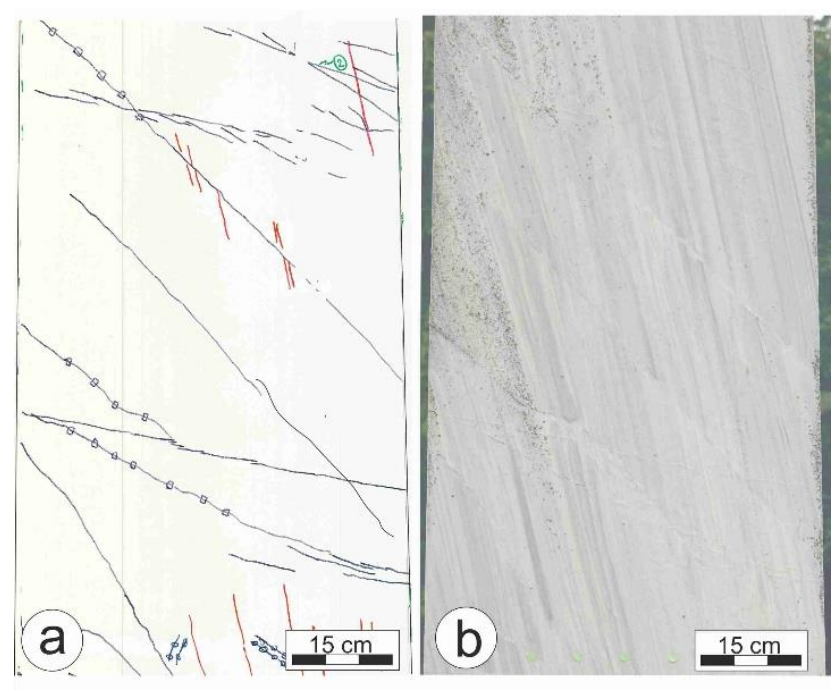

Figure 63 a) Detail of the mapping, performed on a scale of $1: 1$, b) original surface of the same area as the mapping detail, clearly visible are the fine-grained sealed cracks, mapped in a).

The appearance of the greyish marble is mainly controlled by the foliation, an alternating dark and light grey banding on the east and west side of the obelisk. As illustrated in Figure $64 \mathrm{~b}$, the foliation (sf) strikes E-W and plunges to the north. The same orientation can be ascertained for the crack system (c1), which consists of partially opened fractures, coplanar to the foliation. These cracks can be recognized on the $\mathrm{E}$ - and $\mathrm{W}$-side of the obelisk, while there is no traceable connection on the $\mathrm{N}$ - and S-side. Crack system 2 (c2) strikes N-S and plunges to the W. This system consists of prior open fractures, alter- 
nating occasionally with sealed areas and cuts the east and west side of the obelisk horizontally. These cracks have a similar orientation as (m1), a system of sealed cracks, whose course is traceable across the entire obelisk. The third crack system ( $\mathrm{m} 2$ ) consists of sealed cracks, whose spatial orientation changes from top to bottom. It crosscuts the foliation between $30^{\circ}-70^{\circ}$, dipping $\mathrm{N}-\mathrm{E}$, following the-fracture in the lower part.

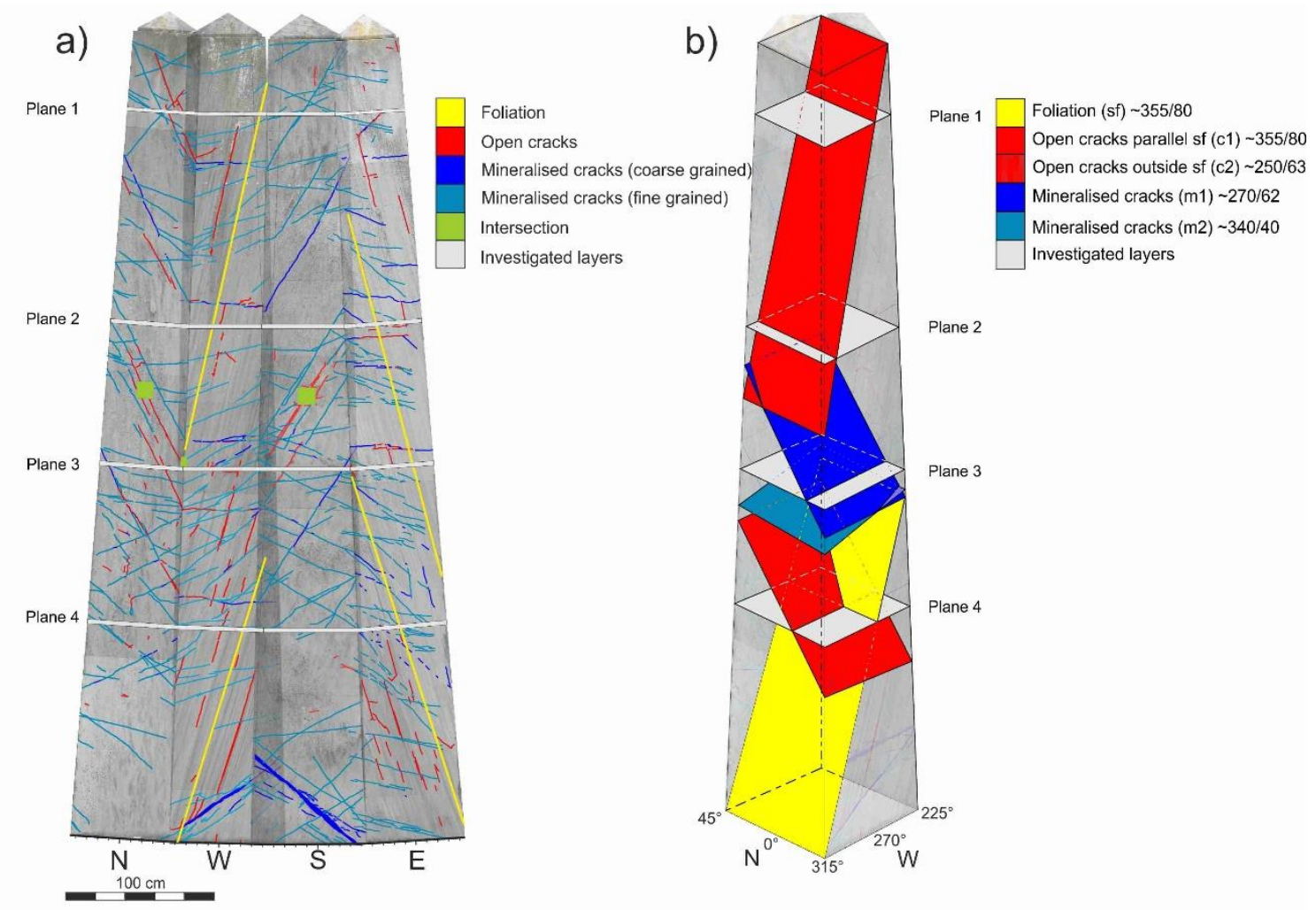

Figure 64 a) Digitized mapping of the obelisk as shown in a flat pattern with respect to the geographic position of the obelisk, b) schematic sketch illustrating exemplaric the orientation for the main structural elements.

\subsection{Rock composition and fabric}

A piece of substituted, weathered Prieborn marble provided by the SPSG was investigated, to acquire additional information about the material. These results were used to cross-check the ultrasonic measurements onsite and the tests under laboratory conditions, to obtain a reliable interpretation.

The microstructure, determined for the reference material, has been investigated by utilizing the uniform coordinate system $(X, Y, Z)$ (Figure 65 a). This was possible as the 
spatial position of the foliation was known. The system was used for all samples and enables the transference of the observations to the obelisk.
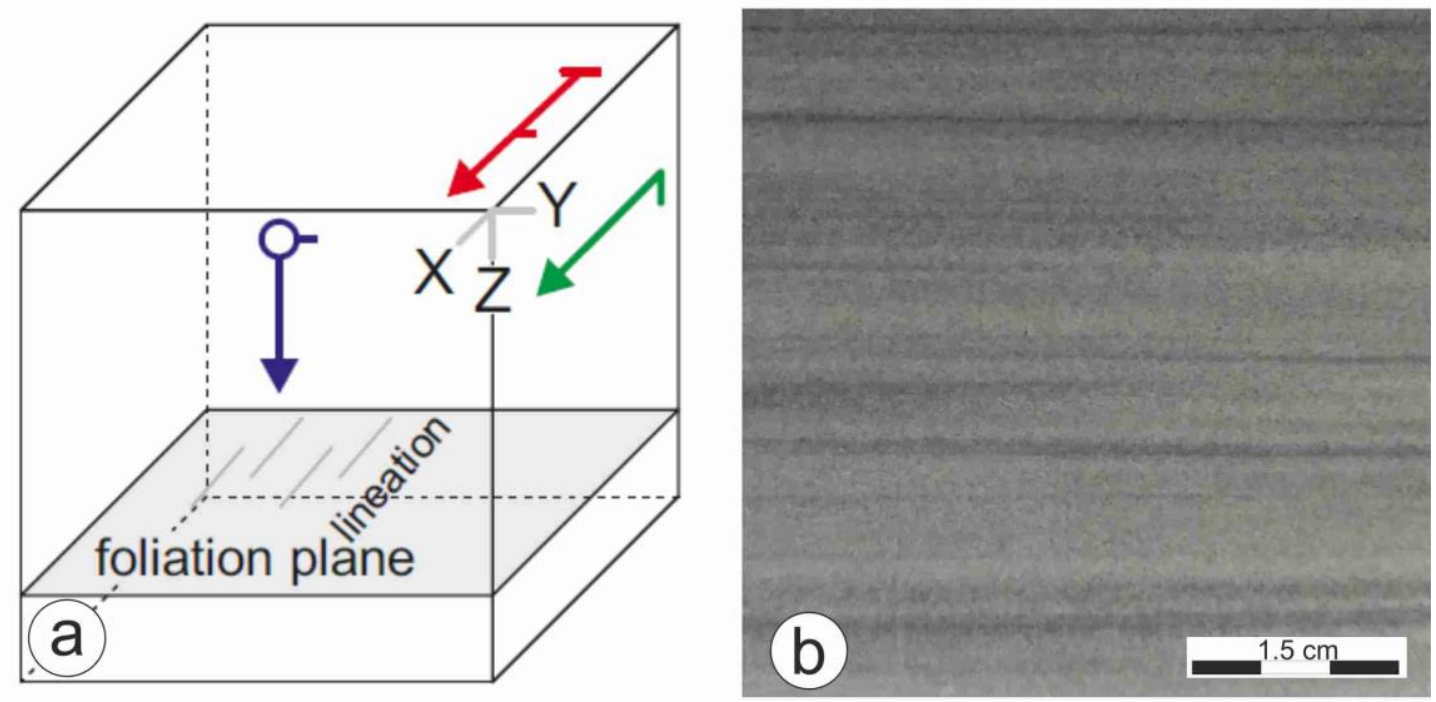

Figure 65 a) Uniform reference coordinate system, used for all investigations, b) macroscopic picture of the Prieborn marble in the XZ-plane.

Prieborn marble is a calcitic Silesian marble, which is part of a metamorphic complex of the western Sudetes. The deposit is in the southeast of Strzelin and about $1 \mathrm{~km}$ east of Przeworno (Prieborn) in Poland, where mining of this marble variety occurred only sporadically in historic times (Ruedrich, 2003). Macroscopically, the marble has a greyish appearance, which is dominated by alternating narrow layers of dark- and light-grey colour (foliation), as can be observed in Figure $65 \mathrm{~b}$.

Microscopic analyses reveal that the reference material is a fine-grained marble, with a general grain size of about $150-300 \mu \mathrm{m}$. The thin sections, analysed for three orthogonal planes, exhibit in some areas an almost granoblastic fabric, with an equi- to inequigranular grain size distribution and mostly straight or slightly irregular grain boundaries (Figure 66). A grain shape preferred orientation of weakly elongated grains can be observed in the $\mathrm{XY}$ - and $\mathrm{YZ}$-section, while it is more distinct for the $\mathrm{XY}$-section, parallel to the foliation (Figure 66). The XZ-plane shows a weak elongation, slightly oblique, parallel to the foliation, with a less dominant elongation perpendicular to the foliation. Twinning in calcite occurs in all sections, with no signs of deformation, while the XZ- and 
$\mathrm{XY}$-sections reveal a preferred orientation of the twin lamellae, also parallel to the foliation. The grain to grain contacts are in some areas decorated with dark particles, probably graphite.

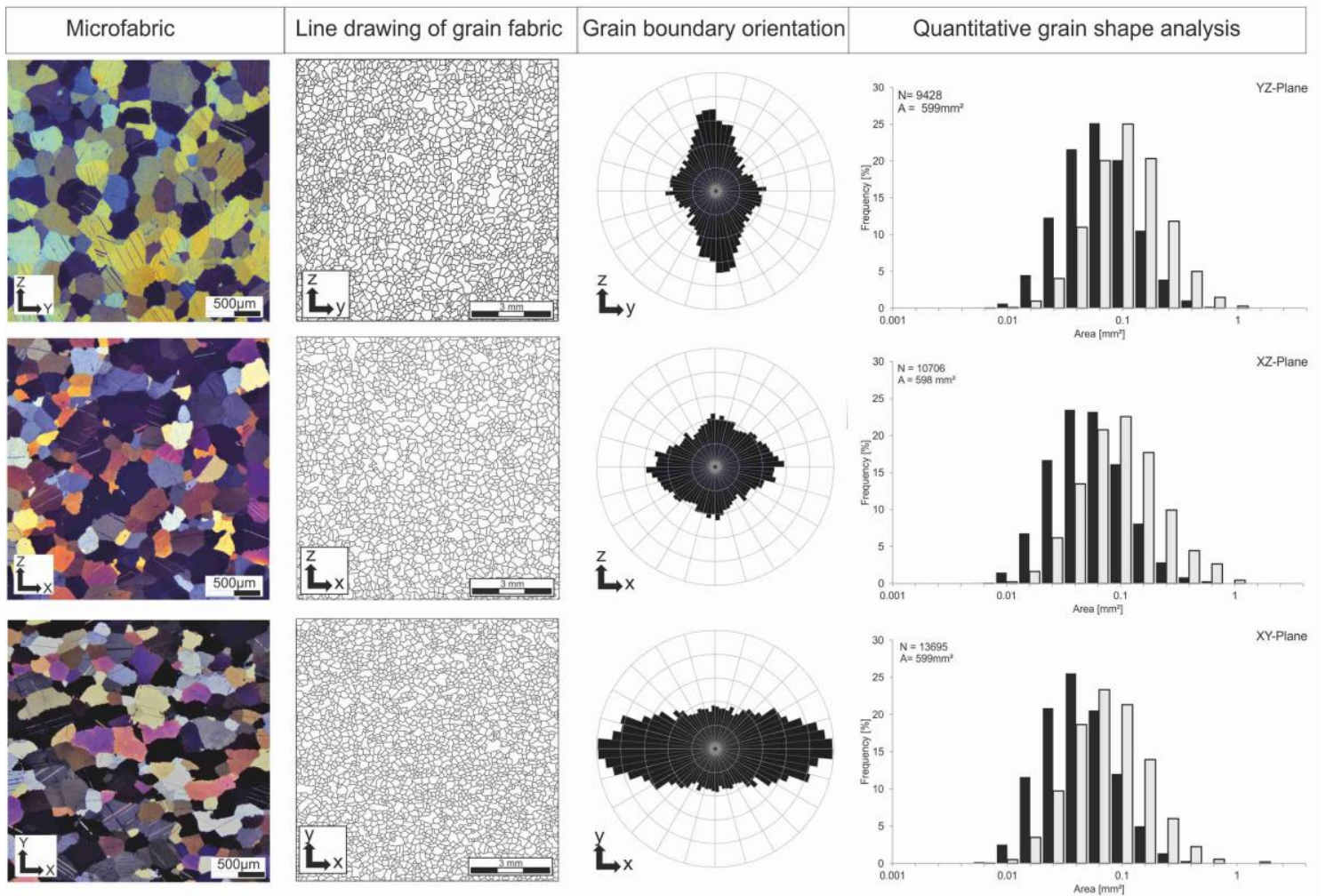

Figure 66 From the left to the right: Microscopic image (cross polars), characteristic line drawing of the grain fabric, grain boundary orientation and quantitative grain shape analysis (grey bars; $A=$ total Area, black bars; $\mathrm{N}=$ total number) for the three orthogonal directions.

Quantitative fabric analyses, performed for all 3 sections, show grain sizes ranging between 78 - $1077 \mu \mathrm{m}$ for the ZY-plane, 73 - $1114 \mu \mathrm{m}$ for the XZ- and $74-1220 \mu \mathrm{m}$ for the YZ-plane, with an average grain diameter of $242 \mu \mathrm{m}$. A gradation of the grain sizes can be observed, revealing a decreasing amount in the small grain diameter class.-Cathodoluminescence analyses by (Ruedrich, 2003), revealed a strong alteration along the rims of the grains for weathered, as well as for fresh samples of Prieborn marble. This is a sign for pre-exploitation alteration of the crystals due to fluid interaction at the deposit. 
The lattice preferred orientation (LPO) was measured by means of X-Ray goniometer (see Chapter 3.3.3 X-Ray Goniometer, EBSD measurements) For the quantitative acquisition of a preferred orientation of the calcite crystals, the c-axis (006), a-axis $\langle 110\rangle$, cleavage plane $r\{104\}$ and twin plane $f\{012\}$ have been analysed (Figure 38).

The analysed LPO, displayed as a lower hemisphere projection, can be described as a caxis fibre type (cf. Leiss and Ullemeyer, 1999) with a distinct, elongated c-axes maximum of $3.3 \mathrm{mrd}$ perpendicular to the foliation plane. The a-axes show a great circle distribution subparallel to the foliation plane and a high intensity of $2.2 \mathrm{mrd}$ (see Figure 38).

\subsection{Ultrasound velocities and tomography}

To determine the present conditions for the obelisk, ultrasonic measurements have been carried out. This method has been used for several years and is, due to its nondestructive application, preferred and established for monitoring measurements, especially for cultural heritage (Snethlage, 2014).

The application of ultrasonic tomography allows the determination of the velocity in the cross-sectional plane. With an optimal coverage this method allows the detection of weakness zones. The ultrasonic tomography was applied at the obelisk, as displayed in Figure 67. The transmitter was positioned at a defined point of measurement, whereas the receiver was placed at defined points on the obelisk (Figure 67a). After completion of a measuring array, the transmitter position was changed to the following defined point and the receiver was positioned at each circumferential point and so on, until the whole section was measured (Figure 67b). The field measurements have been carried out by manual coupling using plasticine as coupling agent for a $46 \mathrm{kHz} \mathrm{P}$-wave transmitter. Even if it would have been desirable to work with higher frequencies, first measurements performed with $250 \mathrm{kHz}$ have shown that they do not penetrate the obelisk. Measurements have been performed for four horizontal cross sections at a height of 0.5 $\mathrm{m}, 2.0 \mathrm{~m}, 3.0 \mathrm{~m}$ and $4.0 \mathrm{~m}$ from top to bottom (see investigated layers Figure $64 \mathrm{~b}$ ). Depending on the amount of transmitter/receiver positions that have been chosen for the sections, the number of ray paths vary between 132 (section 2), 240 (section 3 and 4) and 760 (section 1). 


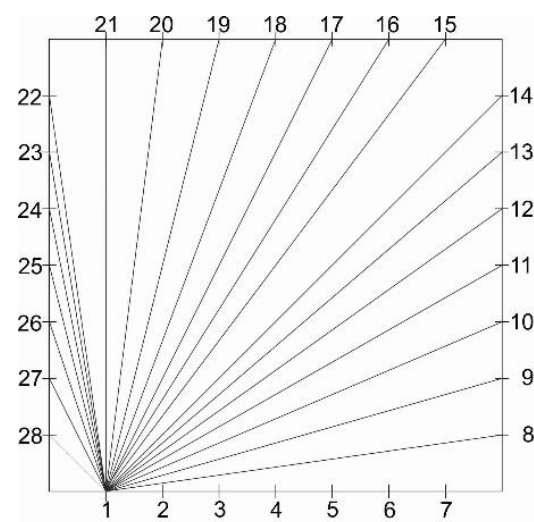

a)

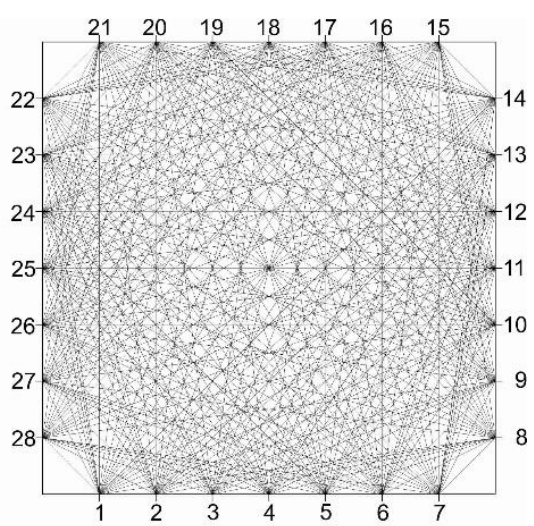

b)

Figure 67 Transmitter and receiver positions for the ultrasound tomography, applied at the obelisk. a) Defined transmitter position and changing receiver positions between point $2-28, b$ ) complete grid for all transmitter and receiver positions, measured for plane 1.

\subsection{Vp versus travel path}

To understand of how the velocity of the rays $(\mathrm{Vp})$ relates to the travel path $(\mathrm{cm})$, it is necessary to plot them against each other. Since Plane 1 on the obelisk contains the most data points, it will be considered here as an example. The resulting diagram is shown in Figure 68. Two prominent features become obvious. First, the mean variation is significantly lower with longer travel paths. While the velocities for the shorter travel paths $(5-15 \mathrm{~cm})$ vary greatly between just over 1.5 and around $5 \mathrm{~km} / \mathrm{s}$, the spreading drops quickly to values around $3 \mathrm{~km} / \mathrm{s}$ at $55 \mathrm{~cm}$ and above. This shows that the standard deviation of $\mathrm{Vp}$ correlates strongly with the length of the path the ray has travelled. Second, the velocity trends differ depending on where the transmitter is positioned. The velocities increase with travel path when the transmitter is located on the western or eastern side. For transmitter positions on the northern or southern side the velocities barely change with travel path, decreasing slightly. Figure 68 shows that the longest rays are the ones, where transmitter and receiver are located on opposing sides (east and west or north and south). Increasing velocities with longer travel paths generally indicate faster ray velocities striking EW. 


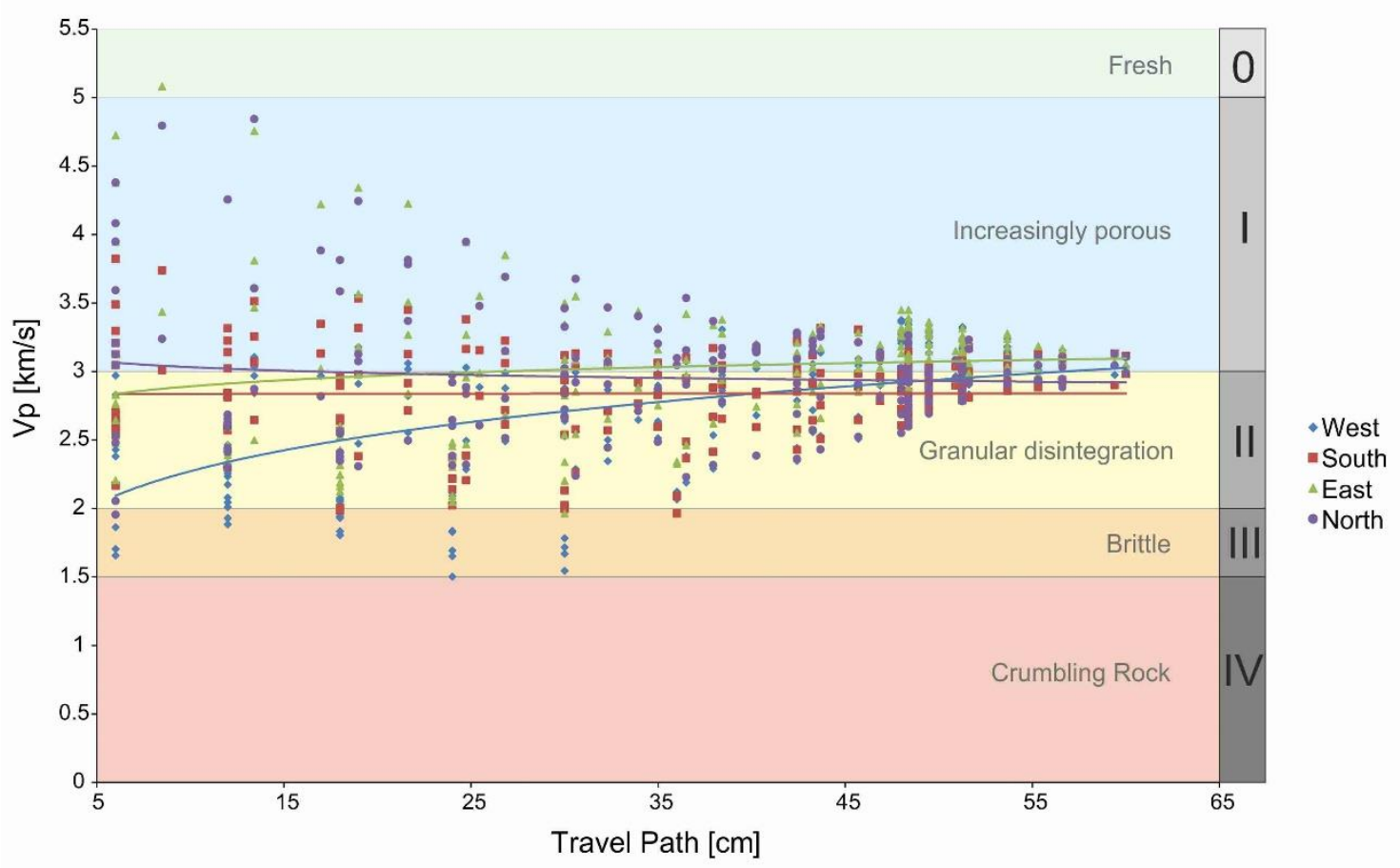

Figure 68 Ray velocity plotted against travel path in combination with the classification of decay after Köhler (2014). The various colours and shapes of the data points depict the transmitter positions on the sides of the obelisk.

Velocities at a distance of $48 \mathrm{~cm}$ are those travel paths that are on the direct opposite side (north-south and east to west). The velocities cover a span of $2.5-3.5 \mathrm{~km} / \mathrm{s}$, while the north-south direction shows lower velocities than the east-west direction. Longer travel paths indicate oblique north-south or east-west directions, where the velocities decrease (east-west) or increase (north to south), before the span of velocities becomes almost equal with $2.8-3.2 \mathrm{~km} / \mathrm{s}$, independent of the direction. Adjacent directions (east-south, east-north, etc.) generally show a homogeneous velocity distribution, independent of the length of travel path.

The lowest velocities are on the western surface, ranging between 1.5 and $2.59 \mathrm{~km} / \mathrm{s}$. The eastern surface shows velocities between 1.96 and $2.68 \mathrm{~km} / \mathrm{s}$, which is slightly higher, but comparable to the western surface. In contrast, the southern plane shows similar low velocities $(1.97 \mathrm{~km} / \mathrm{s})$, but much higher maximum values $(3.31 \mathrm{~km} / \mathrm{s})$. The same pattern can be observed for the northern surface, showing a maximum velocity of $4.26 \mathrm{~km} / \mathrm{s}$. If we take a closer look at the direct velocities, measured in only one direction (north-south and west-east) we can see that in contrast to the high surface velocities, 
the velocities in the north-south direction are lower than in the east-west direction. Velocities between $3.1-3.5 \mathrm{~km} / \mathrm{s}$ indicate for the east-west direction a decay classification of increasingly porous, while the north-south direction ranges between $2.5-3.0 \mathrm{~km} / \mathrm{s}$, indicating granular disintegration. Comparing those values to the surface velocities show that the velocities within the marble are controlled by different factors than those at the surface. These velocity variations combine different effects, since the ranging velocities are caused by weathering, but also include intrinsic effects of anisotropy. Shorter distances have to be analysed critically, due to uncertainties caused by frequency and raypath (Lindner et al., 1999; Siegesmund and Dürrast, 2014).

\subsection{Tomograms}

The travel time of each ray only represents the mean velocity over the distance it covered. For a spatial distribution of the analysed velocities inside the rock, i.e. zones of high or low velocities, a grid of intersecting ray paths is needed. The software GeoTomCG was used to perform a 2D tomographic analysis of the source-to-receiver travel times and to calculate velocities at predefined points inside the grid (GeoTomLLC).

One common disadvantage of tomographic imaging is the problem of mathematical non-uniqueness (Jackson and Tweeton, 1994). More than one solution may fit the data equally well. As a result, an inversion may yield unreliable results. To counter this problem, additional information can be implemented as constraints for the inversion, such as minimum and maximum velocities known from the properties of the rock. The velocities for the inversions in this study were constrained to a minimum of $2.0 \mathrm{~km} / \mathrm{s}$ and a maximum of $4.5 \mathrm{~km} / \mathrm{s}$.

The resulting tomograms are shown in Figure 69. The outermost parts of the tomograms are disregarded because they had only been passed by a few rays, thus rendering the resulting data unreliable. 

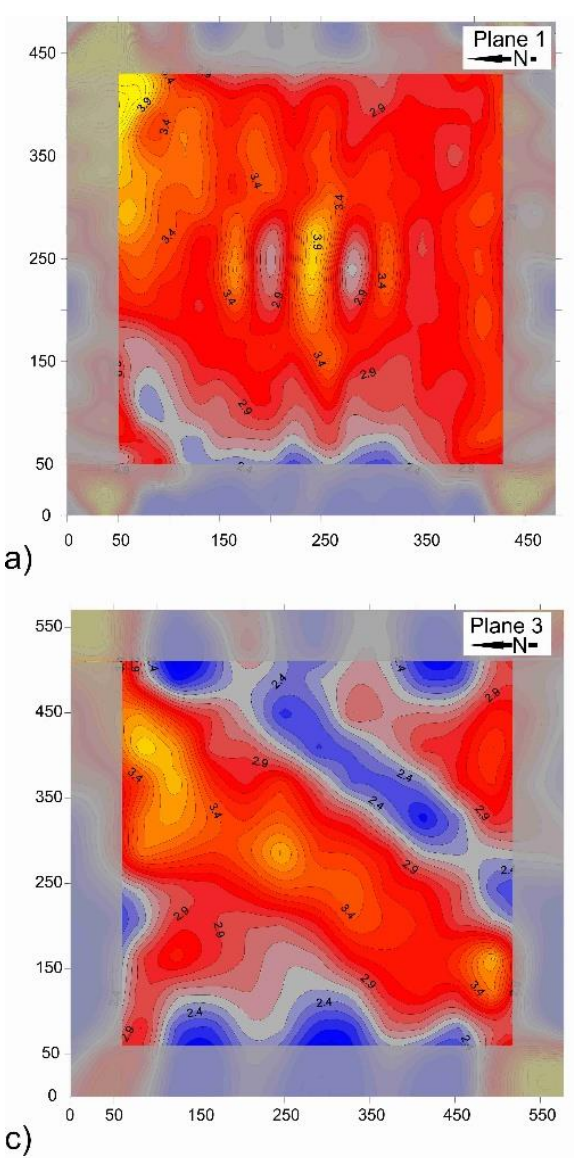

b)
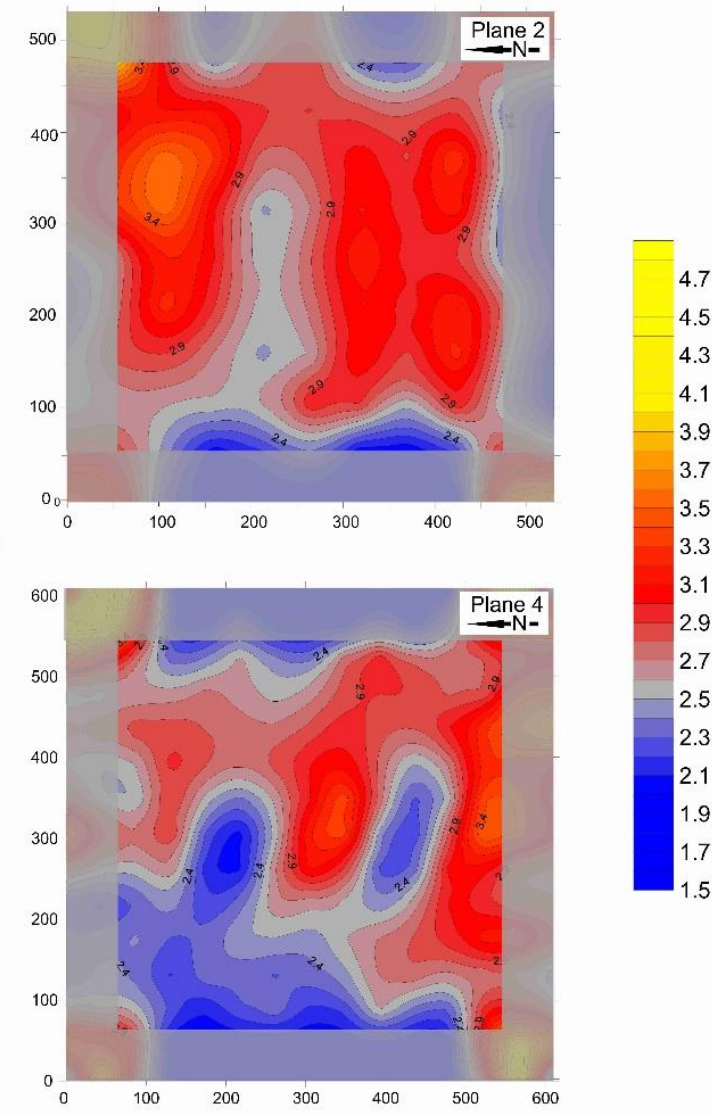

d)

Figure 69 Ultrasonic tomograms of the four investigated layers without anisotropy. Numbers 1-4 correspond to the planes in Fig. 8b. Grey overlays show the parts of low data coverage that have been omitted. The velocities are given in $\mathrm{km} / \mathrm{s}$. The north direction is indicated.

The remaining sections of the tomograms show some similarities. Planes 1,2 , and 4 contain W-E striking zones of high velocity. For plane 1 (Figure 69 a) these zones contain velocities between $3 \mathrm{~km} / \mathrm{s}$ and $4 \mathrm{~km} / \mathrm{s}$. Plane 3 shows a corridor of higher velocities in the SW-NE-direction. Due to the higher number of data points, the tomogram for plane 1 provides a higher resolution, which allows a more detailed analysis of its features. Inside the velocity maximum there is a pronounced, column-shaped area of higher velocities in the centre of the plane. A distinct maximum in the north-eastern corner could be observed for all 4 planes, while its occurrence can only be assured for plane 1 (Figure 69 ), where a sufficient ray coverage is present. The velocities in plane 2 (Figure $69 \mathrm{~b}$ ) range from about 2.5 to $3.5 \mathrm{~km} / \mathrm{s}$ with higher velocities forming a C-shaped channel around an elongated minimum near the centre. The opening of the $C$, i.e. the area of lower velocities, is located towards the western direction. The channel itself consists of 
a distinct maximum in the north-eastern corner and two patches of medium to high velocities on the southern edge. In plane 3 (Figure 69 c), the velocities fluctuate between lower than $3 \mathrm{~km} / \mathrm{s}$ and around $4 \mathrm{~km} / \mathrm{s}$. In this plane a corridor appears striking NE to SW, while none of the other planes shows a comparable phenomenon. The three maxima which can be observed in plane 2 are still present, whereas the south-western and north-eastern areas are joined together. The eastern and western surface shows lower velocities around $2 \mathrm{~km} / \mathrm{s}$. Plane 4 (Figure $69 \mathrm{~d}$ ) generally shows lower velocities than the other sections where the velocities barely exceed $3 \mathrm{~km} / \mathrm{s}$ except for a zone of about 3.5 $\mathrm{km} / \mathrm{s}$ in the southern part. Near the centre a slight maximum can be seen, which is surrounded by two strong minima. The lower velocities, which can be found along the western and eastern surface extend to the centre of the section. Generally, the velocities for all planes decrease from the top (Plane 1, Figure 69 a) to the bottom of the obelisk (Plane 4 Fig. Figure 69 d).

\subsection{Vp and onsite analysis}

After more than 200 years of outside exposure, it can be assumed, that the main influence on the rock fabric is caused by weathering. Therefore, the geographic exposure of the obelisk and main climate effects should be considered (see Brimblecombe, 2014). Climate data posted at the homepage of the Potsdam Institute for Climate Impact Research (www.pik-potsdam.de) reveals that the main wind direction is west, with an average wind force of $5 \mathrm{~m} / \mathrm{s}$. Eastern winds are nearly as frequent, but with lower force. Therefore, the impact of weathering should be more pronounced for the west and east facing surfaces. Decay caused by cyclical influences-of wind, wind driven rain and other changes of humid and dry conditions should be most pronounced on those sides of the obelisk. Another important factor is the change of temperature due to solar radiation. Stress induced by heating leads to fissuring and, eventually, fracturing and results in an increase in porosity (Malaga-Starzec et al., 2002). This stress can be induced by temperatures around $40-50^{\circ} \mathrm{C}$, which is easily reached by a stone surface on summer days. The resulting grain decohesion will be enhanced by the cooling cycles that occur in winter (Steiger et al., 2014). These cyclical changes of temperature will harm a marble, due to its thermal vulnerability. 


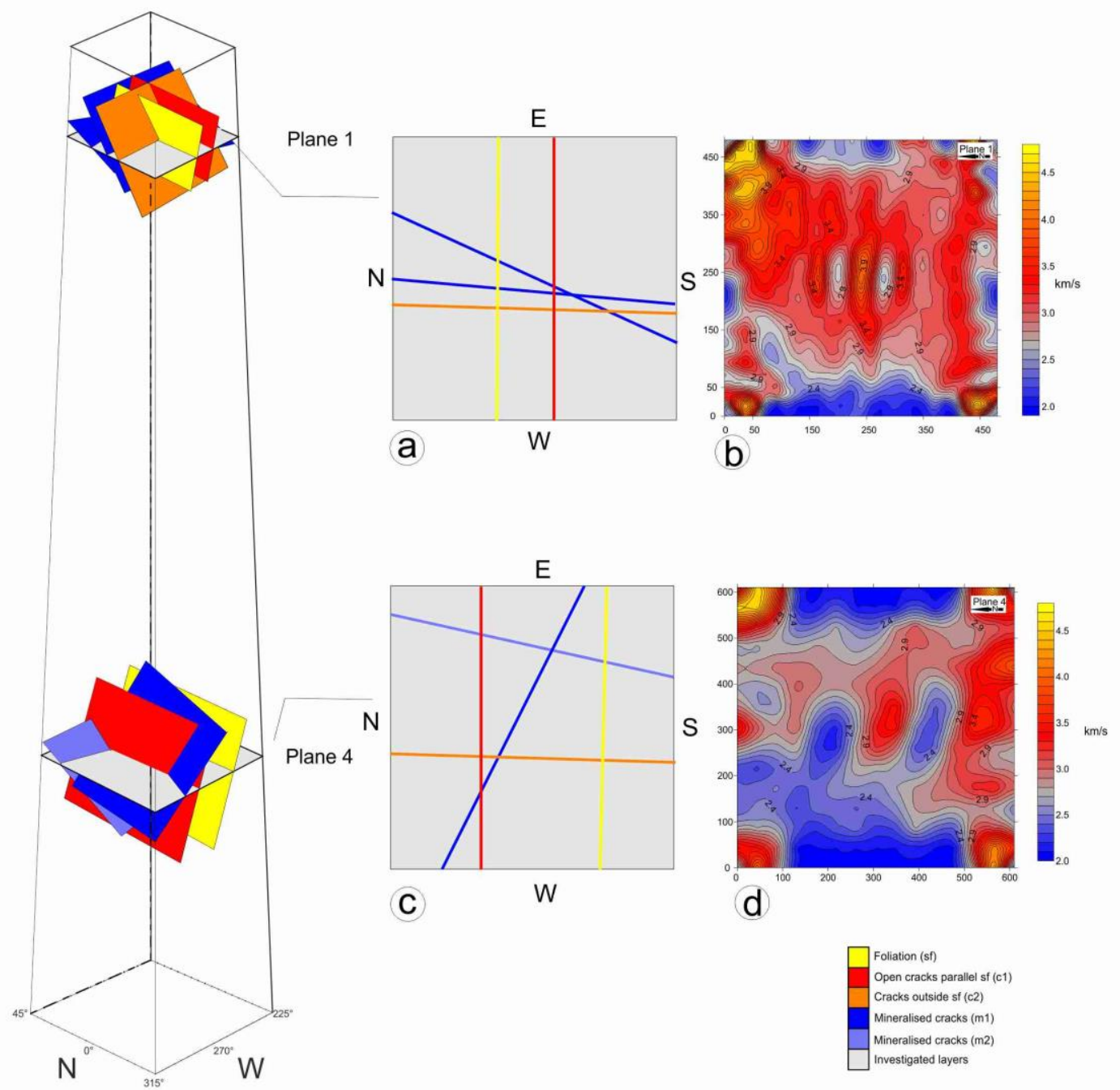

Figure 70 Crack systems and their spatial orientation mapped for plane 1 ( $a$ and $b$ ) and 4 (c and d) besides the traces of those systems on the respective plane ( $a$ and $c$ ) as well as the tomogramm for those planes ( $b$ and $d$ ). Foliation is just drawn as an example, its alternating occurance (about every 1-5 $\mathrm{mm}$ ) is parallel and east-west striking).

For all tomograms, the western facing areas show lower velocities. A directional dependence caused by solar radiation, which we might expect to be most pronounced in the southern direction, cannot be observed. However, the surfaces of the obelisk are nearly vertical, so the high angle of the sun, about $60^{\circ}$ at mid-day in Potsdam during the summer (www.sunearthtools.com/dp/tools/pos_sun.php), may reduce the heating of the south surface relative to the heating of the west surface at lower sun angles later in the day. Without the heating measurements, the location of the greatest damage from solar 
radiation is still uncertain where it can be expected on the obelisk. Besides the geographic position of the obelisk, the tomograms have been compared to the visible decay phenomena, which have been mapped. Figure 70 shows the tomograms for planes 1 and 4 , the observed decay phenomena that were mapped at those heights. No unambiguous correlation can be obtained when comparing this data.

\subsection{Discussion}

The investigated ultrasound velocities determined for the obelisk are generally low and decrease from top to bottom. Effects of weathering can be observed, but their local impact cannot be defined unambiguously. To improve the interpretation of the data, it is necessary to distinguish between effects caused by decay and by material specific velocity variations. Weathered rock samples have been investigated by laboratory velocity measurements to distinguish between intrinsic velocity variations, effects of decay and effect of moisture on the natural velocity variation.

\subsection{What affects Vp?: Controlled alteration under laboratory conditions}

On a cube $(65 \times 65 \times 65 \mathrm{~mm})$ of substituted and already weathered Prieborn marble, artificial alteration was performed to analyse the progressive deterioration of this marble. The sample was heated up to predefined temperatures and subsequently cooled down (see 3.6 Artificial Alteration). After each cycle, the sample was dried at $40^{\circ} \mathrm{C}$ until constant mass and the ultrasound velocities measured in the $\mathrm{X}-, \mathrm{Y}$ - and Z-direction. The resulting velocity development is illustrated in Figure 71 and shows, that the already low velocities could still be reduced. This reduction is clearly visible after heating up to $90^{\circ} \mathrm{C}$ and shows a progressive increase due to the following heating cycles. The amount of decrease in velocity is almost identical for all three directions. The highest velocities are seen in the X-direction, where they drop from around an initial $3.7 \mathrm{~km} / \mathrm{s}$ to $2.9 \mathrm{~km} / \mathrm{s}$ after a temperature exposure of $200^{\circ} \mathrm{C}$. The low velocities in the $\mathrm{Y}$ - and Z-direction are almost the same, dropping from 2.7 and $2.6 \mathrm{~km} / \mathrm{s}$ to 2.0 and $2.1 \mathrm{~km} / \mathrm{s}$, respectively. The 
large decrease in velocities was obtained without moisture impact while heating, which is known to increase the effect of heating (Siegesmund and Dürrast, 2014).

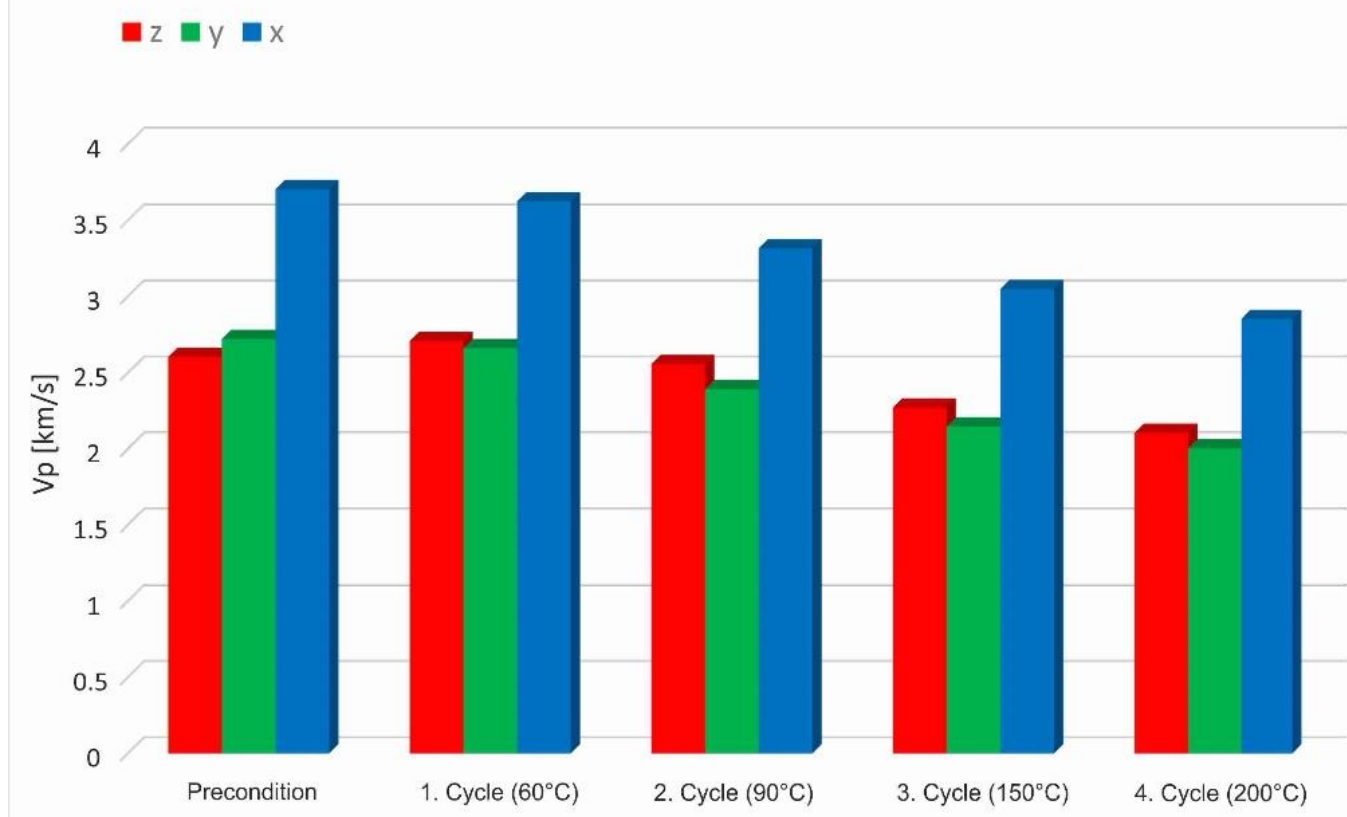

Figure 71 Reduction of $\mathrm{Vp}[\mathrm{km} / \mathrm{s}]$ in the $\mathrm{X}$ (blue), $\mathrm{Y}$ (green) and $\mathrm{Z}$ (red) -direction caused by cyclical heating up to $60^{\circ}, 90^{\circ}, 120^{\circ}, 150^{\circ}$ and $200^{\circ} \mathrm{C}$ and subsequent cooling down to $4^{\circ} \mathrm{C}$.

\subsection{Quantification of velocity reduction: Directional dependence of $\mathrm{Vp}$}

According to the systematic investigations (see Chapter 5.3.2 Ultrasonic measurements) the artificial weathering has shown that the velocities exhibit a directional dependence, which remain observable even with increasing decay. Earlier laboratory work on rock properties have shown that directional differences of velocities stem from the sum of intrinsic properties of the rocks, i.e. the texture of all the rock-forming minerals, crack populations or pores (Dürrast et al., 1999; Ruedrich and Siegesmund, 2001; Siegesmund, 1996; Siegesmund et al., 1999; Weiss et al., 1999; Weiss et al., 2001). With advancing decay of the rock, the impact of cracks and pores on ultrasonic velocities increases, depending on the type and saturation of pores. If the cracks and pores are filled with air, it will decrease the velocities, due to the lower compressional wave velocities 
in air $(\sim 0.3 \mathrm{~km} / \mathrm{s})$, while water $(\sim 1.5 \mathrm{~km} / \mathrm{s})$ will increase the velocities ( see Chapter Influence of humidity and water saturation).

As the results for the cube do not provide the complete spatial distribution of $\mathrm{Vp}, \mathrm{a}$ spherical sample of Prieborn marble with a diameter of $50 \pm 0.05 \mathrm{~mm}$ has been measured. The experimental equipment allows measurements in 192 directions with an ultrasound frequency of $1 \mathrm{MHz}$ for comparison the investigations have been performed on a dry and completely water-saturated sphere and are presented in a stereographic projection for the lower hemisphere.

Figure 72 a displays the spatial velocity distribution for the sphere under water-saturated conditions. The velocity distribution depends on the direction and varies between $6.51 \mathrm{~km} / \mathrm{s}$ in the X-direction and $5.82 \mathrm{~km} / \mathrm{s}$ in the Z-direction. The same sphere, with the same orientation has been measured under dry conditions, where it shows velocities of $2.64 \mathrm{~km} / \mathrm{s}$ in the Z-direction and up to $3.89 \mathrm{~km} / \mathrm{s}$ in the X-direction (Figure $72 \mathrm{~b}$ ). Accordingly, this is reflected in the amount of anisotropy $(A[\%]=((V p \max -\vee p \min ) / V p \max )$ *100), with $10.6 \%$ under water-saturated conditions and a much higher amount of $32.13 \%$ under dry conditions.
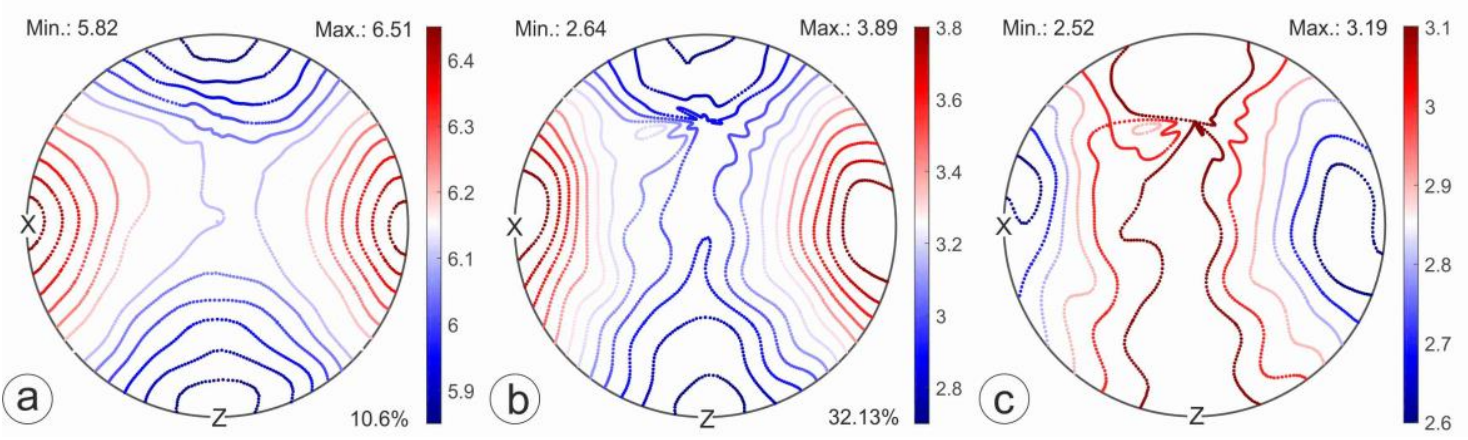

Figure 72 Velocity distribution $V p[\mathrm{~km} / \mathrm{s}]$ under wet (a) and dry (b) conditions for a sphere of Prieborn marble as well as $\mathrm{c}$ ) the difference $\Delta \mathrm{Vp}$. Minimum and maximum velocities are given on the top each plot, while the amount of anisotropy [\%] is given in the right corner (lower hemisphere, stereographic projection).

The controlling fabric elements are the lattice preferred orientation of the calcite minerals, the microcrack populations, and the shape fabric (grain size, grain aspect ratios, grain-shape preferred orientation, c.f. (Siegesmund and Dürrast, 2014). To see if the var- 
iation in the amount of anisotropy is mostly controlled by the lattice preferred orientation, modelling of the intrinsic velocity distribution was performed, using the MATLABbased software MTEX (Bachmann et al., 2010; Hielscher and Schaeben, 2008; Mainprice et al., 2011). The P-wave velocity distribution for the single crystal is given in Figure 73 a, which clearly shows the directional dependence, according to the crystallographic axes. Parallel to the c-axis, the velocity is lower $(5.7 \mathrm{~km} / \mathrm{s})$, while it is much higher with $7.7 \mathrm{~km} / \mathrm{s}$, parallel to the a-axes. To calculate the velocity distribution for the polycrystalline data, the measured texture data was used to calculate the intrinsic Vp distribution, based on the calculated ODF data. The modelled pole figure (Figure $73 \mathrm{~d}$ ) shows a maximum velocity of $6.96 \mathrm{~km} / \mathrm{s}$ in the X-direction and a minimum velocity of $6.32 \mathrm{~km} / \mathrm{s}$ in the Z-direction. The same trend can be seen for the cube which shows the highest velocities in the X-direction. The modelled velocity distribution can be described with an anisotropy of $9.2 \%$, which is in direction and amount of anisotropy consistent with the velocities measured in the water saturated sphere.
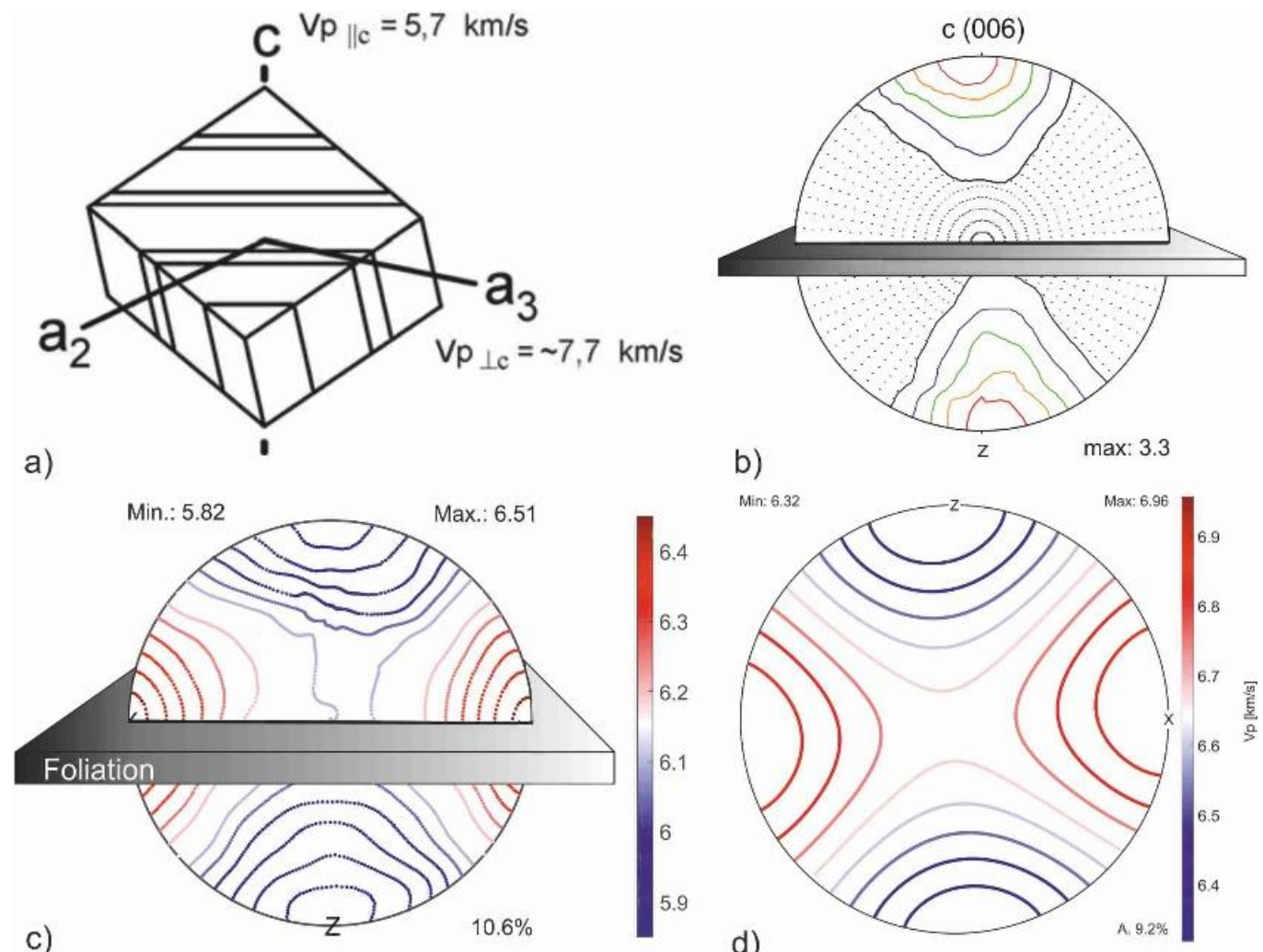

d)

Figure 73 a) Anisotropic ultrasound velocities for a calcite single crystal (adapted from Rüdrich 2003), b) c-axes distribution analysed for the Prieborn marble, considering orientation of the foliation, as well as for $\mathrm{c}$ ) the velocity distribution for a water-saturated Prieborn sphere, in both plots the greyish layer stands for the foliation, $d$ ) is the calculated intrinsic velocity distribution, based on ODF data for a polycrystalline Prieborn marble (lower hemisphere, stereographic projection). 
The variation of velocity under dry and wet conditions is caused by the amount of porosity, which was measured for the sphere as $0.41 \%$. According to the classification of (Köhler, 1991), this is too low, with regard to the low velocities of $2.63 \mathrm{~km} / \mathrm{s}$ an explanation would be again the pore aspect ratio which needs to be considered (see Chapter Relationship of velocity and porosity).

According to the systematic investigations in Chapter 5.3.2.2

Influence of humidity and water saturation, the samples show higher velocities under water-saturated conditions. As the saturation has an important influence on the magnitude and directional dependence of ultrasonic wave velocities, it is essential to gather sufficient information on the state of water saturation of an object which will be investigated (Siegesmund and Dürrast, 2014).

Figure 72 displays $\Delta \mathrm{Vp}$, the difference in the spatial distribution of the velocity reduction between the water-saturated and dry sphere. It is obvious, that the highest decrease of $V p$ is aligned like a channel, perpendicular to the X-direction. This means, the largest decrease of velocity takes place perpendicular to the foliation and in the Y-direction, which is perpendicular to the most pronounced grain elongation (see Figure 66). The Prieborn marble is known for decohesion along grain boundaries, which besides the Prieborn marble, is typical for the Carrara marble as well (Ruedrich, 2003).

\subsection{Ultrasonic-tomography: modelling vs field data}

The investigations performed on the dry- and water-saturated sphere have shown that the possible velocity variation for the Prieborn marble can vary between 9 and $30 \%$ anisotropy, while $30 \%$ represents a totally dry marble and $9 \%$ a completely water-saturated marble. The velocity variation and distribution that should be expected for the obelisk, should range between those values. Figure 74 displays the velocity distribution for the sphere, transferred to the obelisk. A reorientation of the results obtained for the sphere is possible, due to the known geographical position of the foliation in the obelisk (cf. Figure 64) and for the reference material. The highest velocities should be found along the EW-direction (X-direction), while the NS-direction (Y-direction) reveals the lowest velocities. To see, which velocity variations can be expected for the obelisk, the 
sphere was rotated about $80^{\circ}$ until the foliation plane (XY-plane) had the same dipping angle as measured for the obelisk.

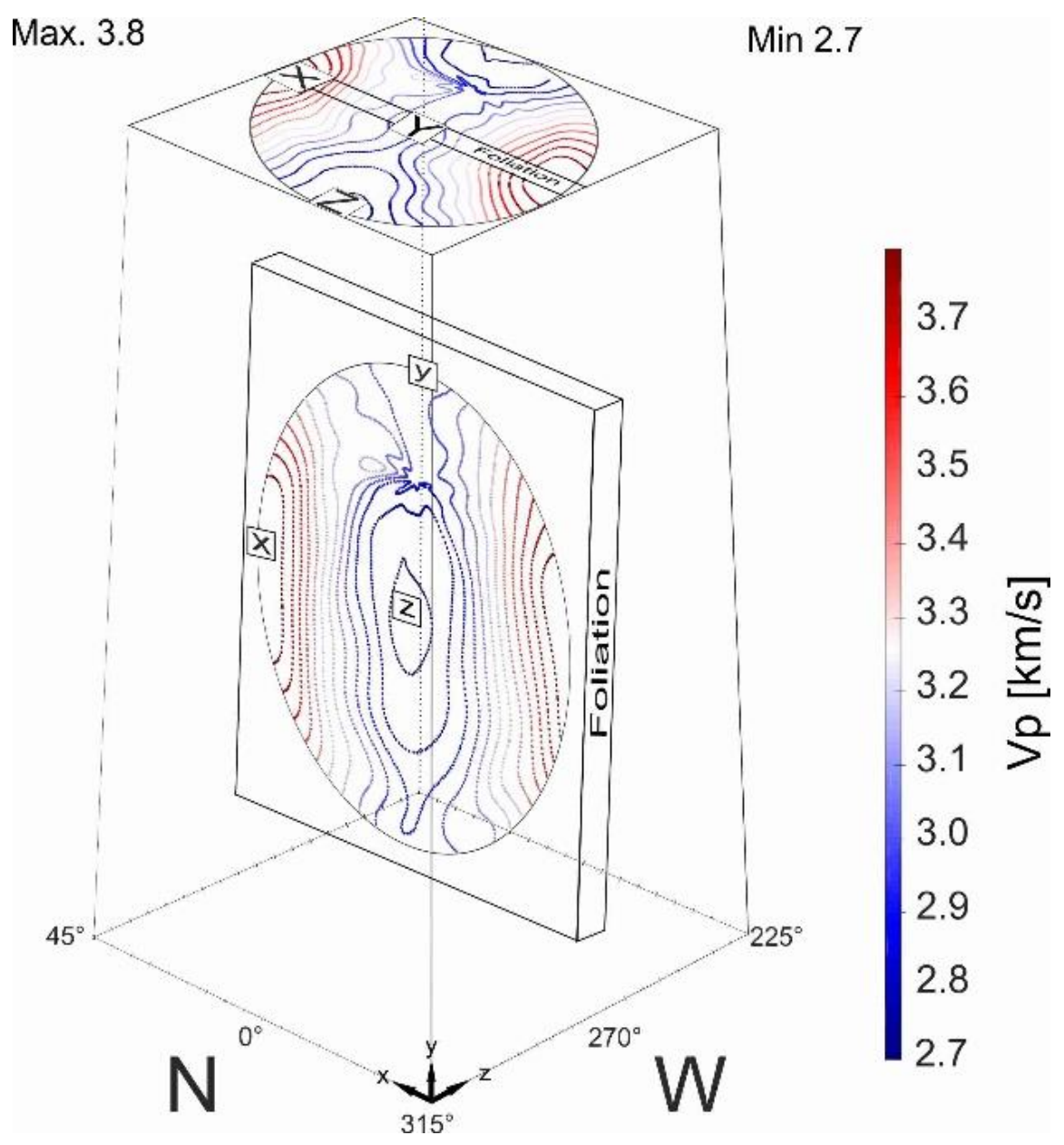

Figure 74 Reorientation of the velocity distribution, determined for the sphere, with respect to the spatial position of the foliation.

The results displayed for the sphere present a 2D projection of a 3D distribution, showing the orientation of the expected velocities. For a 2D sectional profile, as represented in the tomograms for the obelisk, a detailed tomographic measurement has been executed for the sphere, based on the reorientation. This synthetic tomogram of the Prieborn marble sphere has been used for a comparison of data obtained under controlled and dry laboratory conditions with the data from the in-situ measurements. The measurement settings used for the laboratory tomography are similar to the one applied for the obelisk, except the frequency was higher, with $350 \mathrm{kHz}$. Figure 75 outlines the grid used for the different source-receiver-combinations at the sphere. Although the sphere is made out of the same marble variety that underwent comparable degrees of 
weathering as the obelisk, the results cannot be assumed to be identical to the in-situ measurements. However, the materials are the same, so the velocities are expected to be similar.

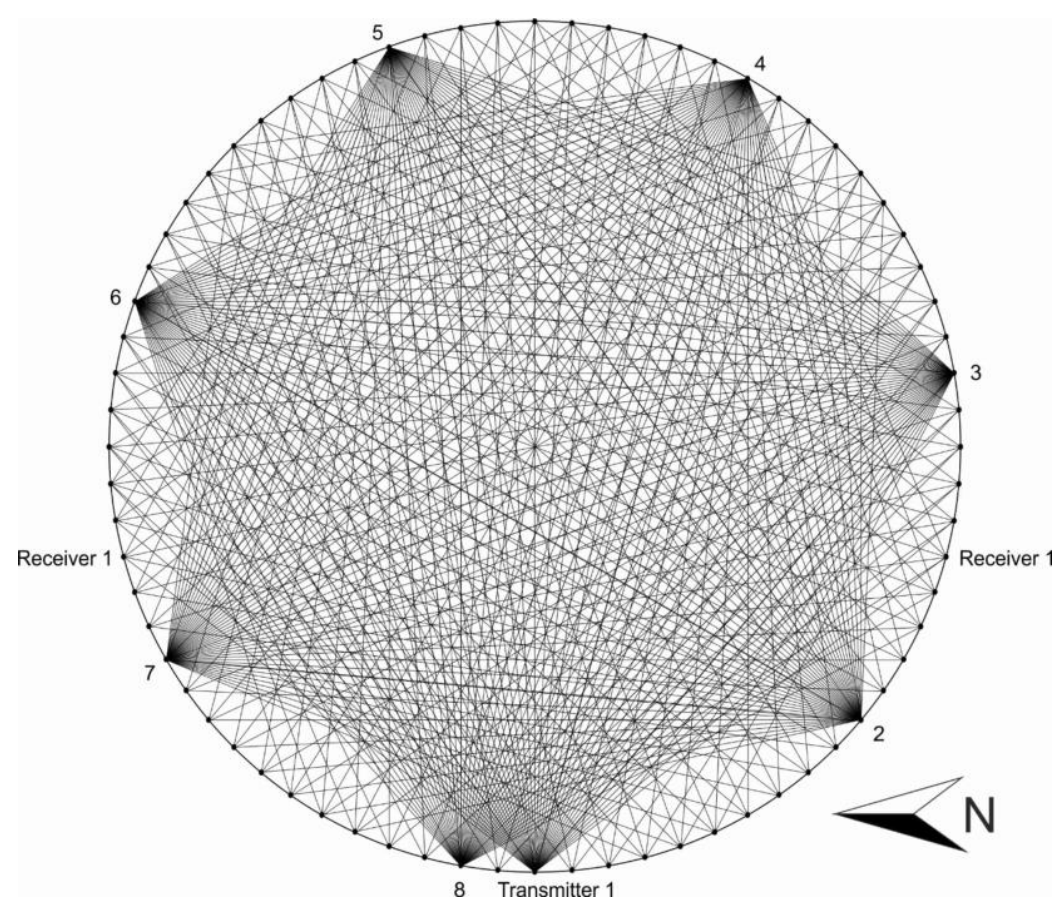

Figure 75 Transmitter and receiver positions for the ultrasound tomography, applied at the sphere.

The general distribution of velocities for the synthetic tomogram displayed in Figure 76 a shows velocities ranging between 2.5 and $4.5 \mathrm{~km} / \mathrm{s}$, similar to the velocities obtained for the planes at the obelisk (Figure 69). The lowest velocities are around 2.5 to $3.0 \mathrm{~km} / \mathrm{s}$ in two divided zones near the centre of the sphere, while the maxima surround the minimum velocities. Velocities in a channel, interrupted in the eastern area of the sphere, range between 3.5 and $4.4 \mathrm{~km} / \mathrm{s}$. As already described, anisotropy is an important feature of this marble variety and has to be considered. One indication for anisotropy is the divided zone in Figure 76a of the lowest velocities in the middle, which is typical for disregarded anisotropy (Wendrich, 2009). 


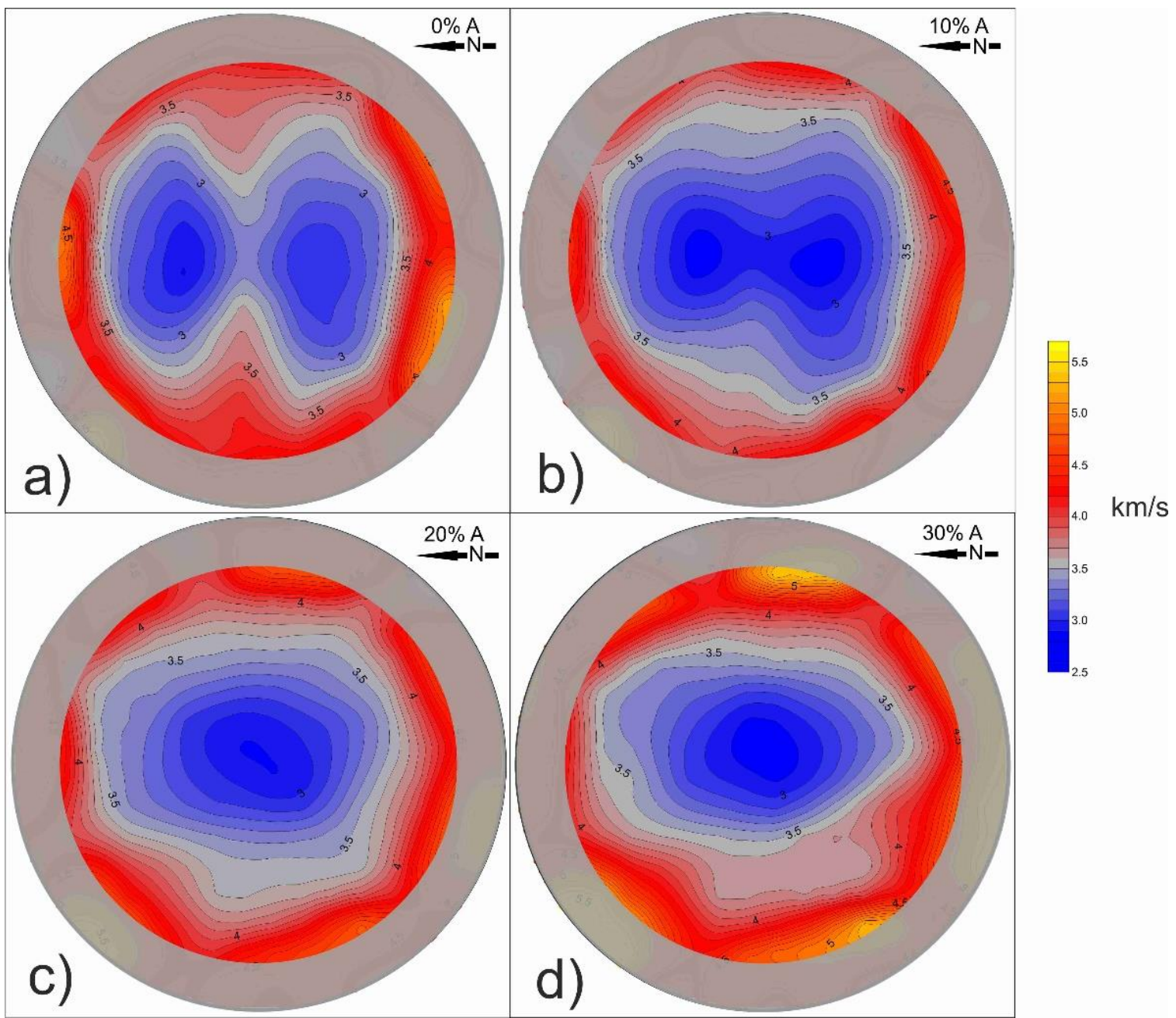

Figure 76 Synthetic tomograms for the sphere with a) no modification, b) $10 \%$ anisotropy, c) $20 \%$ anisotropy and d) $30 \%$ anisotropy, arrow on the top marks the geographic north direction.

The detailed measurements given in Figure 74 show that the highest velocities are oriented in the EW-direction. With GeoTomCG anisotropy can be specified in amount and direction. The measured and calculated anisotropy can vary between 9 and 30\% (Figure 72a, Figure 73d). Those extreme values, depending on external conditions like humidity and temperature, are rarely found in outer exposure. As an illustration, 10 and $20 \%$ of anisotropy (Figure 76 b, c) and also 30\% have been applied for the synthetic tomograms (Figure $76 \mathrm{~d}$ ). These tomograms show a very clear trend: the higher the assumed anisotropy, the higher the overall displayed velocities. All three tomograms exhibit low velocities near the centre, where there are two minima observable for the isotropic and $10 \%$ anisotropy calculated tomograms. These minima disappear with $20 \%$ anisotropy. The tomogram with $30 \%$ anisotropy reveals the beginning of a new division below the mini- 
mum in the western direction, an area of medium velocities around $3.6 \mathrm{~km} / \mathrm{s}$ a. The minima are slightly elongated in the NS-direction, surrounded by higher velocities. Those velocity variations caused by the intrinsic rock properties pretend a more deteriorated core.

\subsection{Anisotropy for tomograms of layer 1 and 4}

To quantify the amount of decay phenomena or even heterogeneities, the anisotropic velocity variation has to be considered. Based on the presented laboratory analyses performed at reference material, it could be established that the anisotropy must be somewhere between $10 \%$ and $30 \%$. Four different tomograms with different assumed values for anisotropy have been calculated for plane 1 (Figure 77) and 4 (Figure 78). These values are $10 \%, 20 \%$ and $30 \%$, while $0 \%$ represents the field measurements without any precondition of anisotropy.

The tomograms for $0 \%$ and $10 \%$ anisotropic conditions in plane 1 are very comparable. The velocities generally increase towards the centre of the plane, from around $3 \mathrm{~km} / \mathrm{s}$ on the edges to $3.5 \mathrm{~km} / \mathrm{s}$ in the middle. In the north-western corner is a corridor, where the velocities drop below $3 \mathrm{~km} / \mathrm{s}$, but increase again towards the edges. In the centre, three slight, column-shaped maxima (up to $3.7 \mathrm{~km} / \mathrm{s}$ ) that are elongated in the EW-direction are visible in both tomograms. They also both show their highest velocities towards the north-eastern corner, where they reach up to $4.5 \mathrm{~km} / \mathrm{s}$. This maximum grows with increasing anisotropy, as it reaches more and more towards the centre. The lowvelocity zone in the north-western corner gradually disappears. The most obvious change can be seen on the three maxima in the centre. At $20 \%$ anisotropy they start to rotate by $90^{\circ}$ and are distinctly elongated in the NS-direction at 30\%. 


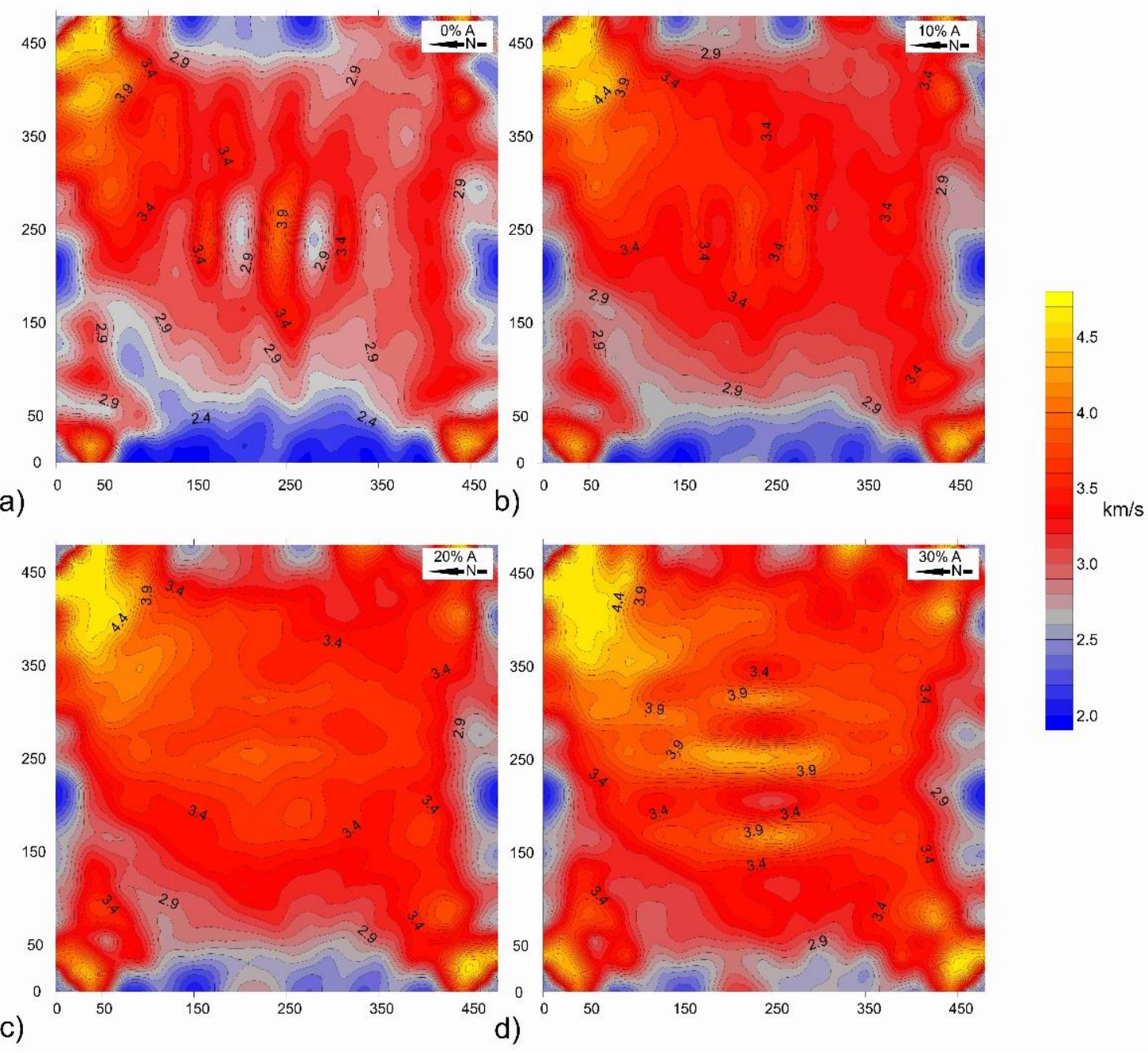

Figure 77 Ultrasonic tomogram of the obelisk calculated for layer 1 with a) no modification, b) $10 \%$ anisotropy, c) $20 \%$ anisotropy and d) $30 \%$ anisotropy, arrow on the top designates the geographic north direction.

The $0 \%$ tomogram of plane 4 (Figure 78 a) shows a maximum in the centre, with velocities reaching up to $3.2 \mathrm{~km} / \mathrm{s}$. This is confined by two strong minima to the south and north, where velocities drop to just over $2 \mathrm{~km} / \mathrm{s}$. They merge into one large low velocity zone towards the northwest. On the southern edge the velocities increase again and reach around $3 \mathrm{~km} / \mathrm{s}$. The two minima confining the central maximum slowly disappear with higher anisotropy. Instead they merge with this maximum and form one large zone of medium to high velocities ( 2.8 to $3.6 \mathrm{~km} / \mathrm{s}$ ). The north-western low velocity corridor remains visible, although the velocities increase slightly.

This examination has shown that anisotropy alone can have a huge control on the shape of the tomograms. To relate the observed damage phenomena to the areas of different 
velocities, it is necessary to determine the anisotropy of the material as accurately as possible.
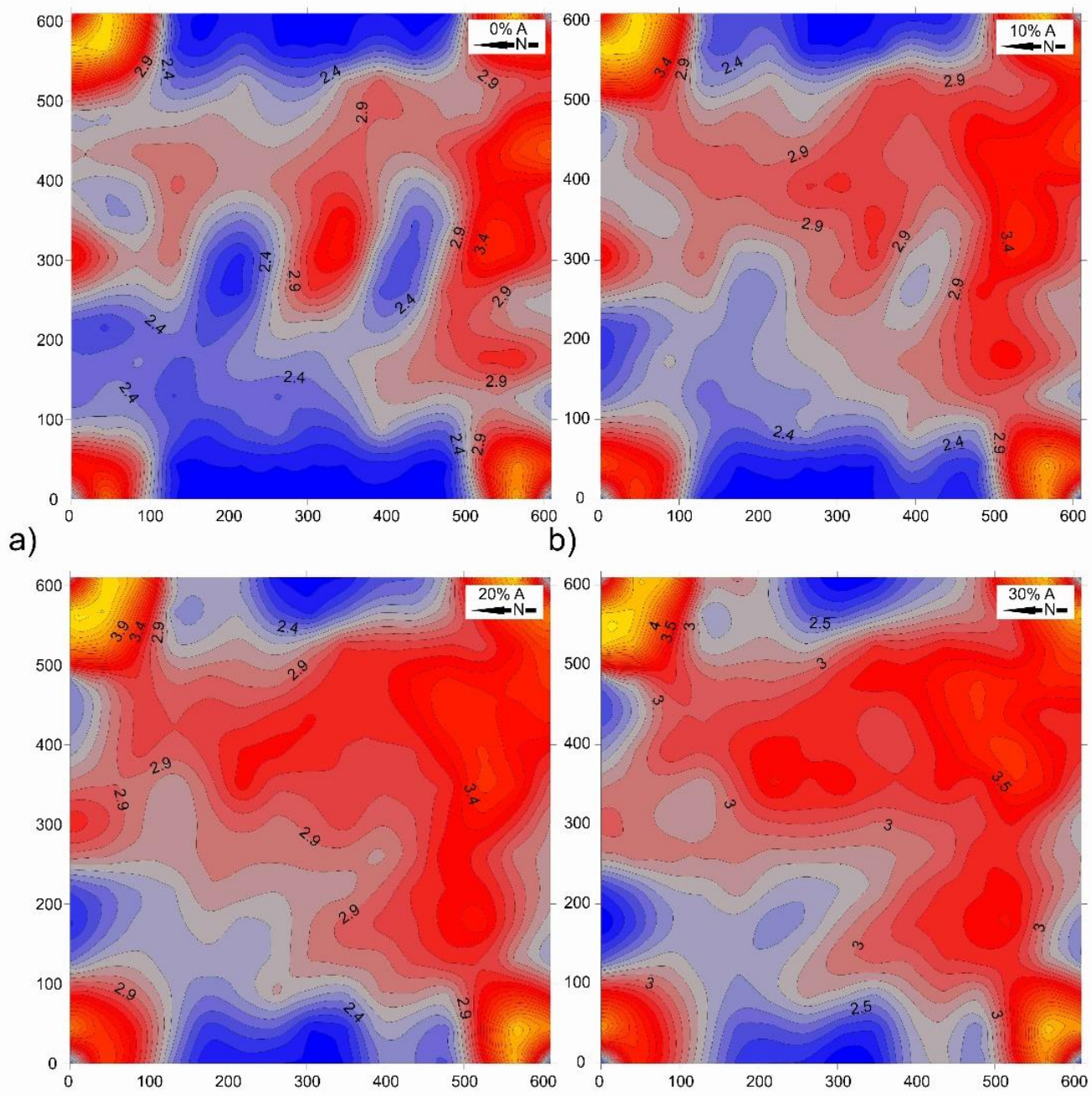

c)

d)

Figure 78 Ultrasonic tomogram of the obelisk calculated for layer 4 with a) no modification, b) $10 \%$ anisotropy, c) $20 \%$ anisotropy and d) $30 \%$ anisotropy, arrow on the top marks the geographic north direction.

The anisotropy for each plane was determined by examining the velocity as a function of direction and by determining the anisotropy giving the best fit to the measured travel times, that is minimizing the root-mean-square (RMS) residual. Comparing the plot of experimental velocities versus direction with a calculated ellipse indicates whether elliptical anisotropy is adequate. Assuming that anisotropy is elliptical is not justified, as anisotropy is frequently not elliptical (Thomsen, 2014). GeoTomCG provides options for both elliptical and non-elliptical anisotropy using the well-known Thomsen parameters. 
Figure 79 and b show the velocity versus the source-to-receiver direction for planes 1 and 4, respectively. In Figure 79 a, an ellipse with an east-west major axis of length $3.25 \mathrm{~km} / \mathrm{s}$ and a north-south minor axis of length $2.70 \mathrm{~km} / \mathrm{s}$ is superimposed on the plane 1 data. The lengths of the ellipse axes were chosen to give a good fit to the plotted velocities. The good fit indicates elliptical anisotropy is adequate. The ratio of the major to minor axis lengths indicates the anisotropy based directly on the plotted velocities, without a tomographic inversion. For plane 1 , that ratio is $3.25 / 2.70=1.20$. For plane 4 , Figure $25 \mathrm{~b}$ shows the velocity versus direction in a similar manner. The superimposed ellipse has major and minor axis lengths of 3.00 and 2.30, respectively, indicating anisotropy of 1.30 . The fit of the ellipse to the data is not as good as for plane 1 but shows that elliptical anisotropy is adequate, and the highest velocity is again north south. With elliptical anisotropy, the percent anisotropy when expressed as a fraction is the same as the Thomsen parameter $\delta$.
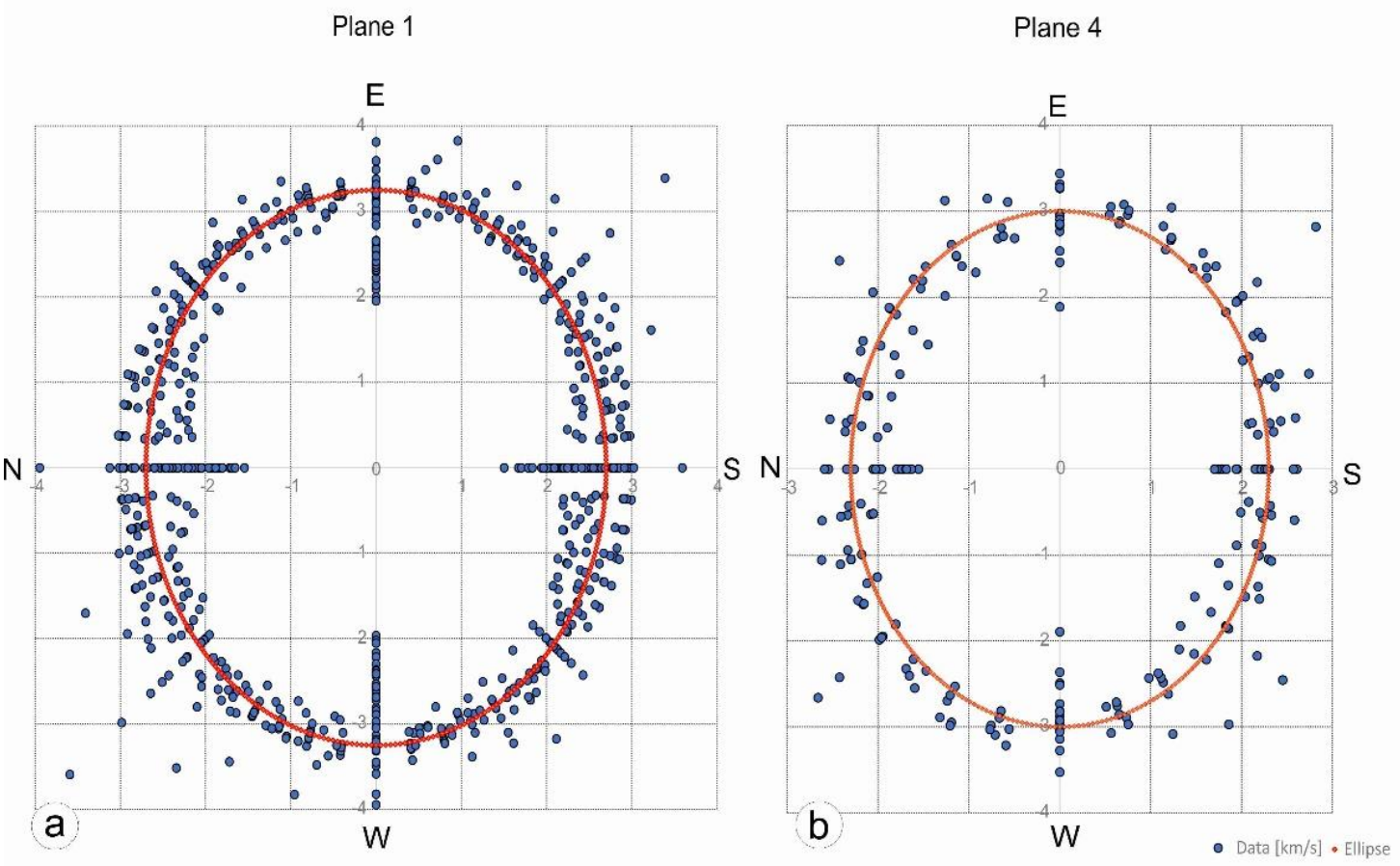

Figure 79 a) Velocity data and ellipse for Plane 1, axes at 3.25 and $2.7 \mathrm{~km} / \mathrm{s}$ and b) Velocity data and ellipse for Plane 4, axes at 3.0 and $2.3 \mathrm{~km} / \mathrm{s}$.

The anisotropies of 1.20 and 1.30 for planes 1 and 4, respectively, were consistent with those determined from the RMS residuals for tomographic inversions (Table 13). The 
dimensionless RMS residual/RMS time provides a normalized indication of goodness of fit.

Table 13 RMS residual [ $\mu \mathrm{s}$ ] and ratio of RMS residual/RMS time [dimensionless] for plane 1 and 4 determined for different anisotropies.

\begin{tabular}{lccc}
\hline PLANE & RMS RESIDUAL $[\boldsymbol{\mu}$ S $]$ & RMS RESIDUAL/RMS TIME & ANISOTROPY \\
\hline $\mathbf{1}$ & 9.888 & 0.075 & \\
& 7.892 & 0.060 & 1.00 \\
& 7.098 & 0.054 & 1.10 \\
& 7.850 & 0.059 & 1.20 \\
$\mathbf{4}$ & 16.91 & 0.087 & 1.30 \\
& 12.82 & 0.066 & 1.00 \\
& 10.36 & 0.053 & 1.10 \\
& 9.77 & 0.050 & 1.20 \\
& & & 1.30 \\
\hline
\end{tabular}

The direction of the highest velocity being east-west is consistent with the strike of the foliation and the major C1 cracks shown in Figure 64 . Signals going directly east-west would not need to pass through the $\mathrm{C} 1$ cracks or the foliation pattern. Signals going north-south would be slowed by cracks and the foliation.

The RMS and the measurements performed on the sphere gave an overview on possible expected velocity variations, showing that a $30 \%$ anisotropy is possible. These values of anisotropy may not be necessarily applicable to any given plane of measurement. They do, however, give constraints to the range of true anisotropy.

Based on the tomographic analyses at the obelisk and the ultrasonic diagnostics done in the laboratory, it can be inferred that the anisotropy for the measuring planes is about $20 \%$. This can be explained by the impossibility of a totally dry or wet obelisk. According to the climate data found at www.pik-potsdam.de, the last heavy rainfalls happened 5 days before the measurements. Since water has the effect of increasing ultrasonic velocities in a given material, the actual velocities in the obelisk are probably even lower than the ones obtained. Due to the known texture, combined with the results of the calculated tomogram for the sphere (Figure 76) and the $360^{\circ}$ ultrasonic measurements under dry and wet conditions (Figure 72), it is known that the measured planes on the obelisk are in an area of pseudo isotropy with the lowest velocities found in the centre, 
surrounded by higher velocities. The detailed mapping has shown that the obelisk features a substantial number of damages and weathering phenomena. Ultrasonic and tomographic measurements have been applied to determine, whether these phenomena will be overlain by intrinsic anisotropic effects. Figure 80 shows the comparison of the visible structural phenomena with the respective tomograms modelled with $20 \%$ anisotropy.

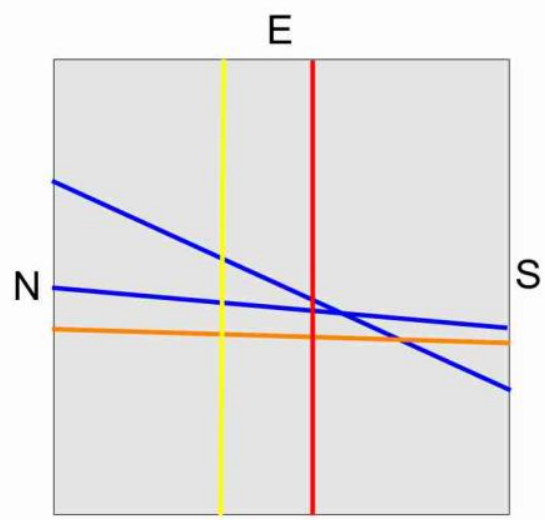

a)

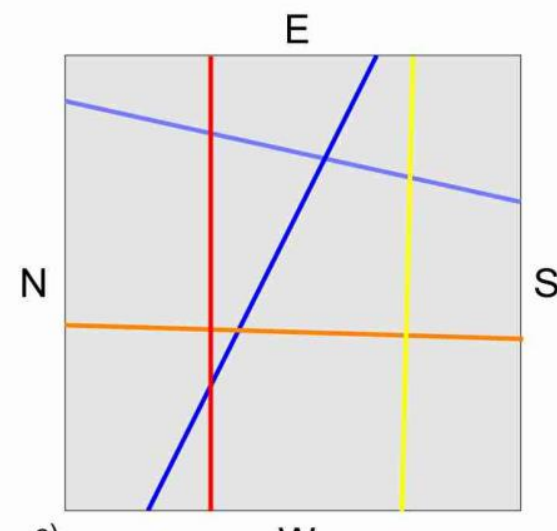

c)
W

W

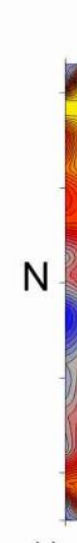

b)

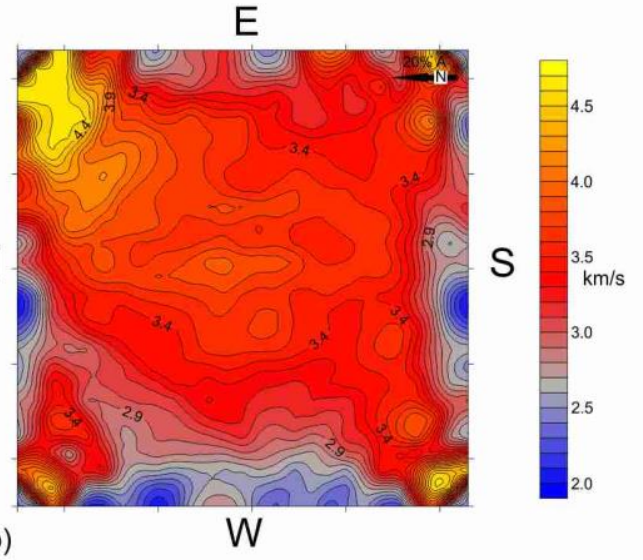

$E$

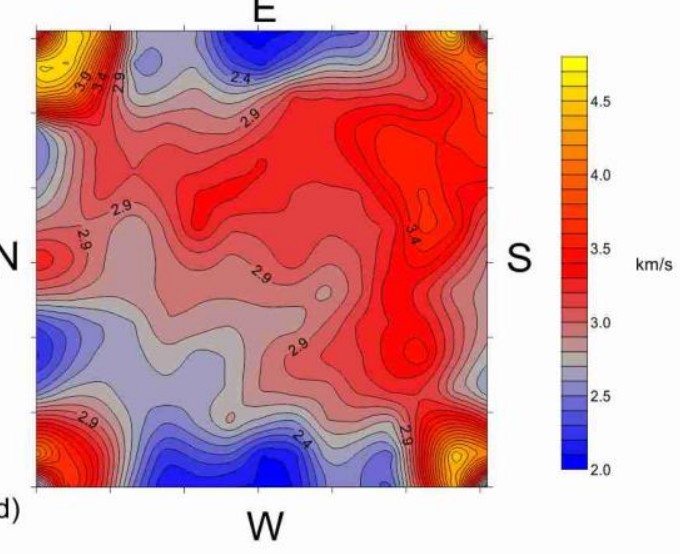

Figure 80 Mapped structures and tomograms with 20\% anisotropy for plane1(a, b) and $4(c, d)$.

The tomograms reveal that the lowest plane (4) shows the highest impact of decay. As could be shown in Figure 72c, crack opening will occur most likely parallel to the foliation. The mechanical load, lasting on the lower part of the obelisk, in combination with 
the almost vertical foliation will probably intensify a crack opening especially in the lower part of the obelisk. Even if the tomograms do not resolve the macroscopically visible crack systems, the distribution of velocities gives a more detailed overview about the progress of decay. In combination with the additional information about the condition of the rock based on the decay mapping, it is possible to distinguish between possible velocity variations, due to the state of weathering and "ghosts", meaning pattern included in the tomograms based on low ray coverage or anisotropic variations due to the LPO.

Although the obelisk shows a relatively high abundance of cracks, the inner parts appear to be less degraded than the outer parts. Areas of very low velocities can be seen along the western and eastern surfaces throughout the entire obelisk, caused by extrinsic influences. An additional trend the tomograms show are the decreasing velocities at the lower measuring planes. The reason of this trend can be explained by the influence of mechanical load, due to the weight of the obelisk. A low velocity area on the northwestern edge of the planes can also be found more or less pronounced on all planes. No unambiguous reasons can be found for this appearance. While for plane 4 the crossing of the two open crack systems could maybe cause this low velocity channel, this cannot be observed for plane 1.

What are the benefits of the results from a tomogram, when compared to the standard and faster evaluation of the transmission velocities? If we take only the velocities from straight, opposing points in plane 1 and 4 , the velocities are higher in the east-west direction than in the north-south direction. This result is consistent with the results from additional data, considering also oblique travel paths. These results can be explained by the influence of micro cracks along grain boundaries which are preferentially orientated parallel to the foliation plane. The velocities analysed in the north-south direction increase from west to east for both planes. The velocities ranging between $2.26 \mathrm{~km} / \mathrm{s}$ and $3.45 \mathrm{~km} / \mathrm{s}$ display alarming conditions that can be classified as class II, granular disintegration. The benefit of the tomogram is that the distribution of velocities is also given for the inner part of the obelisk. Therefore, it can be inferred that the east and west surfaces suffered more than the north and south surfaces, even if transmission values indicate that the east-west direction shows lower velocities compared to the north south direction. 


\subsection{Conclusion}

Tomographic analysis has shown to be able to reveal areas and trends of different velocities inside the obelisk. However, it was not possible to resolve the crack systems discovered by the mapping. There are several possible reasons: The relationship between the frequency used during the measurement and the velocities of the resulting rays are an aspect which has to be considered. Velocities around $3 \mathrm{~km} / \mathrm{s}$ and a given frequency of $46 \mathrm{kHz}$, can only be considered if the structures have a size of at least $5 \mathrm{~cm}$ for them to be resolvable by tomographic measurements. Unfortunately, choosing a higher frequency can prevent the ultrasonic rays from penetrating the rock as it was the case for the obelisk. Another aspect is, due to the regular intervals used for the grid, areas with low, up to no coverage appeared. Maybe an irregular grid can avoid those systematic resolution problems.

Irrespective of whether the evaluation of the ultrasound data is based on transmission or modelled in a tomogram, the interpretation of ultrasound velocities requires the consideration of possible anisotropy (see also Ruedrich et al., 2001; Siegesmund et al., 2004b). The modelled tomograms have shown that anisotropy has a huge influence on the assessment of the results and is not a mathematical error, but an important rock property, which has to be considered. Therefore, direction and magnitude of the anisotropy is an important aspect and has to be chosen carefully before any interpretation.

The macroscopic structures of visible fabric elements, as well as decay phenomena, have to be considered and studied diligently. That information is a first indicator for the orientation of any rock property. The important observations include the foliation, whose spatial position was essential for any further interpretation and reorientation. If the marble variety is known, information about the typical rock properties (e.g. LPO, rock fabric etc.) should be compiled and considered. This can aid in getting a first idea of possible orientations that can be expected and is necessary for a comprehensive interpretation. 


\section{Scharnhorst and Bülow, comparative investigations}

\subsection{Introduction}

The marble sculptures of General von Bülow and von Scharnhorst are two important free-standing monuments of cultural heritage in Berlin, designed by Karl Friedrich Schinkel and realized by Christian Daniel Rauch. Because of their historical and cultural significance as creative work of these two famous representatives of German classicism, the sculptures have been investigated several times by ultrasonic measurements. The question arises, is further outdoor exposure of the two sculptures still possible, or should conservation measures be undertaken such as storage in a museum under controlled climatic conditions where they could be preserved for subsequent generations.

The state of weathering was investigated three times over a period of 12 years. The velocity data were used to constrain the strong degradation after this short period. Winter sheltering was implemented for the last 15 years, since 2004. For the last three years the sculptures were permanently covered to protect them, so that moisture influences are negligible. Direct comparison of tomographic velocity measurements was made with those done in 2006 and the measurements performed in 2018, thus allowing an in-depth analysis of the deterioration of the marble.

\subsection{Historic background}

The sculptures General Gerhard Johann David von Scharnhorst and Friedrich Wilhelm Freiherr von Bülow (Earl of Dennewitz) were placed beside the Neue Wache (New Guardhouse; Figure 81) in 1822 in Berlin and unveiled on June 18, 1822 for the occasion of the $7^{\text {th }}$ anniversary of the victory of the Belle Alliance (Waterloo). Since 1816, the sculptor Christian Daniel Rauch simultaneously worked on both monuments, while K.F. Schinkel drafted the pedestal, as well as predefining the height and exact location of the sculptures. After the models were finished in 1818, Rauch began sculpting the statue 
out of Carrara marble in 1819. The first completed sculpture was General von Scharnhorst, which was positioned on the $13^{\text {th }}$ of June 1822. In 1950 both sculptures were removed from the Neue Wache and stored on the Museumsinsel (Museum Island). In 1960 both eagles were removed from the pedestal before the sculptures were repositioned in 1961. The sculptures were placed at the park between the opera house and the Prinzessinnenpalais (Princesses Palace) on the opposite side of the Neue Wache. Contrary to their earlier placement, they now stood back to back at opposite ends of the park until 1990. They underwent restoration in 1994 and were removed and put into storage in Berlin-Tegel. Since the $22^{\text {nd }}$ of August 2002, they have been repositioned at the Prinzessinnengarten (Princesses Garden), where they have remained until now and aligned as they were at their original location by the Neue Wache.

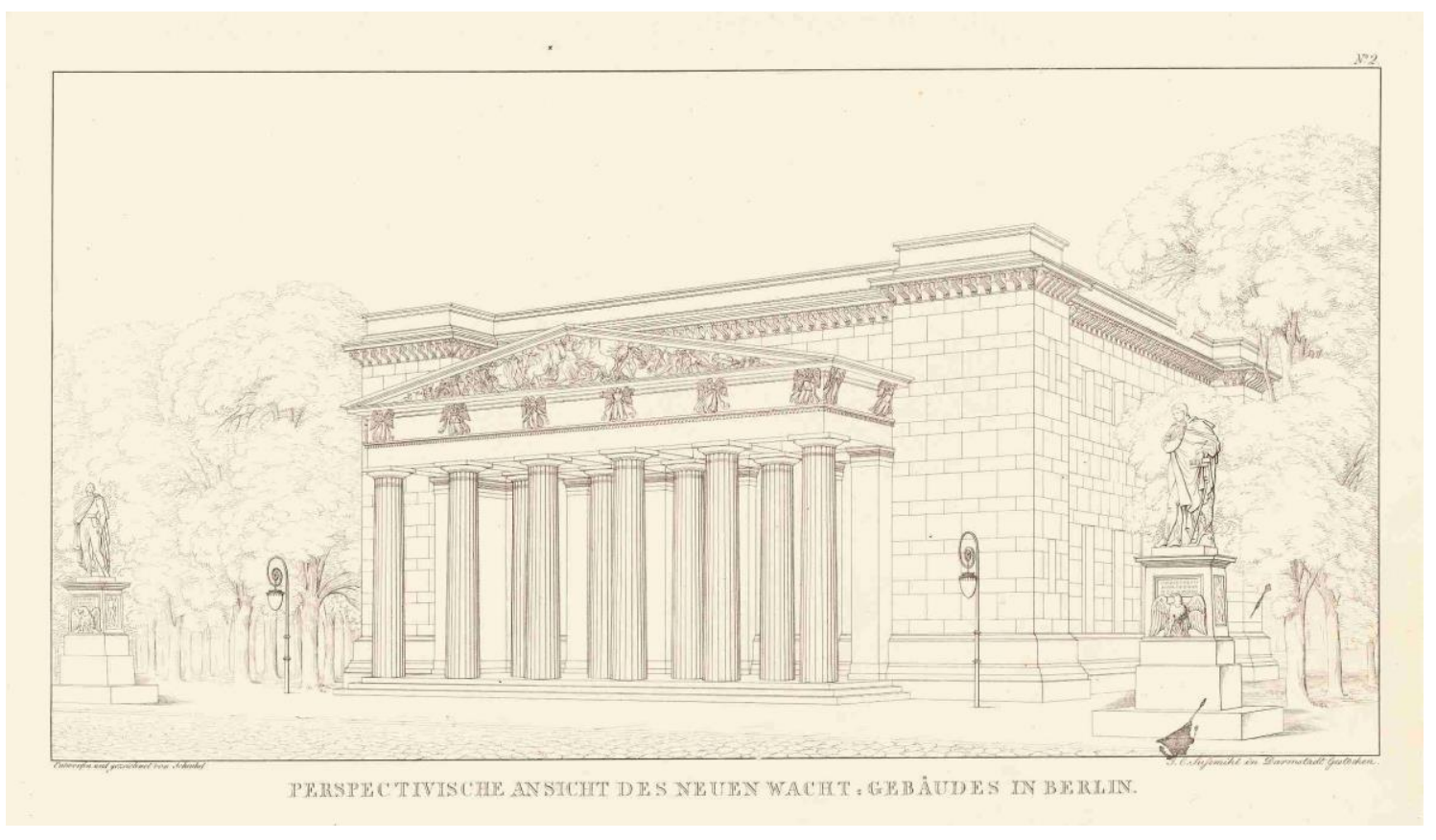

Figure 81 Engraving of Karl Friedrich Schinkel's draft for the Neue Wache (Königswache) Berlin, 1858. In front of the neoclassical building, the monuments of General von Bülow and General von Scharnhorst are displayed in their primary location. (Schinkelzeichnung 1819 Karl Friedrich Schinkel (1781-1841) - Sammlung Architektonischer Entwürfe, Berlin 1858. TU Berlin Architekturmuseum, Inv. Nr. SAE 1858,002).

Both monuments are made of Carrara marble, standing on a pedestal with reliefs and a plain marble base, which was renewed and reduced in height in the 1990s. The former, underlying three-step base was made of a reddish granite (Vanga or Lykesil) and is not preserved. In 2002 it was replaced by a two-step base made of Beuchaer granite porphyry (Fig. 2 a and b). The total height of both monuments at the present is $5.2 \mathrm{~m}$, 
while the sculptures are $2.7 \mathrm{~m}$ in height. Friedrich Wilhelm von Bülow (Figure 82 a) was one of the most successful Prussian generals during the Napoleonic wars and his sculpture presents him in an early $19^{\text {th }}$ century general's uniform. Rauch chose a depiction of Bülow as a man of action with a self-confident appearance and a straight look to the left. His right hand is placed on his hips gathering up his cloak laterally, while the left-hand rests on his sword. The reliefs on the pedestal show the Prussian eagle on the front, while the other three surfaces show variations of the Roman, winged goddess of victory Victoria. Bülow's sculpture gazes toward the sculpture of General Johann David von Scharnhorst (Figure 82 b). He was a reformer of the Prussian army system and introduced compulsory military service, while his major efforts were focused on a liberal policy in the armed forces. Wearing a general's uniform of the early $19^{\text {th }}$ century, he leans against a tree stump, holding a scroll in his left hand. His head is turned to the right with a downwards oriented, thoughtful look which is supported by his right hand, the forefinger is uplifted towards his chin. The reliefs on the pedestal again display the Prussian eagle at the front and the goddess Athena in an antique style, which refer to his merits associated with the construction of a popular army for the wars of liberation. The themes of combat and victory shown on the pedestal replicates the depictions visible at the triangular pediment of the Neue Wache (Figure 81).
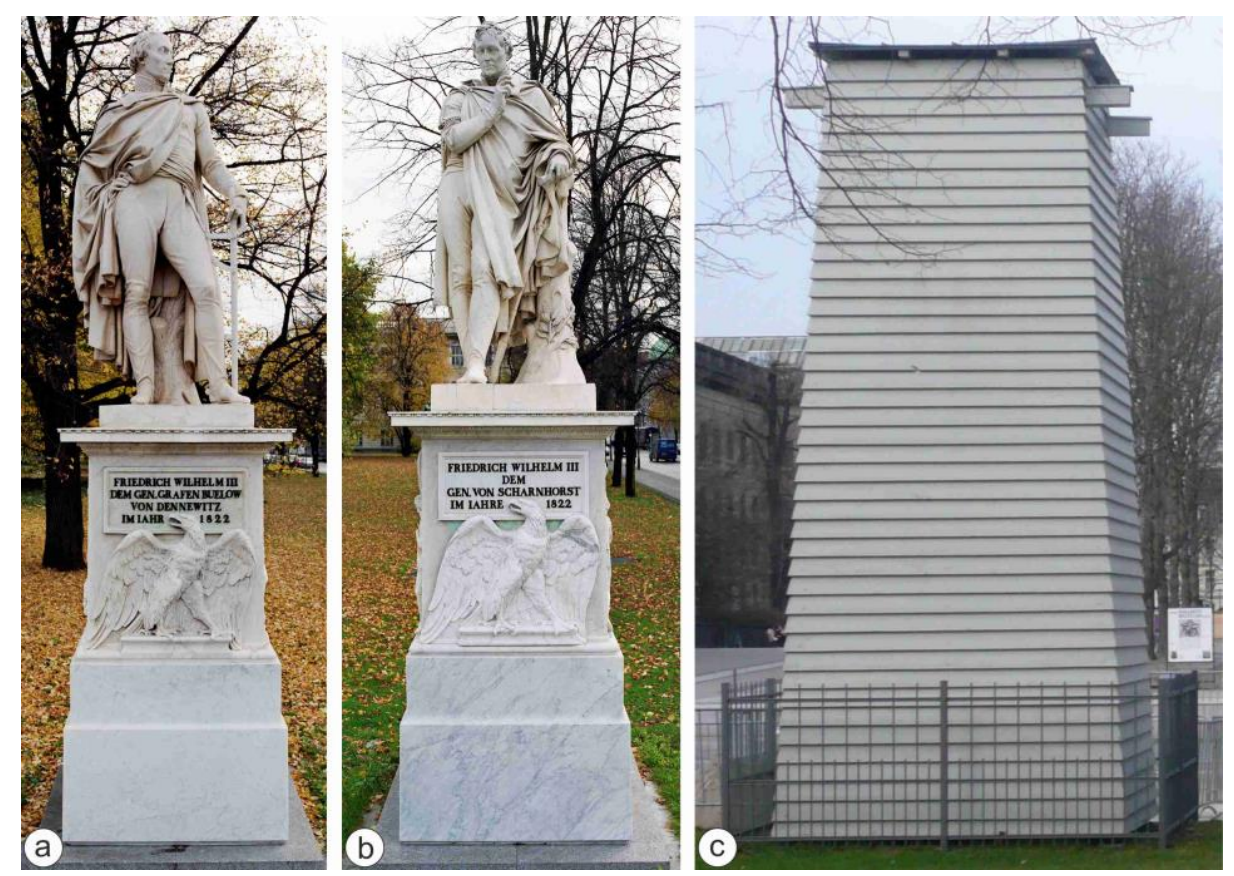

Figure 82 Monuments of General von Bülow (a) and General von Scharnhorst (b) in their current appearance and (c)Sheltering of both monuments at their current location (Kai Zimmermann 2008). 
Within the last 200 years, both sculptures have undergone an assembly and dismantling history combined with vandalism and different measures of restoration and cleaning. Since 2004, the sculptures are placed into an annual protective winter cover made of wood from November to April (see Figure 82c). Inspection and maintenance are now periodically performed, which was initiated in 2009.

\subsection{Damage characteristics}

\subsubsection{Decay phenomena and rock status}

Both sculptures consist of a whitish marble variety known as the Carrara type from Italy. Several types of decay phenomena are visible on the sculptures as shown in Figure 83. Areas which are directly exposed to weathering influences, like arms, hands and garment folds show characteristic sugaring of these surfaces (Figure $83 \mathrm{a}$ ). These are highly pronounced for the left hand and arm of the Scharnhorst sculpture (Figure $83 \mathrm{~b}$ ), where the original surface is almost completely lost. This pronounced surface roughness can be traced back to chemical solution processes, while less exposed areas show almost no alteration of the surface. In some cases, cracks can be found, which are visible due to the increased accumulation of dirt in those areas (Figure $83 \mathrm{c}$ ). Especially the garment folds show many black dots (Figure $83 \mathrm{~d}$ ), which probably are caused by microbial growth and can be found more prevalently in the narrow gaps between the folds. Another phenomenon is an ochre coating spread all over the sculptures, as shown in Figure 83 e. The cause of this coloration is still under discussion since it may be microbial growth or residues of former consolidation measures. Close examination needs to clarify this phenomenon. Several replacements of filigree parts can be found for example in the folds of the coat (Figure $83 \mathrm{f}$ ), where a restoration mortar was used to substitute the missing areas or (Figure $83 \mathrm{~g}$ ) the total substitution by reconstructions made of marble. At the edge of Scharnhorst's coat so-called craquelure can be observed on the surface, with a network of cracks, while the underlying fabric shows strong disaggregation (Figure $83 \mathrm{~h})$. 

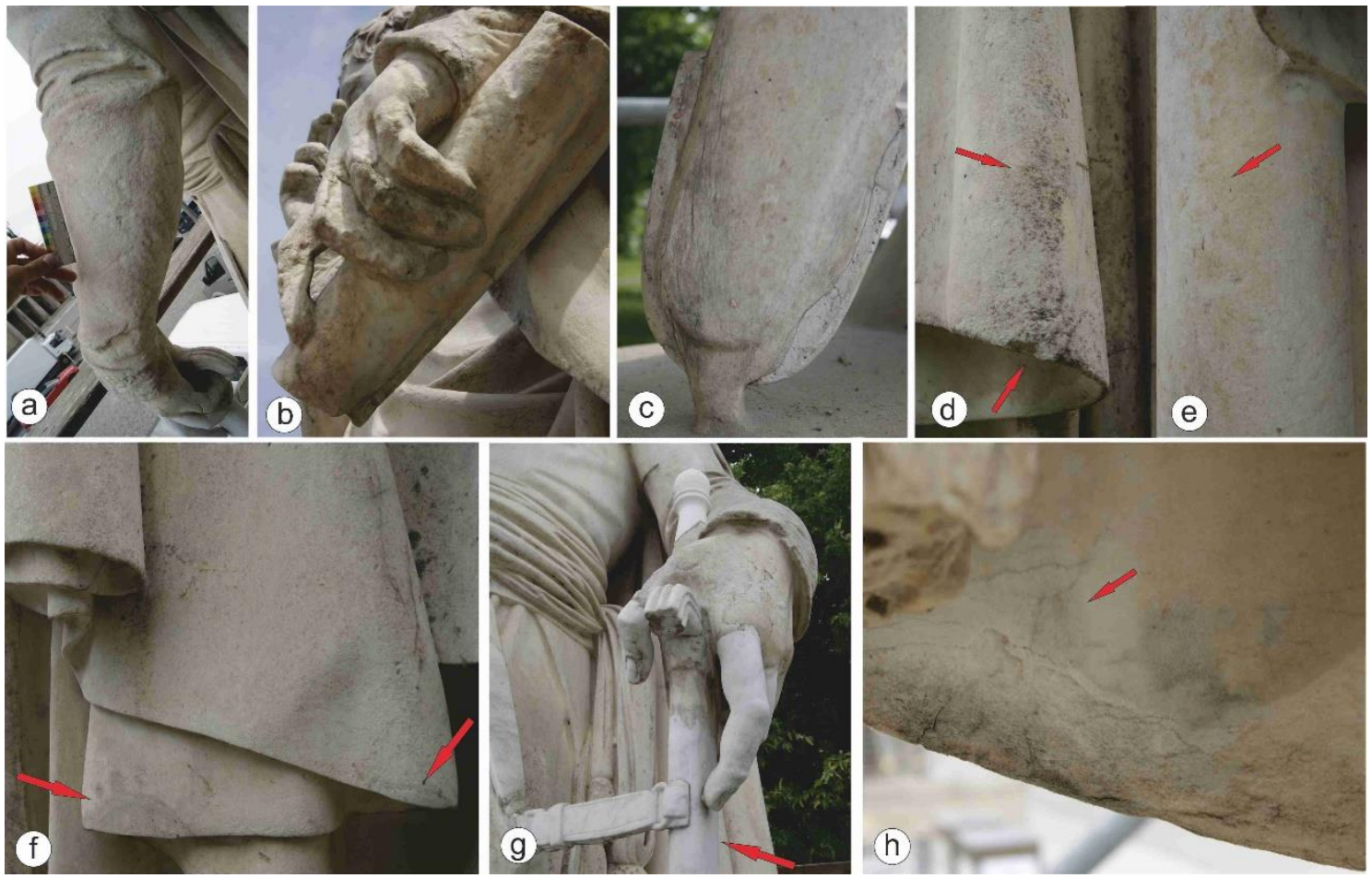

Figure 83 Various decay phenomenon found at the monument of General von Bülow and Scharnhorst with a) Sugaring of exposed surfaces, b) strongly weathered surfaces with sugaring of exposed surfaces, c) cracks, d) microbial growth, e) discolouration, f) lost material which was reconstructed by restauration mortar and g) substitution made of marble and h) craquelure on the surface.

The marbles show macroscopically a grain size of about $300 \mu \mathrm{m}$ for General von Scharnhorst and about $200 \mu \mathrm{m}$ for General von Bülow. A microscopic analysis by thin section was done for the sculpture of General von Bülow. The microfabric in Figure 84 a-d shows an inequigranular grain size distribution, while the grain shape is almost polygonal with interlobate to almost straight grain boundaries. Calcite is the main component of this marble, while accessory quartz and an opaque black mineral, probably graphite, can be found. To see if the fabric of the marble is deteriorated, the thin section was made using a blue coloured resin, to visualize open cracks and open grain to grain contacts. In Figure 4 the left border of the images is parallel to the former surface of the sculpture, showing the fabric in a depth profile. Figure 84 a and c show that small cracks (marked with red arrows) run along the grain boundaries and can primarily be found between the grain to grain contacts, as so-called intergranular cracks. In Figure $84 \mathrm{c}$, an intragranular crack is observable, but this type of crack is less common. The crack distribution shows that they mainly occur in the first millimetres of the surface. They do not spread surface parallel, but slightly oblique into the depth of the drill core. Cracks at the outer areas of the drill 
core, parallel to the core should be disregarded, because they are caused by drilling and not related to weathering. Granular disintegration is observable in this core, but it is only weakly pronounced. Another important method for visualizing these open grain boundaries is the use of scanning electron microscopy (SEM). SEM images were taken at a depth of about $4 \mathrm{~cm}$ (Figure $84 \mathrm{e}$ ) and at $6 \mathrm{~cm}$ (Figure $84 \mathrm{f}$ ) to the former surface. The grain contacts show no signs of granular disintegration at those depths.
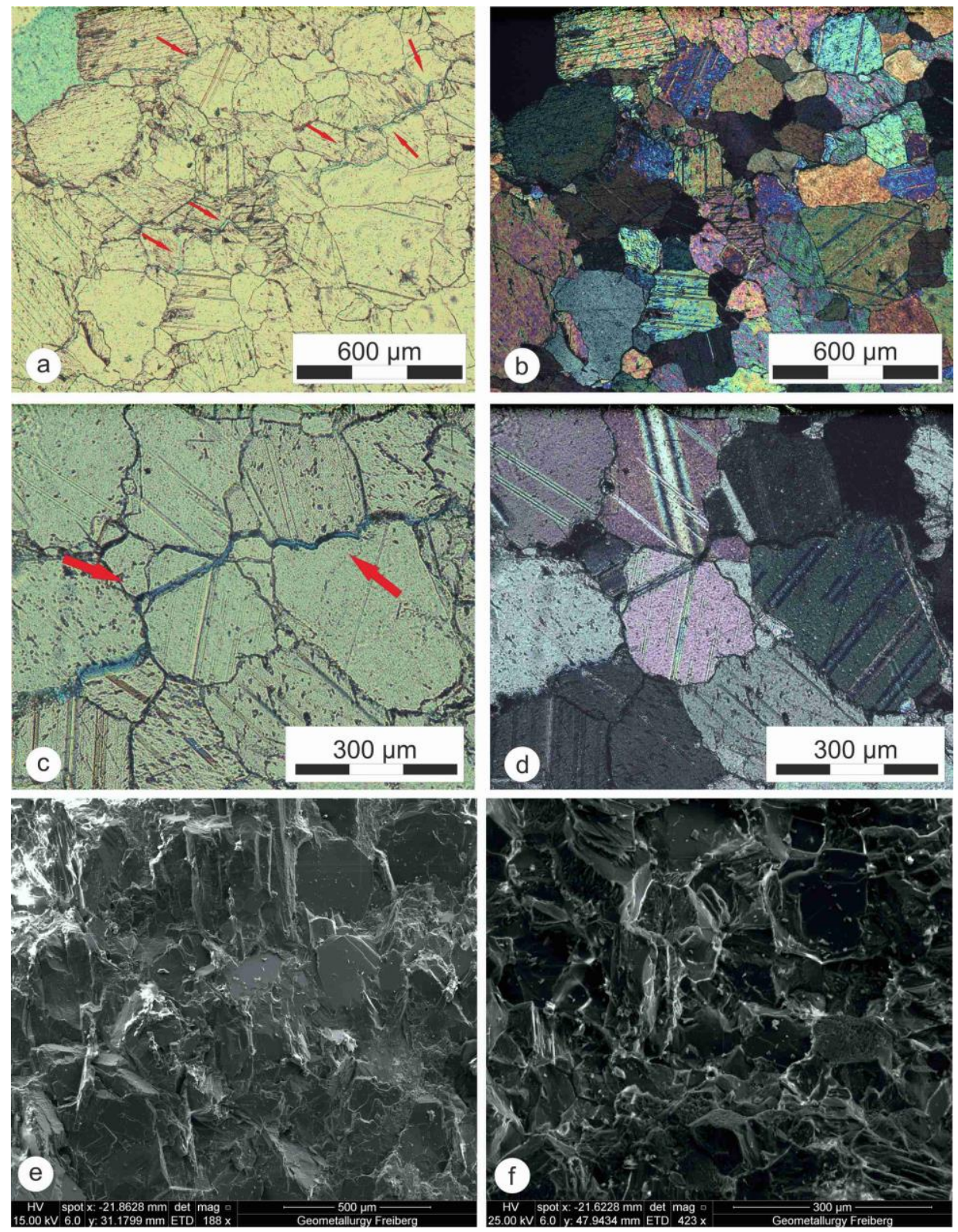

Figure 84 Thin section images with coloured resin to visualize open cracks. The left rim of all pictures is parallel to the former surface of the sculpture. a) polarized image showing the area close to the former surface, with slightly oblique cracks (red arrows) b) cross polarized image of the same region with the same magnification as a); c) detail of a crack system, showing intergranular cracks as the most common crack type, beside an intragranular crack, d) image c) under crossed polarizers, e) Scanning electron microscopy performed for a piece of the marble core taken from a depth of $4 \mathrm{~cm}$ and f) $6 \mathrm{~cm}$. 


\subsection{Rock composition and fabric}

\subsubsection{Lattice preferred Orientation}

The analysed LPO, displayed as a lower hemisphere stereographic projection in Figure $5 a$ and $b$, can be described as an almost girdle like c-axis distribution with a low, elongated c-axes maximum intensity of $1.7 \mathrm{mrd}$ with an oblique orientation (Figure $85 \mathrm{a}$ ). The a-axes (Figure 85 b) show a great circle distribution surrounding the c-axis distribution with a maximum intensity of $1.4 \mathrm{mrd}$. The weak texture is typical for Carrara marble and has been analysed by different authors (e.g. Leiss and Ullemeyer, 1999; Ruedrich, 2003; Ruedrich et al., 2013; Weiss et al., 1999).
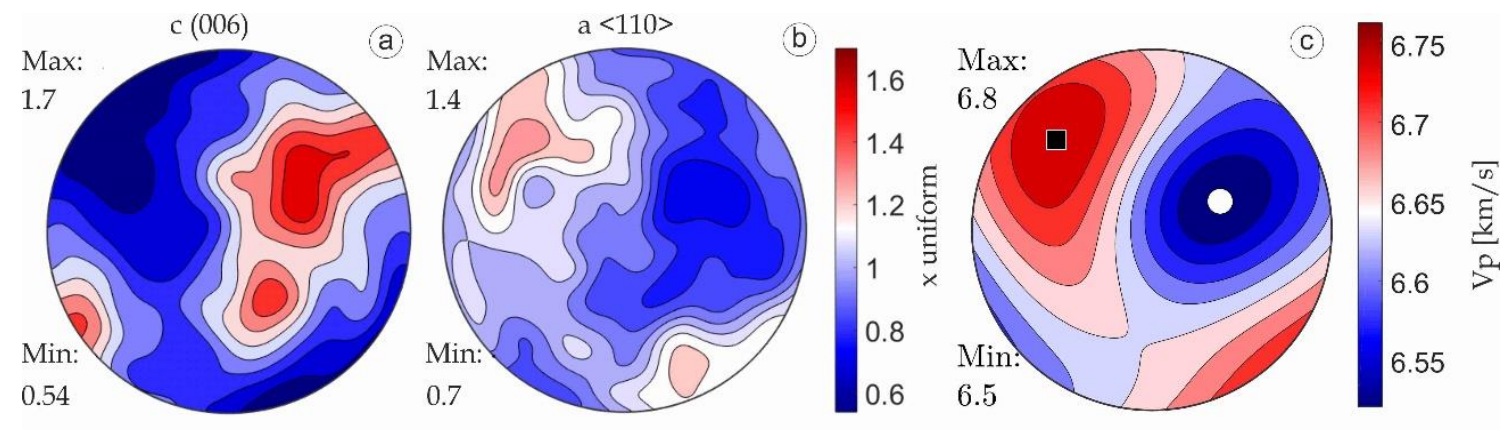

Figure 85 Texture (LPO) given for a) the $\mathrm{c}-(006)$ and $\mathrm{b}$ ) a-axes $<110>$. Intensities are given in mrd (multiple of random distribution), c) 3D velocity distribution $(\mathrm{km} / \mathrm{s})$ modelled from the EBSD data of the sculpture von Bülow (lower hemisphere, stereographic projection).

To see which amount of anisotropy for the ultrasonic velocity is controlled by the lattice preferred orientation, modelling of the intrinsic velocity distribution (see Mainprice et al., 1990) was performed using the MATLAB-based software MTEX (see Bachmann et al., 2010; Hielscher and Schaeben, 2008; Mainprice et al., 2011). To calculate the velocity distribution for the polycrystalline data, the measured texture data was used to calculate the intrinsic Vp distribution, based on the calculated ODF data. The modelled pole figure (Figure $85 \mathrm{c}$ ) shows a minimum velocity of $6.5 \mathrm{~km} / \mathrm{s}$ according to the position of the c-axes maximum (see Figure $85 \mathrm{a}$ ), while the maximum velocity of $6.75 \mathrm{~km} / \mathrm{s}$ is arranged along the a-axes maxima. 


\subsection{Ultrasound velocities and tomography}

\subsubsection{On site ultrasonic diagnostics -}

Field measurements in transmission

In May 2018, non-destructive ultrasonic measurements were applied to the sculptures, to form the basis for further investigations and decisions. Since the ultrasonic method indicates the degree of weathering, the ultrasonic measures were used in transmission and in the tomographic approach. Moisture has a huge impact on the ultrasonic velocity; therefore, it is necessary to ensure that longer dry conditions have existed before the velocities are measured. The sculptures were covered for almost 3 years (see Figure $82 \mathrm{c})$, ensuring a dry state for both sculptures. The night before the measurements were to take place, heavy rainfalls occurred in Berlin. Since the sculptures were wrapped in foil, and seemed to be dry in the morning, moisture influence should be negligible. However, at the pedestal and the head moisture influence cannot be totally excluded to affect the measured velocities.

The measurements were performed with a broadband transmitter, (UP-FH, for further information see www.geotron.de), where the necessary frequency could be chosen with respect to the measuring distance. Thus, one transmitter for all measurements could be used, which increases the accuracy as described above.

Figure 86 a shows the analysed velocities [km/s] measured for General von Bülow during transmission. Each value is colour coded for a specific state of weathering. The analysed compressional wave velocities range between 1.8 and $4.0 \mathrm{~km} / \mathrm{s}$, while the highest measured velocity $(4 \mathrm{~km} / \mathrm{s})$ was detected at the replaced sword. The highest velocity for the original material is $3.5 \mathrm{~km} / \mathrm{s}$ for his right foot. With $2.8 \mathrm{~km} / \mathrm{s}$ the average velocity is very low and is classified as granular disintegration. The overall measured velocities show a distribution that indicates a dependence on how exposed elements are and their geometry. The lowest and most alarming velocities classified as brittle are found at the filigree parts of the sculpture and at the completely exposed areas of the arm. Moreover, even thicker parts of the sculpture such as the trunk exhibit ongoing signs of deterioration with a velocity of $3.1 \mathrm{~km} / \mathrm{s}$. 
Velocities measured for General von Scharnhorst (Figure 86 b) indicate a slightly better weathering state for this sculpture, with a maximum velocity of $4.1 \mathrm{~km} / \mathrm{s}$ at the hip and head and the lowest measured velocity of $1.6 \mathrm{~km} / \mathrm{s}$ at a garment fold. The mean velocity is, compared to General von Bülow, slightly higher with $3.2 \mathrm{~km} / \mathrm{s}$, reflecting the overall better conditions of this sculpture, $66.66 \%$ of the 27 measured velocities can be classified as increasingly porous. The geometry and exposition dependent velocity distribution as measured for Gen. von Bülow can also be observed for the Scharnhorst sculpture, while the thicker areas generally show higher values.

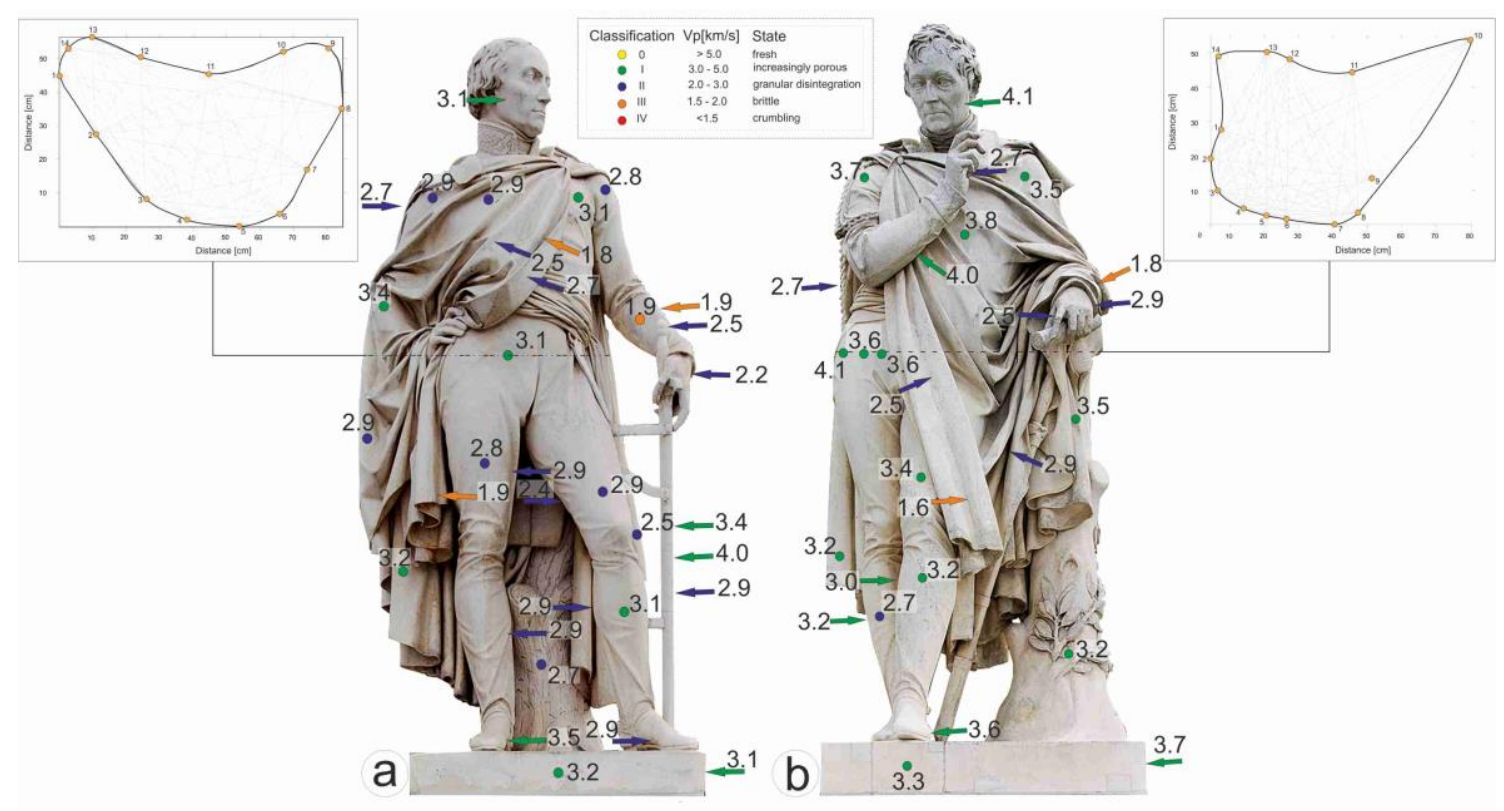

Figure 86 Results of the ultrasonic transmission measurements performed in 2018 for General Bülow a) and General von Scharnhorst b). Arrows indicate the measurement direction from the left to right. Dots represent a transmission direction from the front to the back of the sculpture. The different colours represent the damage classification after Köhler 2018, displayed between the sculptures. Vertical sectional plane for the trunk is given for both sculptures.

\subsubsection{Vp versus Travelpath}

Ultrasound velocity and travel path

The velocities variate according to the length of the ray path. This path length varies between 3-64 cm for General v. Bülow and $2-50 \mathrm{~cm}$ for General von Scharnhorst. To analyse-what impact these lengths have on the velocities of the rays, they are plotted against each other in Figure 87 (blue dots). Most velocities are analysed for ray paths between 2 and $20 \mathrm{~cm}$, which range between 1.8 to $4.0 \mathrm{~km} / \mathrm{s}$ for the first $10 \mathrm{~cm}$ and 2.0 
to $3.5 \mathrm{~km} / \mathrm{s}$ for the distances between 10 and $20 \mathrm{~cm}$ for Bülow (blue dots in Figure $87 \mathrm{a}$ ). The velocities determined for the distances above $20 \mathrm{~cm}$ show a less strong variation of the values with velocities between 2.7 and $3.4 \mathrm{~km} / \mathrm{s}$. The velocities at short travel paths vary more strongly, while velocities at longer ray paths vary less. However, the number of longer travel paths is relatively low. Nevertheless, this velocity variation is not uncommon for weathered marbles and is a logical consequence of deterioration and the low probability that a short ray path will cross unweathered material, whereas long travel paths almost always pass weathered and unweathered, or low weathered, areas of the stone (Blum and Rahm, 1998; Siegesmund et al., 2004b). In comparison, for the General Scharnhorst sculpture (blue dots in Figure $87 \mathrm{~b}$ ) fewer determined velocities are in the class granular disintegration. The weathering state is better than the sculpture of Bülow, but the velocities are low as well. The variation of velocities with a short ray path, smaller than $10 \mathrm{~cm}$ is with 1.7 to $3.2 \mathrm{~km} / \mathrm{s}$ lower than for the Bülow sculpture, while they vary between 2.7 to $4.1 \mathrm{~km} / \mathrm{s}$ for distances between 10 and $20 \mathrm{~cm}$, which is higher than the values measured for Gen. Bülow. The longer ray paths also show a smaller range for this sculpture, while the variation within these distances is between 3.4 and $3.8 \mathrm{~km} / \mathrm{s}$. Therefore, both sculptures have a comparable weathering state, while the sculpture von Scharnhorst shows higher velocities considering the long travel paths, which is reflected in the slightly higher mean velocity of $3.2( \pm 0.62) \mathrm{km} / \mathrm{s}$ compared to the $2.8 \mathrm{~km} / \mathrm{s}( \pm 0.45)$ for Gen. v. Bülow. Both sculptures have suffered during the last decades, while General v. Scharnhorst shows a lower state of deterioration, even if the Bülow sculpture was less exposed to the environment.

Transmission velocities only reflect the mean value for the measured distance and give no information about the inner structure. In addition, ultrasonic measurements have been performed in a tomographic application. The measurements were executed the trunk in the middle of both sculptures at a height of about $1.4 \mathrm{~m}$ above the pedestal (see Figure 86, Figure 87) for 14 different measuring points, with 91 measured travel paths. 
Bülow

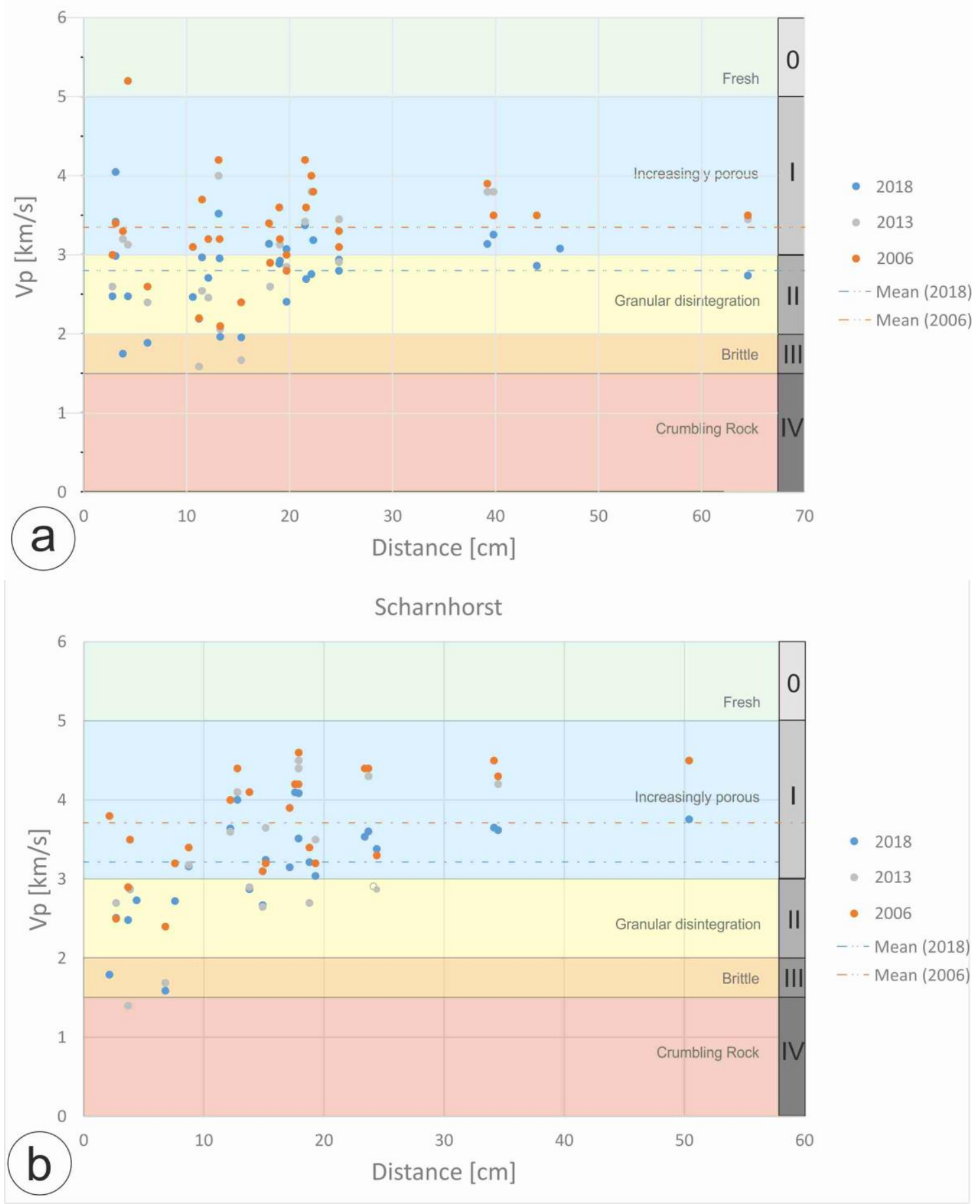

Figure 87 The measured transmission velocities ( $\mathrm{km} / \mathrm{s})$ of von Bülow a) and von Scharnhorst b) plotted according to the distance $(\mathrm{cm})$ the ray needed to travel. The dashed line represents the average velocity. 


\subsubsection{Tomograms}

\section{Ultrasonic tomography}

To process the data, the measured minimum and maximum values, received for the tomographic plane have been used as a limiting factor at the software GeoTom (see Chapter 3.4.2.3 Tomographic inversion). The initial velocity model has been calculated based on the average velocity. These processed tomograms are transferred to the program Surfer and are depicted as contour plots in Figure 88, where the lower margin of both plots refers to the front of the sculptures (north is the viewing direction), while the upper margin refers to the back.
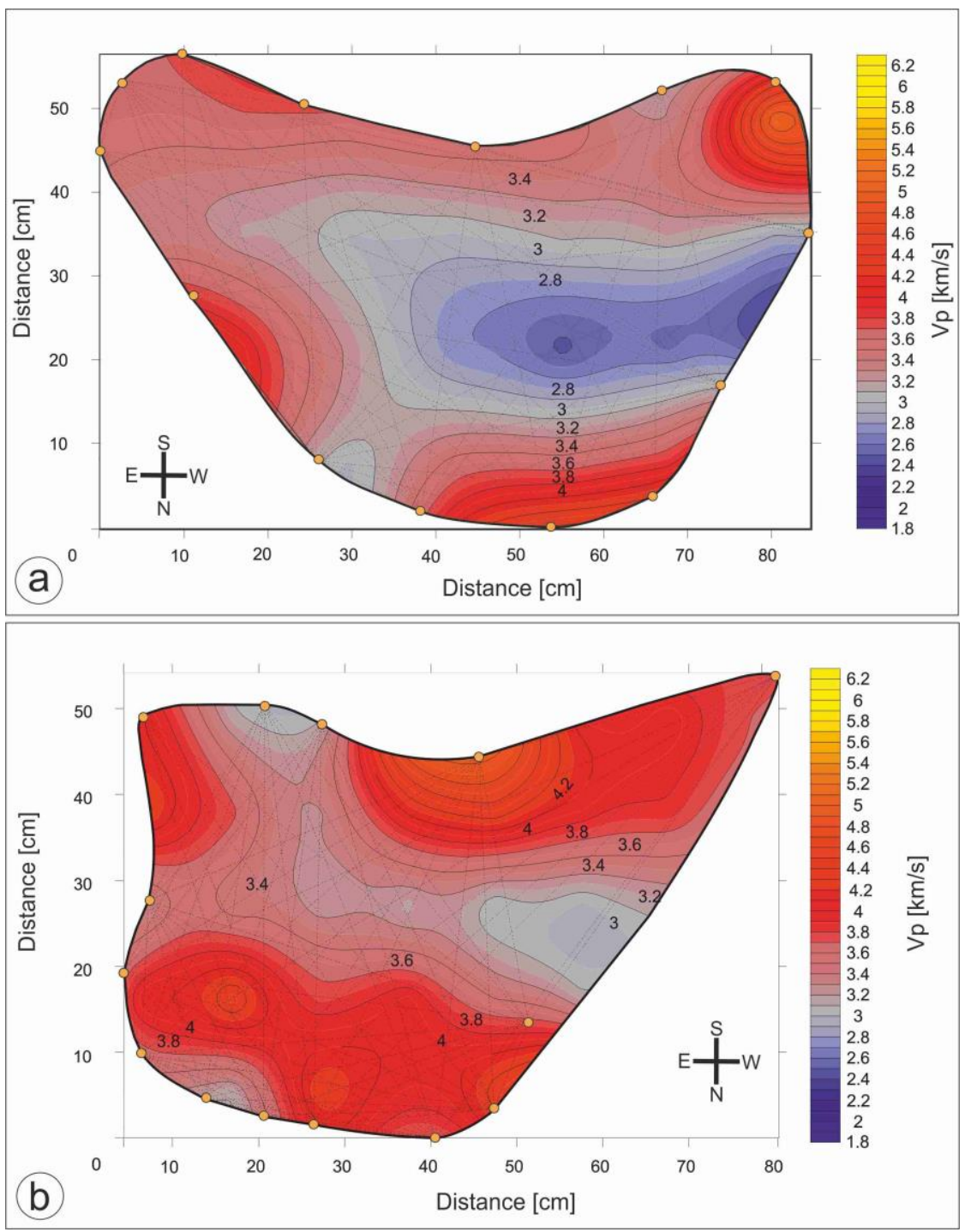

Figure 88 Ultrasonic tomograms of General v. Bülow a) and General v. Scharnhorst b), computed for the horizontal sectional planes shown in Figure 85. Velocities are given in $\mathrm{km} / \mathrm{s}$, the compass direction is given in the left (a) and right (b) corner of the plot. The lower edge of both tomograms represents the front view of both sculptures. 
The tomogram calculated for General v. Bülow (Figure 88 a) shows a small channel of lower velocities $(2.5-2.8 \mathrm{~km} / \mathrm{s})$ in the middle of the sculpture that are elongated to the west. The low velocities in the western part of the tomogram are in an area with low or no ray coverage. The highest velocities can be found in the northern direction, which is the front of the sculpture. The higher ultrasound velocities are arranged like a " $U$ " dipping to the west, surrounding the low east-west striking velocity channel. The majority of the tomogram is characterized by velocities between $2.8 \mathrm{~km} / \mathrm{s}$ and $3.6 \mathrm{~km} / \mathrm{s}$, the highest values can be found selective along the rim of the tomographic plane. This area needs a sensitive and careful interpretation because the number of rays, travelling this area is very low. The tomogram displayed for General v. Scharnhorst (Figure 88 b), shows fewer areas with lower velocities where values range between 3.0 and $5.0 \mathrm{~km} / \mathrm{s}$. The small zone in the western part of the tomogram is again an area with low ray coverage. The highest velocities can be found in the northern part of the tomogram, while the lower velocities run through the tomogram as a belt in the middle of the tomographic plane, striking east-west, further as an area in the north-east and south-east of the tomogram. Most areas show velocities between 3.4 and $4.2 \mathrm{~km} / \mathrm{s}$, confirming the other measurements, that this sculpture is in a slightly better state of condition than v. Bülow.

\subsection{Discussion}

Ultrasonic measurements can provide a non-destructive insight into the structural properties of a material. In the case of objects of cultural heritage, urgent attention is given to the weathering state as well as possible deterioration zones and cracks. This method is proven and powerful, but some basic knowledge is indispensable for accurate velocities and a competent interpretation. Based on this method, decisions regarding conservation and restoration measures can be made, as well as the highest impact decision, the replacement of important sculptures.

In 2018, fortuitous circumstances allowed the comparison of the present results with the velocities acquired in 2013 and 2006 for the sculptures von Bülow and von Scharnhorst. This has given the present study an opportunity for a closer examination of the development of deterioration within the last 12 years. Due to the good documentation of those investigations, most boundary conditions are known, e.g. the equipment used, 
measured areas and the exact distances between transmitter and receiver positions. This improves the comparability of those studies with the latest results. Even if technical conditions, application errors and the possible deviation of $10 \%$ between different measurement teams (see DBU final report AZ. 29544/01), the highest impact causing deviations, is given by possible water saturation.

Ultrasonic velocities of marbles strongly depend on the moisture content of the rock. Marbles can show velocities of $3.0 \mathrm{~km} / \mathrm{s}$ and less in the dry state, while velocities may reach about 6.0 km/s under water-saturated conditions (Menningen et al., 2018b; Ruedrich et al., 2001; Siegesmund et al., 2010; Weiss et al., 2002a). The pore space developing in marbles is small but very efficient in reducing the velocities and also increasing them due to fluid saturation. Therefore, ultrasonic velocity measurements are extremely sensitive on type and degree of fluid saturation (Weiss et al., 2002a)

Before the measurements were done in 2018, the sculptures had been covered for about three years. This means both sculptures were protected from the rain, with the exception of the aforementioned rainfall the night before measuring, and thus can be considered dry. The investigations in 2006 and 2013 were executed after 2 weeks of coverage, while the exact date is not known. In 2006 the measurements were done in November, after 3 months of restoration, when besides different measures a structural strengthening was performed with the application of $3 \%$ Paraloid B72 (Acrylic resin) in acetone to both sculptures. Two weeks before the ultrasonic measurements were done, the sculptures have been completely covered against direct rainfalls. In September and October 200616 days with rainfall have been reported. The amount of precipitation has been low, while the 29th of October showed a higher amount of rain with $13 \mathrm{~mm}$ (see https://www.wetteronline.de/, data for Berlin-Tegel in 2006). Therefore, the influence of water cannot be absolutely excluded, but should be not that high.

\subsubsection{Transmission measurements}

Field measurements in transmission

The applied transmission measurements executed in 2018 were done at the same locations on the sculptures as in the former investigations. Thus, the results of 2018 can be 
compared to them and give an impression about the damage influences on the sculptures within the last 12 years. In 2006 and 2013 the measurements were executed with a $250 \mathrm{kHz}$ transmitter on the filigree parts and $48 \mathrm{kHz}$ for the pedestal. In contrast, the 2018 study used a broadband transmitter, so that one transmitter could be used for all

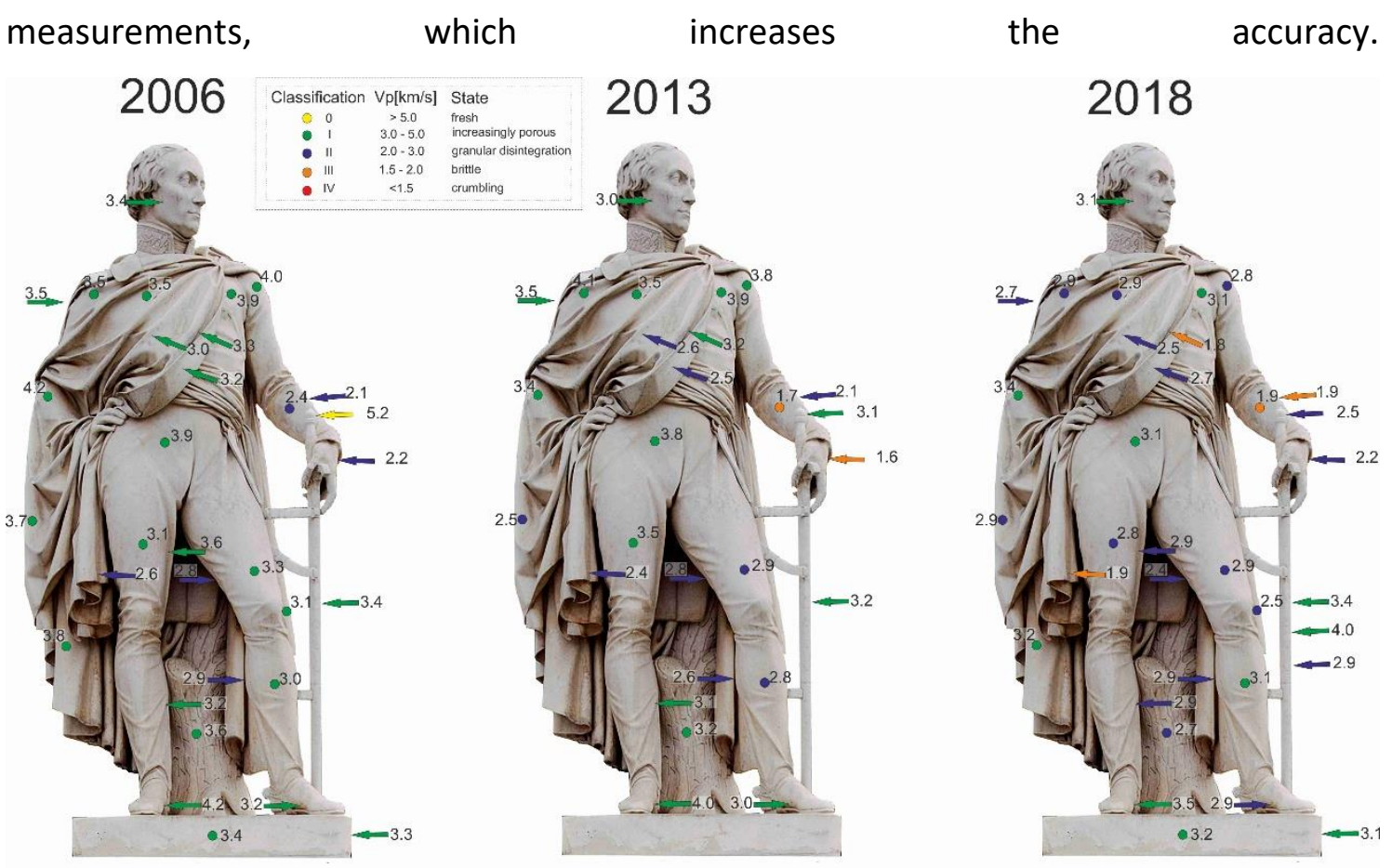

Figure 89 Measured ultrasonic velocities, analysed by using the pulse transmission technique, given for the sculpture of General v. Bülow in 2006, 2013 and 2018. Arrows indicate a lateral (east-west) attachment of the probes, while the dots represent the north-south direction of the arranged probes. Colour code represents the damage classification modified after Köhler 2018. Numbers give the measured velocities in $\mathrm{km} / \mathrm{s}$.

Figure 89 shows the measured velocities [km/s] received for General von Bülow in 2006, 2013 and 2018. The velocities for most parts of the sculpture slowed down during the investigated timespan and changed from the classification of increasingly porous (green) to granular disintegration (blue). The maximum velocity in 2006 was measured on a part of the substituted sword handle with $5.2 \mathrm{~km} / \mathrm{s}$. While the handle slowed down to 2.5 $\mathrm{km} / \mathrm{s}$ the highest measured velocity $(4 \mathrm{~km} / \mathrm{s}$ ) was in 2018 , detected on the substituted sword. As this was an additional measurement no correlating value to the study in 2006 exists. The maximum velocity measured for the original material in 2006 was $4.2 \mathrm{~km} / \mathrm{s}$, in comparison with the maximum of 4.0 in 2013 and $3.5 \mathrm{~km} / \mathrm{s}$ in the present study. The lowest velocity measured in 2006 was $2.1 \mathrm{~km} / \mathrm{s}$ for the left arm, which showed no re- 
duction in 2013 and slowed down to $1.9 \mathrm{~km} / \mathrm{s}$ in 2018. The lowest velocity in 2013 measured on the left hand was $2.2 \mathrm{~km} / \mathrm{s}$, which is the same in 2018 as in 2006. In 2018 the lowest velocity detected was on a mantle fold with $1.8 \mathrm{~km} / \mathrm{s}$, which was much higher in $2006(3.3 \mathrm{~km} / \mathrm{s})$ and $2013(3.2 \mathrm{~km} / \mathrm{s})$. The mean velocity was $3.4( \pm 0.62) \mathrm{km} / \mathrm{s}$ in 2006, $3.0( \pm 0.67) \mathrm{km} / \mathrm{s}$ in 2013 and has decreased to $2.8( \pm 0.46) \mathrm{km} / \mathrm{s}$ in 2018 , which is a reduction of $15.7 \%$ during the last 12 years and $5.7 \%$ within the last 5 years.
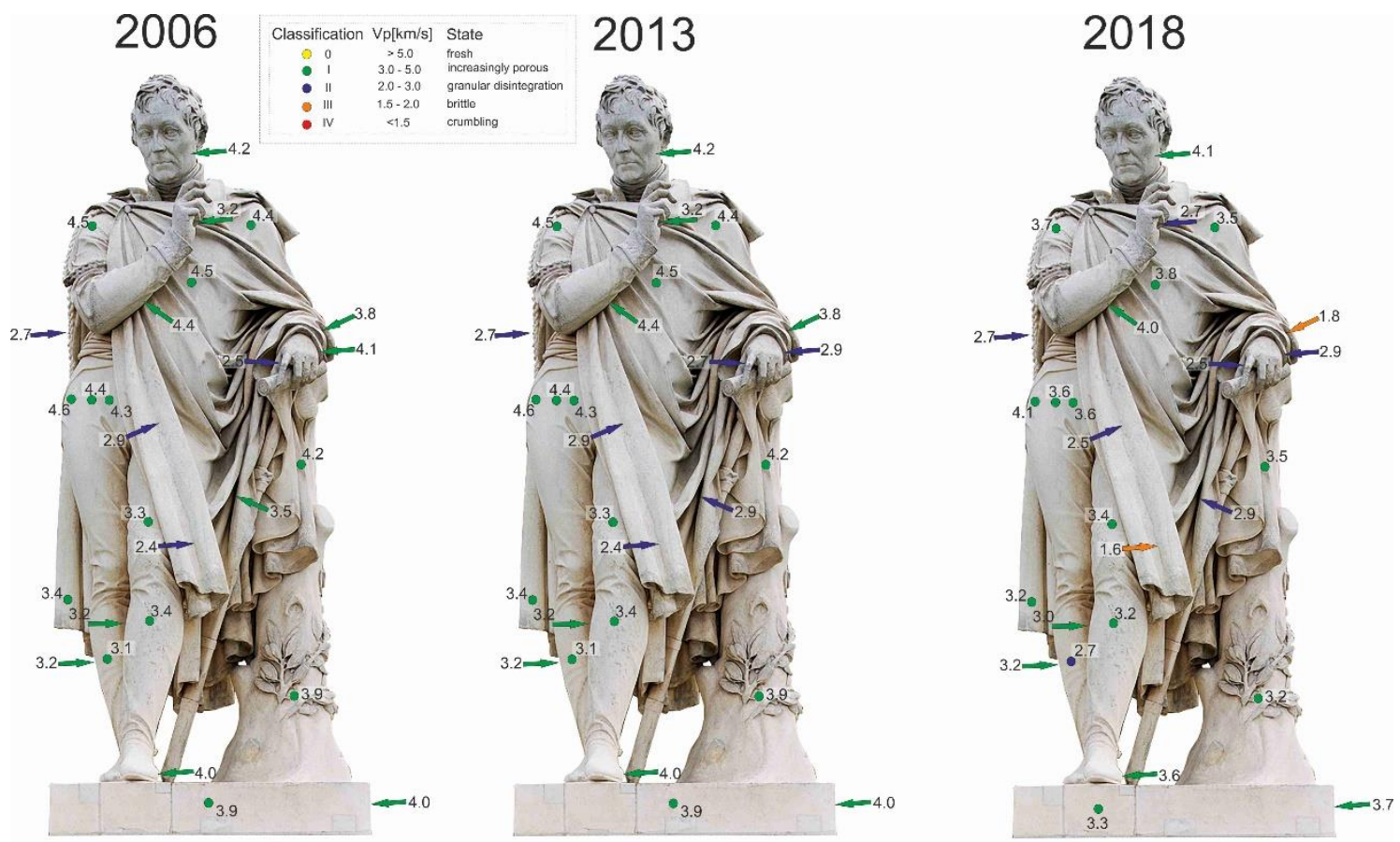

Figure 90 Measured ultrasonic velocities, analysed by using the pulse transmission technique, given for the sculpture of General v. Scharnhorst in 2006, 2013 and 2018. Arrows indicate a lateral (east-west) attachment of the probes, while the dots represent the north-south direction of the arranged probes. Colour code represent the damage classification modified after Köhler 2018. Numbers give the measured velocities in $\mathrm{km} / \mathrm{s}$.

Figure 90 displays the velocity evolution for the sculpture General von Scharnhorst using the same classification and colour code as in Figure 86 and Figure 89. In 2006 the velocities indicate a slightly better weathering state for this sculpture with a maximum velocity of $4.6 \mathrm{~km} / \mathrm{s}$ and a minimum velocity of $2.4 \mathrm{~km} / \mathrm{s}$, whereas the velocities received in 2018 at the same position are now reduced to $4.1 \mathrm{~km} / \mathrm{s}(\max )$ and $1.6 \mathrm{~km} / \mathrm{s}$. They remained almost stable until 2013. The mean velocity decreased from $3.7( \pm 0.63) \mathrm{km} / \mathrm{s}$ in 2006 down to $3.4( \pm 0.88) \mathrm{km} / \mathrm{s}$ in 2013 and $3.2( \pm 0.62) \mathrm{km} / \mathrm{s}$ in 2018. The velocity reduction is about $14.7 \%$ within the last 12 years and $5.1 \%$ since 2013 . The sculpture of Gen. v. Bülow shows a higher decrease of the ultrasonic values and that the deterioration is 
constantly increasing, independent of the preventive measures applied within the last 15 years. Especially the filigree parts such as folds, and completely exposed areas show the lowest and alarming velocities which need to be classified as brittle.

To analyse which impact the path lengths have on the velocities of the rays, they are plotted against each other for General von Bülow in Figure 87a. Most velocities are analysed for ray paths between 2 and $20 \mathrm{~cm}$, which ranged in 2006 (orange dots) between 2.6 and $5.2 \mathrm{~km} / \mathrm{s}$ for the first $10 \mathrm{~cm}$ and between 2.1 and $4.2 \mathrm{~km} / \mathrm{s}$ for distances between 10 and $20 \mathrm{~cm}$. In 2018 (blue dots) these values are lower with 1.8 to $4.0 \mathrm{~km} / \mathrm{s}$ for the first $10 \mathrm{~cm}$ and 2.0 to $3.5 \mathrm{~km} / \mathrm{s}$ for the distances between 10 and $20 \mathrm{~cm}$. The velocities determined for the distances above $20 \mathrm{~cm}$ show a less strong variation of the values with velocities between 3.1 and $4.2 \mathrm{~km} / \mathrm{s}$ in 2006 and 2.7 and $3.4 \mathrm{~km} / \mathrm{s}$ in 2018 . The velocities at shorter travel paths vary more strongly, while velocities at longer travel paths vary less. If the velocities of the last three studies are compared (Figure $87 \mathrm{a}$ ), the ultrasonic velocities measured for General v. Bülow generally slowed down throughout the last 12 years and the most common damage classification changed from increasingly porous to granular disintegration. In comparison,-fewer velocities examined for General Scharnhorst are located in the classification granular disintegration (Figure $87 \mathrm{~b}$ ) and the weathering state can be described as better than the sculpture of Bülow, but the velocities are also low and decreased within the last 12 years. The variation of velocities with a short ray path, smaller than $10 \mathrm{~cm}$ is with 2.4 and $3.8 \mathrm{~km} / \mathrm{s}$ lower than for the Bülow sculpture. They vary between 3.1 and $4.6 \mathrm{~km} / \mathrm{s}$ for distances between 10 and $20 \mathrm{~cm}$ in 2006, which is higher than the values received for Gen. Bülow. In 2018 (blue dots) these velocities are slower with 1.7 to $3.2 \mathrm{~km} / \mathrm{s}$ for the first $10 \mathrm{~cm}$ and 2.7 to $4.1 \mathrm{~km} / \mathrm{s}$ for the distances between 10 and $20 \mathrm{~cm}$. The longer ray paths also show for this sculpture a smaller range, while the variation within these distances was higher in 2006 (3.3 $4.5 \mathrm{~km} / \mathrm{s}$ ) and is now between 3.4 and $3.8 \mathrm{~km} / \mathrm{s}$. Therefore, both sculptures have a comparable weathering state, while the sculpture von Scharnhorst shows higher velocities considering the long travel paths, which is reflected in the slightly higher mean velocity of $3.2( \pm 0.62) \mathrm{km} / \mathrm{s}$ in 2018 compared to the $2.8( \pm 0.46) \mathrm{km} / \mathrm{s}$ for General v. Bülow. Both sculptures have deteriorated during the last decades, however the General v. Scharnhorst sculpture shows a lower state of deterioration, even if this sculpture was longer exposed to environmental influences as v. Bülow. 


\subsubsection{Laboratory measurements}

To see if the distribution of velocities shows any directional dependence, a drill core from the General v. Bülow sculpture was analysed by ultrasonic measurements. The drill core was examined as a depth profile along the $10 \mathrm{~cm}$ drill core with incremental measuring points of $1 \mathrm{~cm}$, starting close to the former surface of the sculpture at $1 \mathrm{~cm}$ and ending at $9 \mathrm{~cm}$ from the end of the core. The depth profile has been measured in two different directions (Figure 91 red and blue graph). A third direction (green graph) represents the value determined for the whole length of the core. Reorienting the core to the compass direction of the von Bülow sculpture, the blue line represents measurements in the east-west direction, whereas the green graph is oriented to the north-south direction. Therefore, the blue and green graphs in Figure 91 depict the velocities measured in the horizontal orientation, equivalent to the horizontal in the sculpture, while the red graphs depict the vertical orientation. The measurements were done under dry (marked with a square) and water-saturated conditions (marked with a circle). The results obtained for the core are depicted in Figure 91 and show an interesting trend for the values under dry conditions. Contrary to the expected trend, the velocities taken at the surface of the core are higher than the values at a depth of $9 \mathrm{~cm}$. The velocities are $4 \mathrm{~km} / \mathrm{s}$ for the first centimetre and slow down to $3.1 \mathrm{~km} / \mathrm{s}$ within the first $3 \mathrm{~cm}$, while the last $6 \mathrm{~cm}$ show a small range within the velocities around 2.7 and $3.2 \mathrm{~km} / \mathrm{s}$. The velocity for the whole length of the core is $3.4 \mathrm{~km} / \mathrm{s}$. Based on these data a directional dependency cannot be detected. This can be caused by a low pronounced preferred orientation as shown in Figure $85 \mathrm{a}$ and $\mathrm{b}$ or because the measurements have been executed at intermediary areas and missed the preferred directions. The velocities under water-saturated conditions show a comparable distribution for the blue graph, measured in the east-west direction, with little higher values between 3.7 and $4.7 \mathrm{~km} / \mathrm{s} \mathrm{com}$ pared to the results for the dry sample ranging between 2.6 and $4.1 \mathrm{~km} / \mathrm{s}$. 


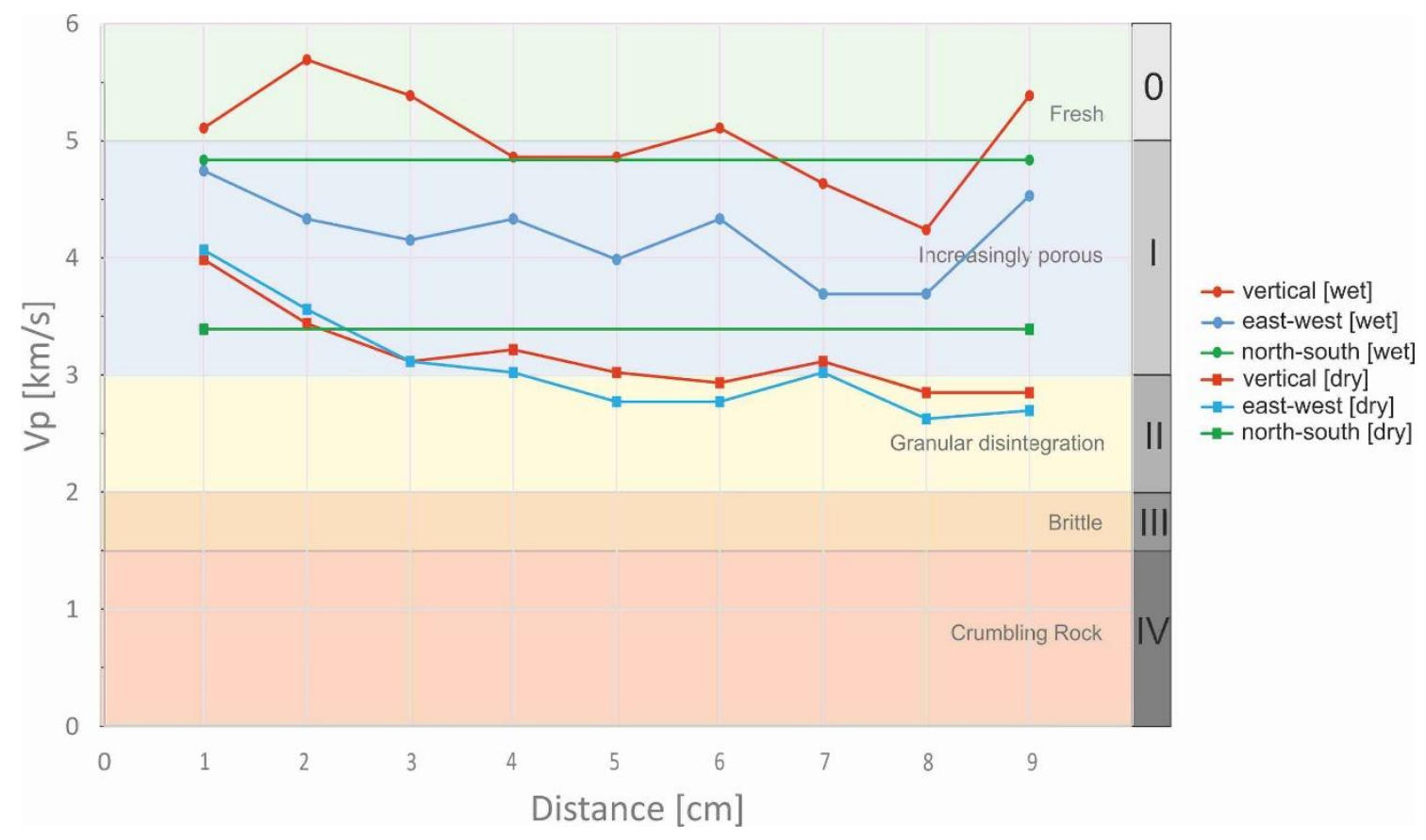

Figure 91 Ultrasound velocities measured for a drill core from the von Bülow sculpture under dry (square markers) and wet conditions (dots). The green line represents the velocity investigated for the whole length of the core, according to the north-south compass direction. The red and blue values were received in the horizontal east-west direction (blue) and vertical direction (red). The measurements were executed as a depth profile, $1 \mathrm{~cm}$ is almost the former surface of the sculpture and $9 \mathrm{~cm}$ depth into the sculpture. Velocities were measured with a distance of $1 \mathrm{~cm}$ between the measuring points.

Both graphs show higher velocities at the surface and lower velocities at a depth of 9 $\mathrm{cm}$. The red graph shows the fastest velocities, which were measured under water-saturated conditions in the vertical direction. The velocities increase from $5.1 \mathrm{~km} / \mathrm{s}$ up to $5.7 \mathrm{~km} / \mathrm{s}$ for the first two centimetres, before they decrease down to $4.3 \mathrm{~km} / \mathrm{s}$ until a depth of $8 \mathrm{~cm}$, where the velocity finally increases for the last centimetre, up to 5.4 $\mathrm{km} / \mathrm{s}$. This behaviour can also be observed for the blue graph under water-saturated conditions, which increases from 3.7 up to $4.5 \mathrm{~km} / \mathrm{s}$. The value for the north-south direction of the core is again within the range of the other two directions. The values suggest that there is a directional dependence of the ultrasound velocities, but these results do not seem to be reliable. In many studies of ultrasound velocity distribution and their development due to weathering, the variation in different directions increases with increasing deterioration, expressed in a higher anisotropy. Therefore, the core shows a contrary trend, with less anisotropy within the different directions in a deteriorated state. It seems to be more plausible that other effects influence these results. The core has a diameter of $20 \mathrm{~mm}$, which triggers different problems that need to be considered. 
First a relatively small change in the short travel time will cause a large change in velocity, which is caused by the relationship of travel time and velocity. Second, the small diameter combined with a big length of the core causes a fast drying of the water-saturated sample. Therefore, the difference between the horizontal and vertical direction under saturated conditions can be influenced by the drying process. Third, the small diameter combined with the frequency of $350 \mathrm{kHz}$ and the chosen probe tip can cause wrong results, especially for the high velocities. Based on the correlation of frequency and wavelength (see Deutsch, 2010), the wavelength caused by the specific wave velocity-frequency combination can be determined. In this study, all wavelengths show sufficient sizes, but nonetheless the diameter of the sample is very small and could influence the results.

Generally, the velocities measured for the core are low and can be classified as granular disintegration (see Figure 91), while at the SEM pictures, taken at a depth of $4 \mathrm{~cm}$ (Figure $84 \mathrm{e}$ ) and at $6 \mathrm{~cm}$ (Figure $84 \mathrm{f}$ ) the marble shows no open grain boundaries. The reasons for higher values, analysed for the surface could be a former consolidation. In 2006 a consolidation with Paraloid B72, an acrylic resin, was mentioned in the restauration history provided by the Bureau for the Preservation of State Monuments Berlin.

\subsubsection{Tomographic inversion}

Ultrasonic tomography 12 years later

In Figure 92, the VP-travel path plots are given for the velocities determined for the tomographic planes for both sculptures in 2006 and in 2018. In 2018 they range between 2.3 and $5.1 \mathrm{~km} / \mathrm{s}$ for General v. Bülow (Figure $92 \mathrm{a}$, blue dots) with an average value of $3.3( \pm 0.44) \mathrm{km} / \mathrm{s}$, while they are slightly higher for General v. Scharnhorst and range between $2.6 \mathrm{~km} / \mathrm{s}$ and $5.1 \mathrm{~km} / \mathrm{s}$ with an average value of $3.8( \pm 0.43) \mathrm{km} / \mathrm{s}$ (Figure $92 \mathrm{~b}$, blue dots). The Vp-travel path plot shows, according to the transmission measurements described before, generally lower velocities for Bülow, with a broader range of them, even for long distances, while the variation is lower for the long distances of General v. Scharnhorst. Even if both sculptures exhibit ultrasound velocities that can be classified as increasingly porous, the slightly better conditions of General von Scharnhorst, with 
fewer values in the category of granular disintegration can be observed easily in Figure

92.

\section{Bülow}

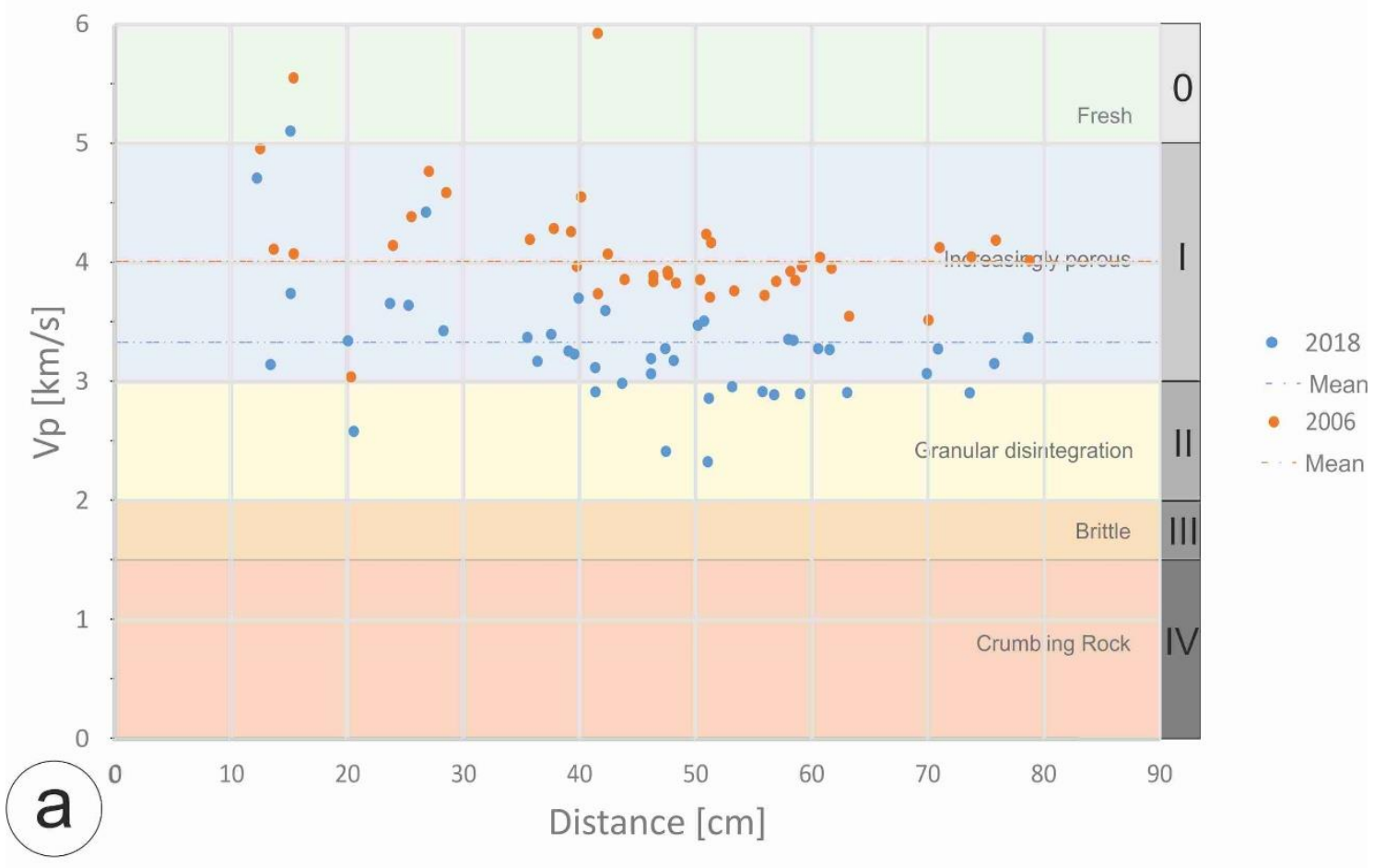

Scharnhorst

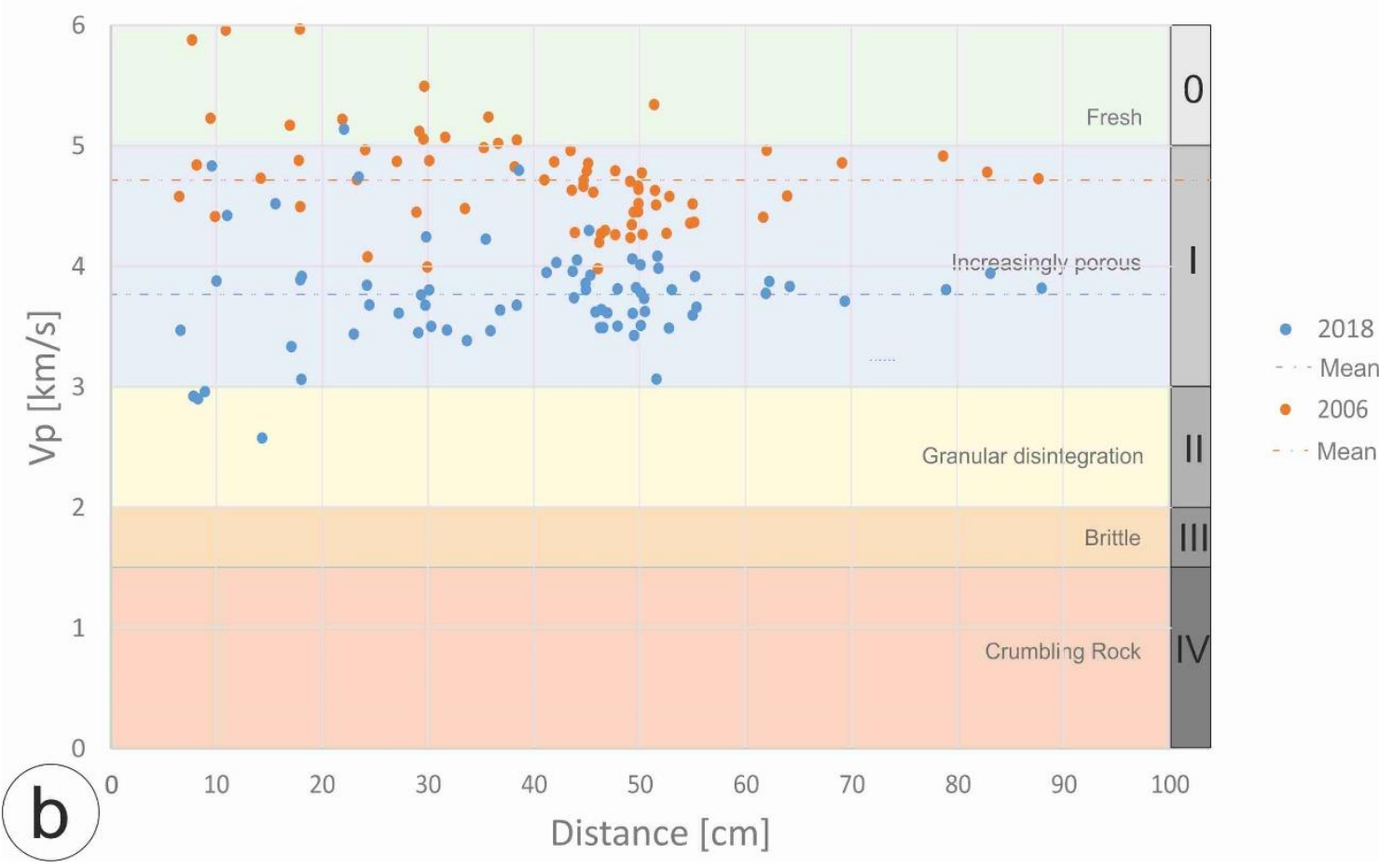

Figure 92 Measured ray velocities ( $\mathrm{km} / \mathrm{s}$ ) of the tomogram for von Bülow (a) and von Scharnhorst (b) in 2018 (blue dots) and 2006 (red dots) plotted according to the distance $(\mathrm{cm})$ the ray needed to travel. The dashed line represents the average velocity. 
Independent of the length of the travel path, all measured the velocities continued to decline since 2006 . The mean velocity of $4.0( \pm 0.5) \mathrm{km} / \mathrm{s}$ declined around $0.7 \mathrm{~km} / \mathrm{s}$ down to $3.3( \pm 0.44) \mathrm{km} / \mathrm{s}$ in the last 12 years for General v. Bülow and around $1.0 \mathrm{~km} / \mathrm{s}$ from $4.8( \pm 0.5) \mathrm{km} / \mathrm{s}$ down to $3.8( \pm 0.43) \mathrm{km} / \mathrm{s}$ for General v. Scharnhorst. The most astonishing result is that even the velocities for long distances of more than $40 \mathrm{~cm}$ show a significant reduction of about $1 \mathrm{~km} / \mathrm{s}$, indicating a strong deterioration. Another interesting aspect is that all velocities for the shorter distances of General v. Bülow, are the same or higher than the values for longer distances. Higher velocities are not uncommon for shorter distances and can be caused by different reasons (e.g. Lindner et al., 1999), but that more or less all measured velocities for short distances of a weathered marble are higher than those for longer distances is quite unusual (e.g. Fleischer, 2002; Ruedrich et al., 2013).

Besides the transmission measurements, a 2D tomographic reconstruction was done for both sculptures in 2006. Since this measuring investigation was well documented, it was possible to choose in 2018 the same height and transmitter - transducer positions as in 2006. Consequently, it was possible to compare the tomograms of 2018 with the tomograms of 2006. An exception is that the better ultrasonic probes in 2018 enabled to detect more signals than in 2006. As a result, the tomograms of 2018, used for the comparison of both investigations and modelling $\Delta V p$, have been reduced to the same amount of measuring points as in 2006. This leads to 41 measured rays for the sculpture General von Bülow and 73 measured rays for General von Scharnhorst.

The tomographic data of 2006 were used to model tomograms and to compare them to the tomograms of 2018, for a better interpretation of the alterations that occurred within the last 12 years. Due to the smaller number-of measured velocities in 2006, the $\Delta V p$ tomograms have been modelled with the same number of travel paths for the 2018 tomograms (small tomograms in Figure $93 \mathrm{~b}$ and $14 \mathrm{~b}$ ). Nevertheless, the tomograms for General von Bülow shown in Figure 93 demonstrate that the distribution of the velocities in 2006 is comparable to the 2018 data set with significantly lower values, regarding their spatial arrangement. Both tomograms show low velocities in the middle of the tomograms with $3.5 \mathrm{~km} / \mathrm{s}$ in 2006 (a) and $2.5 \mathrm{~km} / \mathrm{s}$ in 2018 (b), while the outer part shows higher velocities ranging between 4.2 and $4.8 \mathrm{~km} / \mathrm{s}$ in 2006 and $3.4 \mathrm{~km} / \mathrm{s}$ and 4.0 
$\mathrm{km} / \mathrm{s}$ in 2018. The higher number of measured rays reveals that in 2018 the low velocities in the middle expand to the western surface. Disregarding the additional rays as shown in the small tomogram, this area is invisible, according to the 2006 tomogram.
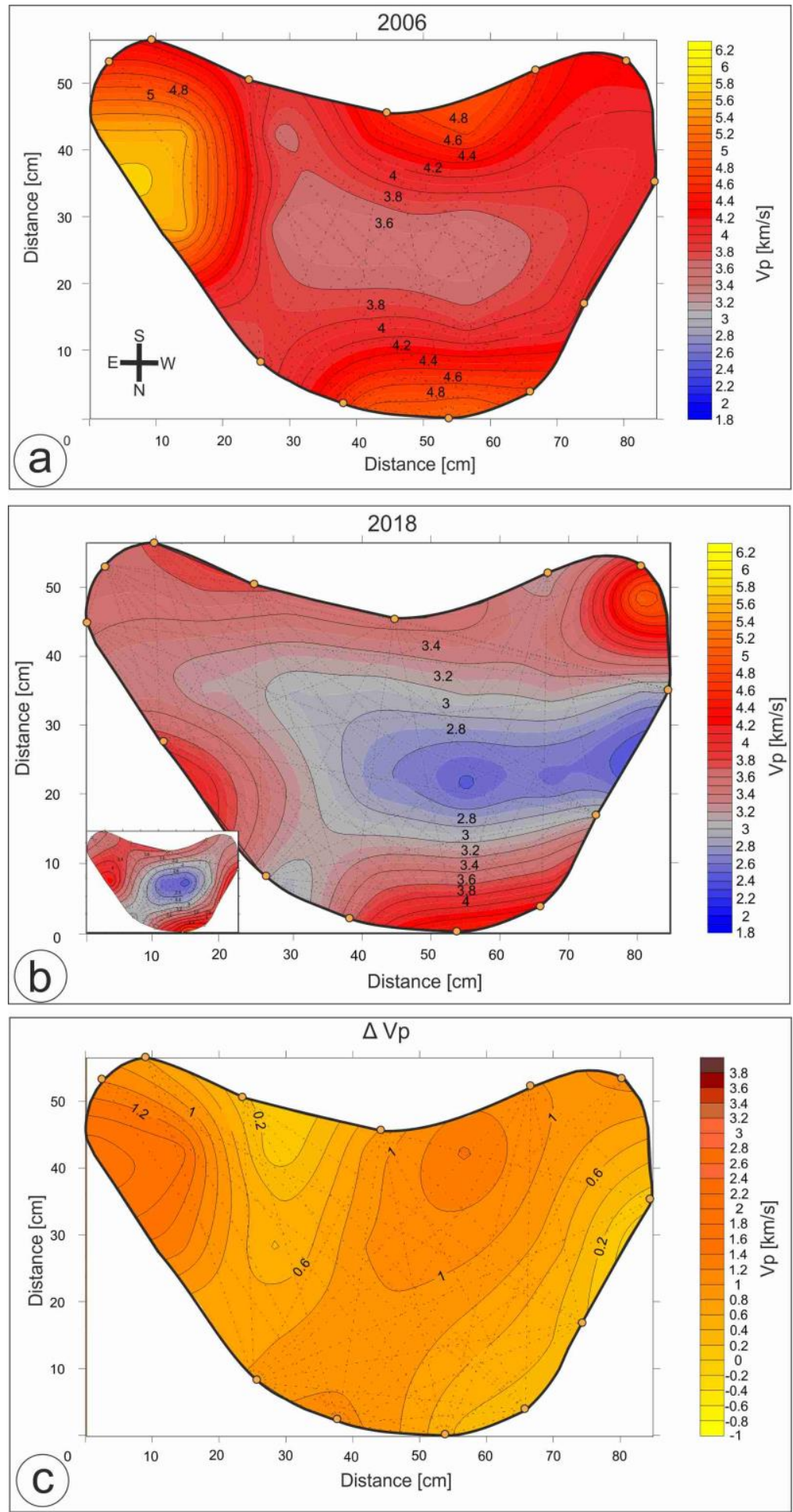

Figure 93 Ultrasonic tomogram for General v. Bülow measured in a) 2006, with lower ray coverage, b) 2018 higher ray coverage and c) $\Delta V p$ modelled by the difference of a) and b), while the number of rays for the measurement in $\mathbf{2 0 1 8}$ was adjusted to the lower number of rays for the 2006 tomogram (small picture in b). 
The $\Delta$-Vp tomogram shown in Figure $93 \mathrm{c}$ depicts that the highest reduction occurs in the eastern part and the middle of the tomographic plane, separated by an area with less reduction, tending to the south, the back of the sculpture.
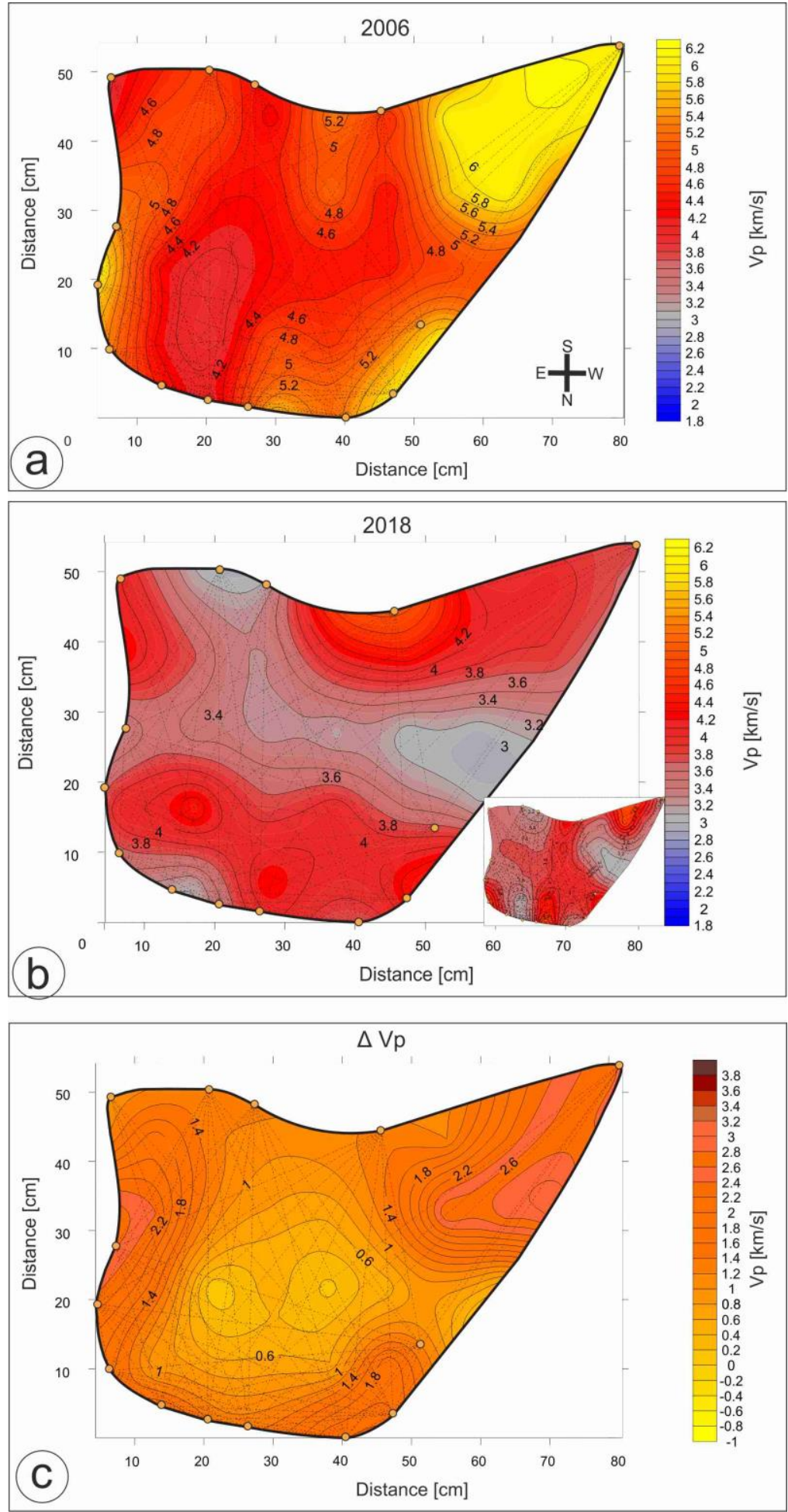

Figure 94 Ultrasonic tomogram for General v. Scharnhorst measured in a) 2006, with lower ray coverage, b) 2018 higher ray coverage and c) $\Delta \mathrm{Vp}$ modelled by the difference of a) and b), while the number of rays for the measurement in 2018 was adjusted to the lower number of rays for the 2006 tomogram (small picture in b). 
The tomograms for General v. Scharnhorst, depicted in Figure 94 show a different distribution. Here the velocities in 2006 (a) ranged between 4.2 and $6.2 \mathrm{~km} / \mathrm{s}$, while the zone in the south-west, showing high velocities was only passed by a few crossing ray paths, therefore this area should be interpreted with care. The velocities of 2018 , shown in Figure 94 b are lower than in 2006 (a), but unlike the tomograms of General v. Bülow, the reduction is primarily located at the outer areas of the sculpture. The $\Delta-\mathrm{Vp}$ tomogram in Figure $94 \mathrm{c}$ shows that the eastern and western area are stronger deteriorated than the middle, where the reduction was not that high.

The distribution of the ultrasonic velocity depends on the lattice preferred orientation. Therefore, the modelled 3-dimensional ultrasonic velocity for the sculpture of General von Bülow (see Figure $85 \mathrm{c}$ ) was rotated about $90^{\circ}$ (Figure 95) to have the same orientation as the 2-dimensional tomograms (Figure 93). The displayed velocity is given at the lower hemisphere and cannot be directly transferred to the measured layer in Figure 93, as they show different dimensions. Nevertheless, the area of low velocities in Figure 93 could be influenced by the texture, while an isotropic velocity distribution could also be possible. Since the 2-dimensional velocity distribution for the specific section could not be determined, no clear determination of the intrinsic velocity distribution can be given for the specific tomographic section. The amount of decay phenomena and heterogeneities can only be quantified if the anisotropic velocity variation is considered. But as the texture is only weakly pronounced and even the measurements at the drill core showed no clear directional dependence, the influence based on anisotropy seems to be negligible.

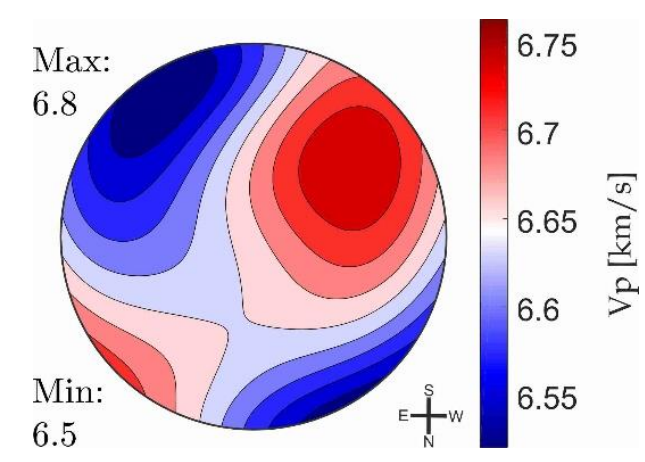

Figure 95 Reoriented, modelled 3D-velocity distribution adjusted to the 2D-tomogram of the sculpture von Bülow. The orientation is the same as for the sculpture, see compass direction. 
Another aspect which influences the damage and the spatial distribution is the geographic exposure of the sculpture (see Brimblecombe, 2014). The western area is the main weather side in Berlin (see www.de.windfinder.com). The long-time span of outside exposure indicates that the main influence on the rock fabric is caused by weathering. Since the main wind direction is west, the impact of weathering should be more pronounced for the west-facing surfaces. Decay caused by cyclical influences of wind, wind-driven rain and other changes of humid and dry conditions should be most pronounced on these sides of the sculptures.

\subsection{Conclusion}

After almost 200 years of exposure, several relocations, vandalism and restauration measures, the monuments of General Scharnhorst and Bülow have been analysed by ultrasonic measurements. The data of three different measurement studies in the last 12 years have been compared to describe the weathering behaviour of two important sculptures with a comparable weathering history. Both sculptures are made of Carrara marble, both sculptures have been exposed to the same environmental influences and both sculptures are, based on the results of the ultrasonic measurements, in alarming conditions.

The correlation of the dimension and the effective degradation mechanisms was described by Siegesmund et al. 2013. The filigree parts such as the folds and the completely exposed areas like the arms show generally the lowest and alarming velocities, which need to be classified as brittle. Due to the small dimension of these areas, the different degradation mechanisms lead to a very strong degree of decay. This can be confirmed by the results for both sculptures, but even thicker parts of the as the trunk exhibit ongoing signs of deterioration with velocities of $2.6 \mathrm{~km} / \mathrm{s}$ for the sculpture of Bülow, signalling the advanced decay progress. Consistent with the results in 2006 and 2013, the sculpture of General v. Scharnhorst is in a better condition, compared to Bülow, but some conspicuous features need to be considered.

The transmission measurements from 2018 indicate that the filigree parts of both sculptures show lower velocities around $2 \mathrm{~km} / \mathrm{s}$, compared to thicker parts with velocities 
between 3 and $4 \mathrm{~km} / \mathrm{s}$. The velocities analysed for the first $10 \mathrm{~cm}$ vary much more for General v. Bülow than for General v. Scharnhorst. Generally, since 2006 the reduction is higher for Bülow than for Scharnhorst.
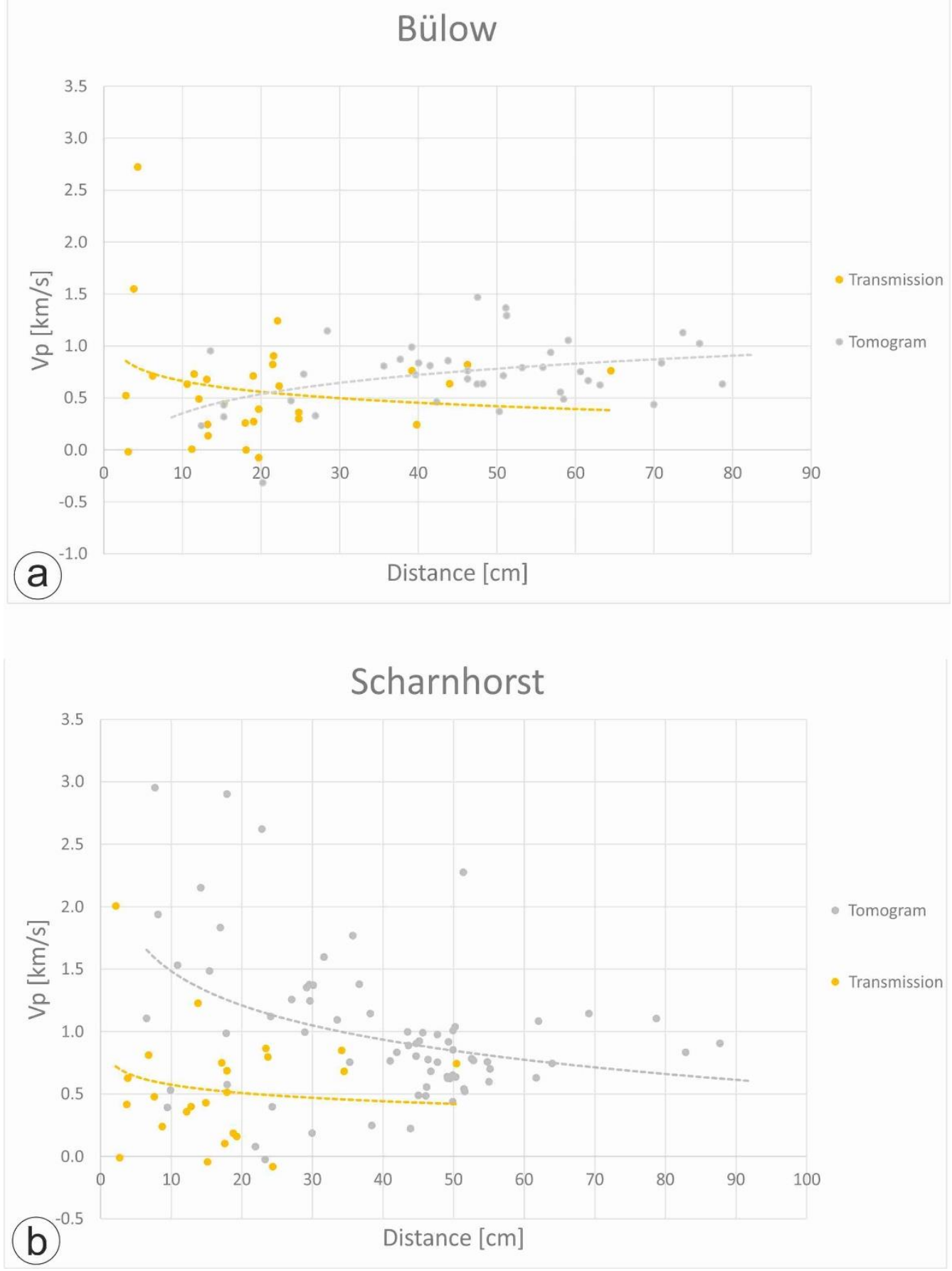

Figure 96 Difference between the measured ray velocities in 2006 and 2018 (km/s) for von Bülow (a) and von Scharnhorst (b). The grey dots represent the reductions for the tomogram, while the orange dots represent the transmission measurements, plotted according to the distance $(\mathrm{cm})$ the ray needed to travel. 
The direct comparison of the velocity reduction for each measured point since 2006, displayed in Figure 96 shows, that the transmission measurements (yellow dots) performed for Bülow (a) show a high reduction for short paths and a lower total reduction for longer distances. This trend changes for the absolute reduction measured for the tomogram (grey dots). Here, the reduction increases with a greater thickness of the sculpture. This observation differs from the observations made for Scharnhorst (Fig. 16 b), where the results for the tomographic plane show the same distribution, with higher reductions for short travel paths as measured for the different transmission measurements. Moreover, the values for the tomographic layer decreased more notably than for the single measurements. This unexpected result for Bülow may be explained by different reasons. First of all, the total number of measurements for a short distance have been smaller for Bülow in 2006 than for Scharnhorst, therefore less velocities could be compared for these distances. Another aspect that could influence these results is a consolidation, which was performed in 2006 for the sculptures. Here 3\% Paraloid B72 was applied to optimise the conditions of that sculpture. The high volatility of the used solvent could lead to an enrichment of that consolidation material on the surface. This could also be an explanation for the higher velocities on the surface and the lower velocities in the middle of that sculpture, analysed by the tomogram. The lower velocity could also be strengthened by the influence of the texture, as described above. In contrast to this, the velocities analysed for General von Scharnhorst show a "normal" distribution with lower velocities for short distances and higher velocities for long distances. The velocities for the tomogram show a high reduction, with an average decrease of 1 $\mathrm{km} / \mathrm{s}$ and a standard deviation of $0.6 \mathrm{~km} / \mathrm{s}$. The monument of Bülow shows an average reduction of $0.7 \mathrm{~km} / \mathrm{s}$ and a standard deviation of $0.3 \mathrm{~km} / \mathrm{s}$. Due to the generally worse conditions for Bülow, the deterioration progress slows down as compared to Scharnhorst.

A surprising aspect is the strong velocity decrease since 2006. In 2004 an annual winter sheltering was initiated for both sculptures between November and April, therefore deterioration increasing effects such as ice crystallization should not affect the decay anymore. The reasons for the decrease must therefore be the ongoing thermohygric deterioration, induced by temperature changes under humid conditions (e.g. Koch and Siegesmund, 2004; Menningen et al., 2018b). Another influence can possibly be a higher 
degree of dryness in 2018, compared to the former measurements, as the sculptures have been covered for three years. The huge influence of humidity to the ultrasonic velocities was reported several times, therefore this effect cannot be excluded, especially for the thicker parts like the torso.

The degree of deterioration for both sculptures shows an alarming state, and therefore restoration measures need to be undertaken. One possibility could be the application of consolidation materials, which is difficult, as there are several requirements that need to be fulfilled. The consolidation materials need to reach a high penetration depth, which is almost impossible based on conventional application methods as rinsing or the usage of a brush as the marble has a very low water uptake. Another aspect is the material itself. Acrylic resins and their application depths are connected to the used solvent and a possible and very common migration back to the surface as soon as the solvent evaporates. Also, the physical properties of the consolidation material can cause further problems. An alternative could be the application of vacuum induced treatments. In October 2018, the Neptune grotto in Potsdam, Park Sanssouci was reopened after a successful acrylic total impregnation (ATI) by Ibach GmbH (Lachmann, 2019). The use of a modified fluid for the so-called ATI 50 treatment should cause lower thermal expansion as the former formulation, as well as the thermal stress, which occurs during the treatment should be lower (Sobott and Ibach, 2019). Another possibility is the transfer of both sculptures to a museum storage to ensure stable environmental conditions, while the sculptures could be replaced with copies.

In conclusion, the analysis of comparative ultrasonic measurements is a powerful tool for providing a deeper knowledge of the weathering behaviour. The careful and transparent documentation of all measurements was in this context the most important aspect for the comparative studies and allowed to distinguish between irregularities, especially as two sculptures with almost the same conditions could be investigated. 


\section{The Columns in the Neuen Garten, Potsdam}

In recent years, the digitization of cultural assets plays an increasingly important role. While objects' surfaces can be displayed in high quality using 3D scanning technology; ultrasound tomography can be applied to monitor the internal state of deterioration. The combination of both techniques to document and evaluate the weathering condition of relevant objects is presented, to demonstrate its effectiveness.

Columns made of Prieborn and Kauffung marble as well as sculptures made of Carrara marble have been analysed. In addition, conventional, manual decay mapping was applied to verify the benefits of the 3D reconstruction in this context.

The automatic preparation of textured surfaces can support and improve the quality of documentation techniques. Three dimensional digital models can serve as an intuitive frame for documentation purposes in the context of conservation and restoration. The combination of tomographic investigations and 3D-reconstruction can improve the accuracy of the weathering evaluation. The 3D-scanning technology provides an easier, contactless, faster and more precise documentation as compared to manual decay mapping. In order to capture the 3D geometry, the Fringe Projection Structured Light method has proven to be a viable approach to quality and practicality. Especially for statues and structural building elements the continuous monitoring of their deterioration degree is desirable. The investigations have shown that quality and degree of detail achievable with recent digitization technologies can support, simplify and improve scientific investigations.

\subsection{General description}

Potsdam (Germany) is famous for its cultural heritage. Many of the impressive buildings and statues in the parks of the Prussian Palaces and Gardens Foundation are made of marble. In order to scrutinise the application of 3D scanning techniques in combination with the ultrasound tomography under environmental conditions, marble columns of the Marmorpalais in Potsdam, have been investigated. The marble varieties used for the 
palace are from former Silesia (i.e. Kauffunger, and Prieborner marble) as well as Italy (Carrara marble). Two columns from this site have been reinvestigated, one made of Prieborner marble which is located close to the lake Heiligen See and one column of Kauffunger marble, located in the inner courtyard. Here, ultrasonic velocities have been measured at different levels and are discussed by comparing their spatial distribution with the results of the traditional manual decay mapping and a 3D scan. The range within the velocities is caused by extrinsic effects as different weathering degrees and structural weaknesses as well as the intrinsic influences caused by the anisotropy of the marbles themselves. As both marble varieties are colourful and show a less complex shape, additionally, different sculptures from the Skulpturenhalle, made of white Carrara marble have been analysed too, with the focus on improving the scanning technique.

\subsection{Marble decay}

The main decay phenomena for the homogeneous, fine-grained whitish Carrara and greyish Prieborn calcite marble is the back-weathering of the surface, associated with a penetrative degradation of the whole fabric. This deterioration is initiated by a decohesion of the polygonal grain to grain contacts, caused by crack growth and finally the loss of material, producing a coarse surface. In the late stages, so-called sugaring will be the consequence. In contrast, the fine-grained Kauffunger marble with its seriate to interlobate grain fabric shows different back-weathering phenomena. Weathering is concentrated on pre-existing crack systems, which have been mineralised or sealed within the formation of this type of calcite marble. Pitting can be found more frequently between already open macro cracks.

\subsection{Characterization techniques}

\subsubsection{Mapping}

Both marble columns have already been mapped in detail (1:1 scale) by Ruedrich et al., 2001. To determine the macroscopically visible structures, those maps were used to analyse the orientation of the foliation (layering), fracture populations and the crack 


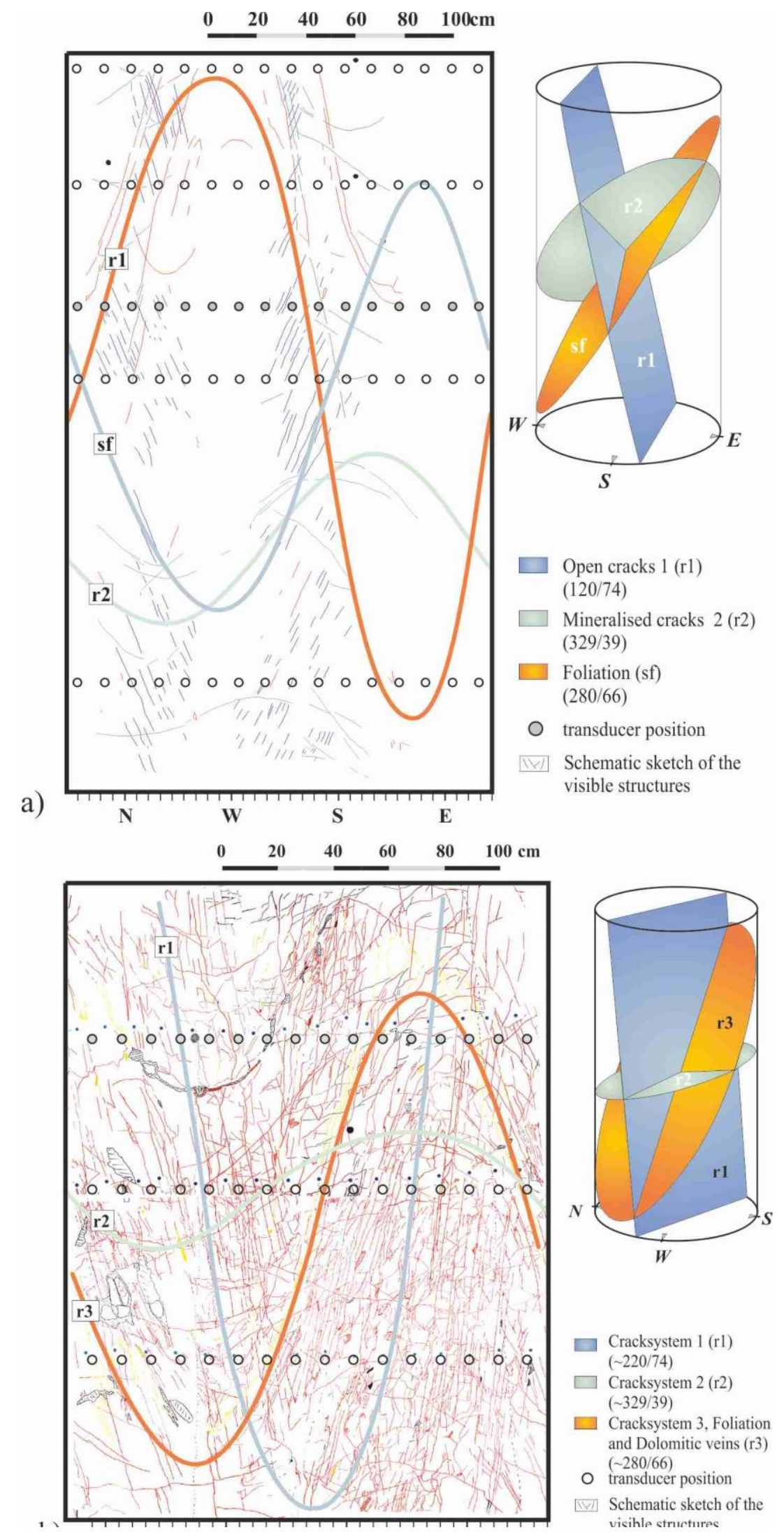

Figure 97 Mapping of visible structures and decay phenomena for the Prieborn column (a) and the Kauffung column (b) modified after Rüdrich 2001.

densities. The Prieborn marble exhibits a foliation by alternating dark- and light layers, 
which developed a strong relief due to different back-weathering intensities. In 2019 this relief was no longer visible, as different conservation measures have been performed within the last 18 years. The mapping (Figure 97 a) showed an open crack system (C1) and a predominantly sealed crack population (C2). In contrast, the very heterogeneous, fine-grained calcitic Kauffunger marble is transected by fine-grained yellow to reddish, irregular calcitic and subordinately dolomitic veins. The foliation is crosscut by two different systems and accompanied by one system of healed and open cracks, which are schematically shown in Figure $97 \mathrm{~b}$. This marble shows an intense cataclastic fabric, where most of the cracks are sealed. As for the Prieborn column, restoration measures have also been applied to this column.

\subsubsection{D-Scanning Technologies}

In order to achieve 3D reconstructions, several technologies are common. Time-of-flight methods send laser pulses and measure the time it takes to reflect them off the object's surface to the receiver. From this information, the distance of the object to the sensor and its geometry can be estimated. These methods are user-friendly and fast, but the data generated in this way may not provide the quality of depth information required in the field of cultural heritage. In particular, large angles between the object surface and the viewing direction can cause problems. Reconstructing certain colours and surfaces can also be difficult. For example, in the case of marble objects, subsurface scattering can falsify the measured depth information (Levoy et al., 2000)

Optical measurement techniques with one or more cameras are somewhat more complex in application, but can achieve significantly higher accuracy in certain scenarios. Standard Structure-from-Motion techniques depend on conspicuous feature points that need to be detected in the camera images and are not always available. The structured light approach, which uses a projector in addition to the cameras, is suitable for circumventing this problem. The active device projects several patterns onto the scene in order to encode the surface independent from features. In this way, dense correspondences can be generated between the cameras and the projector, enabling high precision reconstructions even of uniformly coloured objects. In the scenario of marble objects discussed here, it was found that the influence of subsurface scattering on the method is 
negligibly low and hardly influences the quality of the result. In addition, the influence of object colours and material properties can be further reduced by newly developed methods such as described in Fetzer et al., 2020a. The method of choice in terms of accuracy and applicability has been a structured light approach with two cameras and a projector using multiple frequencies of phase-shifted sine waves for surface coding.

\subsubsection{Ultrasound tomography}

To characterize the inner state of weathering, ultrasonic measurements have been applied in a tomographic approach (e.g. Capizzi et al., 2013; Cardarelli and Nardis, 2001; Ruedrich et al., 2001; Menningen et al., 2018b). The P-wave velocities were measured by transducers of $350 \mathrm{kHz}$. An array of 16 transmitter and receiver positions was oriented along the horizontal plane of the columns and 12 positions for the leg of the Diane. A 2D-velocity distribution based on the measurements was computed by tomographic wave front migration using the Software Geotom CG (see Chapter 3.4.2.3

Tomographic inversion).

\subsection{Auto-Calibration of the Setup}

All reconstruction systems have to be calibrated in order to obtain accurate measurements. Pre-calibrated systems are usually expensive to purchase, have a limited range of use and decalibrate over time. Therefore, they are usually calibrated before each use. In the past, for camera setups, this was done with the help of checkerboards, which had to be placed by the user at several positions and orientations in the scene. This was a considerable effort and made the use of these techniques difficult for amateurs. New auto-calibration methods such as described by Fetzer et al., 2020b and Fetzer et al., 2019 calibrate the devices directly from point correspondences. These correspondences can be robustly obtained from the object surface, that has been encoded by the structured light approach. Thus, no user interaction is necessary, and the procedure is easy to use even for non-specialists, making it suitable for practical application such as in restorations. In addition, the calibration can be carried out separately for each position in order to achieve very accurate reconstructions, without loss of quality over time. Moreover, 
variable hardware setups and adjustments of camera settings to specific scenarios are no longer a problem.

\subsection{Merging, Meshing and Texture Mapping}

In order to obtain a complete reconstruction from all sides, several partial reconstructions must be performed from different perspectives. The partial point clouds have to be merged afterwards, which is one of the main challenges in the creation of a digital copy of an object. However, if asymmetric geometry and/or sufficient texture characterize the object, this is possible automatically. Figure 98(a) illustrates how point clouds from three views are merged. The pictures demonstrate the process on a Vestalin statue from the Skulpturenhalle Potsdam. In order to achieve a closed, high-precision reconstruction with appropriate data size, a mesh is generated from the point cloud that approximates the surface of the object. Finally, a texture and optionally a normal map are mapped onto the mesh (Nöll and Stricker, 2011) Figure 98 (b) visualizes this process. In this way, high-resolution detailed objects with comparatively low memory requirements can be rendered and displayed according to modern standards. Figure 98 (c) and (d) illustrate the high quality of the reconstructions. Even very small damages such as cracks or spallings in the surface can be detected and documented. Figure 98 (c) shows on the left a high-resolution image and on the right the reconstructed point cloud of this region. Figure 98(d) depicts a colored point cloud, where the damaged area is enlarged in the inset.

\subsection{Documentation of Measuring Positions}

The 3D reconstructions are intended to provide visual access to the cultural assets and further information about them. Apart from this, they are ideal for documentation and as basis for monitoring campaigns. In this study, for example, the exact position of the 
measuring points for the applied ultrasound tomography could be documented. In this way they can be clearly assigned and improve the repeatability of further measurements. In addition, they enhance the aligning of the computed tomograms, which helps to compare them with visible decay phenomena. In order to augment the reconstruction, we perform high quality 3D scans to obtain the model. The ultrasound tomography
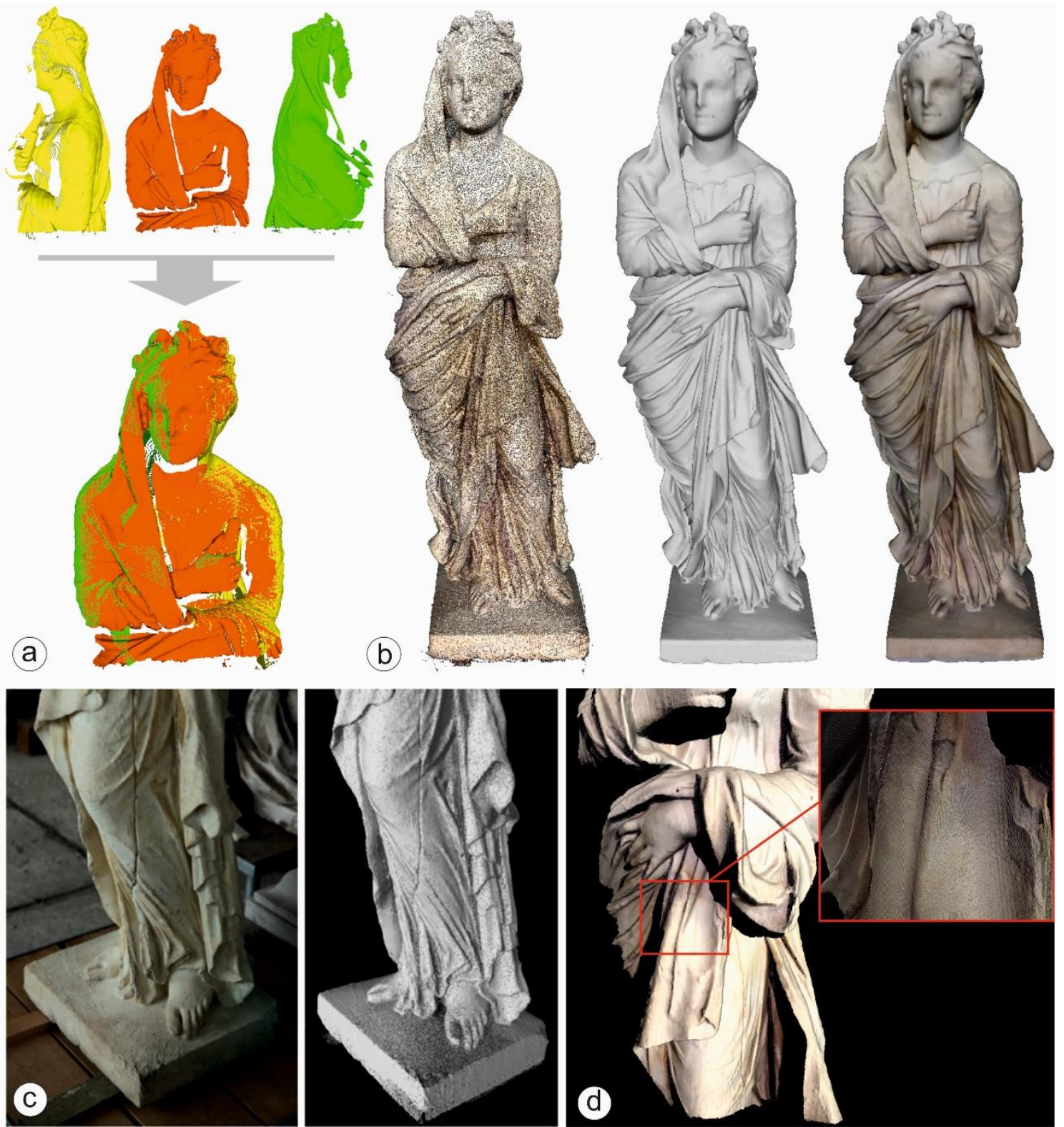

Figure 98 Steps to generate complete reconstructions from multiple views. (a) Alignment of partial point clouds. (b) Point cloud, mesh and textured mesh of the reconstruction. (c) and (d) show how the highresolution reconstructions can document even small damages in the object's surface (Images were contributed by Fetzer, T.).

is then applied, and the measuring points are marked on the object. Again, a reconstruction of the areas with the marked measuring points on the object is carried out. The 
coarse reconstruction is aligned with the previous one and the measuring positions are extracted according to this alignment. They are stored separately and can be augmented to the high-resolution reconstruction if required. Note that the accuracy of the measuring points depends on the resolution of the second scan and the alignment, which can be tuned accordingly. Figure 99 shows a reconstruction of Apoll from the Skulpturenhalle Potsdam, for which measuring points are shown (right) and hidden (left) if required.
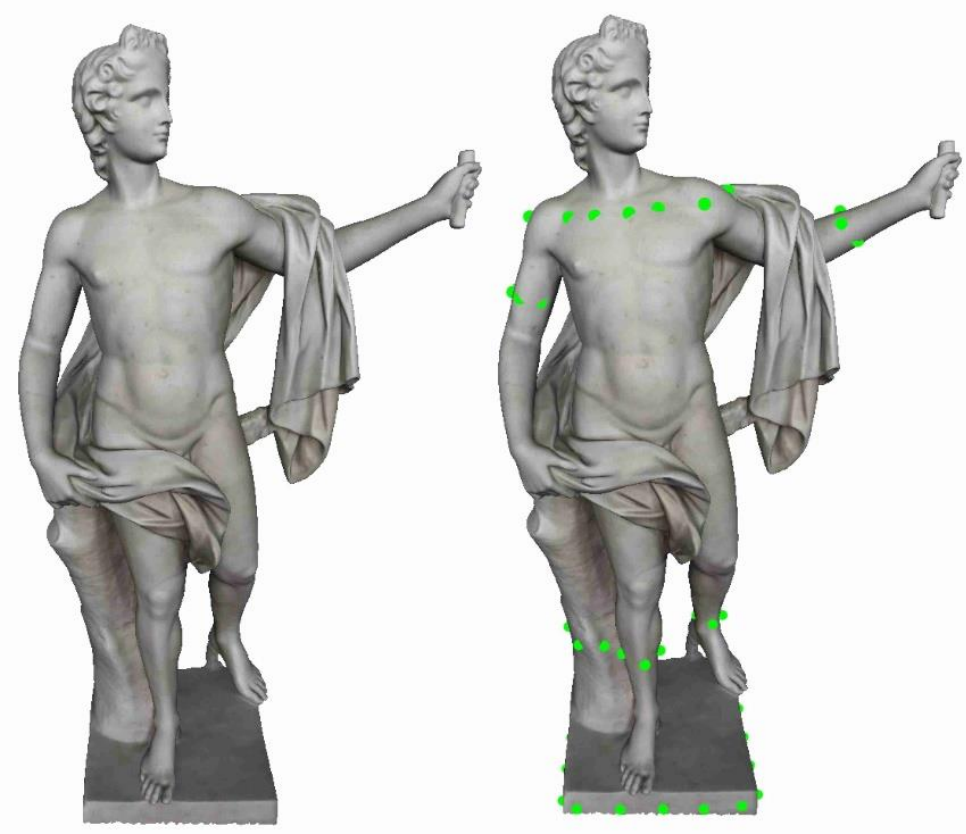

Figure 99 Reconstruction of Apoll without (left) and with (right) measuring points of ultrasound tomography (Pictures contributed by Fetzer, T.).

Another field of application for the digitization of cultural objects, is to document the surface changes of objects, e.g. due to weathering. For monitoring purposes, decay phenomena as cracks and back-weathering of the surface need to be documented as well as restoration and conservation measures. Likewise, structural elements of natural stone such as foliation or sealed cracks can be investigated and documented in this way. Here the texture can be mapped onto a two-dimensional surface. With the help of 3D reconstructions this can be done in an automated way and the surface structures can be digitized and documented over many years. 


\subsection{Ultrasound tomography}

According to ultrasonic measurements in 2001 (see Ruedrich et al., 2001; Siegesmund et al., 2004b), the ultrasonic velocities for the Prieborn column have been investigated at four different cross sections. This work presents the data for the section at a height of $3.23 \mathrm{~m}$, considering the same amount of $20 \%$ anisotropy as in 2001 . In 2019 , the velocities range between 2.4 and $3.0 \mathrm{~km} / \mathrm{s}$ (Figure 100 a), while in 2001 the velocities for the same column at the same height ranged between 3.0 and $4.2 \mathrm{~km} / \mathrm{s}$. While the velocities strongly decreased, the spatial velocity distribution did not change that much. This indicates that the crack growth caused by weathering, is mainly influenced by the intrinsic rock properties. The velocity measurements for the Kauffunger column were performed at three different cross sections at a height of $0.92 \mathrm{~m}, 1.59 \mathrm{~m}$ and $2.12 \mathrm{~m}$. The results for the cross section of $2.12 \mathrm{~m}$ are given in Figure $100 \mathrm{~b}$ and display a wide range of velocities between $2.4 \mathrm{~km} / \mathrm{s}$ up to $5.8 \mathrm{~km} / \mathrm{s}$. In 2001 this range was smaller with velocities between 3.8 and $5.6 \mathrm{~km} / \mathrm{s}$. The spatial velocity distribution fits to the analysed crack distribution (see Ruedrich et al., 2001), indicating that the velocities are mainly controlled by the crack system and the intrinsic effects.

Along with these columns, a sculpture at the Skulpturenhalle has been measured by the tomographic approach. The calf of the Diane, a marble sculpture made of Carrara marble, was measured and a tomogram computed (Figure $100 \mathrm{c}$ ). The velocities range between 2.0 und $3.4 \mathrm{~km} / \mathrm{s}$, while the area of her upper tibia shows the highest velocities (see Figure 100 b). 

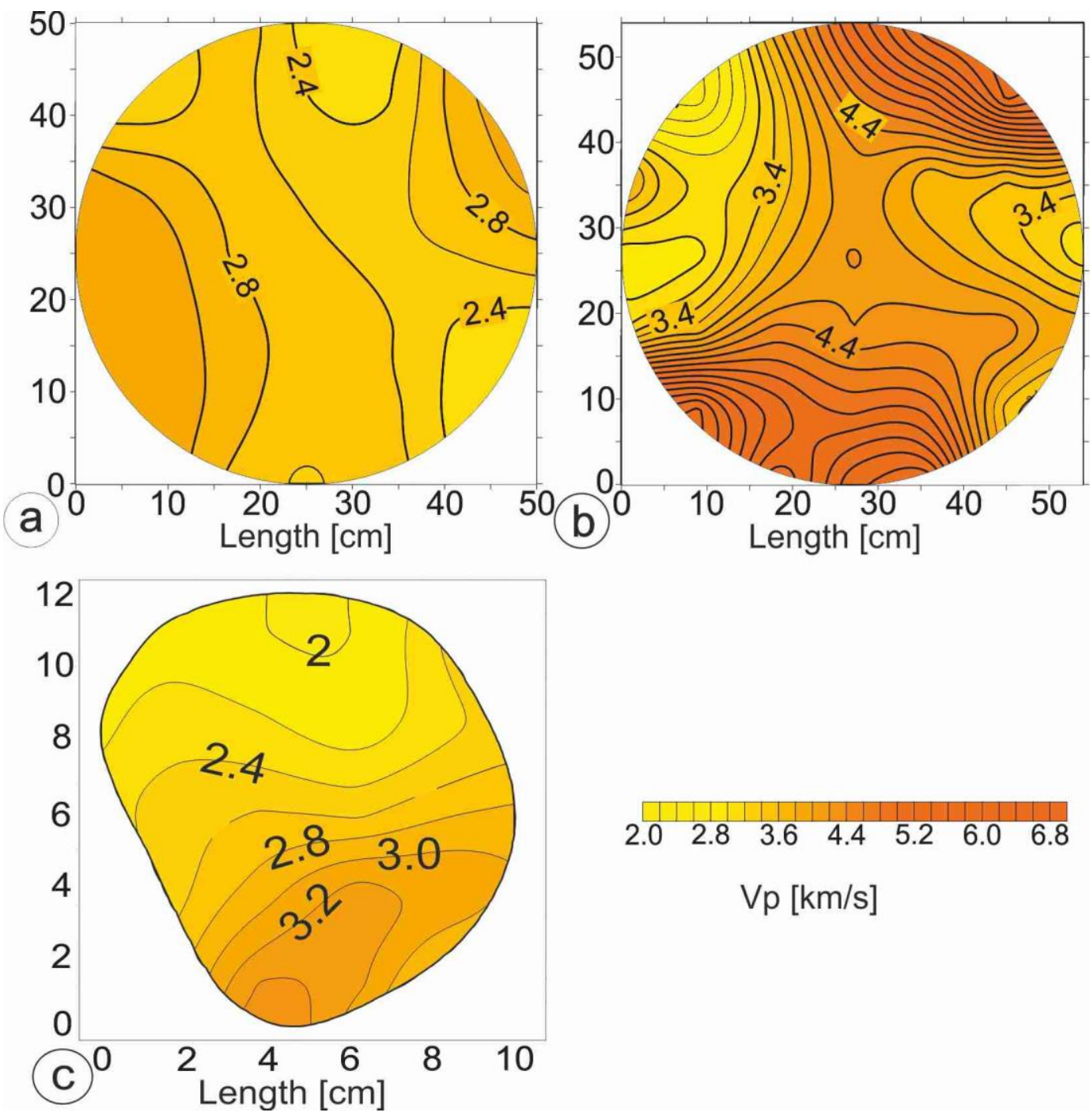

Figure 100 Tomograms of the Prieborner Column (a) and Kauffunger Column (b) as well as the tomogram for the calf of the Diane (c).

\subsection{Discussion and Conclusion}

To determine the benefits of a $3 \mathrm{D}$ reconstruction in terms of documentation, mapping and reorientation the conventional mapping method has been compared to the results of the reconstruction. Figure 101(a) shows the reconstruction of the Kauffunger column. On the right the developed textures are shown. An elaborated manually traced version using a transparent foil (b, bottom) and the automatically developed texture of the reconstruction (b, top). Note that the colours were intensified, and the contrast increased to make features and information visible in this paper. For comparison reasons, the manual texture has been mapped to the reconstruction as well (a, top). The foliation is marked by a sine wave (blue) in both the reconstructed and hand drawn textures. To 
illustrate the comparability of the two textures, (c) shows magnifications of the marked regions in the textures. Features and cracks are clearly and better visible in both variants. Moreover, while manual traces are extremely time-consuming and error-prone due to slippage of the foil, these problems do not occur at all with the automatic approach. In Figure 6 the computed tomograms are placed at the reconstructions. Due to the documentation of the transducer positions as described before, it is possible to position the tomograms perfectly at the reconstruction. Therefore, correlations between macroscopically visible decay phenomena, structural properties as the orientation of the foliation and the tomograms can be analysed immediately. The combination of both previously described methods, allows an accurate, and in-depth investigation as well as being a great monitoring basis and allows many visualization possibilities.

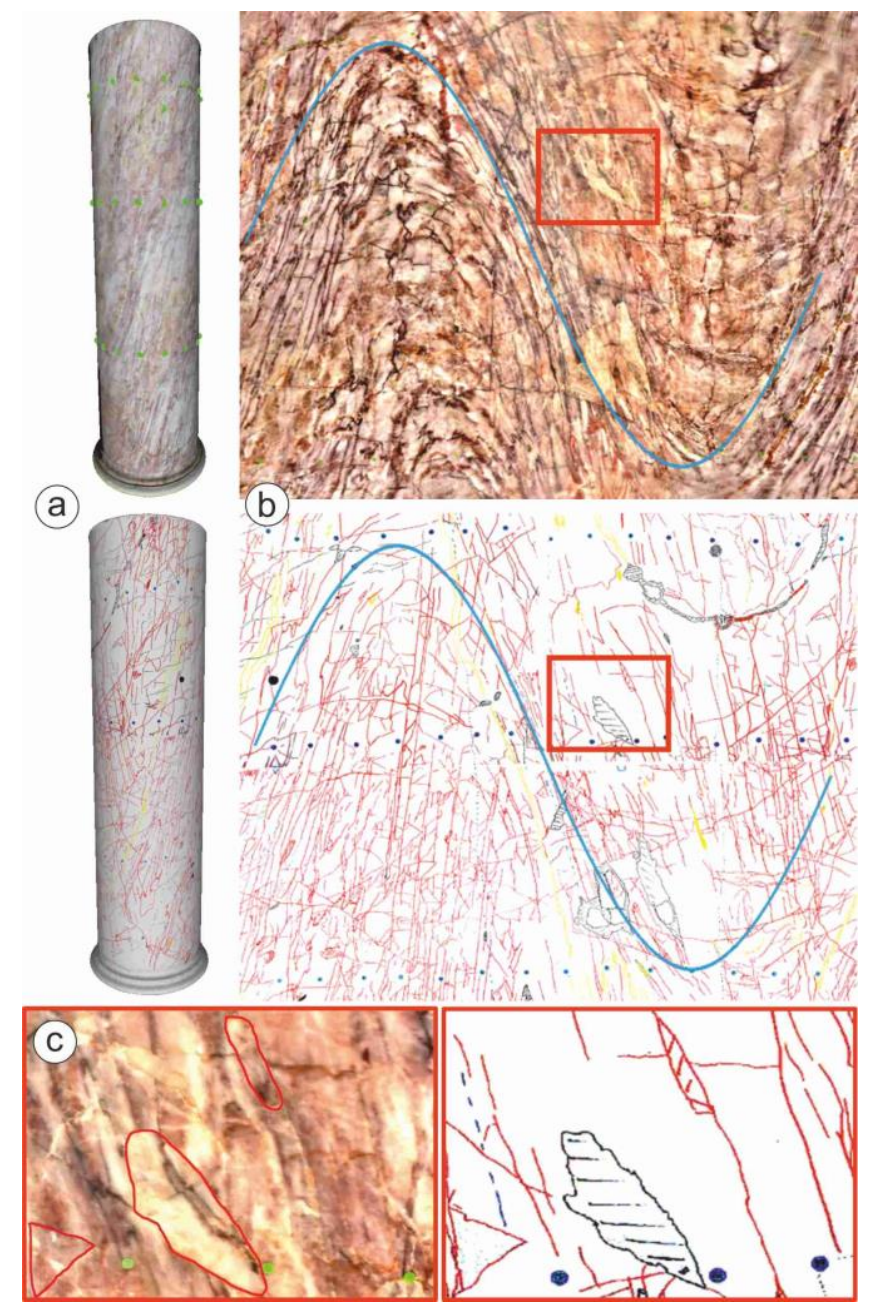

Figure 101 Reconstruction of a marble column of the Marmorpalais in Potsdam (a). (b) shows the manually traced (bottom) and automatically developed (top) texture of the column. (c) depicts enlarged versions of the marked red boxes in order to visualize matching features in the textures. 

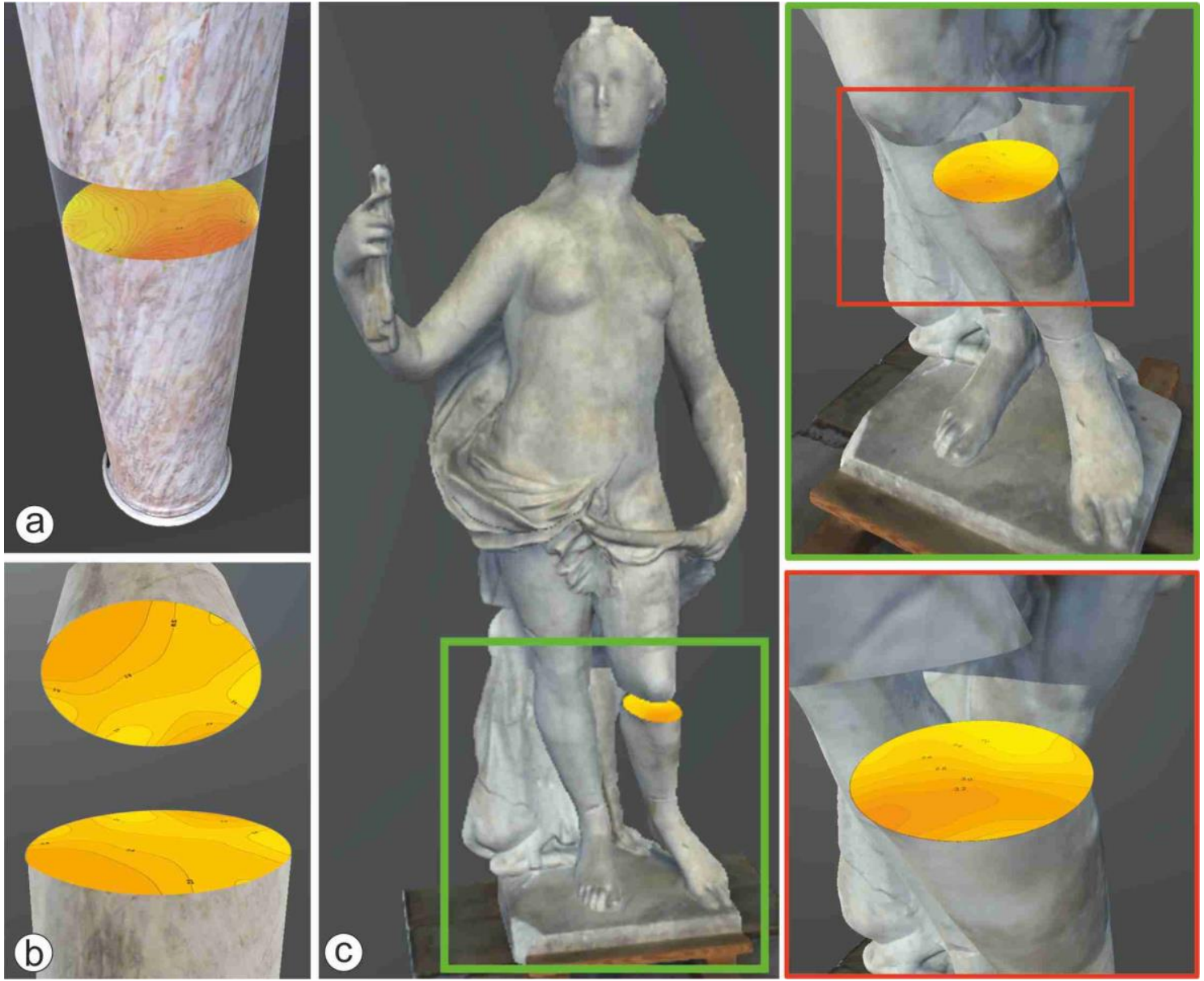

Figure 102 Reconstruction of Kauffunger column (a), Prieborner column (b) and Diane (c) Potsdam including the computed tomograms. The left calf is cut off to make the measured tomography visible(d).(Reconstruction was performed by Fetzer 2020). 


\section{Conservation of marble}

Since the 1970s the weathering of marble, with regard to its loss of cohesion between the individual grains, has been focused on monument conservation and has achieved an increased level of importance. From 1990 to 1999, the Project Eurocare Euromarble (Eureka Project E!496) investigated all aspects of weathering and conservation of marble, with an enormously knowledge increase about the weathering mechanisms, conservation methods and chemicals. This caused numerous methods and materials for the conservation, especially the consolidation of the stone to preserve important cultural assets. Simon, 2001 provides a comprehensive overview about the historical development of materials and methods for the marble conservation. As the consolidation of marble sculptures results from the desire to preserve valuable cultural assets, an important aspect is the non-destructive evaluation of the strengthening effect. Therefore, in this work, all treatments have been determined by ultrasonic measures.

\subsection{Consolidation requirements}

The aim of a consolidation is to compensate the bonding reduction of the crystal bonds that occurs during the course of weathering. This is often the last possibility to prevent a further reduction in strength and the resulting consequential deterioration, especially in an advanced state of weathering. The intention is to achieve a uniform strength profile into the depth of the material which should be comparable to that of the unweathered rock. The consolidation agent should not lead to an over-strengthening of the rock surface, but should penetrate to the healthy core, where the strengthening effect should gently fade away. (Snethlage, 2008)

The consolidation of marble only can be successful if the conservation product and the resulting rock properties after its application are compatible with the untreated rock properties and does not influence them negatively. Various parameters must be considered in comparison with the intact rock in order to determine the suitability. 
Snethlage, 2008 formulated in his "Leitfaden Steinkonservierung" a catalogue of requirements for a strengthening measure, which describes the most important parameters to be considered and defines a framework for an acceptable deviation of the strengthened rock compared to the intact rock.

Other important factors to be added to this catalogue are the ageing behaviour or the durability of the materials and, with regard to the thermal properties of marble, the thermal expansion behaviour.

Generally, all investigations determining the suitability of a consolidation agent should be analysed with regard to the resulting depth profile. This is important since a sudden change within the rock properties can cause damage to the rock, as stresses can build up.

This work tries to determine the general suitability of different consolidation agents; therefore, the aim was to receive a full impregnation in order to achieve the rock properties of the combination consolidation material and marble. An in depth profile would be the next step if any suitability's could be found.

The requirement of reversibility, which is fundamental in restoration work today, cannot be fulfilled within the framework of a strengthening measure. However, since consolidation should be used as a last alternative before the possible loss of substance, and should only be carried out if it has no negative effects on the rock, this often discussed aspect may be given less weight.

Similarly, the requirement that the chosen products need to be safe for humans, animals and the environment before they react cannot be fulfilled for every material as they content harmful solvents.

\subsection{State of the art}

Until today, there were several materials developed, applicated and as unsuitable estimated. The most successful method is the Acrylic resin total impregnation (ATI) which is performed by Jbach $\mathrm{GmbH}$ and is based on the saturation of the pore space with methyl 
methacrylate which polymerises under application of heat. A more detailed overview is given on www.ibach.eu.

Within the last decades they optimized the formulation and improved the properties (Sobott and Ibach, 2019). Until today, this method is very often the last and only possibility to preserve heritage made of marble (Lachmann, 2019). As this method requires the dismantling and transport of the object and effects the whole monument, there is still the necessity of an in situ applicable method. Different materials have been used for these purposes, while a very common material is the prepolymerized acrylic resin Paraloid B72. In Italy, the application of the so called Bologna Cocktail was very common, while the acquisition of the materials was difficult from Germany. Another often chosen consolidation material is the Tetra orthosilicate (TEOS/KSE), while the bonding to the calcitic surface causes problems.

Within the framework of this work 2 different often used types of consolidation materials have been chosen to prove their suitability and their influence on the elastic wave velocities.

\subsection{Conservation materials and application}

The following materials have been used for the consolidation of 5 different marble varieties. All samples were fully saturated under atmospheric conditions with the specific material and left for 24 hours, before they were stored in a solvent-based climate for one week. After 6 weeks, different analyses have been performed to assess the suitability of the different consolidation materials.

\subsubsection{Acrylic resins}

The acrylates used for natural stone consolidation are methacrylates. These are the esters of methacrylic acid, which cross-link by polymerisation to form polymethacrylates and whose properties, such as the glass transition temperature $[\mathrm{Tg}]$, can be adjusted by adding copolymers. The acrylates used in the restoration are prepolymerized polymethylmethacrylates (PMMA) which are dissolved in a solvent and dry physically by evaporation of the solvent. An often chosen material is Paraloid B72, which is a mixture 
of methyl methacrylate and ethyl methacrylate, whereby its glass transition temperature (Tg), relevant for the application, is brought into a suitable range of $40^{\circ} \mathrm{C}$.

For this work, 5\% PMMA solved in Xylol was tested.

The acrylic total impregnation (ATI) developed by H.W. Ibach is an often used treatment to preserve important sculptures and monuments showing strong granular disintegration. Especially cultural heritage made from marble has undergone this treatment as for example sculptures in the Park Sanssouci, Potsdam. This treatment uses methyl methacrylate which polymerises thermally induced to polymethyl methacrylate (PMMA), an acrylic resin. Within the last years, the formulation of this resin has been modified, resulting in a higher glass transition temperature $(\mathrm{Tg})$ of $80-85^{\circ} \mathrm{C}$, and a lower thermal load for the material during the ATI. This new formulation is called ATI50 according to reduced thermal load, while the original formulation is labelled ATI100.

\subsubsection{Silicic acid esters}

Since the 1960 s ethyl silicates have been widely used as a stone strengthener. While their application on sandstones has proven to be a good possibility, their use for marbles is still under discussion. Even if the application leads to a significant measurable strengthening effect, the durability of this treatment on marbles and its effectiveness is known to be limited on this kind of substrate, because of the lack of chemical bonding to calcite (Wheeler, 2005). Nevertheless, ethyl silicate is often used because its low viscosity allows a deep penetration into the weathered marble. Additionally the formation of silica gel in the fissures among calcite grains is able to limit grain loss, although mechanical properties are not significantly improved (Wheeler, 2005; Scherer and Wheeler, 2009). Cyclic thermal loads under laboratory conditions had negative influences on the consolidated marbles, resulting in a strong reduction of the ultrasonic velocities. This is probably caused by the low adhesion between the calcite crystals and the formed gel.

Therefore, the treatment was performed with two different marketable ethyl silicates. The usual tetraethyl orthosilicate (TEOS/KSE) and one product containing a coupling agent for better binding on the carbonate surface (KSE HV). 


\subsection{Modification of petrophysical properties, based on the consolidation.}

The petrophysical properties have been analysed for the same sample for the preweathered state (0), the artificial weathered material (I) and the consolidated material (II). The tests for the general characterization of the consolidation were performed on cubic samples, while the durability was examined with samples for the thermal expansion.

\subsubsection{Ultrasonic measurements}

The ultrasonic velocities have been determined with a frequency of $350 \mathrm{kHz}$, as described at Chapter 3.4.2.1 Transmission. The preweathered, artificial weathered and consolidated samples were investigated within the three main directions $X, Y$ and Z (see Chapter $3.2 \quad$ Sample preparation and orientation).

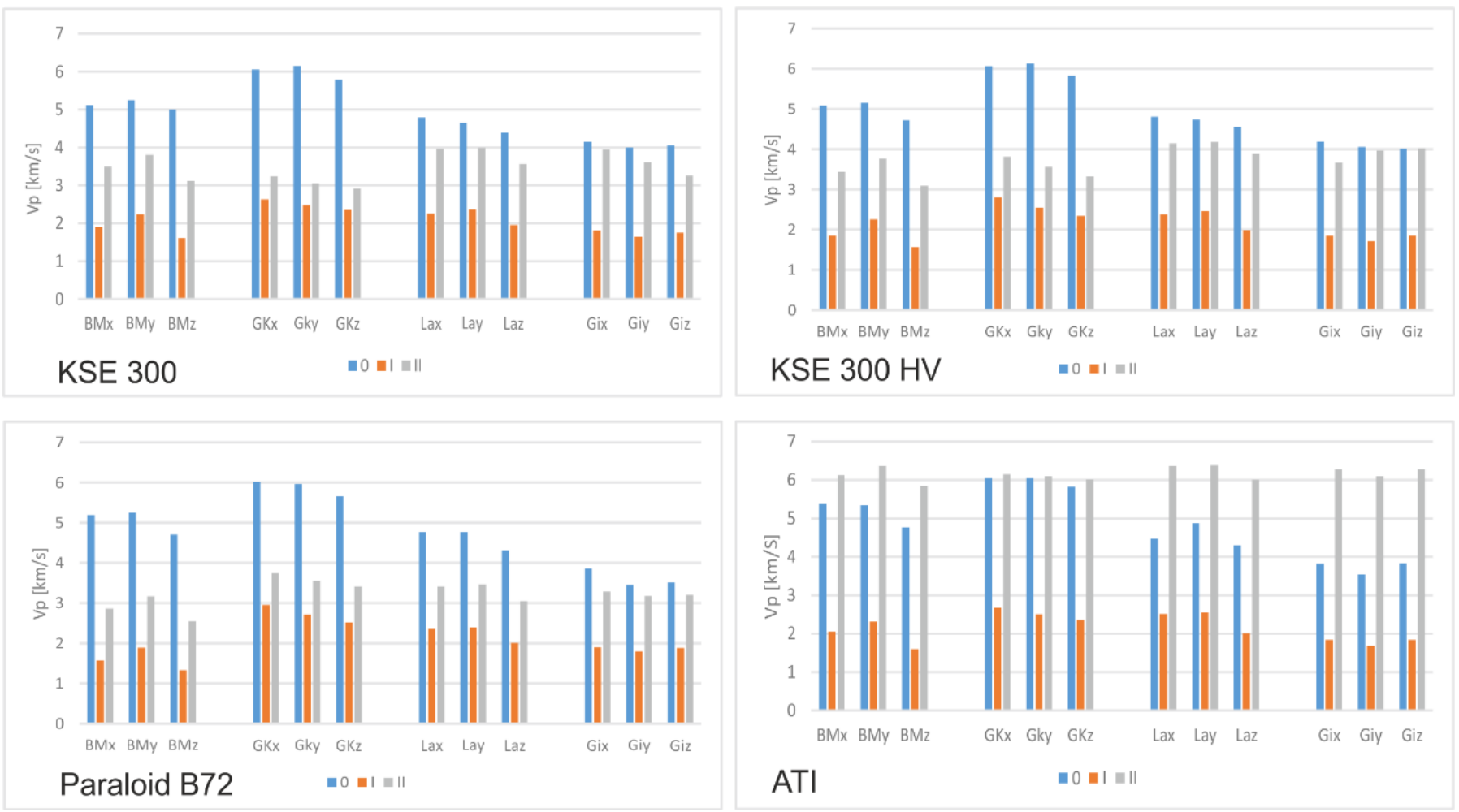

Figure 103 Ultrasonic velocities [km/s] determined for the marble varieties Blanco Macael (BM), Großkunzendorfer (GK), Lasa (LA) and Gioia (GI) in the unweathered state (blue bars (0)), the weathered state (orange bars (I)) and after the consolidation (grey bas (II). Given are the results for the different consolidation materials.

In Figure 103 the results are given for the different consolidation materials. The samples which were treated with KSE show an increase of Vp for all marble varieties, while none achieves the former high velocity. For all samples, the former directional dependence of 
Vp can still be considered, with the lowest velocity in Z-direction. While the results for the Blanco Macael (BM), Lasa (LA) and Gioia (GI) are promising, with velocities between 3 and $4 \mathrm{~km} / \mathrm{s}$, the velocity increase is relatively low for the Großkunzendorf (GK) ranging between 2.9-3.1 km/s. Slightly better results can be observed for the samples, treated with KSE HV. Here, also the GK received higher velocities exceeding $3 \mathrm{~km} / \mathrm{s}$, while the results of the BM are almost the same as for the KSE treated sample. For the Carrara Gioia, the directional dependence of $V p$ is not observable anymore and shows now, the lowest velocities in X-direction and the highest in Z-direction.

The application of the Paraloid B72 caused only little increase of the ultrasonic velocities. The worst result was again received for the GK, while the lowest treated velocities are found for the BM. Generally, the velocity increase is the lowest for the Paraloid B72 treated samples.

The acrylic total impregnation led to velocities which are as high as the velocities of a quarry fresh unweathered marble and higher than the untreated state of all marbles. With velocities ranging between 5.8 and $6.4 \mathrm{~km} / \mathrm{s}$ the consolidation result of all marbles seems to be very good and independent of the former weathering intensity.

Generally, all treatments caused a velocity increase, which was the highest for the ATI and the lowest for the Paraloid B72. Based on these data, a second cycle could be considered for the KSE and Paraloid treatments, to adjust the velocities even further.

\subsubsection{Porosity}

To see if the effective porosity was reduced within the treatment, comparative measurements have been performed for all samples according to DIN 52102 (3.4.1 Porosity). 

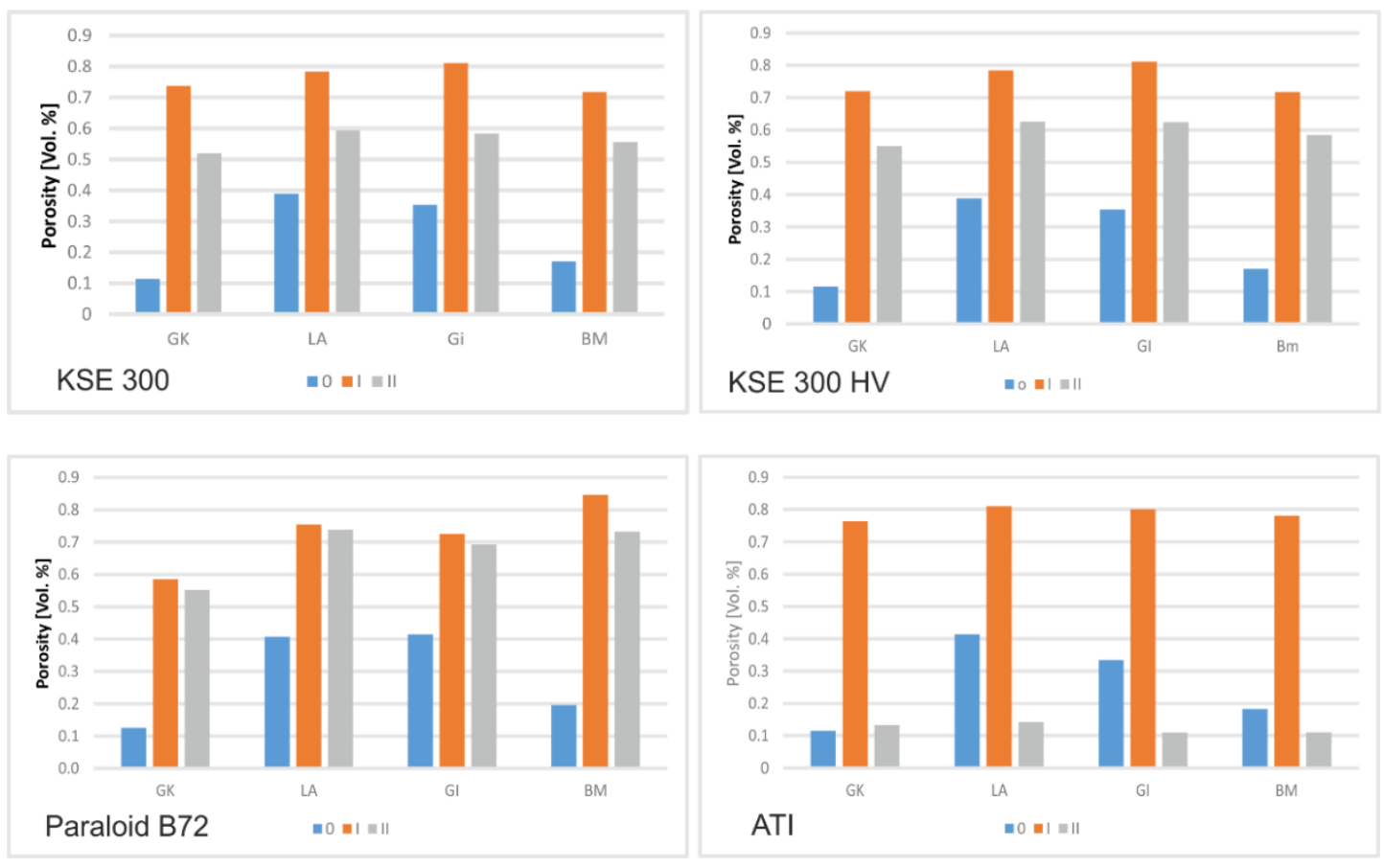

Figure 104 Effective porosity [Vol. \%] for the unweathered (blue bars (0)), weathered (orange bars (I)) and consolidated (grey bars (II)) state of the different marble varieties. Given are the results for the KSE 300, KSE 300 HV, Paraloid B/" and Acrylic total impregnation.

As depicted in Figure 104 the treatment with the KSE based materials caused a low reduction of the porosity in comparison to the weathered state and is still much higher than for the unweathered material. The Paraloid B72 treatment caused almost no porosity reduction and receives comparable values as for the weathered samples. The biggest impact can be observed for the ATI treatment. Here, the porosities are almost the same as for the unweathered GK and lower than for the BM, LA and GI and the pore space seems to be completely filled by the PMMA. These results correlate with the ultrasonic velocities, while the decrease caused by the KSE treatment is little higher than for the KSE HV treatment.

To analyse the surface contact of the consolidation agent, further investigations would be necessary.

On basis of these results, the consolidation for all consolidation agents was more or less successful, with an almost fresh state for the ATI treated samples and at least an increase for the other materials. Promising results were received for the KSE treated samples, especially for the varieties Carrara Gioia and Lasa. 


\subsection{Durability of the consolidation}

To proof the suitability of a consolidation agent, as described in Chapter 9.1 Consolidation requirements, many other analyses should be performed. As the focus of this thesis was the application of ultrasonic measures, attention has been paid on the durability of the consolidation and the ultrasonic possibilities to quantify them.

\subsubsection{Thermal expansion}

The durability of the consolidation was evaluated by cyclical heating as described in Chapter 3.4.5 Thermal expansion. Therefore, the samples were cyclically heated up from $20^{\circ} \mathrm{C}$ to $90^{\circ} \mathrm{C}$ and cooled down again to $20^{\circ} \mathrm{C}$. this cycle was performed for 3 cycles. In Table 14 the results for the average thermal expansion coefficient $\alpha$ are given for the direction of highest $(\mathrm{Z})$ and lowest $(\mathrm{X})$ expansion coefficient for each marble type and consolidation material as well as the untreated marble.

Table 14 Mean thermal expansion coefficient $\alpha\left[10^{-6} \mathrm{~K}^{-1}\right]$ for the $X$ - and Z-direction of the different marbleconsolidation material combinations and the untreated marble.

\begin{tabular}{|c|c|c|c|c|c|c|c|c|c|c|}
\hline \multirow[b]{2}{*}{ MARBLE } & \multicolumn{2}{|c|}{ UNTREATED } & \multicolumn{2}{|c|}{ KSE 300} & \multicolumn{2}{|c|}{ KSE 300 HV } & \multicolumn{2}{|c|}{ PARALOID B72 } & \multicolumn{2}{|c|}{ ATI } \\
\hline & $x$ & Z & $x$ & Z & $x$ & Z & & & & \\
\hline & \multicolumn{10}{|c|}{$\alpha\left[10^{-6} \mathrm{~K}^{-1}\right]$} \\
\hline & 3.15 & 14.20 & 4.93 & 19.5 & 6.98 & 19.9 & 1.48 & 11.5 & 3.77 & 14.4 \\
\hline MACAEL & \pm 0.09 & \pm 0.09 & \pm 1.26 & \pm 1.91 & \pm 1.5 & \pm 1.28 & \pm 0.24 & \pm 0.31 & \pm 0.68 & \pm 1.01 \\
\hline & 8.42 & 14.20 & 8.94 & 20.5 & 9.87 & 14.6 & 4.53 & 12.4 & 5.71 & 11.8 \\
\hline GIOIA & \pm 0.07 & \pm 0.16 & \pm 1.39 & \pm 2.16 & \pm 0.95 & \pm 1.02 & \pm 0.27 & \pm 0.14 & \pm 0.46 & \pm 0.40 \\
\hline & 4.77 & 11.42 & 4.21 & 12.9 & 6.53 & 14.4 & 2.95 & 7.59 & 4.69 & 11.2 \\
\hline LASA & \pm 0.11 & \pm 0.22 & \pm 1.22 & \pm 1.61 & \pm 1.26 & \pm 0.61 & \pm 0.49 & \pm 0.36 & \pm 0.47 & \pm 0.04 \\
\hline & 5.61 & 10.45 & 4.58 & 13.7 & 8.38 & 14.8 & 4.68 & 9.01 & 5.04 & 10.6 \\
\hline ZENDORF & \pm 0.27 & \pm 0.10 & \pm 0.77 & \pm 0.17 & \pm 0.2 & \pm 0.34 & \pm 0.42 & \pm 0.33 & \pm 0.3 & \pm 0.24 \\
\hline & 2.87 & 12.32 & 0.45 & 17.8 & 5.94 & 16.0 & 5.34 & 12.5 & 4.07 & 13.0 \\
\hline WUNSIEDEL & \pm 0.09 & \pm 0.02 & \pm 0.04 & \pm 0.8 & \pm 0.44 & \pm 0.01 & \pm 0.19 & \pm 0.41 & \pm 0.98 & \pm 0.61 \\
\hline
\end{tabular}


It can be observed that the Blanco Macael shows higher $\alpha$-values in combination with the KSE and KSE HV, while they are lower for the Paraloid B72 and almost the same for the ATI. The results for the Lasa, Großkunzendorf and Wunsiedel marble show the same described tendencies as the Blanco Macael. Comparable results can be determined for the Carrara Gioia, while the KSE HV shows almost the same values as the untreated marble and the ATI little lower coefficients. The Wunsiedel marble differs regarding the KSE treatment, here the highest $\alpha$-coefficient in Z-direction is with $17.8 * 10^{-6} \mathrm{~K}^{-1}$ much higher than the untreated sample, while the coefficient in X-direction is almost 0.

It can be summarized that for the first three marble varieties, the standard deviation for the $\alpha$-coefficient of the KSE based samples is higher than for the other samples and marble types. Generally, the KSE based consolidation materials cause the highest $\alpha$-coefficients while the ATI treatment shows almost the same values as the untreated samples. The Paraloid B72 treatment causes mostly lower $\alpha$-coefficients than they were received for the untreated samples.

Exemplaric the hysteresis curves for the Blanco Macael, Gioia and Wunsiedel are given in Figure 105 to Figure 106. The application of KSE leads to a similar expansion -temperature function for the Blanco Macael and the Carrara Gioia as the untreated samples. They have a lower increase for the first cycle, while the following cycles show straighter hysteresis curves. According to the untreated samples, the first cycle leads to an irreversible length change which doesn't increase with the following cycles. The Wunsiedel 
marble on the other hand, shows an almost linear expansion and contraction without any irreversible length change.

Comparable data were observed for the Paraloid B72 and ATI treatment, independent of the marble type, while the ATI treated samples show a low amount of residual strain. The slope of expansion for the ATI and Paraloid B72, shows for the Blanco Macael and
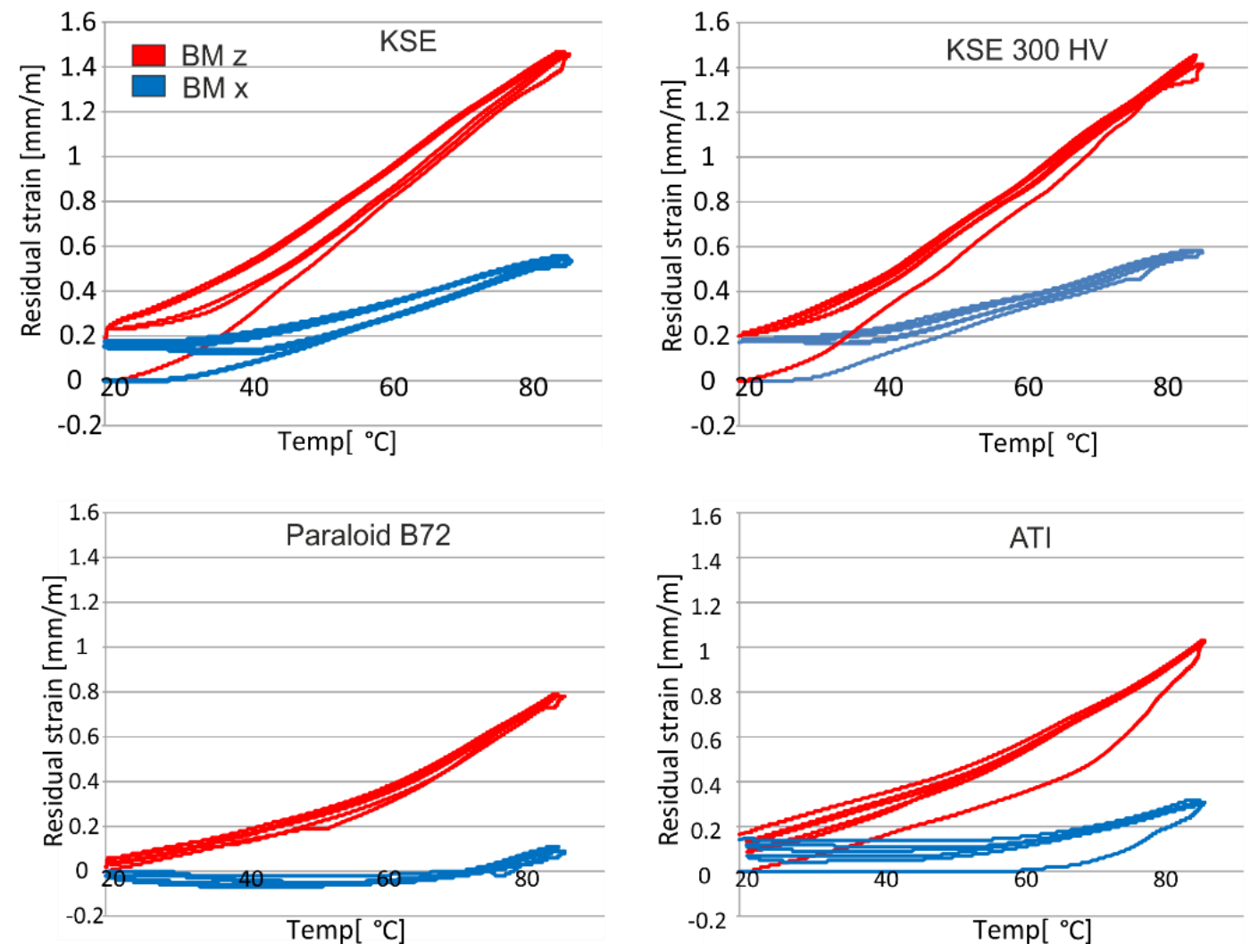

Figure 105 Thermal dilatation $\varepsilon[\mathrm{mm} / \mathrm{m}]$ shown as a loop of hysteresis for the Z- and X-direction of the Blanco Macael, treated with different consolidation materials.

the Carrara Gioia an interesting behaviour, which could be correlated to the glass transition temperature of the acrylic resin, which is higher for the ATI than for the Paraloid B72. Both treatments show a low increase of the slope until the Paraloid B72 samples 
reach about $50^{\circ} \mathrm{C}$ and the $\mathrm{ATI}$ samples about $70^{\circ} \mathrm{C}$, after this temperature the slope increases faster than before, while it is a smooth transition, which can be correlated to a softening of the acrylic resins.
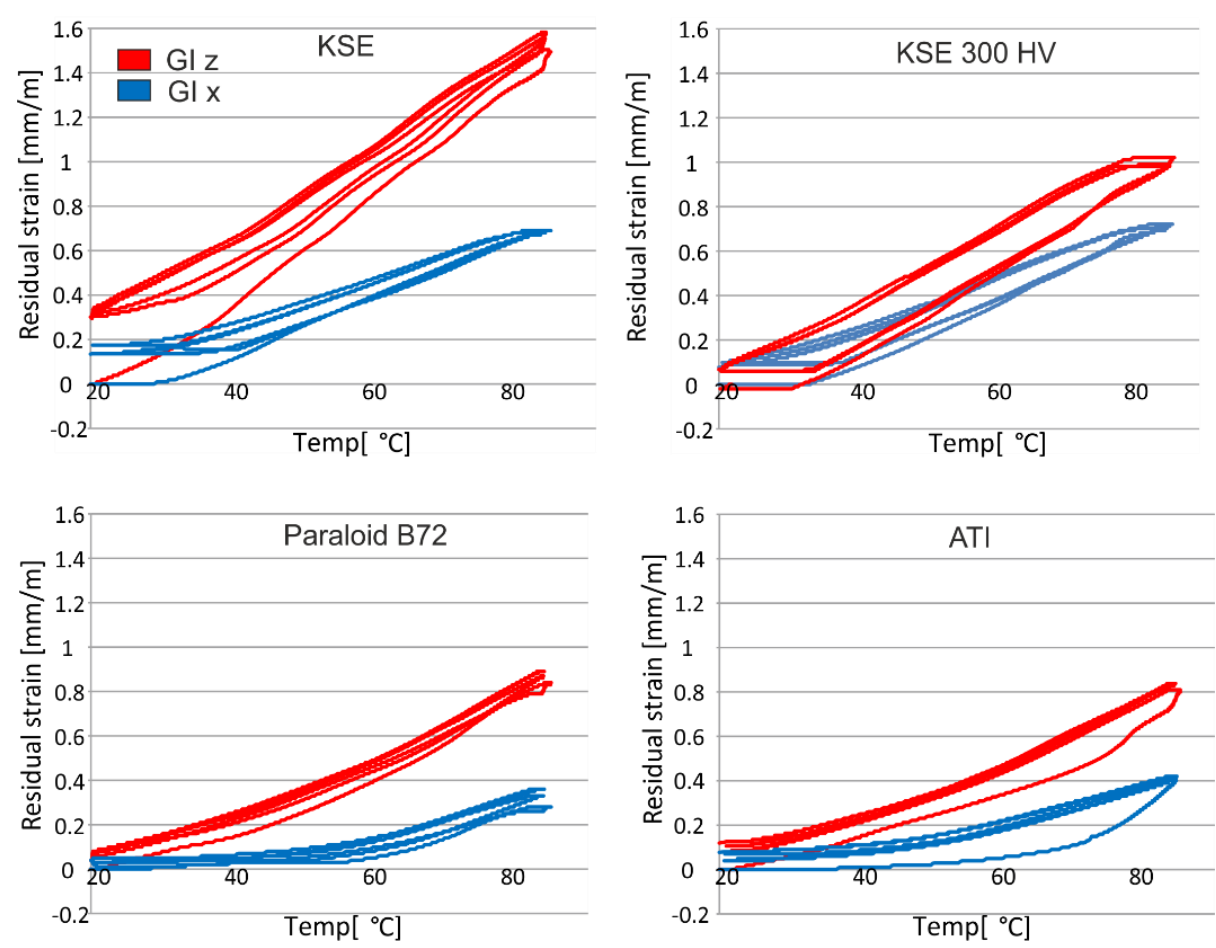

Figure 107 Thermal dilatation $\varepsilon[\mathrm{mm} / \mathrm{m}]$ shown as a loop of hysteresis for the Z- and X-direction of the Carrara Gioia, treated with different consolidation materials.
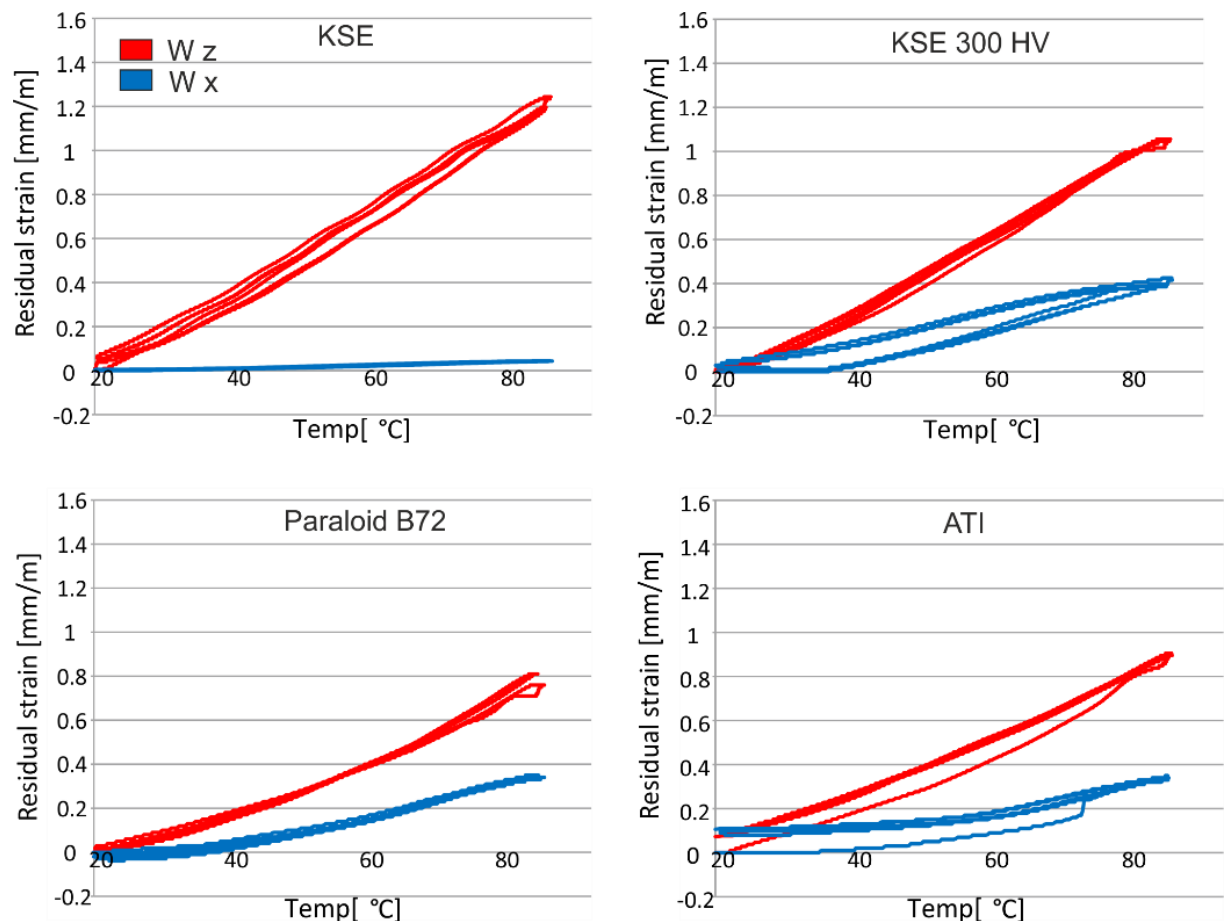

Figure 106 Thermal dilatation $\varepsilon[\mathrm{mm} / \mathrm{m}]$ shown as a loop of hysteresis for the Z- and X-direction of the Wunsiedel, treated with different consolidation materials. 


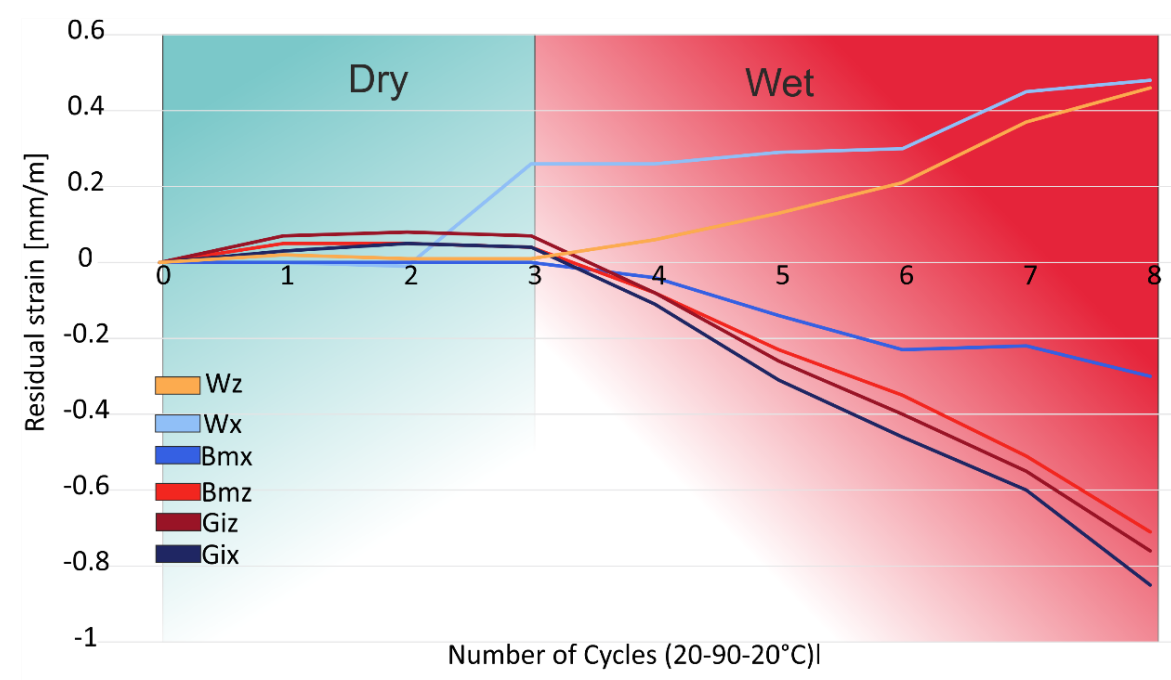

Figure 108 Residual strain $\varepsilon_{\mathrm{RS}}[\mathrm{mm} / \mathrm{m}]$, curves indicate $X$ - and Z- direction. Progressive increase of residual strain of Wunsiedel, Blanco Macael and Gioia, investigated as a function of the number of heating cycles under dry ( 4 cycles, blue) and wet ( 5 cycles, red background) conditions.

Exemplaric for the other materials, in Figure 107 the residual strain under dry and wet conditions is given for the Paraloid B72 treated samples Wunsiedel, Blanco Macael and Carrara Gioia.

While the dry cycles had almost no effect on the samples and caused no or low residual strain, the application of thermohygric cycles causes an increase of the residual strain for the Wunsiedel marble, while the Carrara Gioia and Blanco Macael start to shrink and reach values of almost $-0.9 \mathrm{~mm} / \mathrm{m}$ after 5 wet cycles. This phenomenon could be explained by a collapse of the fabric-Paraloid-System initialized by the influence of the thermohygric cycles. To clarify this aspect, it is necessary to carry out further analyses to determine this behaviour.

\subsubsection{Ultrasonic measurements and dynamic E-modulus}

All samples were measured by ultrasonic means before and after they were artificial alterated, consolidated and again alterated. The results for these analyses can be found in Figure 109. It can be stated that the velocities for the KSE treated samples are higher than the alterated samples and except for the Großkunzendorf, almost the same as the preweathered samples. They show a comparatively higher velocity, than the velocities determined for the cubes (Figure 103) which could be explained by the smaller sample size. 
While the results seem to be promising until this point, the next heating cycles reduce the velocity down to almost the weathered state of the sample. The same results must be stated for the KSE HV. Independent of the marble type, those treatments lose their effectiveness within the thermal load. The Paraloid B72 treated samples show only little increase of their velocities, but regardless of the described thermohygric expansion behaviour, they show almost the same ultrasonic velocities after the thermal load. The ATI samples show, according to the results of the cubes a strong velocity increase due to the consolidation and almost no reduction within the additional thermal load. The highest reduction can be found in Z-direction for the Blanco Macael and the Großkunzendorf, where the velocities decrease about $1 \mathrm{~km} / \mathrm{s}$. Nevertheless, the velocities still suggest a good consolidation state for these samples.

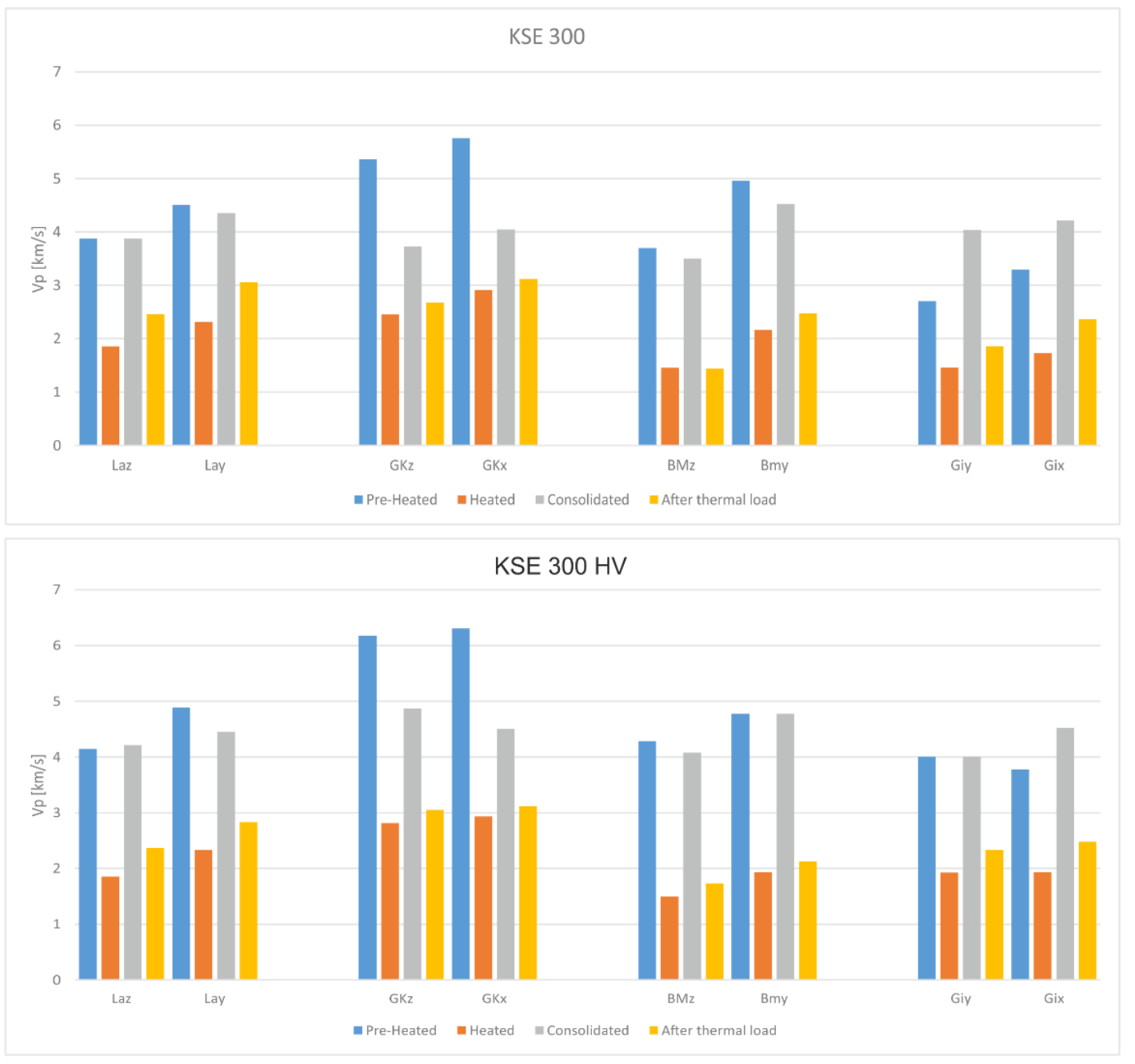

Figure 109 a) Ultrasonic velocities [km/s] determined for the marble varieties Blanco Macael (BM), Großkunzendorfer (GK), Lasa (LA) and Gioia (GI) in the unweathered state (blue bars), the weathered state (orange bars ) after the consolidation (grey bars). And after additional thermal load (yellow bars) Given are the results for the different consolidation materials KSE 300 and KSE 300HV. 

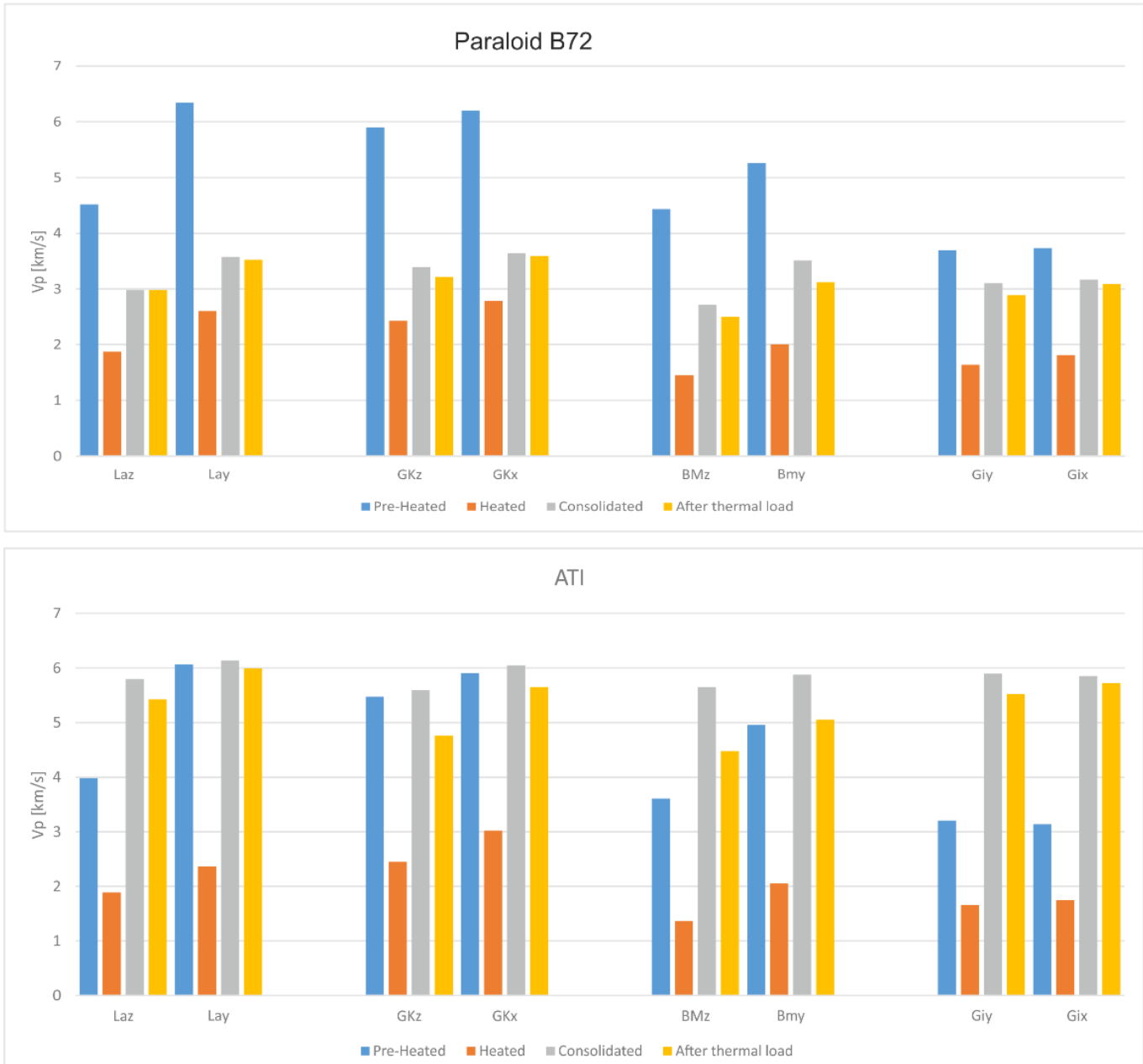

Figure $110 \mathrm{~b}$ Ultrasonic velocities [km/s] determined for the marble varieties Blanco Macael (BM), Großkunzendorfer (GK), Lasa (LA) and Gioia (GI) in the unweathered state (blue bars), the weathered state (orange bars ) after the consolidation (grey bars). And after additional thermal load (yellow bars) Given are the results for the different consolidation materials Paraloid B 72 and ATI.

According to the ultrasonic velocities, the dynamic E-modulus increases within the consolidation and decrease with additional thermal load. The values depicted in Figure 112 $a$ and $b$ show the percentage increase or decrease of the initial dynamic E-Modulus for the different consolidation states. The KSE treatments increase the Edyn up to almost $100 \%$ for the Lasa and the Blanco Macael and little higher for the Carrara Gioia. The Großkunzendorf receives about $50 \%$ of the initial Edyn. Within the thermal load this benefit is almost completely lost. According to the results of the ultrasonic measurement the Edyn decreases to the heated results. 


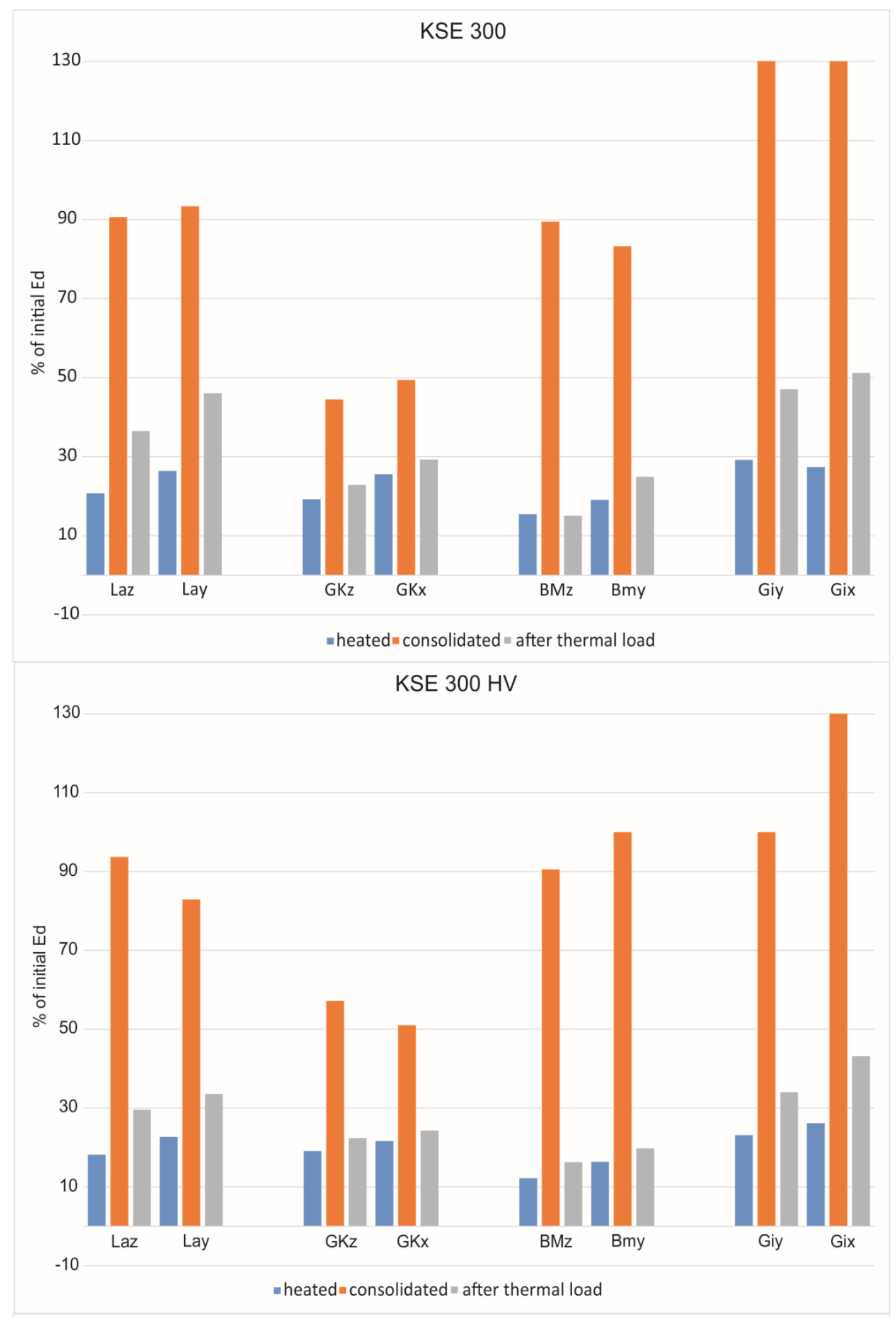

Figure 111 a) Percentage increase or decrease of the initial dynamic E-Modulus for the marble varieties Blanco Macael (BM), Großkunzendorfer (GK), Lasa (LA) and Gioia (GI) for the different weathering and consolidation states. Blue bars indicate the weathered state, orange bars the consolidated state and grey bars the values after additional thermal load. 


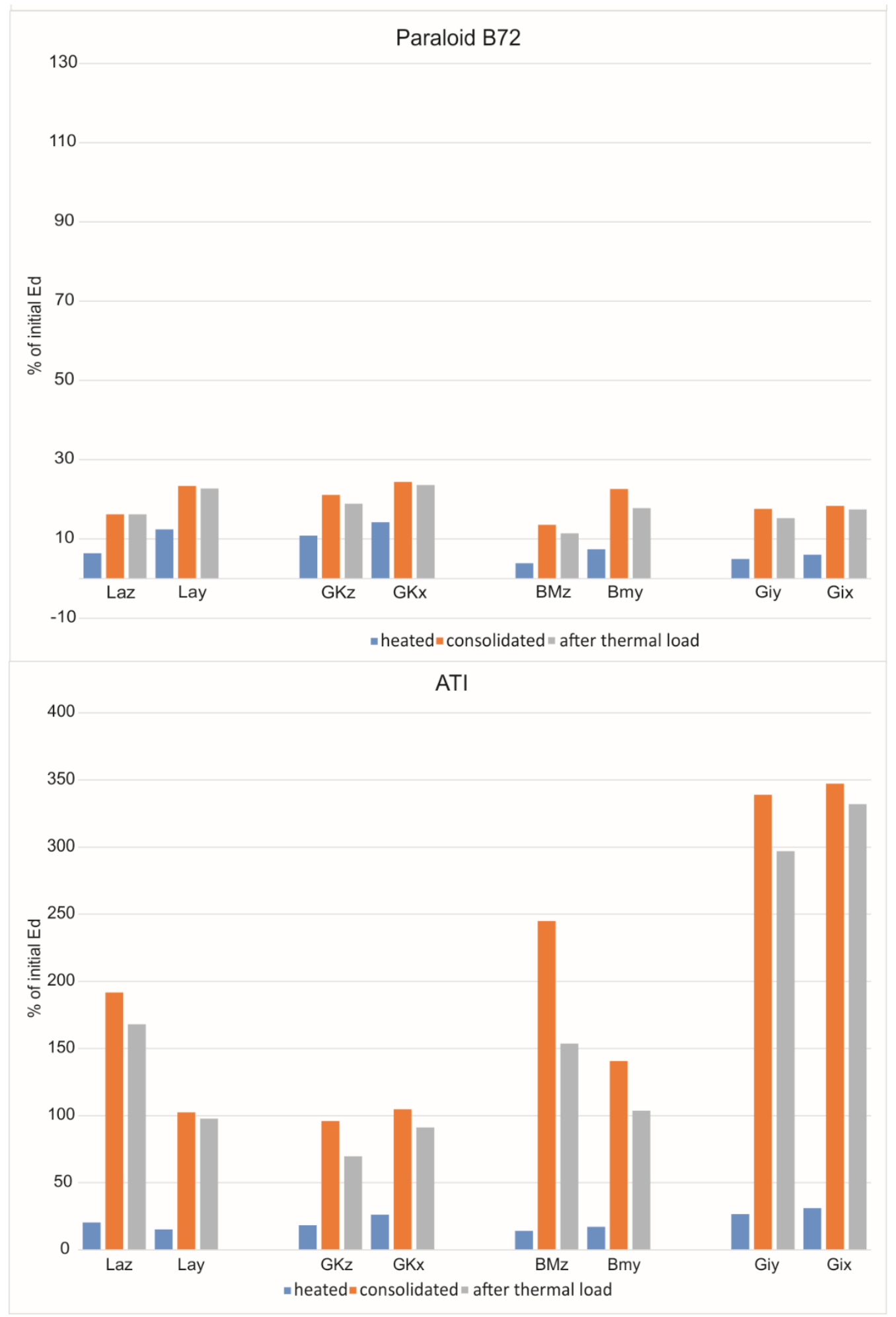

Figure 112 b) Percentage increase or decrease of the initial dynamic E-Modulus for the marble varieties Blanco Macael (BM), Großkunzendorfer (GK), Lasa (LA) and Gioia (GI) for the different weathering and consolidation states. Blue bars indicate the weathered state, orange bars the consolidated state and grey bars the values after additional thermal load. 
The application of the Paraloid B72 does not show a significant increase of the dynamic E-modulus, but is higher than the heated state. Nevertheless, within the additional thermal load, the Edyn stays almost the same as for the consolidated state. The graph for the ATI needs a closer examination, as the other results would have been invisible, the scale differs from the other graphs. Here the maximum value given for the Edyn-axis is $400 \%$ in comparison to the $130 \%$ for the other 3 graphs. The data for the ATI treatment show, that the dynamic E-modulus increases up to $350 \%$ of the initial dynamic E-Modulus for the Carrara Gioia. The best result is received for the Großkunzendorf, which shows for both directions almost the same value, which is additionally almost the same as the initial value. For the Lasa and the Blanco Macael, the Edyn shows a strong directional dependency, which could cause stress within the rock material. The Carrara Gioia has an extremely high Edyn, while it varies only low within the two directions. Further analyses should be carried out to determine the risks and benefits of these results.

\subsubsection{Conclusions}

Aim of this study was, to determine the different consolidation states on basis of the ultrasonic velocities. It was possible to determine the consolidation state and to evaluate the durability of the treatments. On basis of these data it should be focused on the directional dependence of rock mechanical tests for the ATI treatment, the behaviour of the Paraloid B72 within the pore space depending on the temperature and the effect of an additional KSE treatment. All these information could be taken by ultrasonic measurements with a relatively low effort while they can help to improve the choice of further necessary tests.

The data have proven that this non-destructive method is an important tool to analyse the different conditions and can help to focus on the key problems. In combination with the thermal expansion, which needs only a low amount of material, this method allows to initiate further appropriate measures. 


\subsection{Coating to prevent bowing}

The expansion of thin marble slabs, known as bowing, is a spectacular and often observed behaviour of calcitic marbles. The result of this phenomenon is frequently the removal and replacement of those panels as a precaution, which is a significant economic factor. In a previous study, promising results were obtained on the possibility to mitigate and prevent bowing by treating marble with solutions of diammonium hydrogen phosphate (DAP) to form hydroxyapatite with consolidating properties (Sassoni, 2018). Based on these results, a systematic study was started on five different marble varieties.

The treatment is based on the application of a solution of DAP to induce formation of new calcium phosphate phases inside microcracks and on the marble surface. These calcium phosphates have been found to restore mechanical properties of weathered marble by re-establishing cohesion among calcite grains.

In the present study, the application of DAP was performed on unweathered and artificially bowed calcitic marble slabs, in addition to naturally bowed marble panels, taken from the University of Göttingen state library. This enables one to see if the bowing of the marble slabs can be reduced or even be stopped. Besides the bowing behaviour, the thermal dilation of the varieties and their directional dependency was examined. The tests were performed under dry and wet sample conditions for thermal cycles from $20^{\circ} \mathrm{C}$ up to $90^{\circ} \mathrm{C}$ (see 3.4.5 Thermal expansion). Particularly with regard to the irreversible residual strain under unweathered conditions, as well as weathered and treated with the DAP and unweathered and consolidated. The grain to grain cohesion was tested by means of ultrasonic velocities for all samples before and after the artificial bowing, as well as after the consolidation and subsequently after the final bowing cycles. All investigations have been performed according to the specific directional dependency of the varieties under consideration of the maximum and minimum expansion direction. 


\subsubsection{Background}

The so-called bowing of marble slabs is a weathering effect that can be observed on gravestones as well as on historic and modern buildings. Since bowing may result in fracturing and collapsing, causing risks and financial costs, this phenomenon has been frequently studied. The bowing inducing effects have been intensively studied. The influencing parameters seem to be intrinsic properties combined with thermo-hygric influences as well as building physics. An overview is given in Siegesmund et al., 2008 and Koch and Siegesmund, 2004. Different treatments have been used to consolidate marble, while none of them give fully satisfactory results, especially regarding the thermal weathering influences. The most promising results have been currently obtained by the application of a treatment based on hydroxyapatite for the protection and consolidation of marble. Sassoni et al., 2018a found promising results for the application of diammonium hydrogen phosphate (DAP) on Carrara marble slabs. To see whether those results can be transferred to other marble varieties with different fabric properties, the most promising formulation was applied to four different types of artificially weathered calcitic marbles and one example of naturally bowed marble.

\subsubsection{Materials and Methods}

Diammonium hydrogen phosphate

Based on previous results on the ability to consolidate weathered marble (Sassoni et al., 2018b) and to mitigate thermal weathering, the following formulation of the treatment was selected: $1 \mathrm{M} \mathrm{DAP}+1 \mathrm{mM} \mathrm{CaCl}$. Addition of $\mathrm{CaCl} 2$ (in 1:1000 molar ratio to DAP) was performed as it favours formation of new calcium phosphates in a shorter time (Naidu and Scherer, 2014). Previous studies highlighted that this formulation is able to sensibly increase marble cohesion, without significantly occluding pores and micro cracks among grains, so that some deformation of calcite crystals upon temperature variations can occur without stress at grain boundaries. 
The DAP solution was applied by brushing until apparent refusal on the external surface of the specimens. Then the samples were wrapped in a plastic film for 24 hours to prevent evaporation. The samples were then unwrapped, rinsed with water and finally dried at room temperature until constant weight.

\subsubsection{Marble varieties}

The application of the DAP solution was performed according to (Sassoni, 2018)) on five different types of calcitic marble. The Großkunzendorf (GK), the Lasa (LA), Carrara Gioia (GI) marble and the Blanco Macael (BM). Additionally, a removed slab from the University of Göttingen library (SUB), identified as Bianco Carrara Gioia Venato (see Siegesmund et al., 2008) was used as a naturally bowed example of marble. All samples have been prepared from one single block per variety. As shown in Table 15 except for the GK, all marble varieties have a granoblastic grain fabric with straight grain boundaries and medium grain sizes between $284-485 \mu \mathrm{m}$. The GK has a seriate- interlobate grain fabric with interlocking grain boundaries. The average grain size is with $545 \mu \mathrm{m}$ the largest for all five varieties. Except for the Lasa marble, all marbles show a typical c-axis maxima, described as c-axis fibre type, (Leiss and Ullemeyer, 1999) with low to moderate intensities. The c-axes of the Lasa marble are almost girdle like arranged as an a-axes fibre type.

Table 15 The various marble types and description of their grain fabric, average grain size and texture. SUB data were adapted from Siegesmund et al., 2008.

\begin{tabular}{llll}
\hline MARBLE & GRAIN FABRIC & $\varnothing$ GRAIN SIZE & TEXTURE \\
\hline GK & Seriate-interlobate & $545 \mu \mathrm{m}$ & $1.58 \mathrm{mrd}$ \\
LA & Equigranular-polygonal & $419 \mu \mathrm{m}$ & $2.06 \mathrm{mrd}$ \\
GI & Equigranular-polygonal & $284 \mu \mathrm{m}$ & $2.35 \mathrm{mrd}$ \\
BM & Equigranular-polygonal & $495 \mu \mathrm{m}$ & $2.9 \mathrm{mrd}$ \\
SUB* & Equigranular-polygonal & $300 \mu \mathrm{m}$ & $1.3 \mathrm{mrd}$ \\
\hline
\end{tabular}

\subsubsection{Sample treatment}

In order to determine the consolidation effect of the hydroxyapatite treatment, all investigations were performed on (i) fresh, unweathered material, (ii) artificially weathered samples, (iii) artificially weathered and then DAP consolidated samples, and (iv) 
DAP-treated samples subjected to further thermal weathering. Since marble is known to have anisotropic properties, all analyses were performed on oriented samples to take any directional dependences into account. Investigations of the bowing and the ultrasonic measurements were performed on the same sample under different conditions, to analyse the effective change within the properties. Thermal expansion was analysed for unweathered marble and artificially weathered with DAP treated samples. One exception are the naturally bowed samples of the SUB, where no fresh state was evaluated.

Two types of samples were prepared: (i) cylinders with a diameter of $15 \mathrm{~mm}$ and a length of $50 \mathrm{~mm}$, to test their thermal expansion (see Koch and Siegesmund, 2004), and (ii) slabs with a length of $400 \mathrm{~mm}$, a width of $100 \mathrm{~mm}$ and a thickness of $30 \mathrm{~mm}$, to test the bowing behaviour according to the DIN EN 16306. Since the removed panel of the SUB had a thickness of $40 \mathrm{~mm}$, the slabs obtained from this panel had the same thickness. All samples were analysed by ultrasonic measurements, using a $350 \mathrm{kHz}$ probe to evaluate the P-wave in transmission.

The artificial deterioration for the cylinders was caused by repetitively heating up the samples to $200^{\circ} \mathrm{C}$, keeping the temperature for 4 hours and subsequently cooling down to about $4{ }^{\circ} \mathrm{C}$ (Chapter 3.6 Artificial Alteration). The slabs were artificially bowed by 65 cycles as described by Sassoni et al., 2018: the first 40 cycles consisted in heating up to $90{ }^{\circ} \mathrm{C}$ and the last 25 cycles up to $120^{\circ} \mathrm{C}$ to increase the state of deterioration.

\subsubsection{Durability of the consolidation}

\subsubsection{Thermal Expansion}

To analyse the effect of the treatment, the thermal expansion was measured for three dry and five wet cycles in the $X, Y$ and $Z$ direction, while $Z$ is perpendicular to the foliation plane and according to the measured orientation of the c-axes (see Chapter 3.2 Sample preparation and orientation).

After each heating-cooling cycle $\left(20-90-20^{\circ} \mathrm{C}\right)$, the irreversible expansion (residual strain) is illustrated in Figure 113. Depicted are the directions with the highest (red curve) and the lowest (green curve) residual strain in $\mathrm{mm} / \mathrm{m}$. 
All samples show residual strain after the first dry cycle, with no or little increases in the following dry cycles. Only adding water causes a further increase in the residual strain. The residual strain of the DAP treated samples (blue and dark red curves, for the two directions) is also shown. All marble varieties show a decrease of the measured residual strain under dry conditions, corresponding to a higher resistance to thermal weathering. Furthermore, the application of water does not have such a strong influence anymore. In the case of the GI marble, the benefit of the DAP treatment is lower after the dry cycles, but still present at the end of the wet cycles.
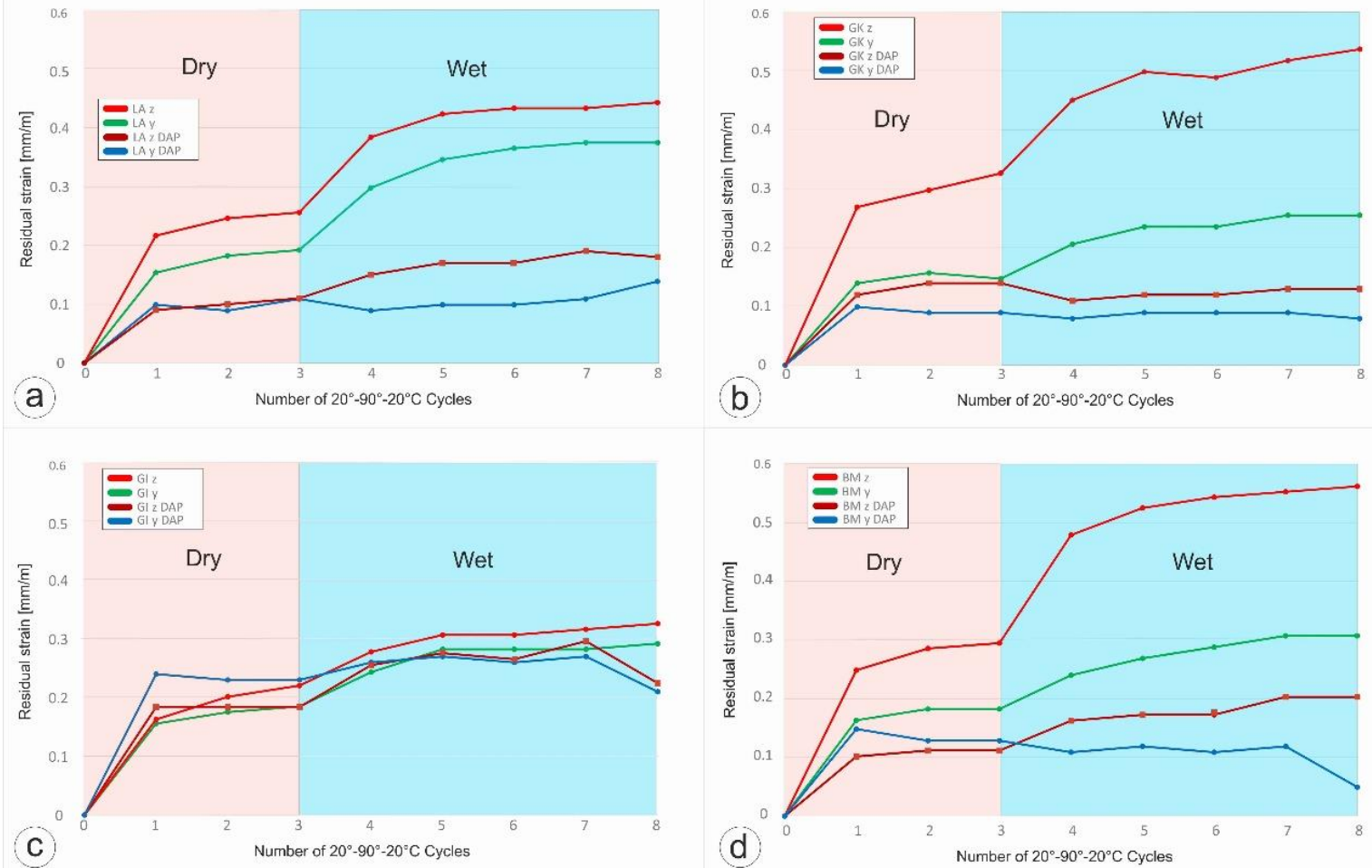

Figure 113 Residual strain after heating-cooling cycles of untreated and treated marbles under dry and wet conditions.

Those results show that the treatment decreases the residual strain. As the analysed DAP samples have been artificially pre-weathered, it cannot be ensured that the decrease is not only caused by the pre-weathering. On the other hand, the application of the DAP does not increase or reactivate the irreversible expansion. 


\subsubsection{Bowing}

In Figure 114 the results are illustrated for the bowing measurements on the slabs. Each graph shows the expansion in $\mathrm{mm} / \mathrm{m}$ according to the number of heating cycles, while 0 is the initial length. For each sample ( $1 z$ and $1 y$ or $x)$ the results for the same slab after the application of DAP (1z DAP or 1x/y DAP) are given. To ensure that the inhibition of further expansion tendencies is not only caused by the previous bowing treatment, additionally one unweathered slab was treated with DAP and underwent the same cycles as the prebowed slabs ( $z$ and $x, y$ DAP).

Almost all marble varieties show a reduction in the bowing intensity independent of the measured direction. Nonetheless, there are differences regarding the development of the bowing inhibition. Except for the Lasa marble in the $z$ direction, all samples show the highest benefit for the first 10 cycles, afterwards the bowing of the treated samples increases as well. BMz and GKz show almost no expansion for the prebowed DAP treated samples, even after 30 cycles, while their second direction shows an increase of expansion for the treated samples. For the BMy slabs, the expansion is higher than in their untreated state.

The GI and SUB slabs show a comparable behaviour: both varieties show a decrease of the bowing intensity after the DAP treatment, which lasts until the 30th cycle, when some increase in the bowing tendency is registered. The GKz, BMz and Laz samples show a slightly different development. The bowing intensity does not change significantly during the 30 cycles and stays more or less constant. The unweathered and with DAP treated samples (light green and light blue bars) show for all varieties a reduction of the bowing intensity that stays below the untreated and the prebowed DAP expansion. Only for the SUB sample do both directions show a strong expansion increase for the 20th to 30th cycles, that is higher than the values received for the DAP treated samples and even higher than the prebowed values. 


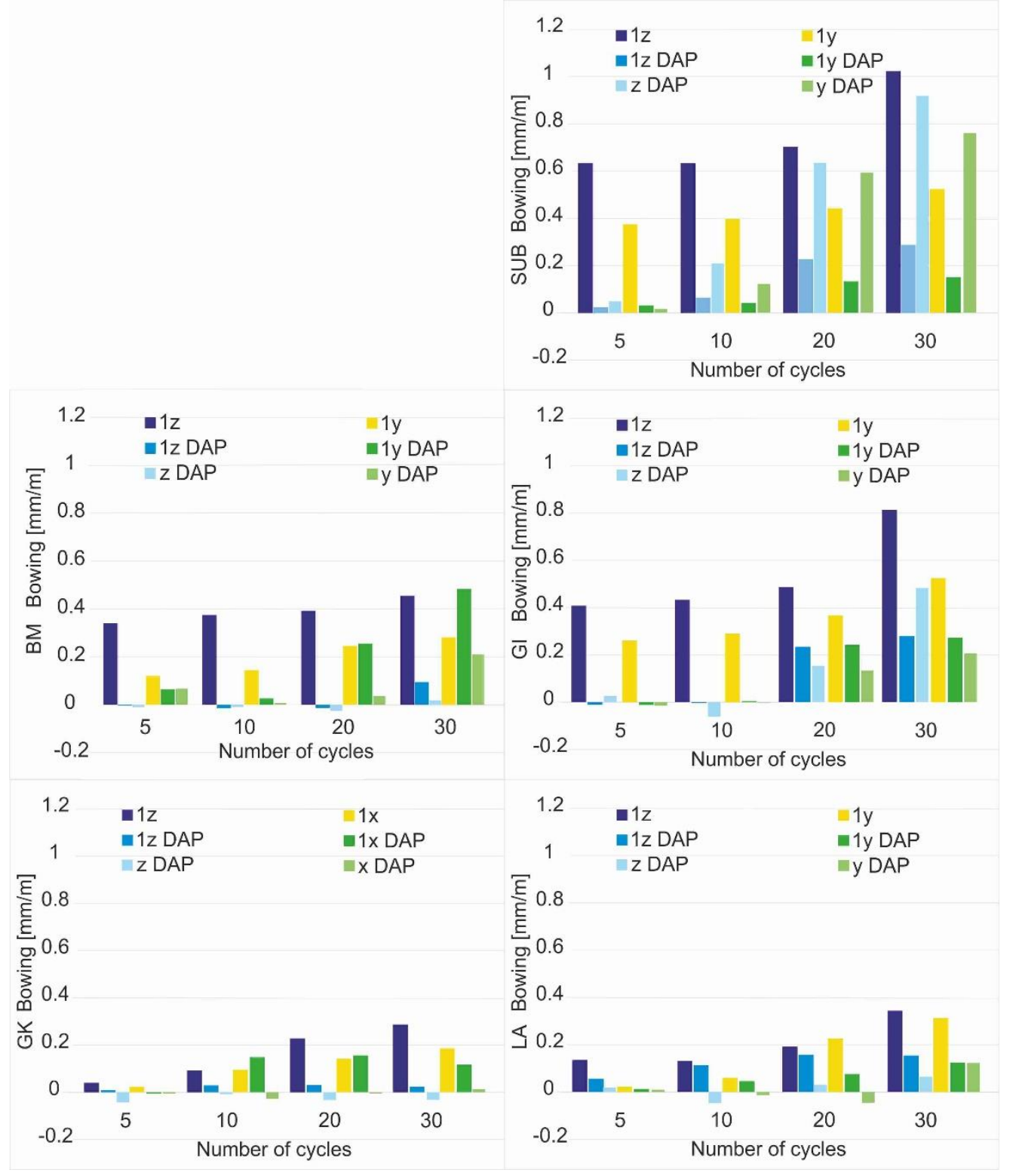

Figure 114 Bowing of untreated and treated marble slabs in the $z$ and $y / x$-direction for all five marble varieties. The length change is given in $\mathrm{mm} / \mathrm{m}$ after 5, 10, 20 and 30 cycles, while 0 is the initial height of the slab. The $1 z / x / y$ data represent the evolution of the bowing behaviour for the unweathered sample. The $1 \mathrm{z} / \mathrm{y} / \mathrm{x}$ DAP samples are the formerly described prebowed samples after the DAP treatment, while the $z / y / x$ DAP samples are unweathered samples where the DAP solution was applied before the bowing.

\subsubsection{Ultrasonic velocities}

Ultrasonic velocities have been measured for both the cylinders and the slabs. The data were obtained for the cylinders before and after heating, after consolidation by DAP and after subsequent thermal cycles.

Figure 115 shows that before heating, samples could be classified as category 0-I (Table 8) which is described as fresh to increasingly porous. After the samples have been 
heated up to $200^{\circ} \mathrm{C}$ and subsequently cooled down, the velocity decreased down to 1.5 $\mathrm{km} / \mathrm{s}$ for the Blanco Macael and lower than $2.8 \mathrm{~km} / \mathrm{s}$ for the other samples. The application of DAP lead to an increased velocity for all samples, indicating an intact to slightly deteriorated marble. After the samples have been subjected to the thermal expansion (three dry and five wet cycles), they still are in a better condition than before the consolidation. To see whether the application of DAP would influence the Young's modulus $\left(E_{d y n}\right)$ in a negative way, $E_{d y n}$ was calculated according to the equation given in Chapter

\subsubsection{Dynamic E-modulus.}

The percentage change of $E_{d y n}$ with respect to the initial value is given in Figure 116.

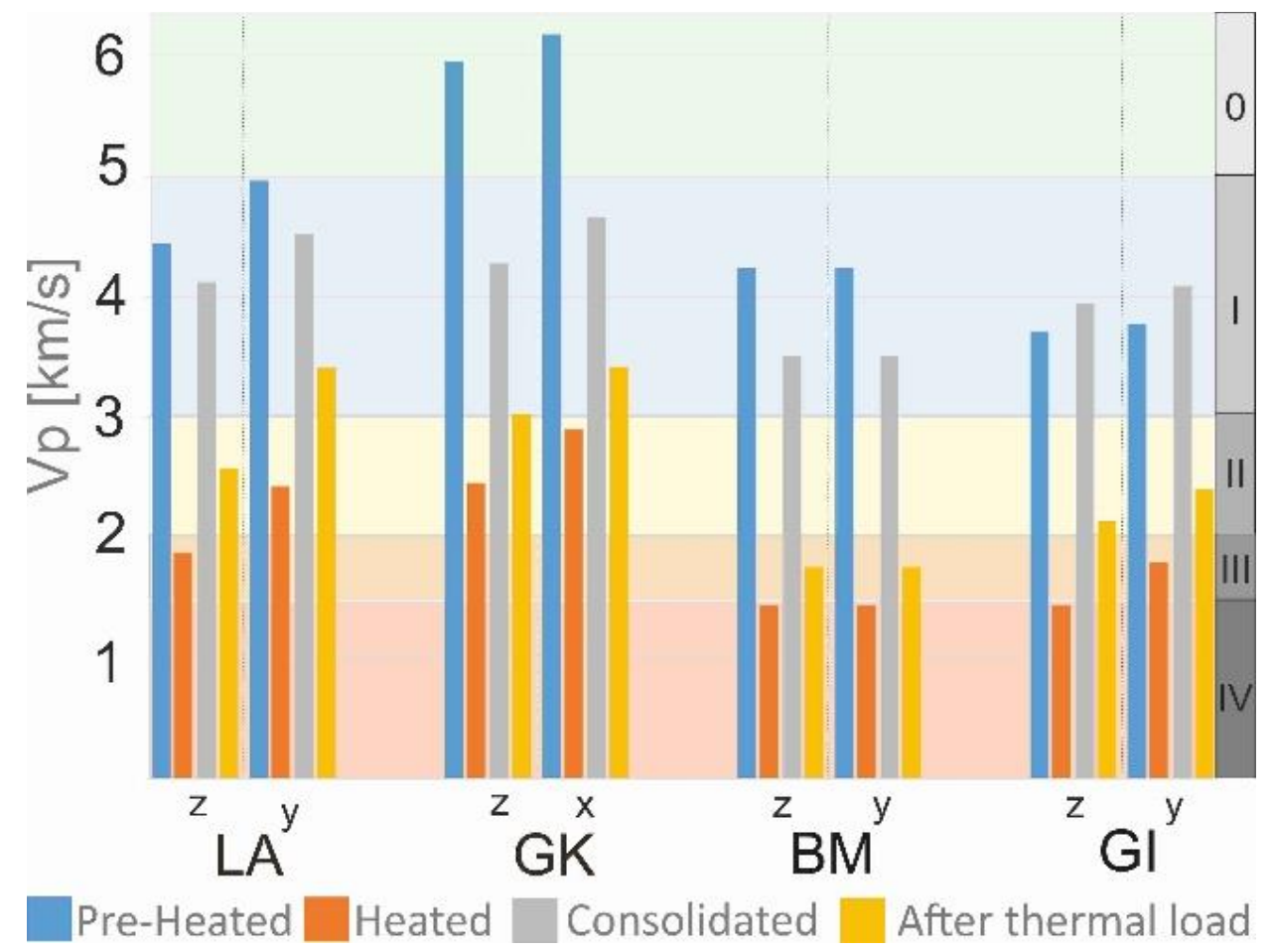

Figure 115 Ultrasonic velocity [km/s] before (blue) and after heating (red), after consolidation by DAP (grey) and after subsequent thermal cycles (orange).

After the samples have been artificially weathered, the Young's Modulus decreased significantly. The consolidation by DAP increased the $E_{d y n}$ for the LA almost to $100 \%$ of the original value and exceeds the initial state for the GI. On the contrary, the $E_{d y n}$ for the BM does not exceed $70 \%$ and could only be recovered up to $60 \%$ for the GK. Nevertheless, consolidation improved the Young's modulus for all the samples. After the samples 
were exposed to thermal weathering again, the values decreased significantly, so that the final value was only slightly higher than before consolidation.

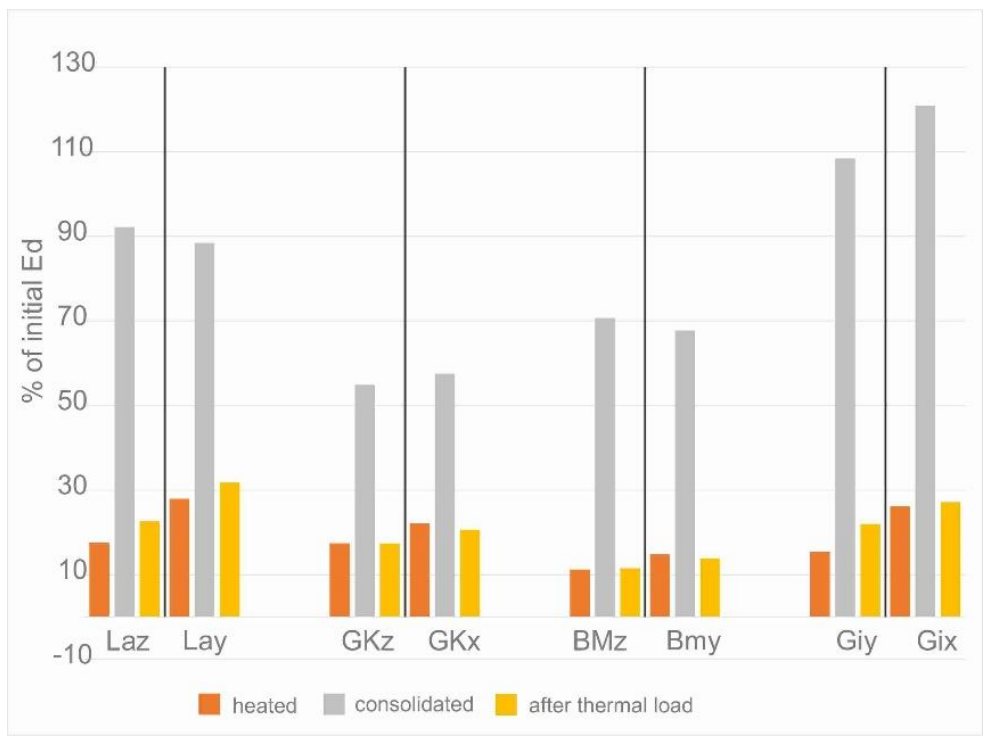

Figure 116 Edyn variation for the preweathered (heated) and consolidated cylinders and the variation after thermal load.

\subsubsection{Conclusions}

The results of the present work show that, for various types of marble with different properties, a reduction in residual strain after thermal cycles can be achieved by treatment with aqueous solutions of diammonium hydrogen phosphate (DAP). Because of the formation of hydroxyapatite among calcite grains, marble cohesion is increased, and the bowing tendency is decreased after treatment with DAP. While for some types of marble bowing was low even after 30 heating-cooling cycles after consolidation, in other cases a progressive loss in cohesion and resistance to bowing was registered. Further tests are in progress to affirm the effectiveness and ascertain the long-term behaviour of DAP treated marbles. 


\section{Conclusions}

Ultrasonic measurements are performed with the aim to get an insight into the structural properties of a material, including information about the weathering state as well as possible deterioration zones and cracks. As every cross-section tomogram is made of a grid of numerous transmission measurements, the same accuracy is necessary as for every ultrasonic transmission measurement. From a technical point of view, several aspects need to be taken into consideration as they influence the ultrasonic results. First of all, coupling of the ultrasonic transducers to the respective surface is an important aspect. An adequate connection is fundamental for a high signal amplitude, which is necessary for an appropriate evaluation of the measurement.

Since the ultrasound velocity correlates with the rock fabric, extrinsic influences, like decay phenomena connected with granular disintegration, are characterized by a decreasing velocity compared to the unweathered material. It should also be noted, that quarry fresh material shows intrinsic velocity variations. Responsible for these fluctuations are the specific bonding situations within the fabric as well as the properties of the respective mineral phases. The propagation of the sonic wave depends on the homogeneity of the material, whereby steel or water is ideal. Therefore, they show only small damping effects on the sonic wave. The more diverse the densities of involved material compounds are, the more the acoustic damping will increase, meaning the sound amplitude will decrease. If there is a density change between neighbouring compounds, the acoustic impedance will also change. The biggest impedance change occurs for a transition of solid state to air, as for example along a crack. Since dry coupling, meaning attachment of ultrasound probes with a plain surface without a coupling agent, will always cause a damping effect comparable to a crack, the application of a coupling agent is necessary. The thickness of this agent needs to fit to the surface conditions but should generally be executed as thin as possible. Especially for important objects and sensitive surfaces, the choice of the coupling agent must be carried out carefully to avoid an irreversible pollution of them. Possibilities are the application of clay, which can be removed by a brush or plasticine covered with a foil, while any damping effect can be tested with a calibration standard. 
Non-destructive ultrasonic measurement often forms the base for further investigations and decisions. Since the ultrasonic method indicates the degree of weathering, it is necessary to execute the analysis with a high degree of accuracy. The European standard EN 14579:2004 needs to be considered as well as the following aspects, where results are received with a reproducibility of less than 5\% deviation (Köhler, 2014).

The very common source of error is the instrument setting, especially an improper or broken cable and power supply as well as discharged batteries. These aspects influence the signal quality, and therefore the exact determination of the travel time. The distance between emitter and transducer needs to be specified very carefully, (less than $1 \%$ deviation according to the EN), bearing in mind, that in coarse-grained materials the distance needs to be approximately 10 times larger than the general grain size. Another aspect is the consideration of the relationship between measured distance and frequency, where the distance needs to be a multiple of the wavelength. The most frequent operation error is the wrong setting for the signal amplification, which needs to be properly scaled. Since the travel time is determined by the first arrival of the signal, wrong settings lead to undersized signals with a higher travel time or an overdriven signal resulting in a travel time which is too short.

These differences can sum up to a number of micro-seconds, which result in discrepancies particularly with regard to short measuring distances. Furthermore, the signal amplitude depends on the coupling to the surface (pressure and coupling agent), transducer arrangement (direct or indirect transmission) and choice of the right frequency, fitting the measuring distance, material damping or the presence of cracks and fabric decay.

A large influence on the velocities is caused by the presence of water in the measured object as described in Chapter 5 Marble varieties and the effect of alteration. The velocities of a deteriorated piece of marble can increase from below $2.0 \mathrm{~km} / \mathrm{s}$ up to $6.0 \mathrm{~km} / \mathrm{s}$, constituting a fresh, unweathered marble, caused by water saturation (see also Ruedrich and Siegesmund, 2001; Siegesmund et al., 2010; Siegesmund and Dürrast, 2014; Weiss et al., 2002a). Therefore, it is mandatory to ensure almost dry conditions 
before the ultrasonic measurements are taken. Otherwise, it is almost impossible to ensure a measured velocity which is not influenced by water saturation and it is necessary to assume lower velocities than the measured velocities.

Besides the described extrinsic effects, the intrinsic properties of the marble mainly influence the measured velocities and their distribution pattern. The most important fabric elements are the crystallographic preferred orientation (CPO) or the lattice preferred orientation (LPO) of the minerals, the existing microcrack populations, and the specific shape fabric, with grain size and grain-shape preferred orientation. These fabrics are responsible for a physical anisotropy expressed inter alia in the directional dependence of the elastic wave velocities. Therefore, this property needs to be considered for an adequate interpretation of the ultrasonic velocities.

This work provides a large set of important data, which are necessary for further investigations about ultrasonic investigations on marble and can help to understand possible anomalies within a tomogram. Additionally these values can help to characterize possible directional dependences for an object made of one of these marble varieties.

It could be exposed that the intrinsic velocity pattern mainly influences the ultrasonic tomograms, therefore further investigations regarding to the intrinsic distribution within a specific 2-dimensional plane are necessary. Synthetic tomograms as shown in Chapter 6. The marble Obelisk at the Neuen Garten, Potsdam, should be produced in different sections of a sphere to receive a velocity distribution pattern that helps to investigate extrinsic effects. Additionally modelling of these data would be a helpful tool.

Generally, for every measurement it is necessary to have a deeper knowledge regarding the investigated material, e.g. the foliation plane should be determined and if possible 3 different directions should be measured to identify a possible directional dependency.

The combination of decay mapping and ultrasonic measures is important and improves the quality of the interpretation. 3D-Scanning methods as described in Chapter 8 The Columns in the Neuen Garten, Potsdam, are in this context an important possibility to improve the quality of the data and facilitate the later combination and interpretation of different results. 
In conclusion, especially the analysis of comparative ultrasonic measurements is a powerful tool, providing a deeper insight to the weathering behaviour and state of marble. The careful and transparent documentation of all measurements is in this context the most important aspect and allows to distinguish between fabric related differences and irregularities. Furthermore, the combination of these methods provides an optimal template for subsequent measurements in the context of monitoring, to analyse the further weathering process.

Additionally, ultrasonic measurements have proven to be a non-destructive method that helps to analyse the different consolidation states. It was possible to determine the consolidation state and to evaluate the durability of the treatments. They can help to ascertain key problems and to initiate further appropriate measures with a relatively low effort.

Regarding the different tested consolidation materials, the ATI is the most promising technique to receive a structural strengthening, as well as the DAP approach to stop the bowing. While the ATI was applied in the last 30 years, the application of Diammonium phosphate needs further investigations to confirm the results presented in this work. 


\section{References}

Ahmad, A., Pamplona, M., Simon, S., 2009. Ultrasonic testing for the investigation and characterization of stone - a non-destructive and transportable tool. Studies in Conservation 54 (sup1), 43-53.

Antonelli, F., Lazzarini, L., Cancelliere, S., Dessandier, D., 2009. Volubilis (Meknes, Morocco): Archaeometric study of the white and coloured marbles imported in the Roman age. Journal of Cultural Heritage 10 (1), 116-123.

Babacan, A.E., Gelisli, K., 2015. Ultrasonic investigations of marble columns of historical structures built in two different periods. Carbonates Evaporites 30 (3), 357-363.

Bachmann, F., Hielscher, R., Schaeben, H., 2010. Texture Analysis with MTEX - Free and Open Source Software Toolbox. SSP 160, 63-68.

Battaglia, S., Franzini, M., Mango, F., 1993. High sensitivity apparatus for measuring linear thermal expansion: preliminary results on the response of marbles. II Nuovo Cimento (C 16), 453-461.

Blum, R., Rahm, U., 1998. Ultraschall-und Bohrwiderstandsmessungen. Arbeitshefte zur Denkmalpflege in Niedersachsen 15, 83-86.

Boudani, M.E., Wilkie-Chancellier, N., Martinez, L., Hébert, R., Rolland, O., Forst, S., Vergès-Belmin, V., Serfaty, S., 2015. Marble Characterization by Ultrasonic Methods. Procedia Earth and Planetary Science 15, 249-256.

Brimblecombe, P., 2014. Environment and architectural stone, in: Siegesmund, S., Snethlage, R. (Eds.), Stone in architecture, 5 ed. Springer, pp. 317-347.

Cabral, J.P., Vieira, M.C., Carreira, P.M., Figueiredo, M.O., Pena, T.P., Tavares, A., 1992. Preliminary study on the isotopic and chemical characterization of marbles from Alto Alentejo (Portugal). Waelkens M, Herz N, Moens L (eds) ASMOSIA II. Ancient stones: quarrying, trade and provenance. Acta Archaeologica Lovaniensia, Monographiae 4, 191-198.

Capizzi, P., Cosentino, P.L., Schiavone, S., 2013. Some tests of 3D ultrasonic traveltime tomography on the Eleonora d'Aragona statue (F. Laurana, 1468). Journal of Applied Geophysics 91, 14-20.

Cardarelli, E., Nardis, R. de, 2001. Seismic refraction, isotropic anisotropic seismic tomography on an ancient monument (Antonino and Faustina temple ad 141). Geophys Prospect 49 (2), 228-240.

Carmignani, L., Cocozza, T., Minzoni, N., Pertusati, P.C., 1978. The Hercynian Orogenic Revolution in Sardinia. Zeitschrift der Deutschen Geologischen Gesellschaft, 485493.

Carmignani, L., Kligfield, R., 1990. Crustal extension in the northern Apennines: The transition from compression to extension in the Alpi Apuane Core Complex. Tectonis Volume 9 (Issue 6), 1275-1303.

Carvalho, J.M., 2008. Cartografia Temática do Anticlinal-Zona dos Mármores. Éter, Évora.

da Silva, J.M., Camarinhas, M.V.F., 1957. Calcários cristalinos de Vila Viçosa-Souzel. d'Almeida, J.M.P., 2000. Estudo Estratigráfico do Sector de Estremoz-Barrancos, Zona de Ossa Morena, Portugal. 
Dandekar, D., P., 1968. Variation in the Elastic Constants of Calcite with Temperature. Journal of Applied Geophysics 39 (8), 3694-3699.

DBU Abschlussbericht 2015, Aktenzeichen: 29544-45 „Erarbeitung eines BewertungsLeitfadens für Ultraschallmessungen an umweltgeschädigten Marmorskulpturen am Beispiel u.a. des Parks Potsdam Sanssouci (UNESCO-Weltkulturerbe)“

DBU Abschlussbericht 2018, Aktenzeichen 33 162/01-45, Risikoziffer Umweltschäden an Denkmälern aus Marmor- und Sandsteinskulpturen erfassen und objektiv bewerten

Deutsch, V., 2010. Die Ultraschallprüfung (UT), 2. Aufl. ed. ZfP - kompakt und verständlich 1. Castell-Verl., Wuppertal, $89 \mathrm{~S}$.

DIN EN 16306:2013-05, Prüfverfahren für Naturstein_- Bestimmung der Beständigkeit von Marmor bei zyklischer Belastung mit Wärme und Feuchtigkeit; Deutsche Fassung EN_16306:2013. Beuth Verlag GmbH, Berlin. doi:10.31030/1910871.

DIN 52102:2013-10, Prüfverfahren für Gesteinskörnungen - Bestimmung der Trockenrohdichte mit dem Messzylinderverfahren und Berechnung des Dichtigkeitsgrades, Beuth Verlag GmbH, Berlin. https://dx.doi.org/10.31030/2054684

DIN EN 13755:2008-08, Prüfverfahren für Naturstein - Bestimmung der Wasseraufnahme unter atmosphärischem Druck; Deutsche Fassung EN 13755:2008, https://dx.doi.org/10.31030/1438560

DIN EN 14581, Prüfverfahren für Naturstein - Bestimmung des linearen thermischen Ausdehnungskoeffizienten; Deutsche Fassung EN 14581:2004

DIN EN 14579:2004, Prüfverfahren für Naturstein - Bestimmung der Geschwindigkeit der Schallausbreitung; Deutsche Fassung EN 14579:2004

Dürrast, H., Siegesmund, S., Prasad, M., 1999. Die Schadensanalyse von Naturwerksteinen mittels Ultraschalldiagnostik: Möglichkeiten und Grenzen. Zeitschrift der Deutschen Geologischen Gesellschaft 150 (2), 359-374.

Fetzer, T., Reis, G., Stricker, D., 2019. Robust Auto-Calibration for Practical Scanning Setups from Epipolar and Trifocal Relations. 16th International Conference on Machine Vision Applications (MVA), 2019, 1-6.

Fetzer, T., Reis, G., Stricker, D., 2020a. Iterative color Equalization for Increased Structured Light Reconstruction: accepted for publication. 15 th VISAPP, 2020.

Fetzer, T., Reis, G., Stricker, D., 2020b. Stable Intrinsic Auto-Calibration from Fundamental Matrices of Devices with uncorrelated Camera Parameters.: accepted for publication. WACV, 2020.

Fitzner, B., Heinrichs, K., 2004. Photo atlas of weathering forms on stone monuments. http://www.stone .rwth-aachen.de. Accessed 7 February 2019.

Fleischer, G., 2002. Beurteilung von Ultraschalluntersuchungen an Natursteinobjekten in der Denkmalpflege. na.

GeoTomLLC, 2. GeoTomCG software is described on the website and can be purchased from GeoTom through contact information on the website.: The user's manual and a demo program are available free from GeoTom. dev.geotom.net. Accessed 7 February 2020.

Gherardi, F., Kapridaki, C., Roveri, M., Gulotta, D., Maravelaki, P.N., Toniolo, L., 2019. The deterioration of Apuan white marble in contemporary architectural context. Journal of Cultural Heritage 35, 297-306.

Gonçalves, F., 1972. Observações sobre o anticlinório de Estremoz. Alguns aspectos geológico-económicos dos mármores. Est Not Trab Serv Fom Min Porto (22(1)), 121-132. 
Gonçalves, F., Oliveira, V., 1986. Alguns aspectos do Precâmbrico da Zona de Ossa Morena em Portugal. O Proterozóico superior de Estremoz. Mem. Acad. Ciênc. Lisboa 27, 111-117.

Gonçalves, F.A., 1974. Notícia explicativa da folha 36-B: Estremoz. Ministério da Economia, Secretaria de Estado da Indústria, Direcção-Geral de ...

Goretzki, L., Füting, M., Köhler, W., 1987. Untersuchungen zur Korrosion der Marmorskulpturen im Park von Potsdam-Sanssouci. Bautenschutz. Bausanierung 10 (3), 104-109.

Goretzki, L.; Schmidt, T. (Hg.) (1991): Die Veränderung von Gesteinseigenschaften durch die Acrylharzvolltränkung. Bautenschutz Bausanierung 1991 (7/91).

Grelk, B., Christiansen, C., Schouenborg, B., Malaga, K., Hoigard, K., Scheffler, M., Dean, S.W., 2007. Durability of Marble Cladding-A Comprehensive Literature Review. J. ASTM Int. 4 (4), 100857.

Grimm, W.-D., 2018. Bildatlas wichtiger Denkmalgesteine der Bundesrepublik Deutschland, 2., erweiterte Auflage ed. Ebner, Ulm.

Gross, C.J., Weber, K., Vollbrecht, A., Siegesmund, S., 1999. Cathodoluminescence and electron microprobe study of dolomitic marbles from Namibia: Evidence for hydrothermal alteration. Zeitschrift der Deutschen Geologischen Gesellschaft 150 (2), 333-357.

Hammes, D.M., Peternell, M., 2016. FAME: Software for analysing rock microstructures. Computers \& Geosciences 90, 24-33.

Hielscher, R., Schaeben, H., 2008. A novel pole figure inversion method: specification of the MTEX algorithm. J Appl Crystallogr 41 (6), 1024-1037.

Hirschwald, J., 1912. Die Prüfung der natürlichen Bausteine auf ihre Verwitterungsbeständigkeit. W Ernst \& Sohn, Berlin.

Holtkamp, Astrid (1999): Marmorkonservierung. Vergleich ausgewählter Festigungsmittel und Applikationsmethoden an einer Probenreihe aus verwittertem Prieborner - Marmor. Unveröffentlichte Diplomarbeit. Fachhochschule Potsdam.

Jackson, M.J., Tweeton, D.R., 1994. MIGRATOM: Geophysical tomography using wavefront migration and fuzzy constraints.

Jacobsen, Helen (2006): Marmorkonservierung. Vergleich ausgewählter Festigungsmittel zur Konservierung von Großkunzendorfer Marmor. Unveröffentlichte Diplomarbeit. Fachhochschule Potsdam.

Jahns, E., 1995. Quantifizierte seismische Anisotropie: Ein skalenübergreifender Vergleich am Beispiel des KTB. Dissertation, Göttingen.

Kessler, D.W., 1919. Physical and chemical tests on the commercial marbles of the United States 123. US Department of Commerce, Bureau of Standards.

Kleber, W., Bautsch, H.-J., Bohm, J., 2010. Einführung in die Kristallographie. Oldenbourg, München, Online-Ressource (470 S).

Klopfer H (1985) Feuchte. In: Lutz P, Jenisch R, Klopfer H et al (eds) Lehrbuch der Bauphysik. Teubner, Stuttgart

Koch, A., 2006. Deformation von Fassadenplatten aus Marmor: Schadenskartierungen und gesteinstechnische Untersuchungen zur Verwitterungsdynamik von Marmorfassaden. Universitätsverlag Göttingen.

Koch, A., Siegesmund, S., 2002. Bowing of marble panels: on-site damage analysis from the Oeconomicum Building at Göttingen (Germany). Geological Society, London, Special Publications 205 (1), 299-314. 
Koch, A., Siegesmund, S., 2004. The combined effect of moisture and temperature on the anomalous expansion behaviour of marble. Env Geol 46 (3-4).

Köhler, W., 1988. Preservation problems of Carrara marble sculptures: PotsdamSanssouci (" radical structural destruction" of Carrara marble). VIth International Congress on Deterioration and Conservation of Stone, Torun, 653-662.

Köhler, W., 1991. Untersuchungen zu Verwitterungsvorgängen an Carrara-Marmor in Potsdam-Sanssouci. Berichte zu Forschung und Praxis der Denkmalpflege in Deutschland, Steinschäden-Steinkonservierung 2, 50-53.

Köhler, W., 2014. Leitfaden für Ultraschallmessungen an Marmorskulpturen, in: Bellendorf, P. (Ed.), Erhaltung von Marmorskulpturen unter mitteleuropäischen Umweltbedingungen. Beiträge des 8 . Konservierungswissenschaftlichen Kolloquiums in Berlin, Brandenburg am 17. Oktober 2014 in Potsdam, vol. 32. Arbeitshefte des Brandenburgischen Landesamtes für Denkmalpflege und Archäologischen Landesmuseums 32. Wernersche Verl.-Ges, Worms, pp. 37-44.

Köhler, W., 2018. Ultraschalldiagnostik- ein essentieller Bestandteil bei der Berechnung der Risikoziffer, in: Drewello, R. (Ed.), Risikoziffer. Umweltschäden an Marmor und Sandsteinskulpturen erfassen und objektiv bewerten = Risk number : determining and objectively assessing environmental damage on marble and sandstone sculptures. Forschungen des Instituts für Archäologie, Denkmalkunde und Kunstgeschichte Abteilung Denkmalkunde Band 12. University of Bamberg Press, Bamberg, pp. 65-78.

Lachmann, 2019. Die Rückkehr des Meeresgottes. Naturstein (02), 42-44.

Lehmann, B., 2007. Seismic traveltime tomography for engineering and exploration applications: EAGE.

Leiss, B., Ullemeyer, K., 1999. Texture characterisation of carbonate rocks and some implications for the modeling of physical anisotropies, derived from idealized texture types. Zeitschrift der Deutschen Geologischen Gesellschaft 150 (2), 259-274.

Leiss, B., Ullemeyer, K., 2006. Neue Perspektiven der Texturanalytik von Gesteinen mit konventioneller Röntgenbeugung, in: Philipp, S., Leiss, B., Vollbrecht, A., Gudmundsson, A. (Eds.), 11. Symposium "Tektonik, Struktur- und Kristallingeologie". Zusammenfassung der Tagungsbeiträge ; [Geowissenschaftliches Zentrum der Georg-August-Universität Göttingen ; 22. - 24. März 2006. Universitätsdrucke. Niedersächsische Staats- und Universitätsbibliothek; Univ.-Verl. Göttingen, Göttingen, pp. 128-130.

Leiss, B., Weiss, T., 2000. Fabric anisotropy and its influence on physical weathering on different types of Carrara marbles. Journal of Structural Geology (22), 1737-1745.

Levoy, M., Pulli, K., Curless, B., Rusinkiewicz, S., Koller, D., Pereira, L., Ginzton, M., Anderson, S., Davis, J., Ginsberg, J., Shade, J., Fulk, D., 2000. The digital Michelangelo project: 3D scanning of large statues, 2000.

Lindner, H., Pretzschner, C., Rost, L., 1999. Ultraschalluntersuchungen an Bauwerken. Zeitschrift der Deutschen Geologischen Gesellschaft 150 (2), 375-386.

Lopes, J.L.G., 2003. Contribuição para o conhecimento tectono-estratigráfico do nordeste alentejano transversal: Terena-Elvas. implicações económicas no aproveitamento de rochas ornamentais existentes na região (mármores e granitos). Lopes, L., 2007. O triângulo do Mármore. Estudo Geológico. Rev Monum 27, 158-167. Lopes, L., Martins, R., 2015. Global Heritage Stone: Estremoz Marbles, Portugal. Geological Society, London, Special Publications 407 (1), 57-74. 
Luque, A., Cultrone, G., Mosch, S., Siegesmund, S., Sebastian, E., Leiss, B., 2010. Anisotropic behaviour of White Macael marble used in the Alhambra of Granada (Spain). Engineering Geology 115 (3-4), 209-216.

Luque, A., Leiss, B., Álvarez-Lloret, P., Cultrone, G., Siegesmund, S., Sebastian, E., Cardell, C., 2011. Potential thermal expansion of calcitic and dolomitic marbles from Andalusia (Spain). J Appl Crystallogr 44 (6), 1227-1237.

Luque Aranda, A., 2011. Andalusian marbles: Durability criteria applied in its use as ornamental stone. Tesis doctoral. Editorial de la Universidad de Granada, [Granada], 1 CD-ROM (215.

Luz, Luís Miguel Nunes Barata de, 2005. Análise crítica ao modelo de desenvolvimento do sector das pedras naturais: o caso dos mármores no triângulo de EstremozBorba-Vila Viçosa 1980-2003.

Mahmutoğlu, Y., 2017. Prediction of weathering by thermal degradation of a coarsegrained marble using ultrasonic pulse velocity. Environ Earth Sci 76 (12), 785.

Mainprice, D., Bachmann, F., Hielscher, R., Schaeben, H., 2015. Descriptive tools for the analysis of texture projects with large datasets using MTEX : strength, symmetry and components. Geological Society, London, Special Publications 409 (1), 251-271.

Mainprice, D., Hielscher, R., Schaeben, H., 2011. Calculating anisotropic physical properties from texture data using the MTEX open-source package. Geological Society, London, Special Publications 360 (1), 175-192.

Mainprice, D., Casey, M., SCHMID, S., 1990. The seismic properties of Alpine calcite and quartz mylonites determined from the orientation distribution function. Mémoires de la Société géologique de France (1833) 156, 85-95.

Maitland, T., Sitzman, S., 2007. Electron Backscatter Diffraction (EBSD) Technique and Materials: Characterization Examples., in: Zhou, W., Wang, Z.L. (Eds.), Scanning microscopy for nanotechnology. Techniques and applications. Springer, New York, NY, pp. 41-75.

Malaga-Starzec, K., Lindqvist, J.E., Schouenborg, B., 2002. Experimental study on the variation in porosity of marble as a function of temperature. Geological Society, London, Special Publications 205 (1), 81-88.

Marshall, J.D., 1991. Cathodoluminescence of geological materials by D. J. Marshall, Unwin Hyman, 1988. No. of pages: 146. Price: $f 60.00$ (Hardback). ISBN 004 5520267. Geol. J. 26 (4), 351.

Matthes, N., 1993. Mineralogie. Springer, Berlin, Heidelberg, New Xork.

Meccheri, M., Molli, G., Conti, P., Blasi, P., Vaselli, L., 2007. The Carrara Marbles (Alpi Apuane, Italy): a geological and economical updated review [Der Carrara-Marmor (Apuaner Alpen, Italien): geologischer und wirtschaftsgeologischer Überblick].

Menningen, J., Siegesmund, S., Lopes, L., Martins, R., Sousa, L., 2018a. The Estremoz marbles: an updated summary on the geological, mineralogical and rock physical characteristics. Environ Earth Sci 77 (5), 53.

Menningen, J., Siegesmund, S., Tweeton, D., Träupmann, M., 2018b. Ultrasonic tomography: non-destructive evaluation of the weathering state on a marble obelisk, considering the effects of structural properties. Environ Earth Sci 77 (17), 1338.

Menningen, J., Siegesmund, S., Krompholz, R., Rieffel, Y. (2020) The marble sculptures General Bülow and Scharnhorst in Berlin - Comparative, non-destructive analysis of the weathering state after 12 years of exposure. Environmental Earth Sciences, 79, 249. 
Moser, D., 2013, Charakterisierung von Schädigungen in Gesteinen bei Impaktprozessen mit zerstörungsfreier Prüfung, Dissertation Technische Universität München

Moura, A.C., Carvalho, C., 2007. Mármores e calcários ornamentais de Portugal. Gestão de Artes Gráficas SA, Amadora.

Naidu, S., Scherer, G.W., 2014. Nucleation, growth and evolution of calcium phosphate films on calcite. Journal of colloid and interface science 435, 128-137.

Navarro, R., Cruz, A.S., Arriaga, L., Baltuille, J.M., 2017. Caracterización de los principales tipos de mármol extraídos en la comarca de Macael (Almería, sureste de España) y su importancia a lo largo de la historia. BGM 128 (2).

Nöll, T., Stricker, D., 2011. Efficient packing of arbitrary shaped charts for automatic texture atlas generation. Computer Graphics Forum, 2011.

North American Geologic-Map Data Model Science Language Technical Team (Ed.), 2004. Report on progress to develop a North American science-language standard for digital geologic-map databases; Appendix B: - Classification of metamorphic and other composite-genesis rocks, including hydrothermally altered, impact-metamorphic, mylonitic, and cataclastic rocks,. Version 1.0 (12/18/2004). Digital Mapping Techniques '04-Workshop Proceedings: U.S. Geological Survey Open-File Report 2004-1451.

O'Connell, R.J., Budiansky, B., 1974. Seismic velocities in dry and saturated cracked solids. J. Geophys. Res. 79 (35), 5412-5426.

Oliveira, J.T. de, Oliveira, V., Piçarra, J.M., 1991. Traços gerais da evolução tectono-estratigráfica da Zona de Ossa-Morena, em Portugal. 0213-4497.

Ondrasina, J., Kirchner, D., Siegesmund, S., 2002. Freeze-thaw cycles and their influence on marble deterioration: a long-term experiment. Geological Society, London, Special Publications 205 (1), 9-18.

Passchier, C.W., Trouw, R.A.J., 2005. Microtectonics, 2nd, Revised and Enlarged Edition ed. Springer-Verlag Berlin Heidelberg, Berlin, Heidelberg, Online-Ressource.

Pereira, M.F., Solá, A.R., Chichorro, M., Lopes, L., Gerdes, A., Silva, J.B., 2012. NorthGondwana assembly, break-up and paleogeography: U-Pb isotope evidence from detrital and igneous zircons of Ediacaran and Cambrian rocks of SW Iberia. Gondwana Research 22 (3-4), 866-881.

Poschlod, K., 1990. Das Wasser im Porenraum kristalliner Naturwerksteine und sein Einfluss auf die Verwitterung. Münchner geowissenschaftliche Abhandlungen: Reihe B, Allgemeine und angewandte Geologie (7), 1-62.

Rüdrich, J., Weiss, T., Siegesmund, S., 2002. Thermal behaviour of weathered and consolidated marbles. Geological Society, London, Special Publications (205), 255-271.

Ruedrich, J., 2003. Gefügekontrollierte Verwitterung natürlicher und konservierter Marmore. Diss Univ Göttingen.

Ruedrich, J., Knell, C., Enseleit, J., Rieffel, Y., Siegesmund, S., 2013. Stability assessment of marble statuaries of the Schlossbrücke (Berlin, Germany) based on rock strength measurements and ultrasonic wave velocities. Environ Earth Sci 69 (4), 1451-1469.

Ruedrich, J., Siegesmund, S., 2001. Deterioration characteristics of marbles from the Marmorpalais Potsdam (Germany): a compilation. Zeitschrift der Deutschen Geologischen Gesellschaft, 637-663.

Rüdrich, J.; Siegesmund, S.; Weiss, T. 2005: Die Marmore des Marmorpalais im Neuen Garten Potsdam. Erhaltungszustand und Möglichkeiten der Konservierung. In: Siegesmund, S., Auras, M., Rüdrich, J., Snethlage S. (Hg.): Zeitschrift der Deutschen Ge- 
sellschaft für Geowissenschaften. Themenheft: Geowissenschaften und Denkmalpflege. Bauwerkskartierung, Natursteinverwitterung, Konservierungsstrategien, Bd. 2005. Stuttgart: E. Schweizerbart'sche Verlagsbuchhandlung (156), S. 129-139. Ruedrich, J., Siegesmund, S., Richter, D., 2001. Marble columns and their state of weathering: structural evidence and ultrasonic tomography. Zeitschrift der Deutschen Geologischen Gesellschaft, 665-680.

Sáez-Pérez, M. P.; Rodríguez-Gordillo, J. (2009): Structural and compositional anisotropy in Macael marble (Spain) by ultrasonic, XRD and optical microscopy methods. In: Construction and Building Materials 23 (6), S. 2121-2126. DOI:

10.1016/j.conbuildmat.2008.10.013

Sanchit Garg, Parminder Kaur, Manoj Pandit, Fareeduddin, Gurmeet Kaur, Asifa Kamboj, Som Nath Thakur, 2019. Makrana Marble: a Popular Heritage Stone Resource from NW India. Geoheritage 11 (3), 909-925.

Sassoni, E., 2018. Hydroxyapatite and Other Calcium Phosphates for the Conservation of Cultural Heritage: A Review. Materials (Basel, Switzerland) 11 (4).

Sassoni, E., Andreotti, S., Scherer, G.W., Franzoni, E., Siegesmund, S., 2018a. Bowing of marble slabs: can the phenomenon be arrested and prevented by inorganic treatments? Environ Earth Sci 77 (10), 4077.

Sassoni, E., Graziani, G., Franzoni, E., Scherer, G.W., 2018b. New method for controllable accelerated aging of marble: Use for testing of consolidants. J Am Ceram Soc 101 (9), 4146-4157.

Scherer, G.W.; Wheeler, G.S. Silicate consolidants for stone. Key Eng. Mater. 2009, 391, 1-25, doi:10.4028/0-87849-365-4.1.

Sheremeti-Kabashi, F., 2002, Untersuchungen der Gefügeanisotropie von Carrara-Marmor und deren Einfluss auf die Verwitterung, Dissertation, Ludwig-MaximiliansUniversität

Shushakova, V., 2013. Marble decay caused by thermal expansion: microstructurebased mathematical and physical modeling. Dissertation Universität Göttingen

Shushakova, V., Fuller, E.R., Heidelbach, F., Mainprice, D., Siegesmund, S., 2013. Marble decay induced by thermal strains: simulations and experiments. Environ Earth Sci 69 (4), 1281-1297.

Siedel, H., Siegesmund, S., 2014. Characterization of stone deterioration on buildings, in: Siegesmund, S., Snethlage, R. (Eds.), Stone in architecture, 5 ed. Springer, pp. 349-414.

Siegesmund, S., 1996. The significance of rock fabrics for the geological interpretation of geophysical anisotropies: With 5 tables. Geotektonische Forschungen 85. Schweizerbart, Stuttgart, $163 \mathrm{~S}$.

Siegesmund, S., Dürrast, H., 2014. Physical and mechanical properties of rocks, in: Siegesmund, S., Snethlage, R. (Eds.), Stone in architecture, 5 ed. Springer, pp. 97-225.

Siegesmund, S., Kracke, T., Ruedrich, J., Schwarzburg, R., 2010. Jewish cemetery in Hamburg Altona (Germany): State of marble deterioration and provenance. Engineering Geology 115 (3-4), 200-208.

Siegesmund, S., Ruedrich, J., Koch, A., 2008. Marble bowing: comparative studies of three different public building facades. Env Geol 56 (3-4), 473-494.

Siegesmund, S., Ruedrich, J., Weiss, T., 2004a. Marble deterioration. Dimension stone. Taylor and Francis Group, London, 211-217. 
Siegesmund, S., Ullemeyer, K., Weiss, T., Tschegg, E.K., 2000a. Physical weathering of marbles caused by anisotropic thermal expansion. International Journal of Earth Sciences 89 (1), 170-182.

Siegesmund, S., Weiss, T., Ruedrich, J., 2004b. Schadensmonitoring mit Ultraschalldiagnostik: Beispiel Marmorpalais in Potsdam. Restauro: Zeitschrift für Kunsttechniken, Restaurierung und Museumsfragen 110 (2), 98-105.

Siegesmund, S., Weiss, T., Tschegg, E.K., 2000b. Control of marble weathering by thermal expansion and rock fabrics. 9th International Congress on Deterioration and Conservation of Stone, 205-213.

Siegesmund, S., Weiss, T., Vollbrecht, A., Ullemeyer, K., 1999. Marble as a natural building stone: rock fabrics, physical and mechanical properties. Zeitschrift der Deutschen Geologischen Gesellschaft 150 (2), 237-257.

Simon, S., 2001. Zur Verwitterung und Konservierung kristallinen Marmors: Untersuchungen zu physiko-mechanischen Gesteinskennwerten, zur Oberflächenchemie von Calit und zur Anpassung und Überprüfung von Gesteinsschutzmitteln. Dissertation, München.

Snethlage, R., 2008. Leitfaden Steinkonservierung.: Planung von Untersuchungen und Maßnahmen zur Erhaltung von Denkmälern aus Naturstein., 3rd ed. Fraunhofer IRB, Stuttgart.

Snethlage, R., 2014. Skulpturenmarmor: Beispiel -Pore Aspect Ratio- Bewertung mit Ultraschall, in: Bellendorf, P. (Ed.), Erhaltung von Marmorskulpturen unter mitteleuropäischen Umweltbedingungen. Beiträge des 8. Konservierungswissenschaftlichen Kolloquiums in Berlin, Brandenburg am 17. Oktober 2014 in Potsdam, vol. 32. Arbeitshefte des Brandenburgischen Landesamtes für Denkmalpflege und Archäologischen Landesmuseums 32. Wernersche Verl.-Ges, Worms, pp. 21-30.

Sobott, R.J., Ibach, H.W., 2019. AVT weiterentwickelt. Naturstein (02), 45.47.

Steiger, M., Charola, A.E., Sterflinger, K., 2014. Weathering and deterioration, in: Siegesmund, S., Snethlage, R. (Eds.), Stone in architecture, 5 ed. Springer, pp. 227-316.

Strohmeyer, D., 2003. Naturwerksteine: Gefuege und gesteinstechnische Eigenschaften.

Taelman, D., Elburg, M., Smet, I., Paepe, P. de, Lopes, L., Vanhaecke, F., Vermeulen, F., 2013. Roman marble from Lusitania: petrographic and geochemical characterisation. Journal of Archaeological Science 40 (5), 2227-2236.

Thomsen, L., 2014. Understanding seismic anisotropy in exploration and exploitation. Society of Exploration Geophysicists.

Tschegg, E.K., Widhalm, C., Eppensteiner, W., 1999. Ursachen mangelnder Formbeständigkeit von Marmorplatten. Zeitschrift der Deutschen Geologischen Gesellschaft 150 (2), 283-297.

Unterwurzacher, M., Obojes, U., 2012. White Marble from Laas (Lasa), South Tyrol - its occurence, use and petrographic isotopical characterisiation. Austrian Journal of Earth Sciences Volume 105 (3), 26-37.

Weiss, T., Leiss, B., Oppermann, H., Siegesmund, S., 1999. Microfabric of fresh and weathered marbles: Implications and consequences for the reconstruction of the Marmorpalais Potsdam. Zeitschrift der Deutschen Geologischen Gesellschaft 150 (2), 313-332.

Weiss, T., Rasolofosaon, P.N.J., Siegesmund, S., 2001. Thermal microcracking in Carrara marble. Zeitschrift der Deutschen Geologischen Gesellschaft 152 (2-4), 621-636. 
Weiss, T., Rasolofosaon, P.N.J., Siegesmund, S., 2002a. Ultrasonic wave velocities as a diagnostic tool for the quality assessment of marble. Geological Society, London, Special Publications 205 (1), 149-164.

Weiss, T., Siegesmund, S., Fuller, E.R., 2002b. Thermal stresses and microcracking in calcite and dolomite marbles via finite element modelling. Geological Society, London, Special Publications 205 (1), 89-102.

Weiss, T., Siegesmund, S., Rasolofosaon, P.N.J., 2000. The relationship between deterioration, fabric, velocity and porosity constraint. Proceedings of the 9th international congress on deterioration and conservation of stone, 215-223.

Wendrich, A., 2009. Zerstörungsfreie Ortung von Anomalien in historischem Mauerwerk mit Radar und Ultraschall-Möglichkeiten und Grenzen.

Wenk, H.-R., van Houtte, P., 2004. Texture and anisotropy. Metall and Mat Trans A 67 (8), 1367-1428.

Wheeler G.S., Alkoxysilanes and the Consolidation of Stone (Research in conservation), The Getty Conservation Institute, Los Angeles, 2005

Widhalm, C., Eppensteiner, W., Tschegg, E.K., 1999. Meßmethoden zur Beschreibung von Gefügeanisotropien in Marmor. Zeitschrift der Deutschen Geologischen Gesellschaft 150 (2), 275-281.

Zeisig, A., Siegesmund, S., Weiss, T., 2002. Thermal expansion and its control on the durability of marbles. Geological Society, London, Special Publications 205 (1), 6580 . 


\section{Anhang}

\section{Danksagung}

Grundlage für die Realisierung der Arbeit war das BMBF Projekt Marmorbild (FKZ: 03VP00292), im Zuge dessen ich mich der Thematik der Marmorverwitterung widmen durfte, wofür ich mich bedanken möchte.

Die Arbeit entstand unter der Betreuung von Prof. Dr. Siegfried Siegesmund, dem ich für die zahlreichen Diskussionen, Anregungen und immer neuen Herausforderungen danke. Das Korreferat wurde durch Herrn Prof. Dr. Rolf Snethlage übernommen, wofür ich mich recht herzlich bedanken möchte und für dessen anregenden Diskussionen im Kreise des Projektes ich sehr dankbar bin.

Zudem möchte ich mich noch ganz besonders bei all den großartigen Menschen bedanken, die ich im Verlauf der Promotionszeit kennenlernen durfte. Zuallererst möchte ich der TekLab Gruppe danken, es war eine großartige Zeit mit anregenden Diskussionen und großartiger Unterstützung. Hier bedanke ich mich bei Christian Knell, Amanda Ricardo und Orsolya Farkas für die schöne Zeit und die großartige Hilfe. Außerdem bei Mathias Hueck, Maxim Bogdanowitsch, Malte Teipel, Falko Malis, Calvin Klein, Stine Ruckert, T. Koch, Sira Kraus, Markus Träupmann, Dimitri, Christian Gross, C. Kloss, Luís Sousa, Alena Broge und Enrico Sassoni. Ohne euch wären viele Dinge nicht gelungen! Bedanken möchte ich mich auch bei Katja Schmeikal und Prof. Hauff für ihre stete Motivation noch im Studium, ohne euch hätte ich mich nie in diese Richtung orientiert. Mein ganz besonderer Dank gilt 
Rebecca Kühn für ihre Unterweisung am Goniometer und dem offenen Ohr für all meine Fragen sowie den netten Gesprächen. Ebenfalls möchte ich mich ganz besonders bei Christopher Pötzl bedanken, dem ich ganz oft das Durchhalten zu verdanken habe! Vielen Dank insbesondere für die letzten Monate!

In der Hoffnung niemanden vergessen zu haben zu guter Letzt mein herzlichster Dank an meine Familie, für ihre Unterstützung, Geduld und offenen Ohren! Doch der größte Dank gilt Sven, der mich nicht nur durch die Masterarbeit begleitet hat, sondern auch noch die Dissertation mitgemacht hat. Ich bin dir unendlich dankbar für deine Unterstützung, das Spenden von Kraft und der unermüdlichen Aufmunterung in allen Zeiten!

Danke 


\title{
Lebenslauf
}

Rahel Johanna Menningen, geb. 9.1.1986, Adenau

\author{
Schulische Ausbildung
}

1996-2005 Erich- Klausener-Gymnasium, Adenau

Abschluss: Abitur

Akademische Laufbahn

\begin{tabular}{|l|l|}
\hline Seit 10.2016 & Promotion Georg-August-Universität, Studiengang Geowissenschaften \\
04.2014 & $\begin{array}{l}\text { M.A. Konservierung, Restaurierung, Fachrichtung Stein, FH Potsdam } \\
\text { Thema der Thesis: Marmorkonservierung }\end{array}$ \\
\hline 10.2010 & $\begin{array}{l}\text { B.A. Konservierung, Restaurierung, Fachrichtung Stein, FH Potsdam } \\
\text { Thema der Thesis: In situ Festigung von Marmor }\end{array}$ \\
\hline
\end{tabular}

Berufserfahrung

\begin{tabular}{|c|c|}
\hline $\begin{array}{l}01.2020 \\
06.2020\end{array}$ & $\begin{array}{l}\text { Wissenschaftliche Mitarbeiterin, Georg-August-Universität Göttingen } \\
\text { Geowissenschaftliches Zentrum, Abt. Strukturgeologie und Geodynamik } \\
\text { Tuffe als Werksteine der historischen Kulturgüter Mexikos: Geologische, } \\
\text { mineralogische und petrophysikalische Parameter als Basis für das Ver- } \\
\text { ständnis der Verwitterung, Konservierung und Erhaltung }\end{array}$ \\
\hline $\begin{array}{l}10.2016- \\
09.2019\end{array}$ & $\begin{array}{l}\text { Wissenschaftliche Mitarbeiterin, Georg-August-Universität Göttingen } \\
\text { Geowissenschaftliches Zentrum, Abt. Strukturgeologie und Geodynamik } \\
\text { Projekt Marmorbild: Innovative Ultraschall-Tomographie und digitale Re- } \\
\text { konstruktion für die zerstörungsfreie Prüfung von Kulturgütern aus Mar- } \\
\text { mor }\end{array}$ \\
\hline 04.2016 & $\begin{array}{l}\text { Akademische Mitarbeiterin, FH Potsdam } \\
\text { Lehrveranstaltung Masterprojekte, im Lehrgebiet: Projekte in der } \\
\text { Konservierung und Restaurierung, 1-Stein (B.A.); Historische Techniken } \\
\text { Master-Projekte in der Konservierung und Forschung } 2 \text { - Stein }\end{array}$ \\
\hline $\begin{array}{l}10.2015 \\
02.2016\end{array}$ & $\begin{array}{l}\text { Lehrauftrag, FH Potsdam } \\
\text { Lehrveranstaltung Masterprojekte, im Lehrgebiet: Projekte in der Konser- } \\
\text { vierung und Restaurierung, 1-Stein (B.A.) }\end{array}$ \\
\hline $\begin{array}{l}07.2008 \\
09.2010\end{array}$ & Steinmetzgesellin, Fa. Naturstein Krause, Hannover \\
\hline $\begin{array}{l}08.2005- \\
07.2008\end{array}$ & $\begin{array}{l}\text { Fa. Naturstein Krause, Hannover } \\
\text { Ausbildung als Steinbildhauerin }\end{array}$ \\
\hline
\end{tabular}




\section{Veröffentlichungen}

- Menningen, J., Siegesmund, S., Lopes, L., Martins, R., \& Sousa, L. (2018). The Estremoz marbles: an updated summary on the geological, mineralogical and rock physical characteristics. Environmental Earth $\quad 191$. https://doi.org/10.1007/s12665-018-7328-3

- Menningen, J., Siegesmund, S., Tweeton, D., \& Träupmann, M. (2018). Ultrasonic tomography: non-destructive evaluation of the weathering state on a marble obelisk, considering the effects of structural properties. Environmental Earth Sciences, 77(17), 601. https://doi.org/10.1007/s12665-018-7776-9

- $\quad$ Menningen, J., Siegesmund, S., Krompholz, R., Rieffel, Y. (2020). The marble sculptures General Bülow and Scharnhorst in Berlin - Comparative, non-destructive analysis of the weathering state after 12 years of exposur Environmental Earth Sciences 79, 249. https://doi.org/10.1007/s12665-020-08984-7

- Menningen, J., Sassoni, E., Sobott, R., Siegesmund, S. (2021) Constraints of the durability of inorganic and organic consolidants for marble. Environ Earth Sci 80, 370. https://doi.org/10.1007/s12665-021-09664-w

- Siegesmund, S., Menningen, J., Shushakova, V. (2021). Marble decay: towards a meausure of marble degradation based on ultrasonic wave velocities and thermal expansion data. Environmental Earth Sciences (Accepted for publication)

Im Zusammenhang mit dem 14th International Congress on the Deterioration and Conservation of Stone publiziert

- Menningen, J., Sassoni, E. Siegesmund, S. (2020). Marble bowing: Prevention by the application of Hydroxyapatite - a systematic study

- Menningen, J.*, Fetzer, T.*, Schäfer, A., Reis, G., Siegesmund, S. (2020). Marble columns and sculptures from the Marmorpalais and Park Sanssouci in Potsdam: Ultrasound tomography and 3D scanning technologies as a tool to constrain the state of weathering.

- $\quad$ Menningen, J.; Siegesmund, S.; Krompholz, R.; Rieffel, Y. (2020). Comparative, nondestructive analysis of the marble sculptures General von Bülow and von Scharnhorst in Berlin.

- Huby, E. ; Thomachot-Schneider, C.; Vàzquez, P.; Fronteau, G.; Menningen, J.; Siegesmund, S. (2020). Dilatation behavior of building stones repaired with a restoration mortar.

- Sousa, L., Menningen, J., Siegesmund, S. (2020). Notes of a bowing behavior on limestone.

- $\quad$ Pirskawetz, S., Menningen, J., Siegesmund, S. (2020). Acoustic emissions- Insights into the decay mechanisms of thermally treated marbles. 